

\title{
Estado de conservación y posibilidades de rehabilitación en ecosistemas semiáridos: el caso del Monte en el Noreste de Río Negro.
}

\author{
Lic. Juan Manuel Zeberio \\ Trabajo de tesis para optar al título de \\ Doctor en Ciencias Naturales
}

Directora: Dra. Graciela Mabel Calabrese

Co-Directora: Dra. Carolina Alejandra Pérez

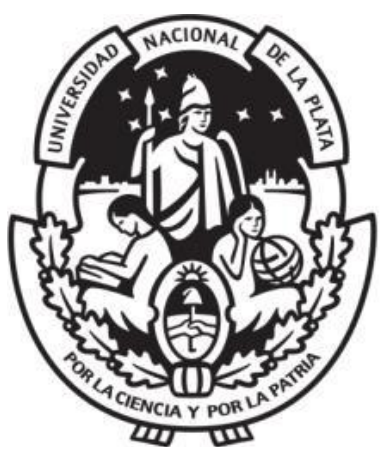

FACULTAD DE CIENCIAS NATURALES Y MUSEO UNIVERSIDAD NACIONAL DE LA PLATA 
Agradecimientos

Resumen

Abstract

Capítulo I: Introducción

1.1- Fundamentación

1.2- Hipótesis 20

1.3- Objetivos

Capítulo II: Caracterización general del área de estudio

2.1- Clima 22

2.2- Geomorfología 25

2.3- Suelos 29

2.4- Vegetación 33

Anexo I

Capítulo III: Estado de conservación de la vegetación del Noreste de la provincia de Río Negro

3.1- Introducción

3.2- Materiales y métodos

3.2.1- Relevamiento de la vegetación 40

3.2.2- Suelos

3.2.3- Usos del suelo 46

3.2.4- Estado de conservación del Monte

3.2.5- Cobertura del suelo

3.3- Resultados

3.3.1- Vegetación

3.3.2- Suelos

3.3.3- Usos del suelo 66

3.3.4- Estado de conservación del Monte 72

3.3.5- Cobertura del suelo 77

3.4- Discusión 84

3.5- Conclusiones 93 
Capítulo IV: Rehabilitación ecológica

4.1- Introducción

4.2- Materiales y métodos

4.2.1- Selección de sitios

4.2.2- Selección de especies y tratamientos pregerminativos

4.2.3- Rehabilitación activa

4.2.4- Rehabilitación pasiva

4.2.5- Evaluación de los efectos de la rehabilitación activa y pasiva

4.2.6- Relación entre variables ambientales y los efectos de la rehabilitación

4.3- Resultados

4.3.1- Caraterísticas de los sitios seleccionados

4.3.2- Tratamientos pregerminativos

4.3.3- Rehabilitación activa

4.3.4- Rehabilitación pasiva

4.3.5- Efecto de la rehabilitación activa y pasiva

4.3.6- Relación entre las variables ambientales y los efectos de la rehabilitación 


\section{Agradecimientos}

Bueno, que decir... finalmente llegó el momento de redactar este apartado que consideré, desde el principio, el último y más lejano. Gracias al apoyo y al aliento constante de las personas con quienes comparto el trabajo, concluyo esta etapa en mi formación. Seguramente que no será la última, ya que este es el inicio de un camino mucho más prolongado y restan muchísimas cosas por aprender para la correcta intervención en estos sistemas naturales tan hermosos y complejos.

Quisiera comenzar agradeciendo a mis directoras, Graciela Calabrese y Carolina Perez, no imagino este trabajo sin ellas. Graciela, me has enseñado la forma de llevar adelante el trabajo con responsabilidad y respeto. Carolina, no solo me has enseñado a discutir y reflexionar valiosos aspectos de la ecología y el tratamiento estadístico de los datos, sino que con tu actuación me has fortalecido en aspectos éticos en el trabajo científico y la formación de recursos humanos. Además, me has ayudado a mantener la constancia y el esfuerzo que esta tarea requiere, y que sin pasión es muy dificultosa.

A mis compañer@s del CEANPa, que no solo me han alentado a lo largo de todo el trayecto sino que hemos compartido extensas y agotadoras jornadas de trabajo en el campo y el laboratorio. La Dra. Silvia Torres Robles y la Dra. Guadalupe Peter me han dejado cuantiosas enseñanzas referidas a aspectos botánicos y ecológicos de la región del Monte y también, de alguna manera, me han transferido su amor y compromiso por este trabajo. A los compañeros becarios, con quienes hemos compartido oficinas y penurias, Dra. Cintia Leder, Ing. Fany Zubillaga, Lic. Martín Luna, les quiero expresar mi agradecimeinto. No solo por prestarme la oreja, sino que además hicieron de regadores, alambradores, sembradores y planilleros en innumerables oportunidades. Al Dr. Marcelo Arturi por su asesoramiento estadístico y a la Lic. María Rosa Derguy por los comentarios acerca del tratamiento de imágenes.

No quiero olvidarme tampoco de los técnicos de INTA EEA Valle Inferior, fundamentalmente del $\mathrm{Mg}$ Mario Enrique, quien no solo fue de gran ayuda en las tareas de campo, sino que también me acerco a varios de los productores rurales del área para poder instalar ensayos e ingresar a sus establecimientos a efectuar diferentes tareas.

Mi agradecimiento va también a los propietarios de los campos donde efectué los ensayos de este trabajo, Eduardo Bosero, Miguel Iturburu y a la familia Erripa. Ellos confiaron plenamente en mí desde el inicio de este trabajo y no solo me brindaron 
acceso ilimitado a sus propiedades, sino que muchas veces dieron el mantenimiento necesario a las clausuras atacadas por el ganado y nunca dudaron ni un segundo de compartir el conocimiento que poseen de estos sistemas y que algunas veces no es tenido en cuenta a la hora de realizar trabajos científicos.

La UNRN y el MINCyT, a través de los programas de fortalecimiento institucional y la formación de doctores en áreas prioritarias, financiaron mediante el PICT 2009/0065, PICTO 2010/0219 y PI 40B156 los trabajos de esta tesis.

Deseo expresar mi más sincero agradecimiento a los revisores (que en este caso no son anónimos) ya que con sus observaciones han permitido mejorar sustancialmente esta tesis.

Y como siempre acostumbramos a guardar lo mejor para lo último, es que deseo agradecer profundamente a mi familia y amigos, con los cuales comparto desde hace muchísimos años los éxitos y los fracasos y que en muchas épocas son un sostén imprescindible.

Gracias

Infinitas!!!! 


\section{Resumen.}

El objetivo del presente trabajo es evaluar el estado de conservación del Monte en el Noreste de la provincia de Río Negro a través del análisis de la composición y la estructura de la vegetación nativa (leñosa y herbácea), de las características físicas y químicas de los suelos, de los usos más frecuentes de la tierra y del avance de la frontera agrícola. Además, se identificaron áreas degradadas en las cuales se desarrollaron ensayos de rehabilitación ecológica. Se evaluaron los tratamientos pregerminativos más adecuados para la producción de ejemplares de especies nativas para realizar ensayos de rehabilitación activa. Se estimaron los niveles de supervivencia y crecimiento a campo de los individuos trasplantados. Por otro lado se evaluó la recuperación de la cobertura en ensayos de rehabilitación pasiva. Se registraron los efectos de la rehabilitación activa y pasiva sobre la cobertura total, la cobertura de especies perennes y la cobertura de especies forrajeras en los sistemas intervenidos.

El análisis multitemporal de las imágenes Landsat de los años 2001, 2007, 2011 y 2014 permitió evaluar la variación de la cobertura de la vegetación del área de estudio y el avance de la superficie desmontada para la implantación de cultivos extensivos de secano. Las categorías de vegetación nativa definidas fueron Monte denso, Monte intermedio, Monte abierto. Monte denso hace referencia a vegetación con una cobertura total superior al 65\%; en el monte intermedio la cobertura de la vegetación de árboles y arbustos es menos densa y oscila entre $35 \%$ y $65 \%$ y monte abierto hace referencia a la vegetación nativa con coberturas inferiores al 35\% donde predominan los arbustos bajos. La categoría Monte denso presentó una retracción en el período 2001-2014 mientras que el monte intermedio se expandió en el mismo período. La categoría de monte intermedio presenta mejor estado de conservación debido a que ofrece protección al suelo superficial contra los factores erosivos, además de estar asociada a mayores valores tanto de diversidad como de cobertura de especies herbáceas.El análisis de las imágenes satelitales permitió también identificar un número creciente de hectáreas de suelo desnudo, con marcadas evidencias de degradación causadas por la erosión hídrica y/o eólica. Estas superficies fueron consideradas a la hora de identificar sitios donde se instalaron los ensayos de rehabilitación.

La estructura y la composición de la vegetación nativa están relacionadas con el uso del suelo y los regímenes de disturbio. El uso del suelo afecta a la vegetación nativa de forma diferencial, de acuerdo a la intensidad y frecuencia de los disturbios, siendo los 
más frecuentes el fuego y el pastoreo. El uso de la tierra, el tipo de intervención, la carga animal, la intensidad de pastoreo, el uso de rotaciones y la ocurrencia de incendios deben ser manejados cuidadosamente para evitar la pérdida de las especies deseables y la arbustificación del sistema. Los disturbios antrópicos han provocado una degradación del ecosistema, que se manifiesta en una marcada pérdida de la diversidad vegetal y un empobrecimiento del sustrato que afecta las actividades desarrolladas en el área.

Los sitios donde se realizaron los ensayos de rehabilitación fueron seleccionados considerando la variabilidad de sus características edáficas, precipitaciones y cercanía al mar, con la finalidad de evaluar el comportamiento de las especies seleccionadas bajo diferentes condiciones ambientales. En los ensayos de rehabilitación activa, las especies Prosopis flexuosa y Schinus johntonii presentaron cierta plasticidad a las diferencias ambientales, mostrando buenas aptitudes para ser usadas en la recuperación de la funcionalidad de zonas semiáridas del Noreste de la Patagonia. En cambio, Condalia microphylla y Geoffroea decorticans presentaron niveles de supervivencia y crecimiento bajos. Las especies herbáceas Nassella longiglumis, Nassella tenuis, Piptochaetium napostaense y Pappophorum caespitosum demostraron tener elevada potencialidad para rehabilitar áreas con marcados signos de degradación edáfica, por su elevada supervivencia y capacidad reproductiva. Estas especies serían recomendables para rehabilitar extensas superficies de suelo desnudo causadas por efecto de fuegos naturales, de sequías conjugadas con un manejo inadecuado de los recursos forrajeros, o la eliminación de la vegetación nativa a tala rasa y posterior abandono de la tierra.

La rehabilitación pasiva permitió recobrar la cobertura de especies perennes, aunque las especies que se registraron poseían escaso valor forrajero. Para rehabilitar grandes extensiones de tierra, la rehabilitación pasiva es una opción a tener en cuenta. La composición florística de la vegetación colonizadora está estrechamente relacionada a la disponibilidad de semillas presentes en el banco y de aquellas provenientes de áreas cercanas, como así también de los regímenes de precipitación. La rehabilitación activa, en cambio, permite influir sobre la composición de las comunidades, lo que a su vez podría permitir la recomposición de la producción forrajera en menos tiempo. Por lo tanto, la sola eliminación del factor causante del disturbio (rehabilitación pasiva) sería suficiente para recuperar la cobertura vegetal, aunque la recuperación de la cobertura de las especies perennes forrajeras se lograría en menor tiempo mediante la reintroducción de las especies deseadas (rehabilitación activa). 


\begin{abstract}
.
The aim of this study is to evaluate the state of conservation of the Monte from Northeast of Río Negro province through the analysis of the structure and floristic composition of vegetation (native plants, woody and herbaceous), as well as physical and chemical characteristics of soil, land use and agricultural expansion. Furthermore, degraded areas were identified in which restoration assays were conducted. Pregerminative treatments were evaluated in order to produce specimens of native species destined to active rehabilitation. Survival and growth in field transplanted specimens were estimated. On the other hand, we evaluate recovery of vegetation through passive rehabilitation. After that, we effectuated the comparison between active and passive rehabilitation effects on ecosystem, especially total coverage, coverage of perennial species and coverage of forage species.
\end{abstract}

Multi-temporal analysis of Landsat images from years 2001, 2007, 2011 and 2014 allowed us to evaluate the variation of vegetation cover and the expansion of extensive crop area in detriment of native woody vegetation. We defined native vegetation categories as "monte denso" (woody coverage > 65\%), "monte intermedio" (coverage $35-65 \%$, intermediate vegetation cover) and "monte abierto" (coverage $<35 \%$, with dwarf shrubs, low vegetation cover). In the period 2001-2014 monte denso show a retraction while monte intermedio expanded. The last category offers soil protection against erosive factors associated to high values of both diversity and cover of herbaceous species, thus is the best conservated. The analysis of satellital images allowed us to identified an increase of bare soil area, whit degradation evidence caused by water and/or wind erosion. We considered these degraded areas to select plots to conduct rehabilitation ecology assays.

Structure and floristic composition of native vegetation are related to land use and disturb regimes. Intensity and frequency of disturbs, such us fire and grazing, affect native vegetation. Land use, intensity grazing, crop rotation and fire events must be carefully managed to avoid desirable species were lost and shrubs encroachment. Antrhopic disturbs have caused ecosystem degradation which is expressed by loss of biodiversity and depleted soil that affects production activities.

We selected sites to install active and passive rehabilitation plots according to soil properties, mean annual precipitations and sea distance, in order to evaluate behavior of 
selected species. As a result of the field experiments, Prosopis flexuosa and Schinus johnstonii showed plasticity under different environmental conditions. These are potential species to be used in recovery of ecosystem functions in semiarid lands from Northeast of Patagonia. Also, herbaceous species such as Nassella longiglumis, Nassella tenuis, Piptochaetium napostaense and Pappophorum caespitosum showed high survival and produced reproductive structures in short time. Herbaceous species are recommendable to use in large areas of bare soil. In contrast, Condalia microphylla and Geofroea decorticans showed low levels of both survival and growth.

Recovery perennial species, although whithout forage value, had result of passive rehabilitation assays. However, to rehabilitate extense dry lands, passive rehabilitation is a choice to keep in mind. Floristic composition of the colonizing vegetation will be related to the availability of seed bank and seeds coming from near areas, as well as precipitation regimes. On the other hand, active rehabilitation practices allow us to influence on the species establishing and to produce forage in a short time. The results of this study suggest that elimination of disturbance factor (passive rehabilitation) would be enough to recovery vegetal cover, though the recovery of forage perennial grasses would be achieved in a shorter period of time through the reintroduction of the desirable species (active rehabilitation). 


\section{Capítulo I.}

\section{Introducción}

\section{1- Fundamentación.}

La habilitación de tierras para la producción agrícola, con la posterior pérdida de productividad y el consiguiente abandono, es un fenómeno registrado a nivel global que cobra destacada importancia en las regiones áridas y semiáridas de todo el mundo (Abraham et al. 2016). Esta dinámica configura un escenario de creciente degradación de los recursos naturales, que se ve acentuado por el cambio climático global, con el aumento en la variabilidad inter e intra- anual de las precipitaciones y el incremento de los períodos de sequía (Chirino et al. 2009). Frente a esta situación se observa una necesidad creciente de asistir en la recuperación de las tierras secas, ya sean áridas, semiáridas o subhúmedas secas. Esta restauración de los atributos ecosistémicos perdidos se basa en recobrar aspectos estructurales y funcionales de los ecosistemas para que sean nuevamente productivos (Abraham et al. 2009; Van Andel y Aronson 2012).

La determinación del estado de degradación de los ecosistemas debe ser un proceso estructurado que permita conocer de forma diagnóstica el estado de los recursos naturales, identificar prioridades y decidir dónde, cuándo y cómo preservar los elementos principales de la diversidad biológica. Es necesario tener en cuenta una amplia variedad de aspectos de los componentes bióticos y abióticos para evaluar el estado de una región o un sistema, ya que mediante la sola clasificación de la diversidad de plantas y animales no es suficiente. De esta forma cobra relevancia el conocimiento de las características edáficas, la conectividad de los diferentes parches de ecosistemas, su distribución y superficie, como así también los procesos y usos antrópicos que se desarrollan en el área (Santibañez-Andrade et al. 2015).

En la República Argentina, donde las tierras secas ocupan el 73\% del territorio nacional, hay zonas degradadas situadas en diferentes regiones tales como La Puna, el Monte de Sierras y Bolsones, el Monte de Llanuras y Mesetas y La Patagonia (Abraham et al. 2011). En algunas de estas áreas el desmonte es una práctica común, observándose amplias superficies de tierras que son arrasadas anualmente para implantar cultivos y que, frente a la pérdida de rentabilidad, son abandonadas con las consiguientes 
consecuencias de degradación de la capa de suelo superficial y ausencia de fuente de propágulos que permita la recuperación (Viglizzo et al. 2012).

El manejo inadecuado del ganado doméstico, con altas cargas y prolongados períodos de permanencia en una misma área conducen al sobrepastoreo. En ambientes áridos y semiáridos, donde los arbustos son parte de la vegetación natural, el sobrepastoreo actúa directamente sobre la composición de la vegetación y afecta el balance entre especies leñosas y herbáceas, lo que conduce a la arbustización y a la pérdida de productividad (van Auken 2009; Maestre et al. 2009; Maestre 2016). Por su parte, el fuego actúa en sentido opuesto, limitando el crecimiento del estrato leñoso y favoreciendo el rebrote del estrato herbáceo (Scholes y Archer 1997). El fuego, históricamente, ha sido utilizado como herramienta para el manejo de la cobertura de la vegetación leñosa y mejorar la calidad y cantidad de forraje, práctica que suele emplearse hasta la actualidad (Bran et al. 2007). Sin embargo, la dinámica de la vegetación post fuego estará sujeta a las condiciones climáticas posteriores al fuego. En ese sentido, la disponibilidad hídrica constituye un factor clave en la recuperación de la vegetación (Marty 2015). En el Monte Oriental, la interacción entre pastoreo, fuego y sequías determina en gran medida la composición y estructura de la vegetación (Kröpfl et al. 2015).

Diferentes áreas de nuestro país son clasificadas de acuerdo con las características ambientales que presentan y se las denomina ecorregiones. Una ecorregión es un territorio geográficamente definido en el que dominan determinadas características ambientales de relieve, geología, grandes grupos de suelos, procesos geomorfogenéticos, tipos de vegetación y faunísticos. Desde el punto de vista evolutivo, se caracteriza por respuestas ecológicamente homogéneas al clima y a la tectónica expresadas por la vegetación, la fauna, el relieve y las actividades antrópicas. El concepto de ecorregión toma en cuenta los componentes biofísicos del territorio, poniendo énfasis en aspectos culturales y productivos que se traducen en diferentes contrastes en el paisaje (Morello et al. 2012).

En la República Argentina se distinguen 16 ecorregiones. La ecorregión Monte de Llanuras y Mesetas se extiende al este de la cordillera de los Andes, desde la provincia de Mendoza, Neuquén y La Pampa, hasta las costas del océano Atlántico en las provincias de Río Negro y Chubut. Limita al Norte con la ecorregión Monte de Sierras y Bolsones, al Oeste con la ecorregión Altos Andes, al Este con las ecorregiones Chaco 
Seco y Espinal, y al Sur con la ecorregión Patagonia (Figura 1.1). El relieve tiende a ser menos abrupto que el de la ecorregión Monte de Sierras y Bolsones y está dominado por llanuras y extensas mesetas escalonadas, distribuidas de forma discontinua. Los relieves dominantes tienen una altura de entre 800-1000 m.s.n.m y las depresiones albergan lagunas y salinas. Los suelos predominantes pertenecen al órden de los Aridisoles y Entisoles, siendo ambos típicos suelos de zonas áridas y semiáridas. Los Aridisoles son suelos con escasa materia orgánica y nutrientes, asociados a vegetación de tipo xerofítica, con escaso porcentaje de cobertura. Los Entisoles son suelos jóvenes, con escaso desarrollo, sin la presencia de horizontes pedogenéticos. Son suelos claros, someros y pobres en materia orgánica. Ninguno de estos suelos es apto para la práctica agrícola extensiva de secano (Morello et al. 2012).

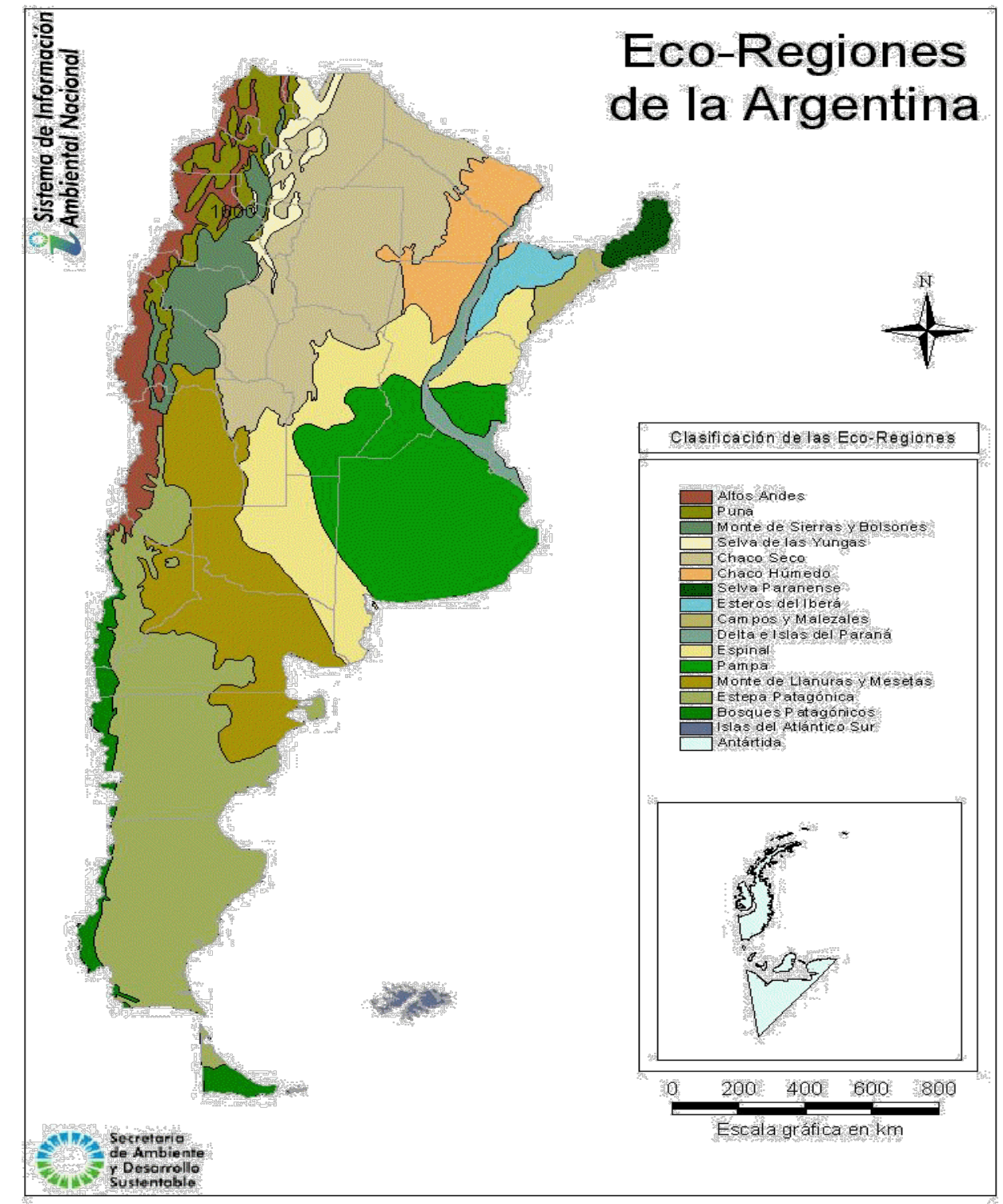

Figura 1.1. Ecorregiones argentinas. Fuente: Sistema de Información Ambiental Nacional 1999. 
El clima es templado-árido, y en el Norte de esta ecorregión las precipitaciones se distribuyen uniformemente durante todo el año. Los valores varían entre los 100 y 200 milímetros. Hacia el Sur, aumenta la influencia del régimen de tipo mediterráneo propio de la Patagonia, con concentración invernal de las precipitaciones. Las temperaturas medias anuales son del orden de los 10 a $14^{\circ} \mathrm{c}$ y las amplitudes térmicas muy marcadas.

La vegetación es homogénea en toda su extensión, tanto en su fisonomía como en su composición florística. La estepa arbustiva dominada por Larrea spp. es la formación que caracteriza a toda la región. A diferencia de la ecorregión Monte de Sierras y Bolsones, la vegetación es más pobre. Desaparecen los bosques y la estepa arbustiva baja se extiende hacia los faldeos. Desde el centro de Mendoza hacia el Sur desaparecen los algarrobales y se reduce la diversidad de una variada gama de familias botánicas como las Cactáceas y Zigofiláceas. Los jarillales (Larrea sp.) predominan tanto en las mesetas como en los taludes de las terrazas fluviales y en las planicies bajas (Godagnone y Bran 2009; Morello et al. 2012).

Dentro de la ecorregión Monte de Llanuras y Mesetas se diferencian dos subregiones; la subregión Septentrional y la subregión Austral. Es en esta última donde se ubica el complejo ecosistémico de Planicies y Mesetas Norpatagónicas, extendiéndose a los largo de tres provincias (Neuquén, La Pampa y Río Negro) hasta llegar al océano Atlántico. En la provincia de Río Negro ocupa los partidos de General Roca, Avellaneda, Pichi Mahuida, Conesa, Adolfo Alsina y San Antonio.

El presente trabajo se desarrolla en un área situada en el Noreste de la provincia de Río Negro. Abarca los partidos de Pichi Mahiuda, General Conesa y Adolfo Alsina, con una superficie total de $33.956 \mathrm{~km}^{2}$ (Figura 1.2). 


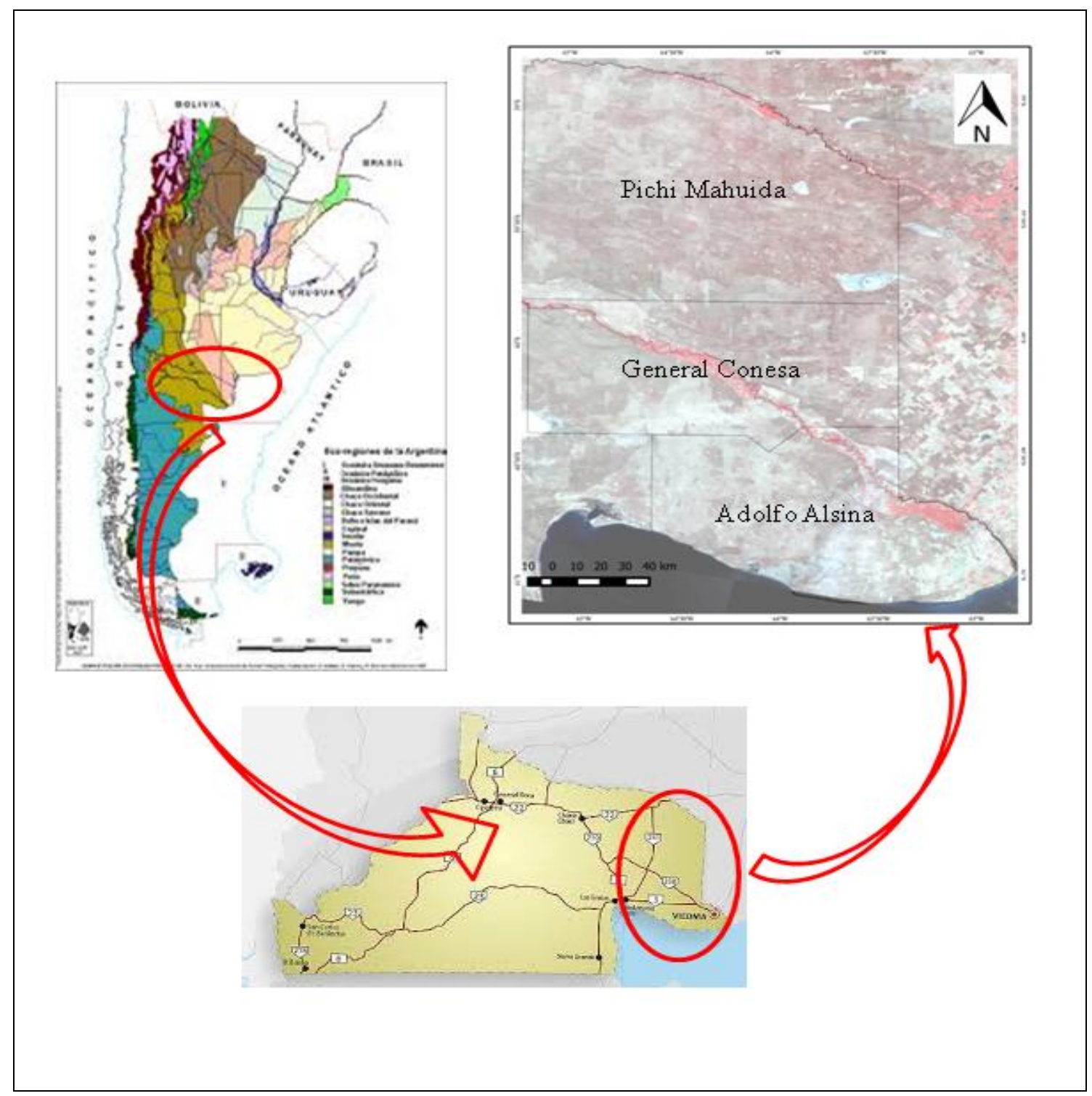

Figura 1.2. Ubicación relativa del área de estudio y departamentos del Noreste de Río Negro.

Algunos autores han realizado trabajos que incluyen al área de estudio. Según León et al. (1998), la región es denominada Monte Oriental o de Transición, subunidad de la provincia fitogeográfica del Monte. Morello et al. (2012) la denomina como Complejo de Planicies y Mesetas Norpatagónicas. Se trata de una franja ecotonal entre el Monte y el Espinal, donde coexisten especies leñosas y herbáceas pertenecientes a ambos sistemas. Estructuralmente es una estepa arbustiva de altura media, en la cual se encuentran elementos arbóreos más o menos aislados que van acompañados por comunidades de pastos y hierbas. Las comunidades vegetales presentes se desarrollan sobre una amplia variedad de suelos y geoformas, imprimiéndole así al paisaje características que lo destacan por su amplia variedad de ambientes (León et al. 1998; Bran et al. 2000; Godagnone y Bran 2009). 
A esta amplia heterogeneidad ambiental debemos agregarle la incidencia que tienen las actividades productivas sobre los sistemas naturales, las cuales causan disturbios de forma variable y de distinta frecuencia e intensidad. Podemos considerar como un disturbio a cualquier evento relativamente discreto que irrumpe en la dinámica natural de un ecosistema, comunidad, o población, generando cambios en los factores físicos y biológicos que conforman el medio afectado (Thibault et al. 2004; Fraterrigo y Rusak 2008). Por lo tanto, toda actividad desarrollada por el hombre interviniendo en el ecosistema es considerada un "disturbio", más allá de la magnitud y la naturaleza del mismo.

\subsection{1- Factores de disturbio en el Noreste de la provincia de Río Negro.}

Los agroecosistemas son ecosistemas manejados por el hombre para la producción de alimentos y fibras, por lo que son sometidos a frecuentes e intensas modificaciones, tanto de sus componentes bióticos como abióticos (Soriano y Sala 1983). Además de los componentes físicos y biológicos, las características de estos ecosistemas están influenciadas por los factores socioeconómicos que operan, como las tendencias del mercado, las políticas comerciales estatales y de las empresas, los precios y políticas fiscales. Éstas influyen tanto sobre los productos generados, como sobre los sistemas de producción y las tecnologías que se utilizan (Bilenca et al. 2009).

La producción agropecuaria trae aparejada una serie de profundas transformaciones que afectan prácticamente todos los procesos ecológicos y los flujos de materiales y energía en los ecosistemas. En este sentido, los cambios en el uso del suelo, ligados a la habilitación de nuevas tierras para la producción agrícola, están considerados entre las principales fuerzas que inciden sobre el cambio global y entre los factores de mayor impacto sobre la diversidad biológica (Sala et al. 2000). En el Noreste de la Patagonia estos cambios en el uso del suelo son muy marcados y consisten en transformar la matriz productiva de la región, pasando de actividades pecuarias a actividades agrícolas. Este avance de la frontera agrícola se realiza mediante la habilitación de tierras antes ocupadas por pastizales naturales y monte (Ayesa et al. 1986; Pezzola y Winschel 2004; Bran et al. 2007; Rueda et al. 2013).

En el Noreste de la provincia de Río Negro las actividades productivas predominantes son la ganadería extensiva y la agricultura de secano (Kröpfl et al. 2007; M.A.G.y P. 
2010; Peter et al. 2012). La ganadería extensiva suele ser considerada el uso del suelo más compatible con la conservación de los recursos naturales al compararla con la agricultura extensiva de secano. Sin embargo, este uso puede resultar negativo, indiferente o positivo cuando se lo compara con situaciones de exclusión completa de las actividades agropecuarias (Cingolani et al. 2008).

Milchunas et al. (1988) postulan que las respuestas de las comunidades vegetales al pastoreo de grandes herbívoros van a depender de la disponibilidad de agua del suelo y de la existencia o no de co-evolución entre los hervíboros y la vegetación. De acuerdo con la historia evolutiva de pastoreo de las diferentes comunidades vegetales, poseerán mayor o menor resiliencia frente a disturbios generados por herbivoría.

McNaughton (1985) encuentra en las praderas del Serengueti que, aquellas que fueron clausuradas al pastoreo de grandes herbívoros, tienen menores índices de productividad primaria neta (PPN) al ser comparadas con praderas que sufren la defoliación de herbívoros de diferentes tamaños y pesos, ya sea durante la estación seca o húmeda. También indica que, de acuerdo a la posición del paisaje en que se encuentre una comunidad dada, tendrá mayor o menor disponibilidad de recursos $\mathrm{y}$, por ende, una diferencia en la PPN. Las tierras más altas son menos húmedas respecto de las bajas $\mathrm{y}$, es en estas últimas, donde se concentran los mayores niveles de diversidad y productividad. Generalmente, cuanto más diverso es un ecosistema, mayor resistencia tendrá frente a las fluctuaciones impuestas por un disturbio como el pastoreo (Díaz et al. 1999; 2007).

En términos generales hay consenso en que la región patagónica ha evolucionado con altas cargas de grandes herbívoros silvestres, como los Guanacos (Lama guanicoe), los cuales necesitan altos volúmenes de forraje para satisfacer sus necesidades alimenticias (Lauenroth 1998). Además, presenta una amplia heterogeneidad paisajística lo cual le confiere una amplia variabilidad espacial de la distribución de la PPN, siendo mayor en sitios subhúmedos y decreciendo conforme aumenta el grado de aridez (Aguiar 1999; Oesterheld et al. 1998; León et al. 1998). Adler et al. (2004; 2005) comparan estepas arbustivas áridas y semiáridas del Noroeste de Norteamérica y de Patagonia, ambas con características edáficas y climáticas similares pero con diferente historia evolutiva de pastoreo. Estos autores establecen que las diferencias evolutivas en ambos ecosistemas son observables a través de la comparación de las características morfológicas y 
químicas de las diferentes especies (altura total de las plantas, longitud de las hojas, contenido de carbono y nitrógeno, contenido de sílice). Estas características, indirectamente, permiten inferir la evolución de estos sistemas, argumentando que aquellos sitios que presentan especies de baja calidad nutricional son los que han evolucionado con altas cargas de pastoreo, ya que esta disminución en la calidad del forraje es considerada como una estrategia de defensa contra la herbivoría. De acuerdo con estos trabajos, los pastizales de la región patagónica, que presenta especies de menor altura, con vegetación de porte rastrero o arrosetadas, con menores niveles de nitrógeno y mayor contenido de fibra, habrían evolucionado con marcada presión de pastoreo.

Con la llegada de los pobladores extranjeros y el ganado ovino a finales del siglo XIX comienza un proceso de degradación de los pastizales. Los pastizales patagónicos, conformados por especies leñosas y herbáceas, ofrecen forrajes de diversas calidades, lo que sumado al hábito selectivo del ganado doméstico, empobrece la calidad del sistema y produce la pérdida de especies de alto y mediano valor forrajero (Adler et al. 2005). La sobrecarga animal es señalada como principal causa del empobrecimiento y, en algunos casos, la eliminación completa del estrato herbáceo (Bisigato y Bertiller 1997; 1999; Bisigato et al. 2005; Bisigato et al. 2008; De León 2004; Díaz et al. 2007). De no realizarse un manejo adecuado de los rodeos, implementando rotaciones y descansos, comienzan a decrecer las especies deseables, a hacerse más frecuentes las intermedias y las indeseables, hasta el punto en que las especies dominantes son las indeseables, poco frecuentes las intermedias, y no están presentes las deseables (De León 2004; Sabattini et al. 2002; Díaz et al. 2007). Además de la ausencia de especies herbáceas de alta preferencia por el ganado doméstico, en algunos sectores fuertemente impactados por la sobrecarga animal sólo se encuentran algunos individuos de especies herbáceas que están restringidos al interior de las matas de arbustos que les ofrecen protección contra la herbivoría (Aguiar 1999). También el régimen de tenencia de las tierras, con potreros de amplia extensión y escasas divisiones y aguadas, actúan de forma negativa sobre el manejo de los recursos forrajeros involucrados. Es muy habitual observar gradientes de sobreutilización de la vegetación en cercanías de las aguadas. Se observan signos de sobrepastoreo en las zonas cercanas a las aguadas y una disminución de la presión a mayores distancias de éstas, provocando una sobreutilización de algunos sectores y la subutilización de otros. Las áreas más cercanas a las aguadas son las que presentan 
menor proporción de especies preferidas por el ganado (Bisigato y Bertiller 1997; Bisigato et al. 2005; Cingolani et al. 2005; 2008).

Un efecto negativo relacionado con la cría extensiva de ganado es la compactación del suelo. Esta es la pérdida de los espacios porosos de la capa superficial del suelo ocupados por aire y agua (Hang et al. 1995). El pisoteo de los animales va reduciendo estos espacios dificultando o impidiendo la normal infiltración de las precipitaciones, el establecimiento de nuevos ejemplares de especies vegetales leñosas y herbáceas y el ciclado de nutrientes (Adler et al. 2005; Cingolani et al. 2008; Funk et al. 2012). A las elevadas cargas animales de las últimas décadas, le siguieron años (2005-2012) en los que la presión de pastoreo fue disminuyendo producto de un período poco favorable para la producción agropecuaria de secano, obligando a los productores a descargar los campos (M.A.G. y P. 2010). Este es un fenómeno reciente que origina cambios que aún se están investigando (Maestre 2016).

La agricultura extensiva de secano es considerada la actividad productiva que más negativamente impacta sobre los recursos naturales de la región. La habilitación de nuevas superficies para la implantación de monocultivos son causantes de severos disturbios sobre los ecosistemas naturales. Para llevar adelante estos cultivos se aplican técnicas y tecnologías que fueron desarrolladas para zonas más húmedas y extrapoladas a esta región (Demaría et al. 2008). Estas técnicas consideran la eliminación completa de la vegetación nativa mediante el desmonte mecánico a tala rasa. Los suelos, que muestran elevados índices de erodabilidad, quedan expuestos a los intensos vientos tan característicos de la región, perdiéndose las aptitudes productivas de los campos de la zona (Ayesa et al. 2010; Gaitán et al. 2009; Botero y Russo 2000). Existe una situación intermedia, entre el desmonte a tala rasa y la ganadería de monte, el desmonte ganadero, que consiste en eliminar la cobertura arbustiva y arbórea más densa para favorecer el rebrote del estrato herbáceo, o la implantación en franjas de verdeos para mejorar la oferta de forraje de zonas naturalmente pobres.

La cobertura vegetal natural leñosa juega un rol preponderante en la amortiguación de episodios climáticos extremos, como fue la sequía que se registró en el período 20052010 (De Berasategui 2004; Martin com. pers.). Durante esta sequía, no solamente tuvo lugar una significativa reducción de la cobertura del suelo, sino que también se produjo una erosión eólica muy importante, la cual trajo aparejada la pérdida de la capa fértil y 
el banco de semillas, incrementando la degradación de los ecosistemas de la zona (Zeberio 2012).

Las tierras cubiertas por vegetación nativa se vieron afectadas por diferentes procesos de cambio en el uso del suelo. Como producto del avance de la frontera agropecuaria y el consiguiente abandono de zonas de cultivo por eventos naturales adversos, se observan amplias superficies de suelo con severos síntomas de degradación que necesitan de alguna intervención activa para revertir esta situación.

Diversos autores han observado y cuantificado este proceso en diferentes lugares del país. Demaría et al. (2008) cuantificaron el reemplazo de los pastizales pampeanos en la provincia de San Luis por monocultivos y forrajes para el ganado y caracterizaron ese reemplazo de comunidades vegetales entre los años 1985 y 2001 empleando imágenes Landsat TM. El área cubierta por pastizales naturales se redujo de un $92 \%$ a un $43,8 \%$, incrementándose también la tasa anual de transformación, que evidencia el cambio de uso del suelo. Pezzola y Winschel (2004) evaluaron el proceso de degradación ocurrido desde el año 1975 hasta el 2002 en el partido de Patagones. A través del estudio multitemporal cuantifican la degradación del monte nativo. Esta degradación se vio impulsada por políticas de desarrollo de la época. Los organismos provinciales ofrecían créditos para efectuar desmontes e incorporar tierras a la producción agrícola de secano, más precisamente la producción de trigo. Es importante destacar que esta zona es considerada un área marginal para la producción de este cereal, registrándose rindes muy bajos (800-1100 kg ha ${ }^{-1}$ ). En su análisis, Pezzola y Winschel (2004), estiman la pérdida de monte en 386.542 ha entre los años considerados. Estas tierras desprovistas de cobertura vegetal y expuesta a los factores erosivos, muestran avanzados signos de degradación. Además, Lini (2008) realiza un análisis del desmonte en el departamento de Adolfo Alsina, General Conesa, y sur de Pichi Mahuida, entre los años 1986 y 2006, estimando que en todo ese sector se perdió un total de 36.973 hectáreas de monte nativo para la implementación de cultivos de secano.

Ante este escenario de cambio en el uso de la tierra en una zona con marcado déficit hídrico, con un índice de aridez que sitúa a la región como semiárida, Abraham et al. (2016) encontraron signos incipientes de desertificación.

La desertificación es la pérdida de productividad de un sistema determinado, dado por un empobrecimiento o destrucción de sus componentes físicos y biológicos, causados 
por una excesiva sobreutilización combinada con factores climáticos extremos (Whitford 2002). La Convención de las Naciones Unidas de lucha contra la Desertificación define la desertificación como la degradación de las tierras secas (áridas, semiáridas y subhúmedas secas), fenómeno originado por las actividades humanas y las variaciones del clima. Un factor fundamental es la inadecuada utilización de los recursos naturales, la aplicación de tecnologías no adaptadas y la sequía (Abraham et al. 2011; 2016).

La desertificación genera marcados cambios en los factores físicos y biológicos de una región. Los efectos observables son la disminución paulatina de la cobertura vegetal, la pérdida de suelo, pérdida de materia orgánica, acumulaciones de arena y escorrentía. En la mayoría de los ecosistemas del mundo estos síntomas se relacionan, además, con la merma de la PPN, la desaparición de especies con valor forrajero, el reemplazo de especies herbáceas por especies leñosas, entre otras (Whitford 2002). Numerosos ejemplos son observables en diferentes ecosistemas áridos y semiáridos del mundo, El Shael, Etiopia, España, Australia y la Patagonia argentina son claros ejemplos de esto (Aronson et al. 2007; Maestre et al. 2009; Gaitán et al. 2014; García-Palacios et al. 2010; Cortina et al. 2006; 2011; Aguiar y Sala 1999; Ludwing et al. 2005).

\subsection{2- Posibilidades de recuperación de la estructura y las funciones ecosistémicas.}

Frente a este escenario de cambio en los usos del suelo y degradación de los recursos naturales, la restauración ecológica aparece como una herramienta importante que aporta los lineamientos generales para recuperar las áreas degradadas. A medida que un ecosistema se degrada es posible observar cambios negativos en los componentes bióticos y abióticos como así también en las relaciones que existen entre ellos (King y Hobbs 2006). El proceso de degradación es visualizado a través de cambios en la cobertura de la vegetación. Un ejemplo de ello es la arbustización de pastizales y/o el aumento del suelo desnudo. Si los factores que producen la degradación persisten o se intensifican, los procesos erosivos pueden llevar a la pérdida de suelo y disminución de la capacidad productiva de los mismos (Aronson et al. 1993; Cortina et al. 2006).

Las tierras secas poseen tiempos de recuperación muy lentos y cuanto más umbrales de degradación se van superando, más lenta y costosa es la recuperación (Bradley y Mustard 2005; Bradshaw 1996). En este sentido, partiendo del análisis de los diferentes componentes del ecosistema, será posible identificar el umbral de degradación 
superado, el factor desencadenante de la degradación, como así también el tipo de práctica que se requiere para revertir el estado actual del ecosistema (Aronson et al. 1993; King y Hobbs 2006).

La finalidad de la restauración ecológica es devolver a los ambientes degradados las funciones ecológicas perdidas, reparando los caracteres físicos y biológicos propios de esas comunidades. Sin embargo, nunca se podrá regresar al estado que poseían antes de la irrupción del factor desencadenante de la degradación (Alexander et al. 2011; Ovalle et al. 1999; Clewell y Aronson 2007; Perrow y Davy 2002; Bradshaw 1996). Los objetivos de la restauración ecológica son recuperar los elementos y el funcionamiento de un ecosistema y transformar los ambientes recuperados en relictos que no vuelvan a ser intervenidos y mantenerlos como museos vivos (Fraterrigo y Rusak 2008; van Andel y Aronson 2012). Sin embargo, existe una serie de disciplinas que derivan de la restauración ecológica y utilizan los mismos principios, aunque los fines perseguidos son diferentes. Así aparece la remediación ambiental, la reclamación ambiental y la rehabilitación (Figura 1.3). Esta última, a diferencia de las demás, pretende devolver a los ecosistemas degradados algunas de las funciones ecológicas pérdidas y, además, recuperar su productividad para que puedan seguir siendo explotados por el hombre, aunque de forma sostenible (Fraterrigo y Rusak 2008; Bradshaw 1996). En aquellas zonas donde se ha perdido la cobertura vegetal y la capa superficial de suelo se busca detener la degradación, dotando de cobertura a la superficie del suelo y así acelerar los procesos sucesionales. En zonas productivas, con pastizales naturales que presentan síntomas de degradación edáfica, pérdida de productividad por la invasión de especies indeseables o la colonización de especies arbustivas, se busca favorecer mediante la aplicación de técnicas adecuadas, el reclutamiento de las especies deseables y mejorar las condiciones de esos sistemas (Whitford 2002; Hobbs y Cramer 2008; Cortina et al. 2006). 


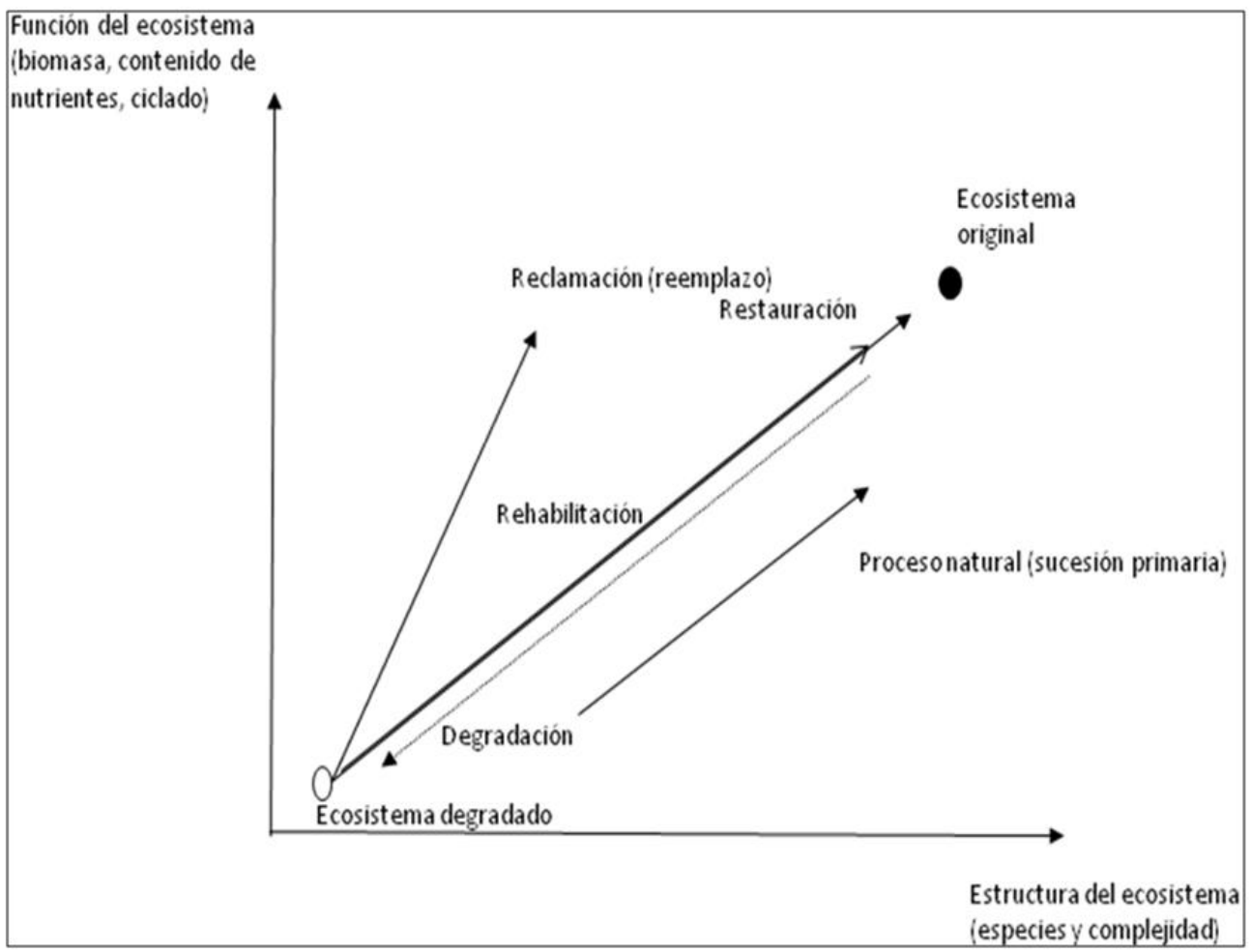

Figura 1.3. Opciones que puede seguir un ecosistema degradado. Fuente: Bradshaw y Chadwick 1989.

También existen, dentro de la restauración y la rehabilitación de ecosistemas diferentes posturas, frente al tipo de intervención a llevar adelante sobre el ecosistema. Así, se diferencia la restauración activa y la restauración pasiva. La primera propone actuar de forma proactiva frente al escenario de degradación que observamos. Elimina el agente causante del disturbio y asiste en la recuperación de ese ecosistema, ya sea reintroduciendo ejemplares de especies que han sido extintas a nivel predial o, en aquellos sistemas que han perdido su cobertura vegetal, introduciendo ejemplares de especies nativas que disparen la sucesión ecológica. Estas especies pueden ser facilitadoras o especies que ofrezcan algún servicio adicional como puede ser la fijación de nitrógeno atmosférico, aporte de carbono orgánico al suelo, etc. La restauración pasiva presupone solamente eliminar el disturbio y dejar que la sucesión ecológica continúe con el reclutamiento de individuos de las especies que aún están presentes (Dobson et al. 1997; Valladares y Gianoli 2007; Hobbs y Cramer 2008; Alexander et al. 2011).

Los proyectos de restauración, en sentido amplio, además del conocimiento científico deben contemplar aspectos sociales, económicos y ambientales (Chazdon et al. 2017). La conveniencia de llevar a cabo un proyecto de recuperación de un área degradada no 
debe definirse sólo en función del grado de conservación del ecosistema sino también de las necesidades de los habitantes del área involucrada. La intensidad de o de los disturbios y el grado de deterioro del ecosistema determinarán si la recuperación de su funcionalidad requiere de una intervención activa o sólo será suficiente la remoción de los factores de disturbio para lograr los objetivos planteados en plazos relativamente aceptables.

Los ecosistemas naturales del Noreste de la provincia de Río Negro son generadores de cuantiosos servicios ecosistémicos, como puede ser el secuestro de carbono atmosférico en la biomasa vegetal y el suelo. Además, ofrecen refugio a innumerables especies silvestres de aves, reptiles y mamíferos y dan soporte a las actividades productivas destinadas a satisfacer las necesidades de la población (Aguiar 1999; Bertiller 1999; León et al. 1998). Así, aparece la rehabilitación como una alternativa de marcada importancia para afrontar el avance de la desertificación de tierras secas en el Noreste patagónico.

En la estepa patagónica los trabajos realizados sobre rehabilitación de tierras degradadas son escasos y con diferente nivel de profundidad (Zuleta et al. 2007; Funk et al. 2012; Kowaljow y Rostagno 2013). Para el área del presente estudio no se han desarrollado prácticas de este tipo.

Frente a este escenario, donde se ejerce una presión creciente sobre las tierras y los recursos naturales renovables destinados a la producción agropecuaria de secano, es imperante contar con un diagnóstico de la situación en que se encuentran los sistemas naturales involucrados y tomar medidas para la gestión y recuperación de estas zonas.

Para ello, en este trabajo se plantearon las siguientes hipótesis y objetivos.

\section{Hipótesis}

- En el Noreste de la provincia de Río Negro los disturbios antrópicos (pastoreo, cambios en el uso del suelo y manejo del fuego) han provocado una degradación del ecosistema, que se manifiesta en una marcada pérdida de la diversidad vegetal y un empobrecimiento del sustrato que afecta las actividades productivas desarrolladas en el sector.

- Con el manejo adecuado y la implementación de acciones tendientes a la 
recuperación, tales como la reintroducción de especies, es posible generar una mejora sustancial de las áreas degradadas del Monte favoreciendo su rehabilitación.

\section{Objetivos}

General

Identificar y caracterizar áreas con diferente estado de conservación de la vegetación del Monte en el Noreste de Río Negro, en términos de estructura y composición, con la finalidad de evaluar las posibilidades de rehabilitación de las mismas donde fuere necesario y proponer acciones de rehabilitación adaptadas a ecosistemas semiáridos.

Específicos.

- Describir la composición y la estructura de la vegetación del Monte en el Noreste de la provincia de Río Negro e identificar los principales factores climáticos, edáficos y de uso del suelo que influyen en el desarrollo de las comunidades vegetales.

- Analizar la incidencia de los factores climáticos (temperatura y precipitaciones), edáficos (densidad aparente, textura, $\mathrm{pH}, \mathrm{Ce}^{-}$, $\mathrm{RAS}$, contenido de materia orgánica, nitrógeno total y fósforo y) y tipos de uso (tipo de actividad, intensidad de pastoreo, manejo de los rodeos y ocurrencia de incendios) sobre la estructura y diversidad de la vegetación, asociados con los procesos de degradación.

- Analizar el uso histórico y actual de la tierra y su incidencia en el cambio vegetacional.

- Realizar la zonificación del Monte del Noreste de Río Negro basada en las características florísticas de la vegetación, el uso de la tierra y los distintos niveles de degradación identificados.

- Plantear estrategias de rehabilitación aplicables en áreas degradadas del Monte del Noreste rionegrino, establecidas previamente. 


\section{Capítulo II}

\section{Caracterización general del área de estudio}

El área de estudio se ubica en el Noreste de la provincia de Río Negro. Según León et al. (1998), desde el punto de vista fitogeográfico, esta región se incluye en el Monte Oriental o de Transición. Morello et al. (2012), teniendo en cuenta las ecorregiones, la incluye en el Complejo de Planicies y Mesetas Norpatagónicas. La escala de análisis regional permite poner en evidencia la heterogeneidad de la vegetación, los suelos y la geomorfología (García 2006). Se realiza una descripción de los principales factores ambientales que influyen sobre la presencia y desarrollo de las comunidades vegetales nativas del área de estudio (Figura 1.2).

\section{1- Clima}

Por efectos generados por su latitud y su cercanía a la zona costera, el área de estudio presenta un régimen térmico moderado por efectos marítimos, con temperaturas medias anuales del orden de $14-15^{\circ} \mathrm{C}$. Las temperaturas de los meses más cálido y más frío, es decir de los meses de enero y julio, son de $22-24{ }^{\circ} \mathrm{C}$ y de $7-8{ }^{\circ} \mathrm{C}$, respectivamente (Figura 2.1).

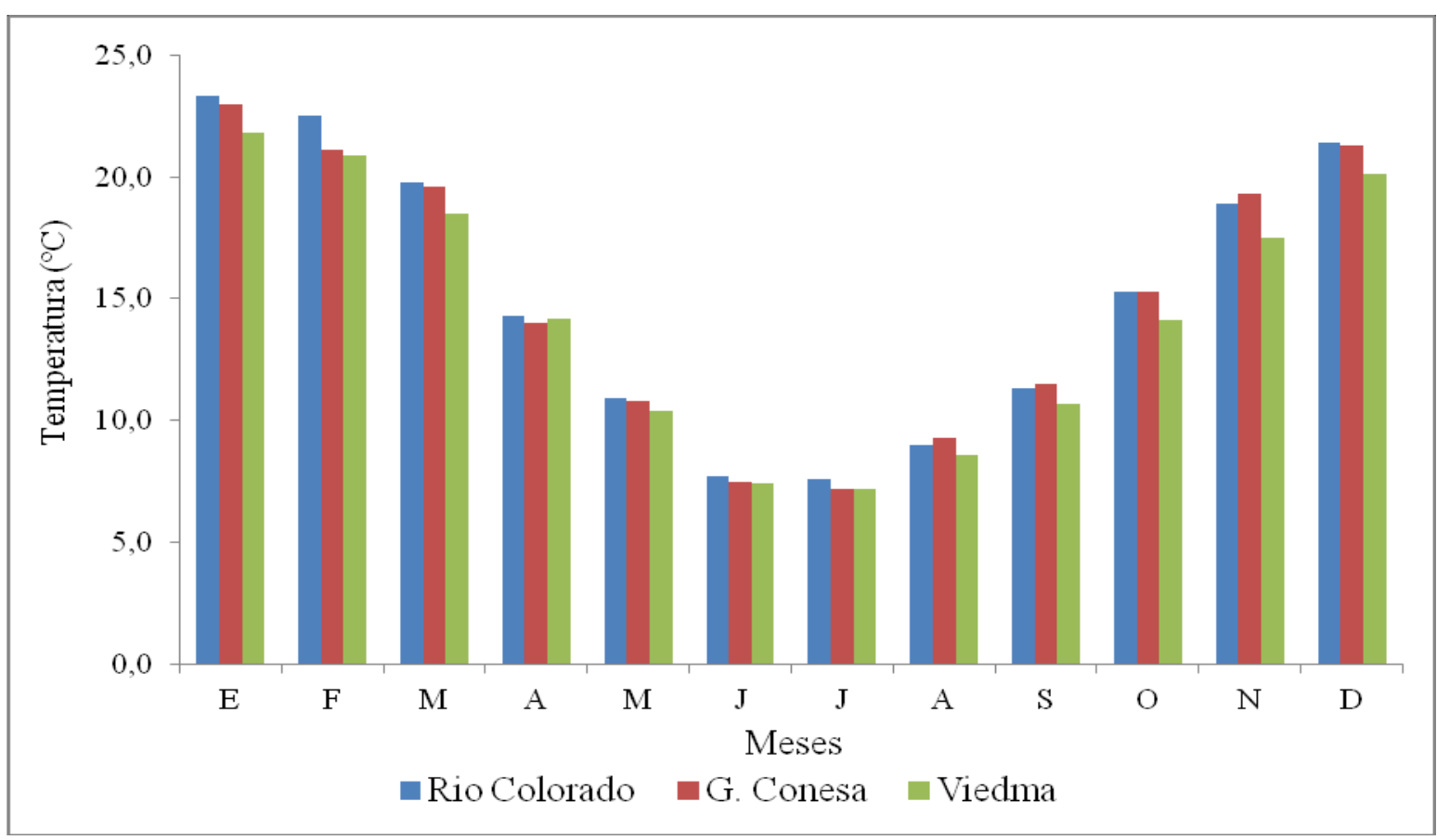

Figura 2.1. Temperatura media mensual en el período 1965- 2004. Fuente: Godagnone y Bran, 2009.

Para el área, el clima se corresponde con el tipo climático $\mathrm{Db}_{2}{ }_{2} \mathrm{da}$ ', denominado 
semiárido mesotermal, caracterizado por presentar una concentración de las precipitaciones de predominio estival aunque se observa una tendencia a una distribución bimodal, con máximos observados en los meses de mayo y de octubre. Además, presentan poco o ningún excedente de agua en el período de crecimiento de las plantas (De Berasategui 2004; Godagnone y Bran 2009) (Figura 2.2).

Las precipitaciones se caracterizan por presentar un leve aumento desde la zona Oeste, donde se registran las menores cantidades anuales $(250 \mathrm{~mm})$, aumentando en dirección Este- Noreste. Los promedios anuales se incrementan de manera gradual hasta el límite Este de la provincia, donde se registran $311 \mathrm{~mm}$ en la ciudad de Viedma y $424 \mathrm{~mm}$ en la ciudad de Río Colorado (De Berasategui 2004; Godagnone y Bran 2009; León et al. 1998) (Figura 2.2).

Durante el semestre primavera-verano, que es el de mayor importancia desde el punto de vista agronómico, las precipitaciones son irregulares por su distribución y deficitarias para los cultivos. Esto se debe tanto a los mayores requerimientos hídricos de las diferentes especies vegetales, que se encuentran en pleno crecimiento, como a la incidencia de las altas temperaturas y los vientos predominantes y de gran intensidad que provienen, generalmente, de sectores $\operatorname{secos}(\mathrm{N}$ y NO). Durante el período otoñoinvierno las lluvias se producen con mayor regularidad, resultando en un régimen menos deficitario debido a que las temperaturas son menores, la humedad relativa es mayor y los vientos más moderados (De Berasategui 2004; Godagnone y Bran 2009).

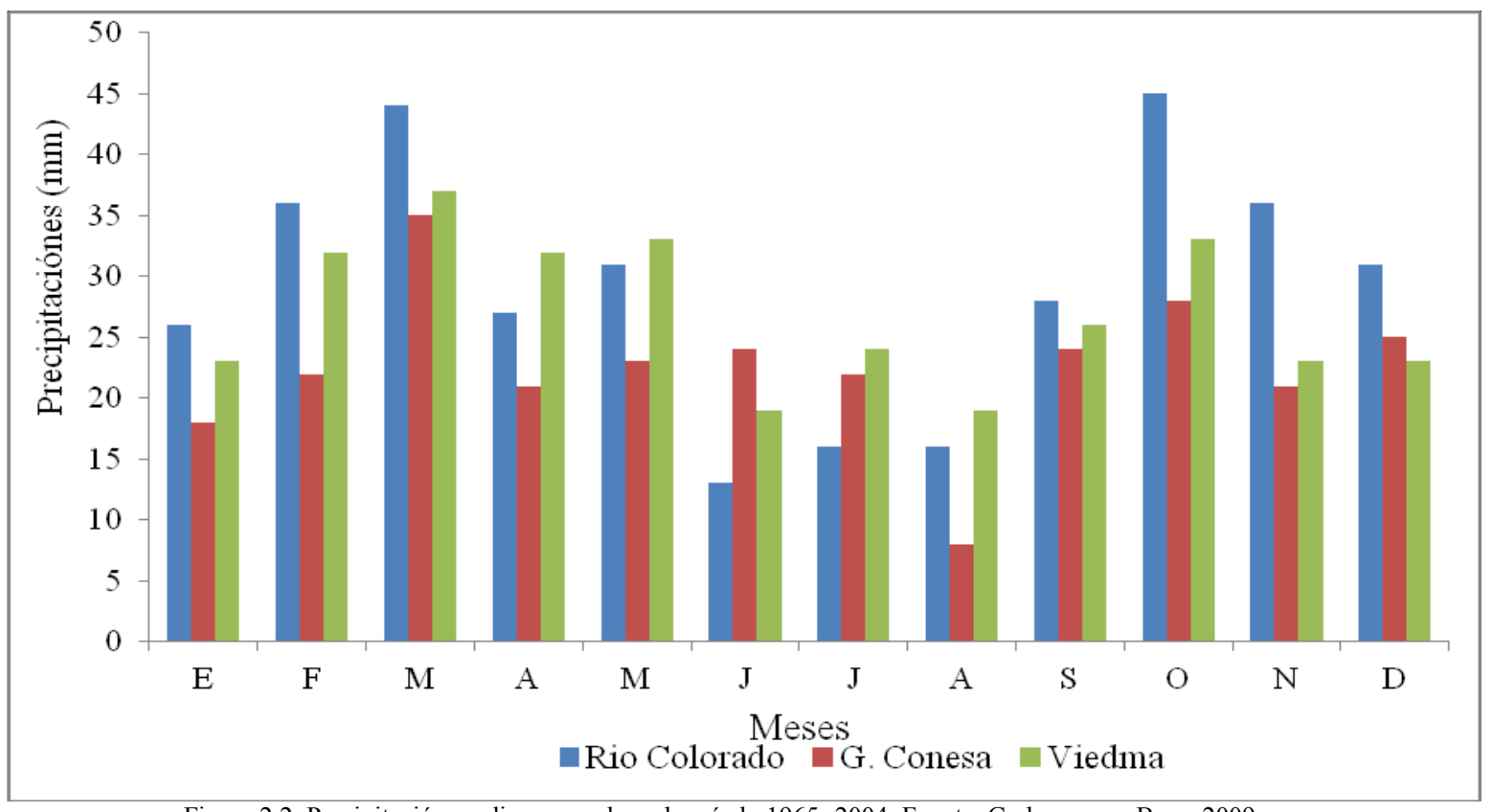

Figura 2.2. Precipitación media mensual en el período 1965- 2004. Fuente: Godagnone y Bran, 2009. 
Entre los años 2005 y 2010 se registró en el área de estudio una fuerte sequía, con precipitaciones inferiores a la media histórica (Figura 2.3).

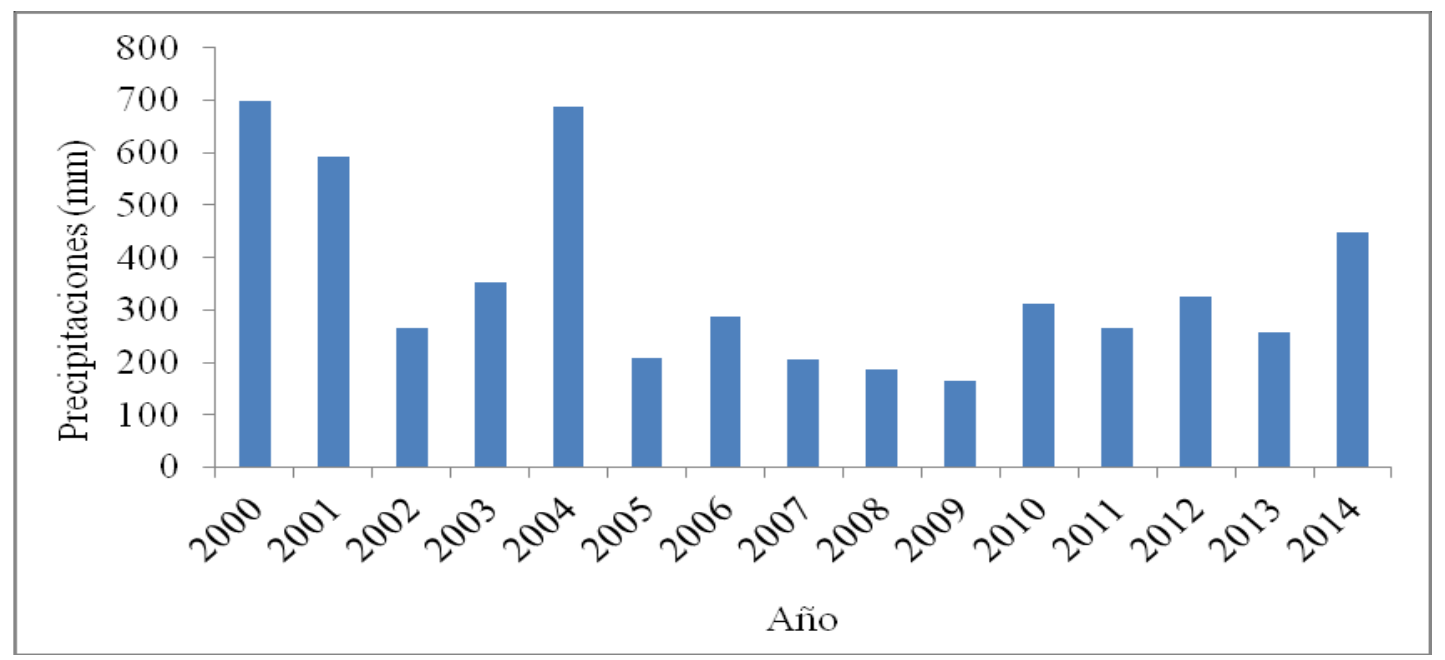

Figura 2.3. Precipitaciones medias anuales en el período 2000- 2014. Fuente: EEA INTA Valle Inferior del Río Negro.

En la zona costera del área, se registran vientos de origen marítimo, los cuales vienen cargados de vapor de agua y presentan dirección SSE. Hacia el O se incrementa la frecuencia de vientos de dirección Norte y Noreste, presentando los períodos de calma más bajos registrados en la provincia de Río Negro (Figura 2.4). La velocidad media, a los 10 metros de altura, muestra promedios variables entre los 10 y los $14 \mathrm{~km} / \mathrm{h}$. La velocidad del viento y la dirección está sujeta a variaciones topográficas, a la orientación de las pendientes, reparo, etc. Debido a la intensidad y regularidad, se reconoce que este meteoro es el que mayor impacto tiene sobre la población y las actividades que esta lleva a cabo. De los factores climáticos considerados, el viento es el que mayores variaciones presenta de acuerdo al sitio donde se lo observe. Además, el viento incide negativamente sobre la ganadería extensiva, ya que produce mayores demandas evapotranspirativas en el período primavero-estival, que es el período en que mayor presión se ejerce sobre la vegetación natural. 


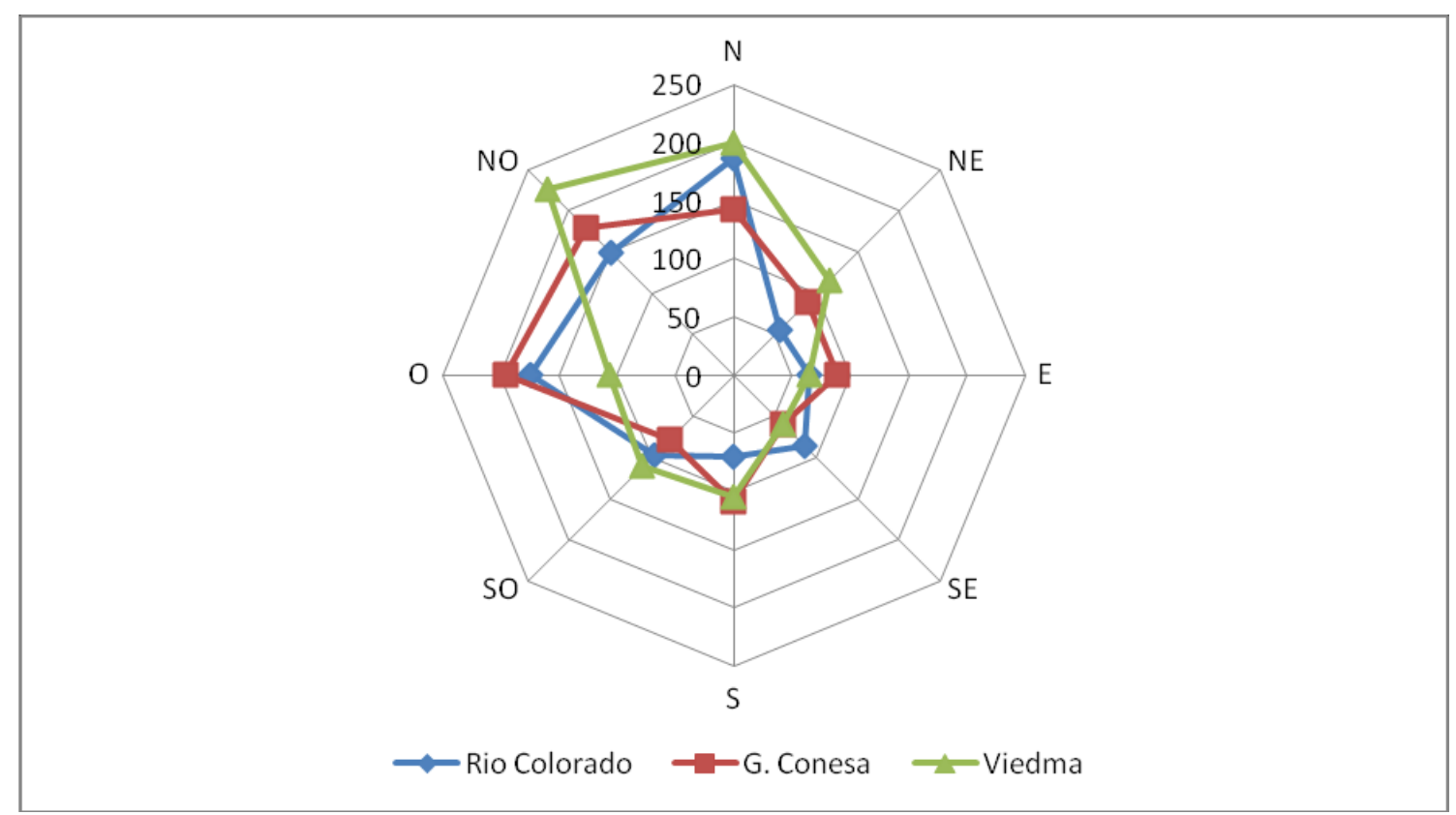

Figura 2.4. Frecuencia media de la dirección del viento, expresada en fracciones de 1000. Fuente: Godagnone y Bran, 2009.

\section{2- Geomorfología}

En el área de estudio se han descripto diferentes unidades geomorfológicas. Algunos autores distinguen en el Noreste de la provincia de Río Negro los ambientes geomorfológicos denominados planicies interfluviales mesetiformes y planicie loéssica (Godagnone y Bran 2009). Sin embargo, dentro de estos ambientes, Etcheverría et al. (2006), Etcheverría y Folguera (2009) y Martínez et al. (2001), con otra escala de trabajo, describen con más detalle los ambientes geomorfológicos que componen el paisaje del Noreste de la provincia de Río Negro. Los ambientes descriptos por estos autores son denominados Planicie Loéssica, Ambiente Mesetiforme, Bajos y Ambientes Eólicos (campos de dunas) (Figura 2.5).

El ambiente Planicie Loéssica se encuentra representado en el sector ubicado al Este, en cercanías a la costa atlántica, donde la capa de loess adquiere un espesor más importante, cubriendo mesetas y bajos, otorgándole al paisaje un aspecto más suavizado y suavemente ondulado. En cercanías del océano Atlántico, esta capa adquiere un espesor tal que se torna dificultoso reconocer altos y bajos, formando un paisaje chato solo interrumpido por canales de marea y bajos aislados. En el Oeste del área, aparece como una delgada capa de sedimentos de material fino sobre el paisaje mesetiforme, con espesores que no superan los $50 \mathrm{~cm}$ (Etcheverría et al. 2006; Etcheverría y Folguera 2009; Godagnone y Bran 2009; Martínez et al. 2001). 
El ambiente mesetiforme se corresponde con una antigua planicie aluvial disectada, formada por facies distales y abanicos aluviales, ubicándose en casi toda el área de estudio en las zonas más alejadas del océano Atlántico. Este ambiente es una amplia planicie mesetiforme recortada por numerosas depresiones entre las que se diferencian los bajos mayores y menores y los paleocanales, que serían antiguas vías de escurrimiento o cursos de agua. Abarca una amplia superficie, con una suave pendiente local con dirección NO- SE, donde predomina una cubierta de depósitos fluviales gruesos. El ambiente mesetiforme se pierde hacia el E donde los sedimentos fluviales son cubiertos por sedimentos loessicos que producen un suavizado del paisaje. Se distinguen dos niveles; uno más antiguo, ubicado al Norte y otro más moderno, ubicado al Sur, con una cota más baja. El nivel de la planicie aluvial más antigua varía entre los 100-150 m.s.n.m y termina en una fuerte escarpa de erosión. La planicie de cota menor, ubicada al Sur de la zona estudiada, está muy disectada en cercanías del Río Negro, producto de la acción erosiva de un antiguo brazo que drenó por ese sector (Etcheverría et al. 2006; Etcheverría y Folguera 2009; Martínez et al. 2001).

Los bajos presentan, en general, formas elipsoidales y bastante irregulares. Su profundidad puede llegar a ser de 50 metros y los diámetros variables, desde unos pocos kilómetros hasta 20 kilómetros cuando se genera coalescencia de bajos adyacentes, como ocurrió al sur del Río Negro. Estos tienen una dirección NO- SE, y en los más profundos se observan deslizamientos y caídas de rocas hacia la parte central. También se registran acumulaciones eólicas como consecuencia de la deflación que moviliza los sedimentos finos del sector. La mayoría de estos bajos presentan en su interior barreales y deposiciones evaporíticas, como salinas y salitrales. Tienen una red de drenaje de tipo centrípeto con colectores efímeros. Algunos de estos bajos presentan barrancas de varios metros de altitud (Etcheverría et al. 2006; Etcheverría y Folguera 2009; Martínez et al. 2001).

Los Paleocanales, que corresponden a antiguos cursos, presentan formas elongadas con dirección NO- SE. Generalmente, son poco profundos y suelen tener varios kilómetros de longitud. En la parte Norte del área, sobre el nivel más elevado de la planicie aluvial, se ha desarrollado una red de paleocanales formada por antiguos cursos del abanico aluvial, que posee diseño anastomosado y terminan de forma abrupta como valles colgantes. En la porción Sur del área de estudio los paleocanales surcan la planicie en cercanías del Río Negro debido a la acción erosiva de antiguos brazos del río que 
desaguaron por ese sector (Etcheverría et al. 2006; Etcheverría y Folguera 2009; Martínez et al. 2001).

El Ambiente Eólico de campo de dunas se ubica en el sector Sur del área de estudio. Está constituido por dunas de alturas superiores a los 10 metros, de gran longitud de onda, algunas de ellas activas y otras fijadas por la vegetación y posteriormente achatadas por degradación. La orientación está en relación a la dirección de los vientos predominantes en el área, es decir de dirección Sur- Norte. Las dunas presentan formas barjanoides, con su cara de avalancha hacia el Norte (Etcheverría et al. 2006; Etcheverría y Folguera 2009; Martínez et al. 2001). 


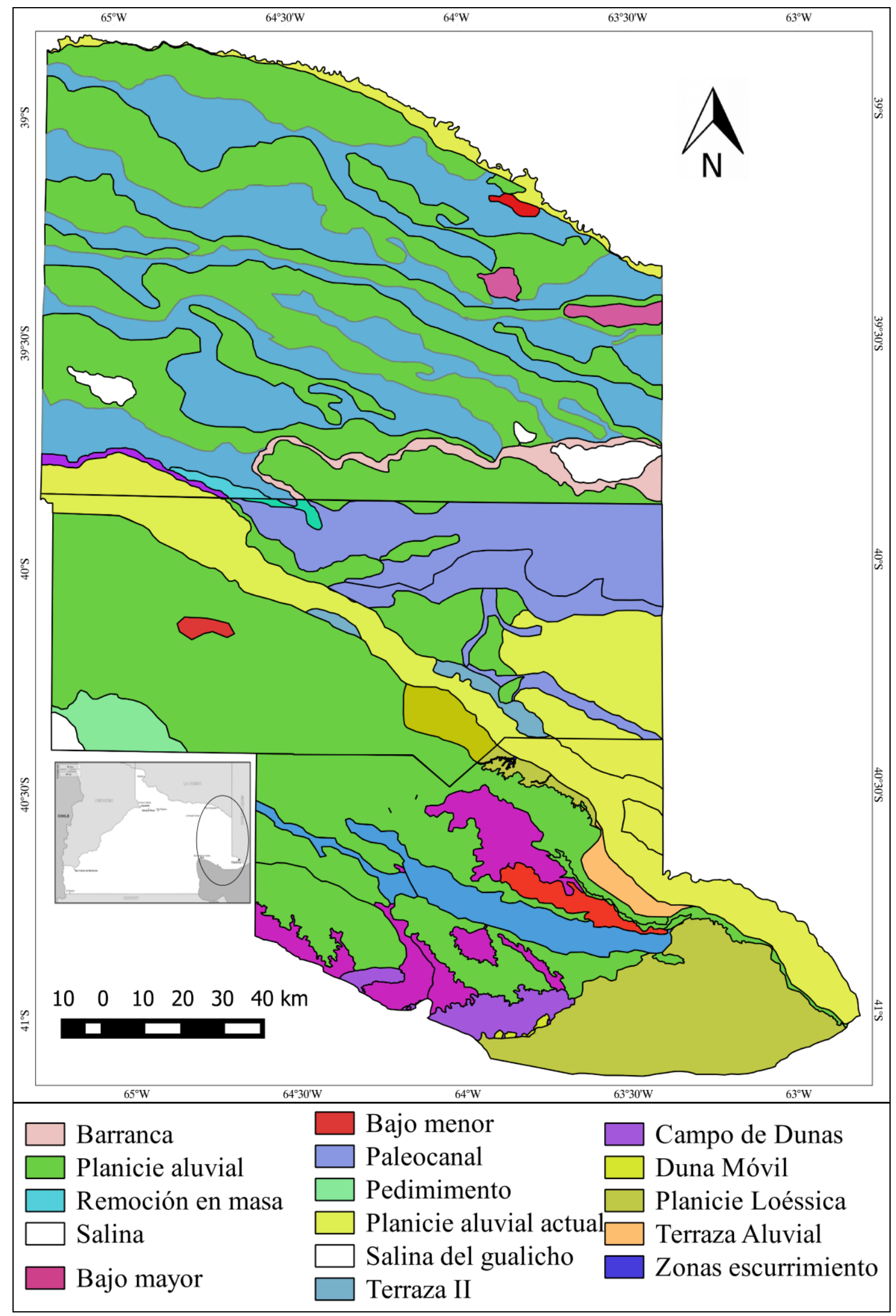

Figura 2.5. Mapa geomorfológico de los partidos Adolfo Alsina, General Conesa y Pichi Mahuida. Fuente: Echeverría y Folguera, 2009. 


\section{3- Suelos}

Las variaciones en el clima atmosférico se encuentran reflejadas en los climas edáficos, formando los regímenes de temperatura y humedad que permiten caracterizar a los suelos de una región, que son tomados por Soil Survey Classification como propiedad diagnóstica fundamental en todos los niveles jerárquicos de la clasificación (desde órdenes hasta familias y series) (Godagnone y Bran 2009; Panigatti 2010).

Según Van Wambeke y Scoppa (1980), el régimen de temperatura media anual en la provincia de Río Negro, a una profundidad de $50 \mathrm{~cm}$ es dominantemente mésico (temperatura mayor a $8{ }^{\circ} \mathrm{C}$ e inferior a $15^{\circ} \mathrm{C}$ ), exceptuando la parte Norte del territorio, que incluye nuestra área de estudio, donde el régimen es térmico (mayor a $15^{\circ} \mathrm{C}$ y menor a $\left.22^{\circ} \mathrm{C}\right)$.

Los regímenes de humedad del suelo se basan en el nivel de la capa freática y la presencia o ausencia de agua disponible para las plantas. Estos regímenes afectan a la formación del suelo y a la gestión y uso del mismo. Los régimenes de humedad varían de ácuico, perúdico, údico, ústico, xérico y arídico (Godagnone y Bran 2009; Jaramillo 2002; Gardi et al. 2014).

Dentro del ámbito provincial se han reconocido siete órdenes de suelo, aunque en la zona de estudio sólo están presentes los Aridisoles, los Entisoles y los Molisoles (Figura 2.6; Anexo I, tabla 1) (Godagnone y Bran 2009).

Los Aridisoles son suelos asociados a climas áridos y semiáridos con vegetación xerófila, caracterizados por no poseer agua aprovechable para las plantas durante largos períodos de tiempo. El agua en el suelo está retenida a más de 15 bares, o el suelo presenta sales, o ambas condiciones, que le impiden a las plantas obtener el agua y emplearla para sus procesos vitales. La ausencia de lavado en los perfiles constituyentes de estos suelos es una característica diagnóstica, y esta condición resulta de la poca cantidad de agua aprovechable que contiene el perfil. Además, esta propiedad, hace que las reacciones físico-químicas sean poco intensas si se las compara con las existentes en regiones más húmedas. Otra característica muy común es la presencia de pavimentos del desierto, que están formados por la contracción de las tierras finas o el hundimiento o secado rápido de las mismas. La grava puede ser transportada a la superficie del suelo por acción del aire atrapado cuando el suelo se humedece por acción de la lluvia. Otra 
característica destacada de estos suelos es la presencia de capas de acumulación de carbonato de calcio $\left(\mathrm{CaCO}_{3}\right)$ que aparecen a profundidad variable (Godagnone y Bran 2009).

Dentro de los Aridisoles, que ocupan la mayor parte de la provincia, están los Argides, Calcides, Cambides, y Salides. Dentro de los Argides se reconocen los Haplargides y Paleargides, y los Natrargioles y Petroargioles. Sin embargo, los de mayor representatividad en el área de estudio son los Haplargides, que están distribuidos en las mesetas basálticas y planicies aluviales antiguas. Además de las planicies, ocupan depresiones y pendientes, tienen un perfil medianamente profundo y están conformados por un horizonte argílico, uno transicional $\mathrm{BC}$ (a veces ausente) y un horizonte $\mathrm{C}$ (Etcheverría et al. 2006; Etcheverría y Folguera 2009).

Los Entisoles son suelos cuya evolución incipiente no les ha permitido desarrollar horizontes genéticos. En algunas ocasiones se pueden encontrar epipedones como el ócrico y antrópico.

La baja fertilidad y la presencia de materiales iniciales tóxicos para el crecimiento de las plantas limitan la diferenciación biológica del perfil del suelo, siendo una de las fuerzas principales para dificultar su desarrollo. Por otra parte, la saturación con agua, o aún la inundación del suelo por períodos largos, también inhibe el desarrollo del horizonte.

El orden de los Entisoles está presente en todo el ámbito provincial, destacándose varios grandes grupos. Entre ellos, en la zona de estudio, se encuentran los que presentan régimen de humedad údico (Udifuventes), los que presentan régimen de humedad xérico (Xerofluventes, Xerortentes, y Xeropsamentes) y los que presentan un régimen de humedad arídico (Torripsamentes, Torriortentes y Torrifluventes) (Godagnone y Bran 2009).

Los Molisoles son suelos que se caracterizan por presentar un horizonte superficial muy oscuro, relativamente fértil, profundo y rico en bases. La mayoría de estos se encuentra bajo vegetación de pastizales, aunque también bajo vegetación arbustiva.

La actividad biológica es muy importante en la génesis de los Molisoles y está estrechamente relacionada a la materia orgánica y posterior descomposición sub superficial de todos los residuos en presencia de cationes bivalentes, particularmente 
$\mathrm{Ca}^{+2}$. La evolución de la materia orgánica bajo estas condiciones conduce al fenómeno de melanización, el cual es responsable del oscurecimiento del suelo.

En el área de estudio, los Molisoles se encuentran representados por el suborden de los Ustoles y, dentro de los Ustoles, se han reconocido a los Haplustoles y Argiustoles, encontrados bajo régimen ústico. 


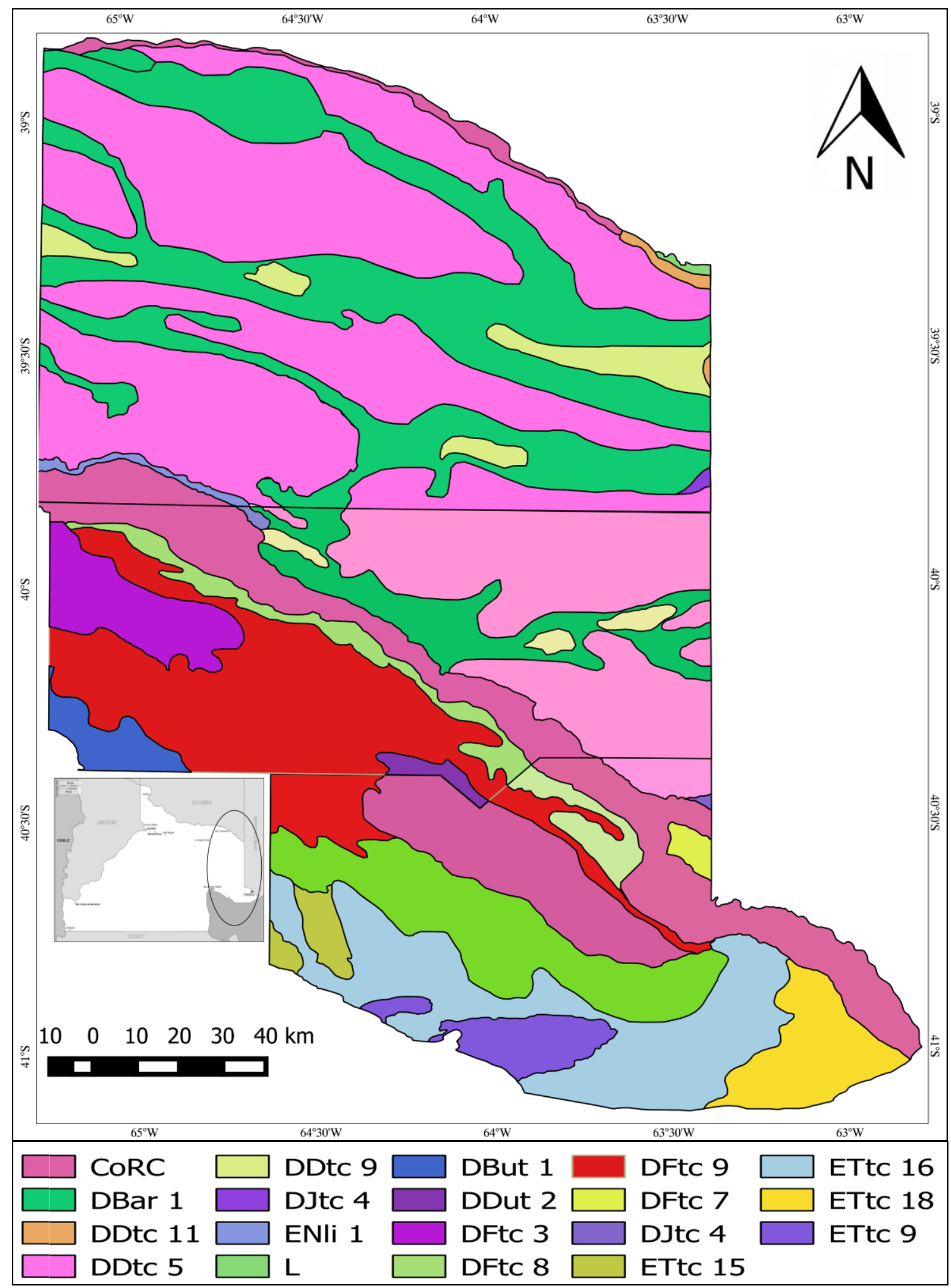

Figura 2.6. Suelos de los partidos Adolfo Alsina, General Conesa y Pichi Mahuida. CoRC: Complejo indiferenciado. ENli 1: Torripsamente lítico/ Torripsamente típico. DDtc 5: Natrarguides típico/ Torripsamente típico. DBar 1: Haplarguides arénico/ Torripsamente típico. DDtc 9: Natrarguides típico/ Torriortentes lítico. DJtc 4: Paleortides típico/ Haplarguides típico. DDtc 11: Natrarguides típico/ Fluvacuente típico. L: Lago-Laguna. DDut 2: Natrarguides ustólico/ Calciortides típicos. DFtc 9: Calciortides típicos/ Natrarguides ustólico. DBut 1: Haplargides ustólico/ Salortides acuólico. DFtc 3: Calciortides típicos/ Natrarguides típico. DFtc 8: Calciortides típicos/ Natrarguides ustólico. ETtc 18: Torripsamentes típicos/ Calciortides típicos. ETtc 16: Torripsamnetes típicos/ Calciortides típicos. ETtc 15: Torripsamentes típicos/ Calciortides típicos. ETtc 9: Torripsamentes típicos. DDut 1: Natrarguide ustólico/ Cambortides fluventicos. DFtc 7: Calciortides típicos/ Calciortides tí-picos. Fuente: Geo INTA. 


\section{4- Vegetación}

Varios autores han clasificado la vegetación del área de estudio desde diferentes miradas. Desde la fitogeografía, León et al. (1998) clasificaron la vegetación de la zona como de transición entre el Monte Austral y el Espinal, otorgándole el nombre de Monte Oriental. Godagnone y Bran (2009) identificaron diferentes tipos fisonómicoflorísticos para describir la vegetación de la zona. Morello et al. (2012) definieron, en base a diferentes componentes ambientales, la ecorregión Monte de Llanuras y Mesetas. De acuerdo con Morello et al. (2012), esta ecorregión se divide en subregión septentrional y subregión Austral. Esta última subregión se divide en varios complejos, entre los que se encuentra el complejo de Planicies y Mesetas Norpatagónicas, siendo ésta donde se emplaza el área de estudio del presente trabajo.

Independientemente del criterio de clasificación del área, los autores mencionados describen la vegetación del área perteneciente a los partidos de Pichi Mahuida, General Conesa y Adolfo Alsina como una estepa arbustiva de altura variable, nunca superior a los 3 metros, conformada por elementos arbustivos y herbáceos con elementos arbóreos presentes aunque aislados y agrupados en manchones (Godagnone y Bran 2009; León et al. 1998; Morello et al. 2012).

En áreas de pendientes suaves y depresiones extensas se desarrollan comunidades dominadas por Larrea divaricata Cav. y Schinus johnstonii F.A. Barkley, donde Chuquiraga erinacea D. Don erinacea, Prosopis alpataco Phill F. alpataco y Prosopidastrum globosum (Gillies ex Hook. \& Arn) Burkart aparecen como especies acompañantes. Dentro de estos ambientes, también se desarrollan comunidades de Larrea divaricata y Monttea aphylla (Miers) Benth. \& Hook que suelen ir acompañadas por Condalia microphylla Cav., Schinus johnstonii, Chuquiraga erinacea, Prosopis alpataco, Bredemeyera microphylla (Griseb.) Hieron. var. Microphylla, Junelia seriphioides (Gillies \& Hook. Ex Hook.) Moldenke y Acantholippia seriphioides (A. Gray) Moldenke (Godagnone y Bran 2009; Morello et al. 2012).

En los bordes de los bajos y áreas salinas aparecen comunidades halófitas dominadas por Cyclolepis genistoides D. Don, Lycium sp., Prosopis alpataco, Atriplex lampa (Moq.) Gillies ex Small y Suaeda divaricata Moq., formando una estepa arbustiva baja (León et al. 1998). 
En zonas que presentan pendientes suaves y suelos de texturas gruesas, cubiertos por sedimentos de origen eólico, se desarrollan comunidades dominadas por Larrea divaricata, Condalia microphylla, Schinus johnstonii, Monttea aphylla, Chuquiraga erinacea y Acantholippia seriphioides (Godagnone y Bran, 2009). En cambio, en áreas planas con suelos de texturas finas, las comunidades están dominadas por Chuquiraga erinacea y Condalia microphylla. Estas suelen ser acompañadas por Lycium sp., Monttea aphylla, Prosopidastrum globosum, Larrea divaricata, Prosopis alpataco y Schinus johnstonii. Existen una variante a las comunidades anteriormente descritas, las cuales son dominadas por Larrea divaricata y se desarrollan en suelo de texturas franco arenosa a arenosa, y caracterizadas por ser zonas de acumulación de los sedimentos acarreados por el viento.

En áreas planas y convexas, las comunidades están dominadas por Larrea divaricata y Chuquiraga erinacea y acompañadas por Condalia microphylla, Prosopis alpataco, Schinus johnstonii y Acantholippia seriphioides. En zonas con suelos someros se observa un reemplazo de la especie Larrea divaricata por Larrea cuneifolia Cav., siendo ésta la especie dominante.

Las comunidades vegetales dominadas por Prosopis alpataco y Condalia microphylla se pueden desarrollar en planos altos y en microdepresiones con suelos arenosos. Las especies acompañantes de estas comunidades son Prosopis flexuosa, Geoffroea decorticans (Gillies ex Hook. \& Arn.) Burkart, Larrea divaricata, Schinus johnstonii, Chuquiraga erinacea, Acantholippia seriphioides y Ephedra ochreata Miers.

En el Noreste del área de estudio, donde las pendientes son más suaves, los suelos presentan texturas medias a gruesas y una profundidad efectiva mayor a cincuenta centímetros. En estas áreas, las especies dominantes son Prosopis alpataco y Larrea divaricata y están acompañadas por Condalia microphylla y Geoffroea decorticans. Esta última especie, aparece formando manchones aislados resaltando por su color verde y por su altura respecto del jarillal. Además, está presente Prosopis flexuosa DC. Var. Depressa F.A. Roig, Prosopis caldenia Burkart, Lycium sp. y Brachiclados lycioides D. Don (Godagnone y Bran 2009; León et al. 1998; Morello et al. 2012).

El estrato herbáceo está conformado por especies graminiformes y latifoliadas, algunas tóxicas y poco consumidas por el ganado y otras de alto valor forrajero. Están ampliamente distribuidas por toda la región las especies perennes Nassella tenuis (Phil.) 
Barkworth, Nassella longiglumis (Phil.) Barkworth, Jarava plumosa (Spreg.) S.W.L. Jacobs \& Everett, Piptochaetium napostaense (Speg.) Hack, Pappostipa speciosa (Trin. \& Rupr.) Romasch, Pappophorum caespitosum R.E.Fr, Poa ligularis Poir, Poa lanuginosa Ness ex Steud y Aristida mendocina Phil. Las especies anuales más importantes son Schismus barbatus (L.) Thell, Bromus brevis Ness., Bromus unioloides H.B.K. y Hordeum murinum L. Entre las especies latifoliadas y de buena palatabilidad encontramos Erodium cicutarium (L.) L'Hér. ex Aiton, Medicago mínima (L.)Bartal., Dichondra microcalix Meisn., Daucus pusillus Michx., Plantago patagónica Jacq., Habranthus jamesonii (Baker) Ravenna y Oxalis laciopetala Zucc. Todas ellas, a pesar de presentar excelentes aptitudes como especies forrajeras, ofrecen un volumen de forraje muy bajo y están presentes solamente en épocas en que las condiciones ambientales son propicias para desarrollar su ciclo vital (Bran et al. 2007; Giorgetti et al. 1997).

En épocas posteriores a la sequía ocurrida entre los años 2005-2010, y en zonas que habían perdido su cobertura vegetal, fue posible observar la aparición de especies exóticas que llegaron a la zona, proveniente de otras áreas. Salsola kali L. (cardo ruso) tuvo un crecimiento explosivo colonizando vastas áreas de las región, fundamentalmente en el Este del departamento de Adolfo Alsina donde la agricultura extensiva de secano dejó grandes sectores de suelo sin cobertura. Irschfeldia incana (L.) (Mostacilla) y Diplotaxis tenuifolia (L) DC. (Flor amarilla) mostraron un comportamiento similar, aunque su aumento en la cobertura no fue tan masivo como ocurrió con el cardo ruso. Estas especies, aunque ofrecieron cobertura al suelo y protección contra los factores erosivos, han causado algunos inconvenientes en el manejo de la hacienda y en el mantenimiento de la infraestructura de las diferentes unidades productivas de la zona.

En cuanto a la estructura de la vegetación presente, es común encontrar dos estratos herbáceos. Uno inferior, constituido por las especies de hábito de crecimiento rastrero y uno superior constituido por las especies de porte más erecto, como las especies graminiformes (Godagnone y Bran 2009).

La vegetación leñosa puede presentar hasta 5 estratos, dependiendo de su estado de conservación, en relación al uso al cual haya sido sometido y a los factores naturales que la han afectado. Godagnone y Bran (2009) distinguen un estrato inferior compuesto 
por subarbustos enanos (0-0,25 metros de altura); un segundo estrato, subarbustivo alto (0,26- $0,5 \mathrm{~m})$; un estrato arbustivo bajo $(0,51-1 \mathrm{~m})$; un estrato arbustivo medio (1,01- 2 $\mathrm{m})$; y un estrato arbustivo alto y/o arbóreo bajo con alturas entre 2,01 y 5 metros.

La cobertura del suelo por parte de la vegetación está estrechamente relacionada a su historia de uso. En el caso del uso ganadero que se hace del Monte, la vegetación se ve afectada tanto por los distintos tipos de ganados doméstico que se cría como por las diferentes presiones de pastoreo ejercida sobre las comunidades naturales y las técnicas de manejo de la cobertura leñosa aplicada para favorecer el rebrote de hierbas (Godagnone y Bran 2009). 
Anexo I. 
Tabla 1. Atributos de las unidades de suelo presentes en el área de estudio.

\begin{tabular}{|c|c|c|c|c|c|c|c|c|c|}
\hline ID & Suelo dominante & Suelo secundario & Suelo terciario & Limitante & Prof. (cm) & Drenaje & Textura & Pend. & Alcalin. \\
\hline CoRC & Complejo indiferenciado & --- & --- & Mal drenado- Alcalinidad y salinidad & --- & Deficiente & --- & 0 & Moderada/fuerte \\
\hline ENli 1 & Entisol/Torripsamente/T. litico & Entisol/Torripsamente/ T. típico & --- & $\begin{array}{l}\text { Baja retención de humedad/ } \\
\text { erosión eólica/profundidad }\end{array}$ & 30 & Excesivo & Arenosa franca & 1 & No sódico \\
\hline DDtc 5 & Aridisol/Natrarguides/N. tipico & Entisol/ Torripsamente/T. típico & $\begin{array}{l}\text { Aridisol/Palearguides/ } \\
\text { P. petrocalcico xerolico }\end{array}$ & alcalinidad- erosión eólica & 100 & Bien drenado & Franco arenosa & 1 & Moderada \\
\hline DBar 1 & Aridisol/haplarguides/H. arenico & Entisol/Torripsamente/T típico & --- & $\begin{array}{l}\text { Baja retención de humedad/ } \\
\text { erosión eólica e hídrica }\end{array}$ & 100 & Bien drenado & Franco arenosa & 3 & No sódica \\
\hline DDtc 9 & Aridisol/ Natrarguides/ N tipico & Entisol/Torriortentes/ T lítico & --- & Salinidad- Alcalinidad- profundidad somera & 100 & Bien drenado & Franco arenosa & 1 & Moderada \\
\hline DJtc 4 & Aridisol/ Paleortides/P. tipico & Aridisol/Haplarguides/H. típico & --- & Susceptibilidad a la erosión eólica & 50 & Algo excesivo & Franco arenosa & 0 & Poca \\
\hline DDtc 11 & Aridisol/Natrarguides/N. tipico & Entisol/Fluvacuente/F. típico & --- & Alcalinidad superficial- Drenaje deficiente & 100 & Moderado & Franco arenosa & 0 & Muy fuerte \\
\hline L & Lago/ laguna & --- & --- & --- & --- & --- & --- & 0 & --- \\
\hline DDut 2 & Aridisol/Natraaguides/N. ustolico & Aridisol/Calciortides/C. típicos & Entisol/Torriortentes/T. ustolico & $\begin{array}{l}\text { Alcalinidad- Salinidad-/ } \\
\text { Baja retención de humedad }\end{array}$ & 105 & Algo excesivo & Franco arenosa & 1 & Moderada \\
\hline DFtc 9 & Aridisol/Calciortides/C. tipicos & Aridisol/Natrarguides/N.ustolico & Aridisol/Cambortides/C. fluventicos & Erosión eólica & 100 & Algo excesivo & Franco arenosa & 3 & Moderada \\
\hline DBut 1 & Aridisol/Haplargides/H. ustolico & Aridisol/Salortides/S. acuolico & ---- & Alcalinidad y salinidad superficial & 100 & Bien drenado & Franco arenosa & 3 & No sódico \\
\hline DFtc 3 & Aridisol/Calciortides/C. tipicos & Aridisol/Natrarguides/N. típico & --- & Erosión hídrica- salinidad- alcalinidad & 100 & Algo excesivo & Areno franca & 3 & Moderada \\
\hline DFtc 8 & Aridisol/Calciortides/C. tipicos & Aridisol/Natrarguides/N.ustolico & ---- & $\begin{array}{l}\text { Erosión hídrica- Alcalinidad/ } \\
\text { Baja retención de humedad }\end{array}$ & 100 & Algo excesivo & Areno franca & 3 & Moderada \\
\hline ETtc 18 & Entisoles/ Torripsamentes/ T. típicos & Aridisoles/ Calciortides/ C. típicos & Aridisoles/Cambortides/ C. típicos & Erosión eólica y baja retención de humedad & 60 & $\begin{array}{l}\text { Algo excesivamente } \\
\text { drenado }\end{array}$ & Arenosa & 3 & No sódico \\
\hline ETtc 16 & Entisoles/ Torripsamnetes/ T. típicos & Aridisoles/Calciortides/C. típicos & & $\begin{array}{l}\text { Erosión eólica/ baja retención de Humedad/ } \\
\text { poca profundidad efectiva }\end{array}$ & 60 & $\begin{array}{l}\text { Algo excesivamente } \\
\text { drenado }\end{array}$ & Arenosa & 3 & No sódico \\
\hline ETtc 15 & Entisoles/ Torripsamentes/ T. típicos & Aridisoles/ Calciortides/ C. típicos & & $\begin{array}{l}\text { Erosión eólica/ alcalinidad/ } \\
\text { baja retención de humedad. }\end{array}$ & 60 & $\begin{array}{l}\text { Algo excesivamente } \\
\text { drenado }\end{array}$ & Arenosa & 3 & No sódico \\
\hline ETtc 9 & Entisoles/ Torripsamentes/ T. típicos & --- & & Erosión eólica/ Alcalinidad & 60 & $\begin{array}{l}\text { Algo excesivamente } \\
\text { drenado }\end{array}$ & Arenosa & 3 & No sódico \\
\hline DDut 1 & Aridisol/ Natrarguide/ N. ustólico & $\begin{array}{l}\text { Aridisol/ Cambortides/ } \\
\text { C. fluventicos }\end{array}$ & & Alcalinidad/ erosión hídrica & 105 & $\begin{array}{l}\text { Algo excesivamente } \\
\text { drenado }\end{array}$ & Franco arenoso & 1 & Moderada \\
\hline DFtc 7 & Aridisol/ Calciortides/C. típicos & $\begin{array}{l}\text { Aridisol/ Calciortides/ } \\
\text { C. típicos }\end{array}$ & Entisol/ Torripsamente/ T. típico & Susceptibilidad a la erosión eólica & 100 & Excesivo & Franco arenosa & 0 & No sódico \\
\hline
\end{tabular}




\section{Capítulo III}

\section{Estado de conservación de la vegetación del Noreste de la Patagonia}

\section{1- Introducción}

La estimación del estado de conservación de los sistemas naturales de un área determinada es una herramienta importante para la conservación de los recursos naturales involucrados en la producción y para la planificación de su uso sustentable. Es importante conocer las características de la vegetación nativa que integran las comunidades presentes, como así también los parámetros físicos y químicos de los suelos y los factores causantes de disturbios, tanto naturales como antrópicos, que influyen en el desarrollo y la estabilidad de los ecosistemas (Alvarez et al. 2006; Santibañez-Andrade et al. 2015; Torrella et al. 2011). En el Noreste de la Patagonia los disturbios antrópicos han provocado una degradación de los sistemas naturales, que se manifiesta por una marcada pérdida de la diversidad vegetal y un empobrecimiento del sustrato que afecta el desarrollo de las comunidades nativas presentes en el sector (Kröpfl et al. 2015).

En el Noreste de la Patagonia las actividades productivas dominantes son la cría de ganado y la agricultura, quedando esta última circunscripta a los valles de los ríos de la región (Giorgetti et al. 2006). Sin embargo, en las últimas décadas, se ha descripto un fuerte avance de la frontera agrícola. El cultivo extensivo de granos ha ocupando tierras antes usadas en la cría de ganado. Este avance de la frontera agrícola ha causado un doble efecto sobre los ecosistemas de la región. Por un lado, la habilitación de nuevas tierras para la implantación de monocultivos extensivos requiere la eliminación total del monte nativo mediante el desmonte a tala rasa. Esto deja amplias superficies de tierras sin cobertura vegetal perenne que, ante la ocurrencia de fenómenos climáticos adversos, pasan prolongados períodos de tiempo a merced de los fuertes vientos imperantes en la zona provocando la pérdida de la capa superficial. Por otra parte, el desplazamiento de la ganadería ha causado el incremento de la presión en los campos de monte. Este incremento se evidencia en el aumento de la cantidad de cabezas de ganado por unidad productiva (presión de pastoreo) que, en muchos casos tiene como consecuencia un empobrecimiento y posterior desaparición de las especies más preferidas por los animales domésticos y la proliferación de las menos deseables, hasta tornar los ecosistemas en ambientes improductivos, con avanzados signos de degradación 
(Pezzola y Winschel 2004; Sabattini et al. 2002; Zeberio 2012; Zeberio et al. 2015).

Los sitios mejor conservados son considerados aquellos en los cuales la cobertura de la vegetación leñosa y herbácea predomina sobre el suelo desnudo y se observan mayores valores de diversidad específica (Alvarez et al. 2006; Eldridge et al. 2011; Gaitán et al. 2014; Maestre y Puche 2009; Maestre et al. 2016; Torrella et al. 2011). Además, desde el punto de vista edáfico, aquellos suelos que no presentan signos de degradación superficial, ya sea ésta por la compactación o por la aparición de síntomas de erosión, serán considerados suelos saludables. La reducción del contenido de materia orgánica y nutrientes del suelo, redundan en una menor fertilidad, mientras que la presencia de sales actúa como un factor que dificulta el normal desarrollo de las comunidades vegetales, apareciendo sólo aquellas especies adaptadas a las condiciones de salinidad (Delgado-Baquerizo et al. 2013; 2015; Maestre et al. 2015). Por lo tanto, al asociar los factores ambientales con aquellos causantes de disturbio podemos establecer cuál es el efecto que los diferentes usos del suelo tienen sobre los sistemas naturales (Foster et al. 2003; Verheyen et al. 2003).

En el presente capítulo se evalúa el estado de conservación del Monte, en el Noreste de la provincia de Río Negro, a través del análisis de la composición y la estructura de la vegetación nativa (leñosa y herbácea), de las características físicas y químicas de los suelos y de los usos más frecuentes de la tierra. Además, se evalúa el avance de la frontera agrícola en el área y cómo los diferentes usos modifican la cobertura vegetal y los parámetros de diversidad y uso de los mismos.

\section{2- Materiales y métodos}

\subsection{1- Relevamiento de la vegetación nativa}

- Selección de los sitios

La selección de los sitios dentro del área de estudio fue realizada a partir de datos bibliográficos y sobre la base de la interpretación visual y clasificación no supervisada (Chuvieco 2008) de imágenes Landsat TM del año 2010. A partir de la clasificación se obtuvieron las coberturas de acuerdo al tipo de vegetación: vegetación leñosa densa, vegetación leñosa semidensa, vegetación leñosa abierta, pastizal/muy baja cobertura de leñosas. Además, fueron identificadas otras coberturas como el suelo desnudo, los médanos/ arenales, las áreas cultivadas, las salinas y el agua superficial. Utilizando 
cartas topográficas confeccionadas por el servicio Geológico Minero Argentino (SEGEMAR), cartas de suelos (INTA), y de visitas a campo, se ajustó y se mejoró la clasificación anterior.

Se realizó un recorrido preliminar de alguna de las áreas detectadas en las imágenes, para corroborar en el terreno la presencia de las unidades de vegetación definidas previamente. Esta comprobación se realizó mediante la estimación visual de la cobertura de plantas herbáceas, arbustivas y arbóreas. De esta manera fueron establecidos 30 sitios de muestreo en un área de $39.956 \mathrm{~km}^{2}$ distribuidos en los departamentos de Pichi Mahuida, General Conesa y Adolfo Alsina. (Figura 3.1). Fueron identificadas las unidades geomorfológicas en que se ubicaba cada sitio de muestreo según la cartografía presentada en el capítulo II (Figura 2.5). En la región geomorfológica Planicie aluvial se ubicaron 14 sitios (AA2, AA8, AA9, AA11; GC3, GC4, GC7, GC8, GC10; PM3, PM6, PM7, PM8, PM9), en la unidad geomorfológica Planiecie loéssica se ubicaron 6 sitios (AA1, AA5, AA6, AA7, AA10; GC9) y en la unidad geomorfológica Paleocanales se ubicaron 10 sitios (AA3, AA4; GC1, GC2, GC5, GC6; PM1, PM2, PM4, PM5).

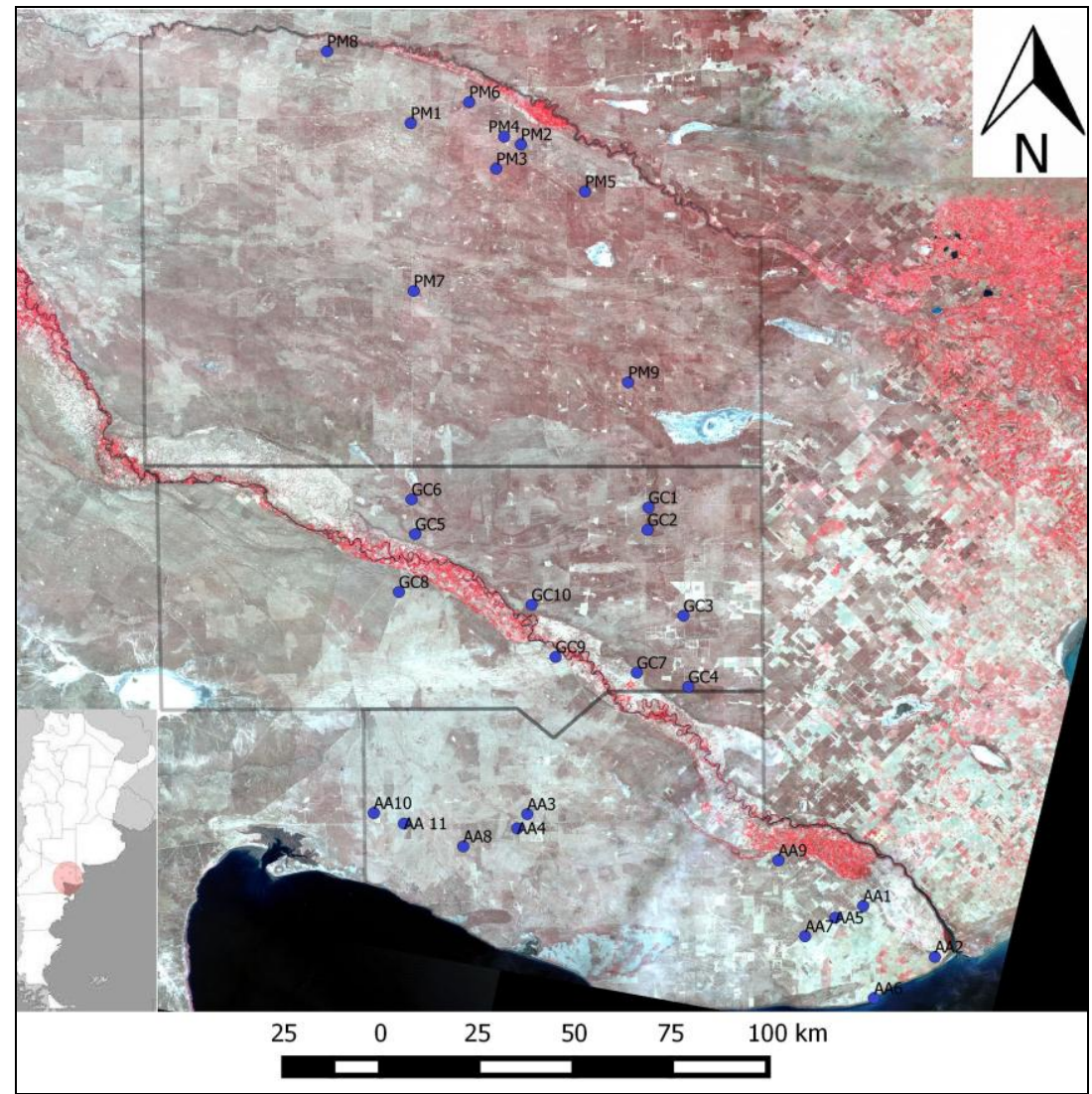

Figura 3.1. Sitios de muestreo en los departamentos de Adolfo Alsina (AA), General Conesa (GC) y Pichi Mahuida (PM). 
- Muestreo de la vegetación

El relevamiento de la composición y variables estructurales de la vegetación se realizó en parcelas, cuya área mínima de muestreo se estableció a partir del aumento progresivo de su superficie, comenzando con parcelas de 1x1 m de lado, luego 2x2 m de lado, y así aumentando sucesivamente la superficie hasta que el incremento en el número de especies registradas se hizo nulo. El área mínima así obtenida fue de 8x8 metros (64 $\mathrm{m}^{2}$ ), aunque por razones operativas se adoptaron parcelas de $10 \times 10$ metros $\left(100 \mathrm{~m}^{2}\right)$. De este modo se relevaron 30 puntos de muestreo mediante la instalación, en cada uno de ellos, de 3 parcelas de $100 \mathrm{~m}^{2}$ dispuestas sistemáticamente a lo largo de una transecta, con un intervalo fijo de distancia entre una y otra, mayor o igual a $80 \mathrm{~m}$ (Kangas y Maltamo 2006; Mateucci y Colma 1982). Se utilizó un posicionador global (GPS) para identificar el lugar de muestreo establecido sobre las imágenes y para identificar la localización de cada parcela.

Se realizó un inventario florístico para caracterizar la composición de la vegetación leñosa y herbácea. Para ello, en cada una de las parcelas, se registró la presencia/ausencia de especies y, para reconocer a cada una, se colectó y herborizó material botánico en estado reproductivo, el cual fue determinado con lupa binocular y bibliografía adecuada en el laboratorio. Para evaluar la estructura de la vegetación leñosa se relevó la altura y la cobertura de cada individuo. La cobertura se estimó mediante la medición de la proyección de la copa al suelo de los árboles y los arbustos presentes (diámetro máximo de la copa y un diámetro perpendicular al mismo).

Se cuantificó la cobertura de las especies leñosas considerando los siguientes estratos:

Estrato arbóreo: Aquel conformado por especies de porte arbóreo, con alturas superiores a los dos metros.

Estrato arbustivo alto: Aquel conformado por especies arbustivas con alturas superiores a un metro.

Estrato arbustivo bajo: aquel conformado por especies arbustivas de porte bajo (inferior a $1 \mathrm{~m}$ ) y especies subarbustivas. En este estrato también fueron consideradas las especies de arbustos que alcanzan un mayor grado de desarrollo pero, por posibles factores causantes de disturbio, al momento del censo presentaban un menor nivel de desarrollo. 
En el caso de las herbáceas se estimó su cobertura utilizando la metodología de transectas tipo Canfield (1949) o puntos de intercepción. Para ello, a lo largo de una transecta de 10 metros de longitud, situada al centro de la parcela, se realizó un toque cada $10 \mathrm{~cm}$, bajando una aguja de forma perpendicular a la transecta y a la superficie del suelo, registrando la intercepción puntual de la especie en cuestión. La cobertura de cada una de las especies registradas se efectuó estimando la proporción de toques de cada especie respecto del número total de toques en toda la transecta en cada una de las parcelas evaluadas (Kangas y Maltamo 2006; Mateucci y Colma 1982; Moreno 2001).

Para las especies registradas se indicó la forma de vida (árboles, arbustos, subarbustos, herbáceas graminiformes y herbáceas dicotiledóneas) y la familia a la que pertenecían. Además, se recopiló información acerca de cuál es el origen de la especie (status), si ésta es nativa o adventicia. En este trabajo una especie fue considerada nativa si su área de distribución se corresponde con el Monte. Fueron consideradas especies adventicias aquellas exóticas introducidas, voluntaria o accidentalmente por el hombre, y que lograron naturalizarse en la zona (Steibel et al. 2000). Además, para las diferentes especies presentes, se registró su hábito de crecimiento (rastrero o erecto) y su potencial como fuente de forraje (palatable o no palatable). La información fue obtenida del Catálogo de Plantas Vasculares de la República Argentina (Zuloaga et al. 1994; Zuloaga y Morrone 1996; 1999a; 1999b) y de la base de datos IRIS "Flora del cono sur" (Instituto Darwinion: http://www.darwin.edu.ar/Proyectos/FloraArgentina/fa.htm.).

Se cuantificó el número de formas de vida. Para cada sitio de muestreo se estimó la frecuencia de especies, tanto leñosas como herbáceas, incluyendo únicamente aquellas que aparecían en al menos 2 de las 3 parcelas relevadas. Las especies herbáceas anuales no fueron consideradas en la estimación debido a su alta variabilidad inter e intra anual ligada principalmente a la imprevisibilidad de las precipitaciones (Whitford 2002). Además, se estimó la riqueza de especies según su valor de uso forrajero. Se consideró la cobertura de la vegetación herbácea perenne y de cada uno de los estratos de la vegetación leñosa (arbóreo, arbustivo alto y arbustivo bajo) y también la diversidad de la vegetación leñosa mediante el índice de Shannon-Wiener $\left(\mathrm{H}^{\prime}\right)$. Esta última medida se obtuvo sólo para las especies leñosas ya que son las que están menos sujetas a los ritmos de pastoreo y presentan una menor variabilidad estacional y espacial comparada con las especies herbáceas. 
Los análisis se efectuaron agrupando los sitios de acuerdo a la unidad geomorfológica en que se ubicaron. Para los valores medios de riqueza de especies endémicas, nativas y forrajeras, y para la cobertura de los diferentes estratos, se efectuaron comparaciones empleando el test de Kruskal- Wallis de ANOVA no paramétrico.

\subsection{2- Suelos}

\section{- Análisis del suelo superficial}

En los mismos sitios donde fue relevada la vegetación, se llevó a cabo un muestreo del suelo superficial. En cada una de las parcelas se tomó una muestra compuesta del perfil del suelo, entre la superficie y los $30 \mathrm{~cm}$ de profundidad. En aquellos lugares donde no fue posible alcanzar la profundidad deseada, por la presencia de una capa lo suficientemente potente de $\mathrm{CaCO}_{3}$ (carbonato de calcio o tosca), se tomó hasta la profundidad en que comenzaba el contacto lítico. El sector del cual fue tomada la muestra fue de la porción exterior de la isla de vegetación, donde las condiciones de parche se hacen más difusas y comienzan a dominar las condiciones de inter-parche, representativas de las situaciones más difundidas en la zona.

Las muestras fueron tomadas con pala de punta. Para ello se hizo un pozo de inspección, destinado a observar las características de los horizontes del suelo y, sobre uno de sus laterales se realizaron tareas de acondicionamiento y corte de la sección que abarcaba, hasta la profundidad deseada. Una vez extraída, fue colocada en un balde plástico y homogeneizada, luego se tomó una alícuota de aproximadamente 1,5 Kg. Esta porción de la muestra fue colocada en una bolsa plástica y transportada al laboratorio donde se le efectuaron los análisis necesarios para determinar sus propiedades físicas y químicas.

Previamente al proceso analítico, las muestras de suelo fueron acondicionadas. El acondicionamiento consistió en colocarlas sobre papel de diario y dejarlas al aire, durante 48/76 horas, para que pierdan el contenido de humedad. El material sobre el cual fueron secadas no ofrecía intercambio ni alteración de las propiedades del suelo. Posteriormente, las muestras de suelo secas fueron tamizadas en un tamiz de ensayo de 2 milímetros. Fueron separados los restos vegetales más gruesos y las piedras y gravas de mayor tamaño. A aquella fracción que no atravesó la malla del tamiz de 2 milímetros se la porfirizó. Para ello se usó un mortero de porcelana y en él se deshicieron los agregados de forma tal que la granulometría de la muestra fuese lo más homogénea 
posible.

Todas las muestras fueron almacenadas luego de recibir los tratamientos previos y dispuestas en bolsas plásticas.

Tanto el acondicionamiento de las muestras como los análisis fueron efectuados en el laboratorio de la Estación Experimental Agropecuaria de INTA Valle Inferior. En éste se cuantificaron la textura del suelo (arena \% y limo + arcilla \%), $\mathrm{pH}$, conductividad eléctrica $\left(\mathrm{Ce}^{-}\right)$, relación de adsorción de Sodio (RAS), calcáreo $\left(\mathrm{CaCO}_{3} \%\right)$, materia orgánica (MO \%), nitrógeno total $(\mathrm{Nt} \%)$ y fósforo $(\mathrm{P}(\mathrm{ppm}))$.

Para los procesos analíticos desarrollados en el laboratorio de suelos se desarrollaron las técnicas descriptas por De Inalbon y Valenzuela (2005).

- Evaluación de la compactación.

En un sector aledaño al sector donde fueron tomadas las muestras de suelo, se tomó una muestra para evaluar el grado de compactación mediante la determinación de la densidad aparente.

Para este propósito se empleó un cilindro de acero inoxidable, con el borde inferior biselado. El tamaño del cilindro fue de $8 \mathrm{~cm}$ de alto y un radio de $7,5 \mathrm{~cm}$, con un volumen total de la muestra colectada de $325,32 \mathrm{~cm}^{3}$. Las muestras obtenidas se colocaron en bolsas plásticas, previamente taradas, y luego pesadas con balanza de precisión (0,1 gramos). En el laboratorio las muestras fueron colocadas en bandejas de aluminio, de las que se conocía previamente su peso, y secadas en estufa a una temperatura de $80^{\circ} \mathrm{C}$ hasta alcanzar el peso constante.

Para determinar la densidad aparente del suelo se utilizó la siguiente relación.

$$
\text { Dap }=\text { PS/ Vol. Cil. }
$$

Donde: Dap= densidad aparente

$\mathrm{PS}=$ peso seco de la muestra en gramos

Vol. Cil. $=$ volumen del cilindro en $\mathrm{cm}^{3}$

- Análisis de los datos

Los análisis se efectuaron agrupando los sitios de acuerdo a la unidad geomorfológica 
en que se situaron. Se realizó un análisis de la varianza (ANOVA) para comparar los valores medios de las diferentes variables físicas y químicas evaluadas en los suelos de cada unidad geomorfológica y en cada sitio de muestreo. Se realizaron comparaciones con el test LSD de Fisher con un nivel de significancia de 5\%. El software utilizado en ambos procedimientos fue Infostat (Di Rienzo et al. 2008).

\subsection{3- Usos del suelo}

- Mapeo y análisis de usos.

Partiendo del análisis visual de imágenes satelitales se evaluó la superficie del suelo ocupada por diferentes usos. Las imágenes utilizadas corresponden a los satélites de la serie Landsat y a los sensores Landsat 4 MSS del año 1986, del sensor Landsat 5 TM del año 1992 y del sensor Landsat 8 OLI del año 2015. Las unidades fueron mapeadas utilizando sistemas de información geográfica. El software empleado fue Q- Gis versión

\subsection{2 (www.qgis.org).}

Paralelamente, se entregaron encuestas a los productores en cuyos establecimientos se realizaron los relevamientos de la cobertura y composición de la vegetación y la obtención de las muestras de suelo. Se obtuvo respuesta de 19 productores, con información acerca de la actividad desarrollada en sus establecimientos entre los años 2010 y 2015, fecha en la que se realizaron los relevamientos. Se registró el uso dominante del suelo, es decir, si éste era puramente ganadero o se efectuaban tareas de siembras intercaladas con el monte para favorecer la oferta de forraje (uso mixto). También se recabó información sobre la carga animal con que se suelen poblar los campos de la región. Dado que en la zona hay presencia de ganado vacuno y ovino, se homogeneizó el dato transformando las existencias de ganado ovino a equivalente vaca (Bayer 2011). De acuerdo al número de animales ésta puede ser alta $\left(>0,12 \mathrm{ev} / \mathrm{ha} . \mathrm{año}^{-1}\right)$,

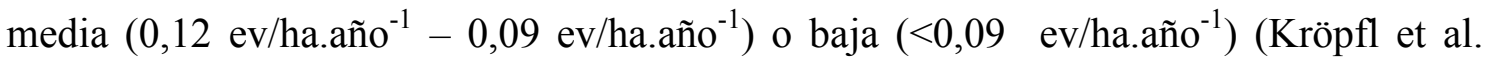
2015). Además se obtuvo información acerca del tipo de manejo de los rodeos: rotación (movimiento de la hacienda por distintos sectores del predio); o año redondo (sin movimiento de la hacienda), la ocurrencia de incendios que afectaron sus propiedades y si realizan algún tipo de manejo de la cobertura leñosa para favorecer el rebrote de pastos y hierbas.

Toda la información fue sistematizada, analizada y volcada a un sistema de información geográfica. Como producto final obtuvimos un mapa con los usos históricos que se han 
hecho de la tierra. El software empleado para la elaboración de los mapas fue Q- Gis versión 2.12 (www.qgis.org).

- Análisis de los datos

Los datos recabados de las encuestas de uso del suelo, tanto histórico como actual, fueron analizados empleando tablas de contingencia. Se estimó la frecuencia de unidades productivas con diferentes tipos de manejo de los recursos (como el tipo de actividad desarrollada, el manejo de la cobertura de las leñosas o la ocurrencia de incendios) y los estadísticos descriptivos (promedios y desvíos) de la superficie de las unidades productivas, del número de cuadros en que están subdivididos, del número de aguadas que poseen y de la carga animal. El software utilizado fue Infostat (Di Rienzo et al. 2008).

\subsection{4- Estado de conservación del monte}

Para establecer diferentes grados de conservación de los sitios muestreados se realizaron análisis de componentes principales (ACP) entre las diferentes variables estudiadas de uso del suelo, características físicas y químicas de los suelos y variables de la vegetación. El ACP entre los sitios y usos del suelo incluyó la intensidad de pastoreo (alta y baja), ocurrencia de incendios, tipo de actividad productiva, presencia o ausencia de rotación en el pastoreo. En el caso del ACP entre sitios y variables edáficas se consideraron RAS, pH, \%MO, \%Nt, Ce, $\mathrm{CaCO}_{3}, \mathrm{Ca}, \% \mathrm{~A}, \% \mathrm{Limo}+\mathrm{Arcilla}$. El ACP entre los sitios de muestreo y variables de la vegetación tuvo en cuenta la cobertura y la riqueza específica de los estratos arbóreo, arbustivo alto, arbustivo bajo, herbáceo y el índice de diversidad H'. El software utilizado fue Infostat (Di Rienzo et al. 2008).

Para analizar en qué medida los ACP realizados se corresponden, para inferir el grado de conservación de los sitios muestreados se empleó el test de Mantel. Esta prueba estima el grado de correspondencia entre variables. Para ello emplea la distancia euclídea entre distintas variables evaluadas, calculadas en cada análisis de componentes principales (López de Luzuriaga y Olano 2006). Para este análisis el software utilizado fue XLSTAT (Addinsoft 2007).

\subsection{5- Cobertura del suelo}

A partir del proceso de clasificación supervisada se analizaron las variaciones en la 
cobertura de la vegetación leñosa y herbácea y se identificaron las áreas sin cobertura entre los años 2001 y 2014. El algoritmo seleccionado para efectuar la clasificación supervisada fue el de máxima probabilidad (Maximum likelihood) (Chuvieco 2008).

Las imágenes satelitales utilizadas para este objetivo fueron Landsat 5 TM de los años 2001, 2007 y 2011, y del sensor Landsat 8 OLI del año 2014, todas correspondientes al mes de febrero. Las imágenes seleccionadas fueron adquiridas en el mes de febrero para poder efectuar comparaciones entre años diferentes de la cobertura vegetal leñosa y herbácea perenne y observar los sitios ocupados por cultivos, suelos labrados y suelos desnudos. Las imágenes corresponden al path 227 y 228 y al row 87 y 88 y fueron obtenidas de dos fuentes distintas; las de 2011 proporcionadas por la Comisión Nacional de Actividades Aeroespaciales (CONAE) y las correspondientes a los años 2001, 2007 y 2014 obtenidas del servidor del Servicio Geológico Minero de los Estados Unidos de América (http://eros.usgs.gov/remote-sensing).

Fue necesario realizar correcciones previas de las imágenes para quitar errores y distorsiones causadas por la atmósfera y por los sensores durante la adquisición de los datos (Chuvieco 1995; 2008; Hantson et al. 1988). El software usado en todas las etapas de procesamiento $\mathrm{y}$ análisis de las imágenes satelitales fue ENVI versión 5.1 (http://m.harrisgeospatial.com/).

- Clasificación digital supervisada

Los sitios de muestreo donde se llevaron a cabo los censos de vegetación y de suelo fueron digitalizados y utilizados como áreas de entrenamiento para el proceso de clasificación supervisada. Debido a la proximidad entre las fechas de las tareas de campo y la adquisición de las imágenes de 2011, se identificaron en ellas las firmas espectrales de cada clase. En total se generaron entre 10 y 15 polígonos por cada clase definida. Las clases identificadas fueron: 


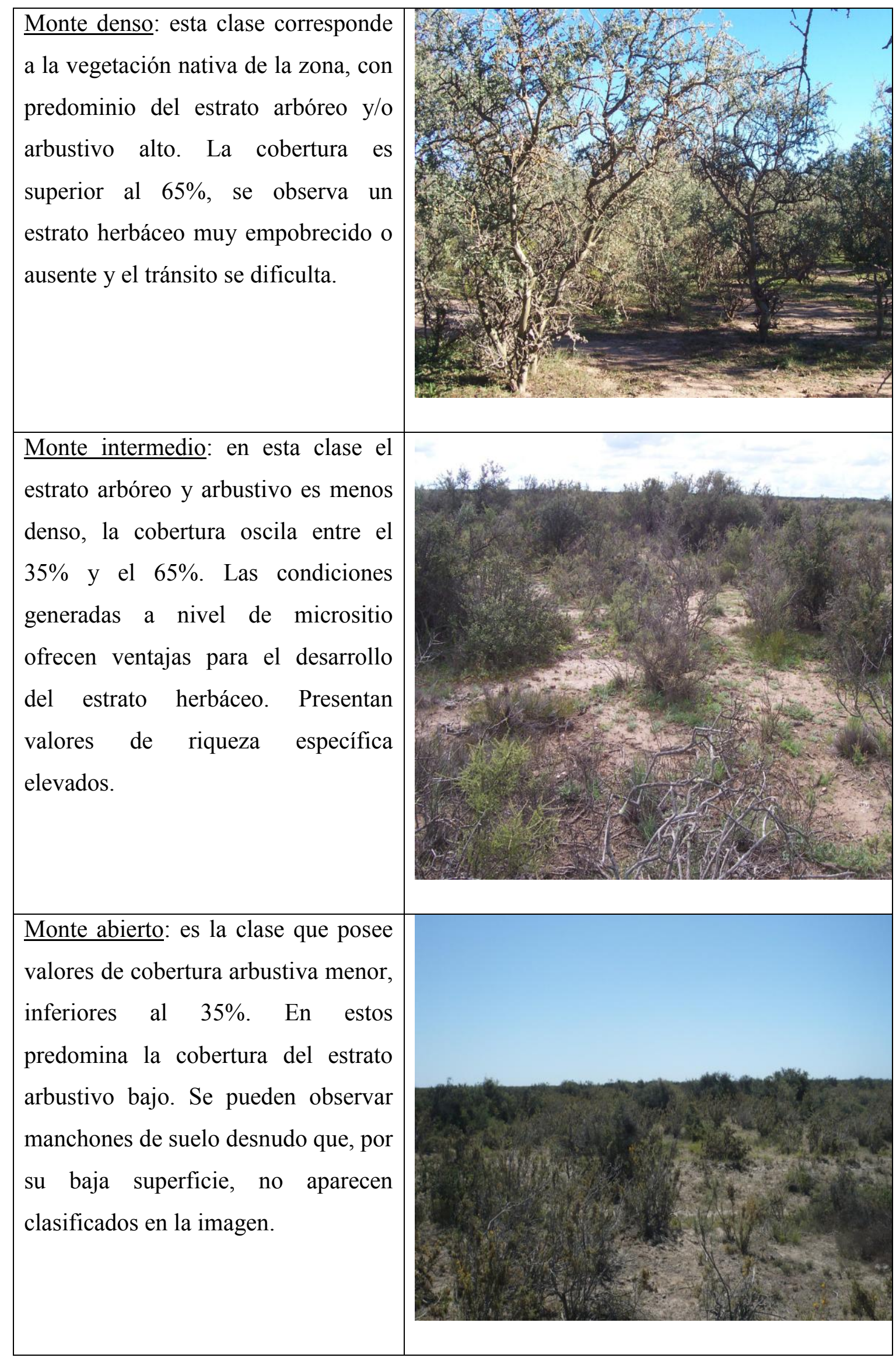




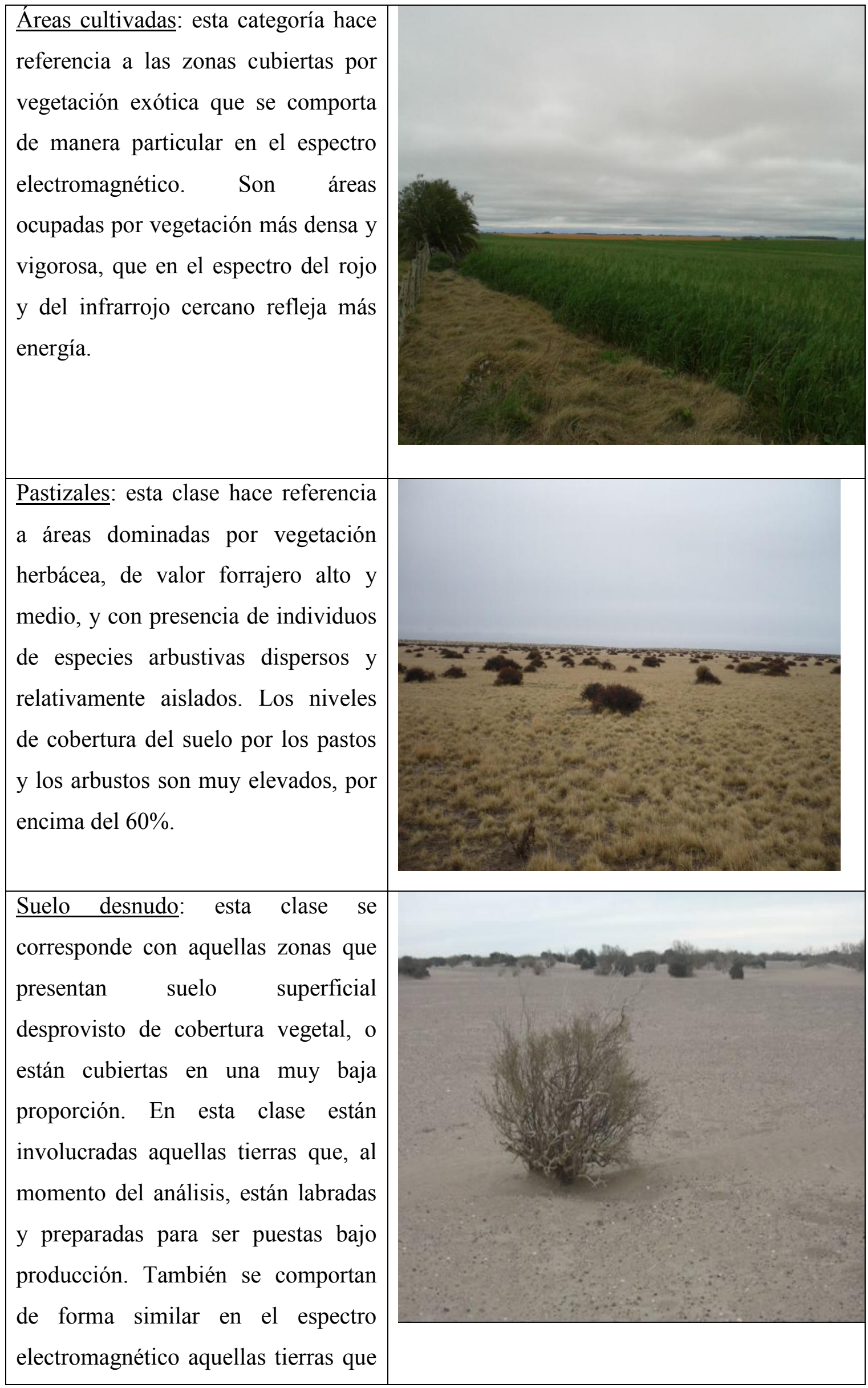




\begin{tabular}{|c|c|}
\hline $\begin{array}{l}\text { han sido labradas, abandonadas, y no } \\
\text { han vuelto a ser colonizadas por } \\
\text { especies nativas o exóticas, tanto } \\
\text { leñosas o herbáceas, de ciclo de vida } \\
\text { perenne. Solo en épocas donde las } \\
\text { condiciones ambientales son } \\
\text { favorables, fue posible identificar } \\
\text { individuos de especies herbáceas } \\
\text { anuales muy dispersos. }\end{array}$ & -1 \\
\hline $\begin{array}{l}\text { Médanos, áreas de voladuras y } \\
\text { deposición de arena: áreas } \\
\text { correspondientes a médanos móviles, } \\
\text { campos de dunas costeras e } \\
\text { interiores, y deposiciones de arena } \\
\text { que son producidas por las voladuras } \\
\text { de los suelos puestos bajo actividad } \\
\text { agrícola extensiva de secano. Por } \\
\text { acción erosiva de los vientos los } \\
\text { materiales son transportados y } \\
\text { depositados en sitios cercanos. }\end{array}$ & \\
\hline $\begin{array}{l}\text { Salinas: concreciones salinas que se } \\
\text { corresponden con bajos endorreicos. } \\
\text { Con la expansión y retracción del } \\
\text { régimen hídrico, estas zonas pueden } \\
\text { pasar a ser pequeños cuerpos de agua } \\
\text { superficial temporales y en las épocas } \\
\text { más secas volver a ser bajos salinos. }\end{array}$ & 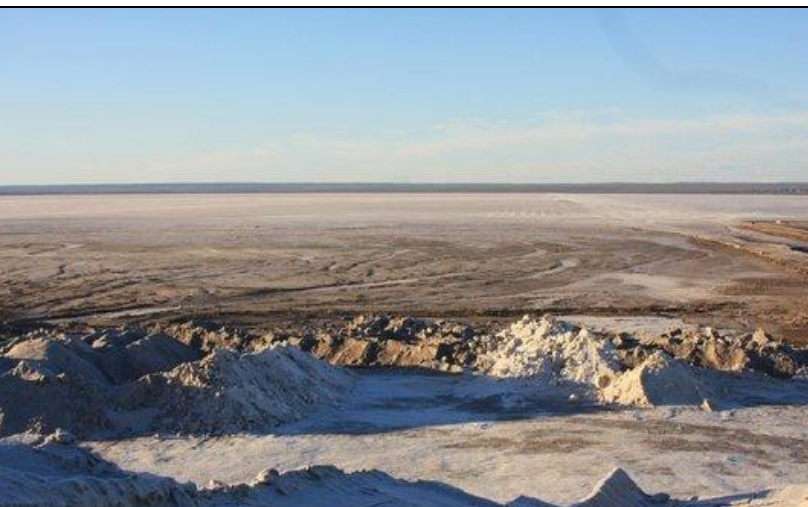 \\
\hline
\end{tabular}




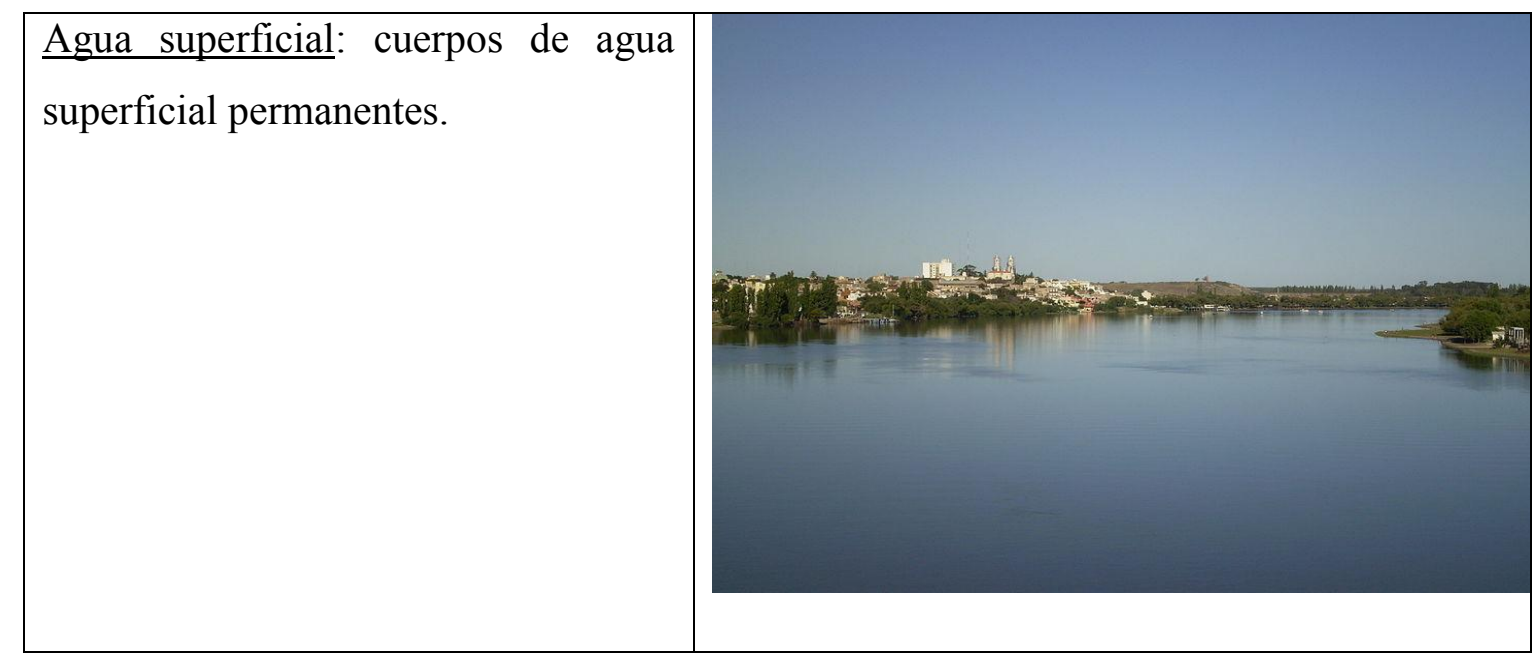

Para localizar las áreas de entrenamiento se utilizaron materiales de apoyo, tales como GPS, imágenes Quick Bird de Google Earth, SAS Planet, cartas topográficas y cartas geológicas.

La clasificación supervisada permitió obtener la superficie del suelo ocupada por cada clase en cada una de las imágenes clasificadas. Se empleó posteriormente el estadístico Kappa, que estima el grado de ajuste o precisión de la clasificación supervisada mediante la diferenciación entre el acuerdo mapa realidad observada y el que cabría esperar aleatoriamente (Chuvieco 2008).

\section{3- Resultados}

\subsection{1- Vegetación}

- Formas de vida

La forma de vida con mayor número de especies en el área de estudio fue la arbustiva, seguida de herbáceas graminiformes y leñosas subarbustivas. Sólo fueron registradas tres especies arbóreas, Geoffroea decorticans, Prosopis flexuosa y Prosopis caldenia (Figura 3.2). 


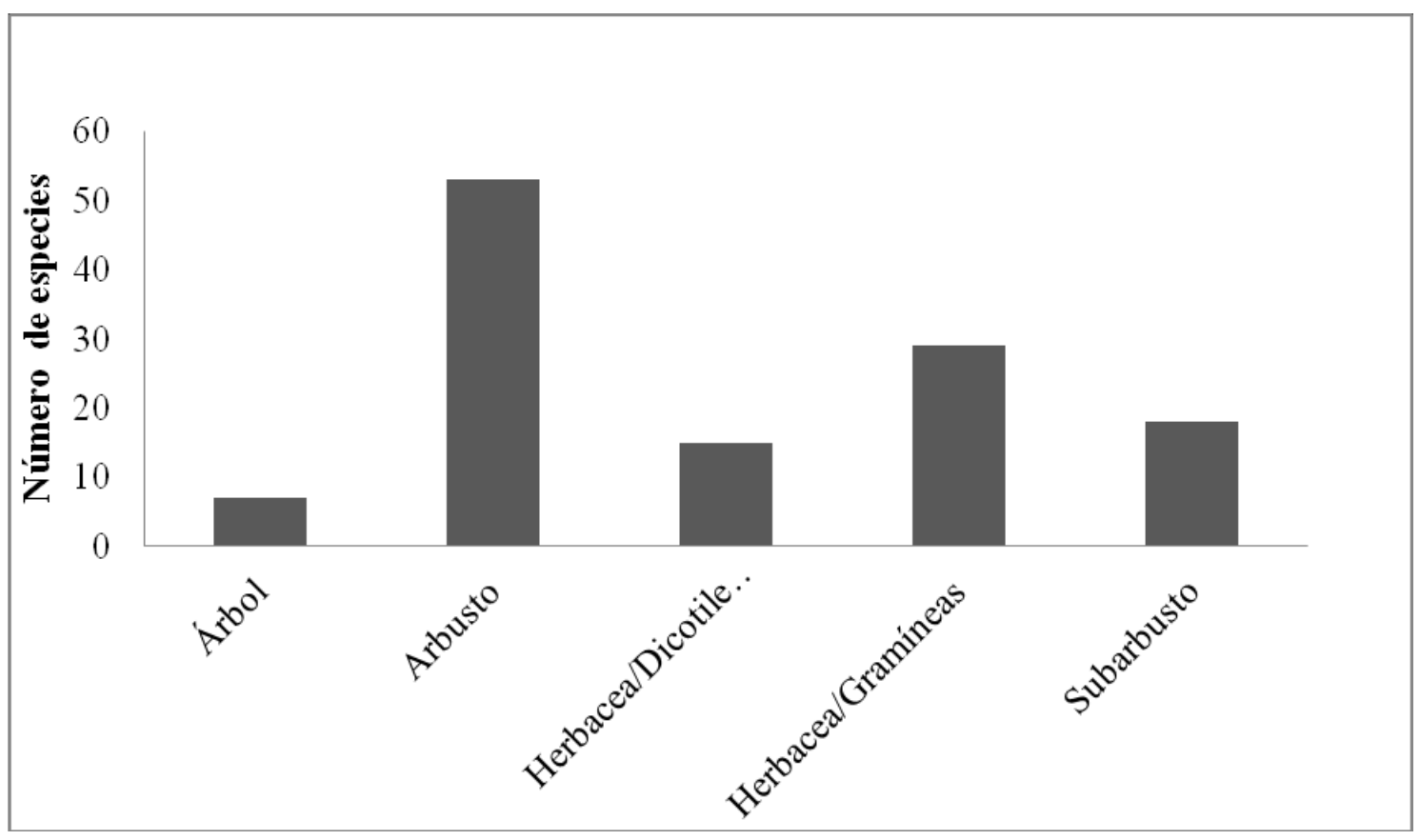

Figura 3.2. Número de especies según su forma de vida.

En la Planicie aluvial y los Paleocanales la forma de vida arbórea estuvo mejor representada (3 especies) que en la Planicie loéssica, donde sólo fue registrada una especie. En la Planicie aluvial se registraron 21 especies arbustivas, 20 especies en los Paleocanales y 17 especies en la Planicie loéssica. Por otra parte, el número de herbáceas graminiformes en las tres unidades geomorfológicas estudiadas varió entre 8 y 13 especies. Las herbáceas dicotiledóneas variaron entre 4 y 7 especies según la unidad geomorfológica (Figura 3.3).

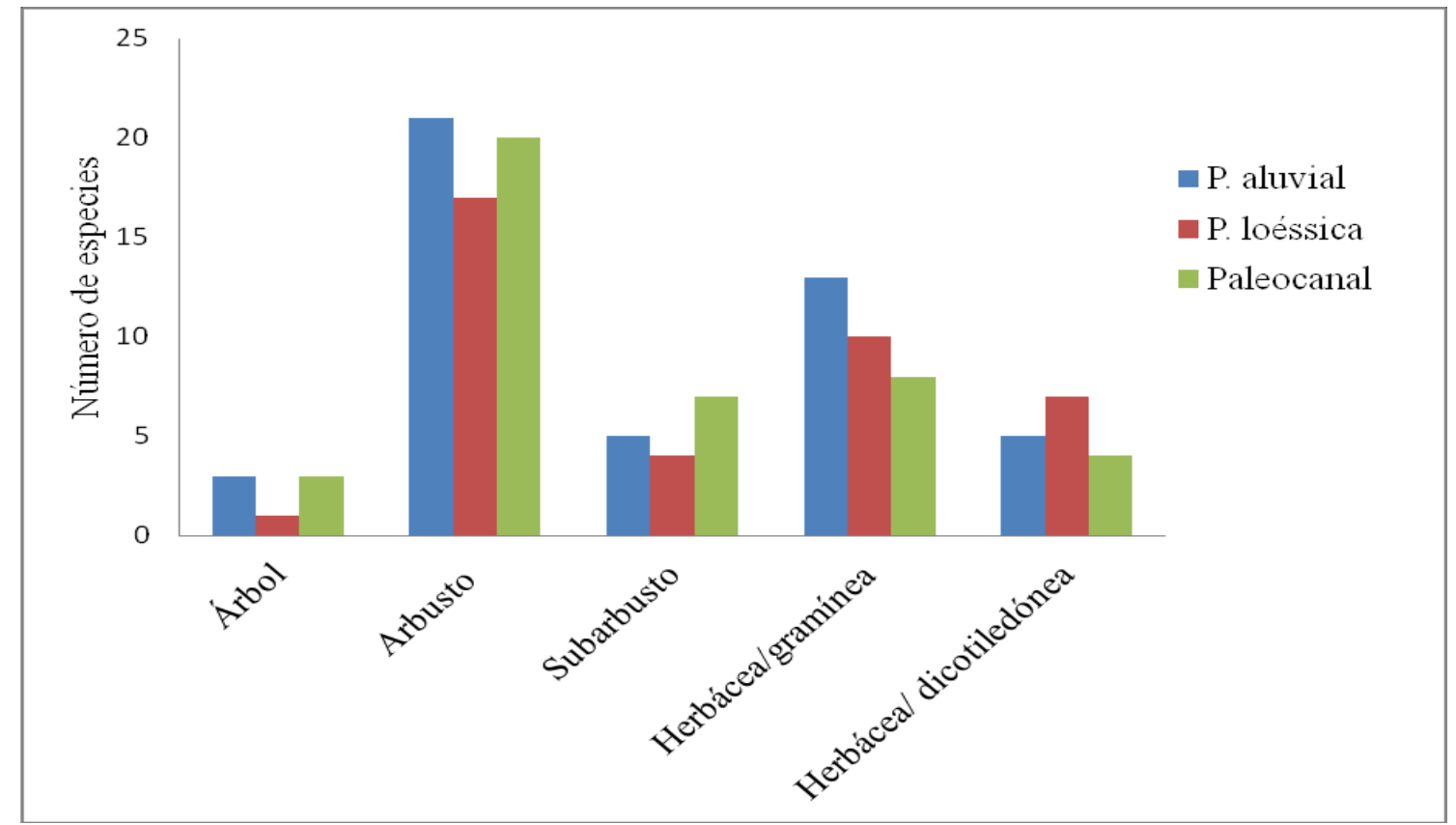

Figura 3.3. Número de especies según su forma de vida en Planicie aluvial, Planicie loéssica y Paleocanales. 
Las especies identificadas fueron clasificadas de acuerdo a su taxonomía (familia), al origen (nativas, adventicias), al hábito de crecimiento, a la fenología y a la palatabilidad (grado de preferencia por parte del ganado doméstico) (Anexo II, Tabla 1).

- Frecuencia de especies leñosas

Las especies arbóreas presentaron alta frecuencia en las tres unidades geomorfológicas analizadas. En la Planicie aluvial y en los Paleocanales se destacan Prosopis flexuosa y Geoffroea decorticans, mientras que $P$. caldenia presentó muy baja frecuencia (Anexo II, Tabla 1). En tanto, en la Planicie loéssica, Geoffroea decorticans, la única especie arbórea presente, mostró una elevada frecuencia (Figuras 3.4, 3.5 y 3.6).

Las especies arbustivas Condalia microphylla, Lycium chilense, Lycium tenospinosum, Larrea divaricata, Prosopis alpataco, Schinus johnstonii, Senna aphylla, Chuquiraga erinacea y Acantholippia seriphioides fueron las más frecuentes en las tres unidades geomorfológicas muestreadas. Además, Prosopidastrum globosum y Ephedra triandra fueron más frecuentes en los Paleocanales que en las otras dos unidades (Figuras 3.4, 3.5 y 3.6).

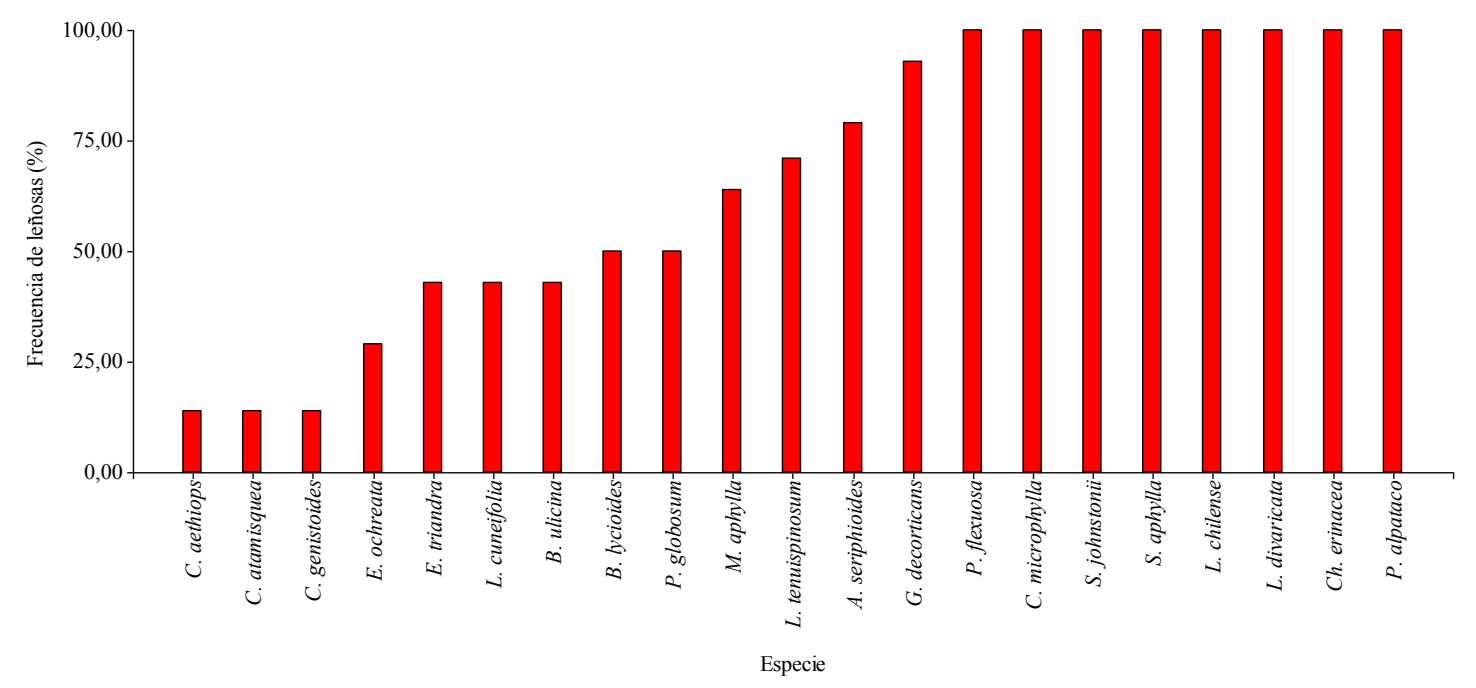

Figura 3.4. Frecuencia de especies leñosas, expresadas en porcentaje (\%), en la unidad geomorfológica Planicie aluvial. 


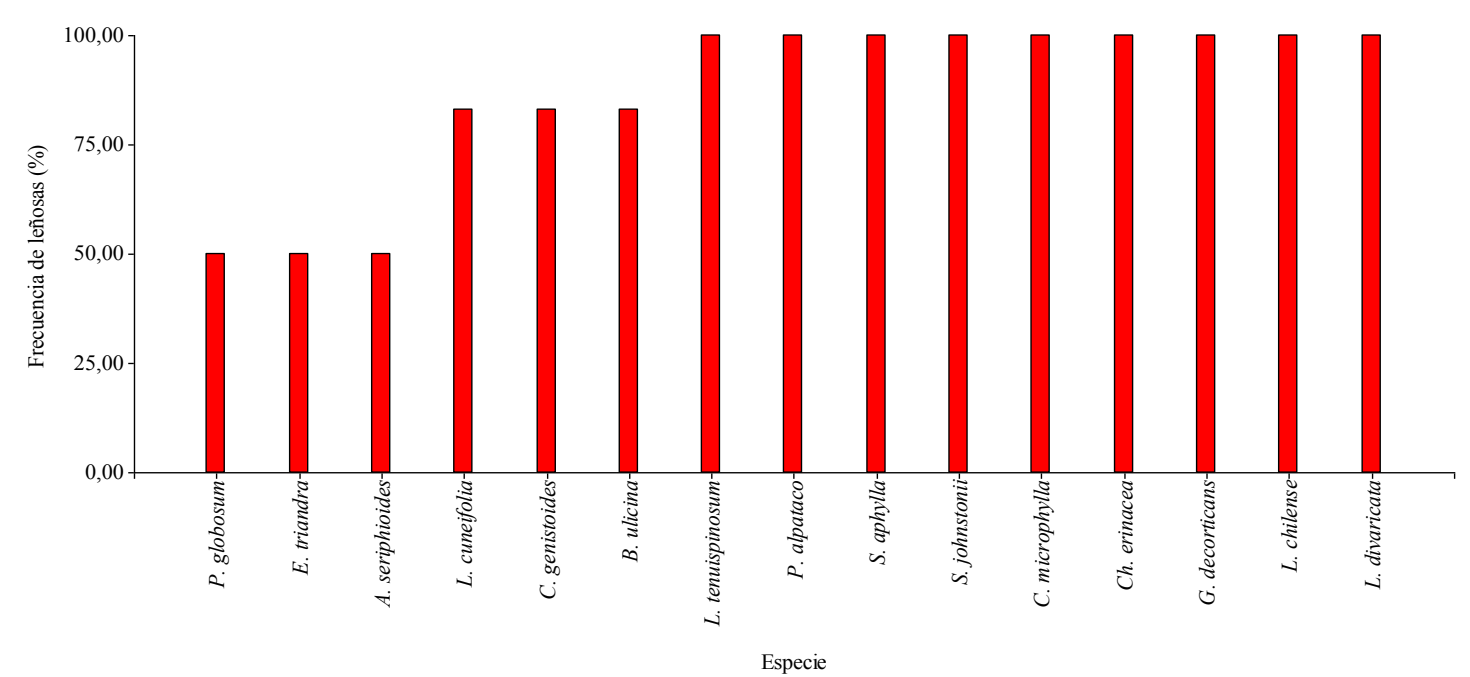

Figura 3.5. Frecuencia de especies leñosas, expresada en porcentaje (\%), en la unidad geomorfológica Planicie loéssica.

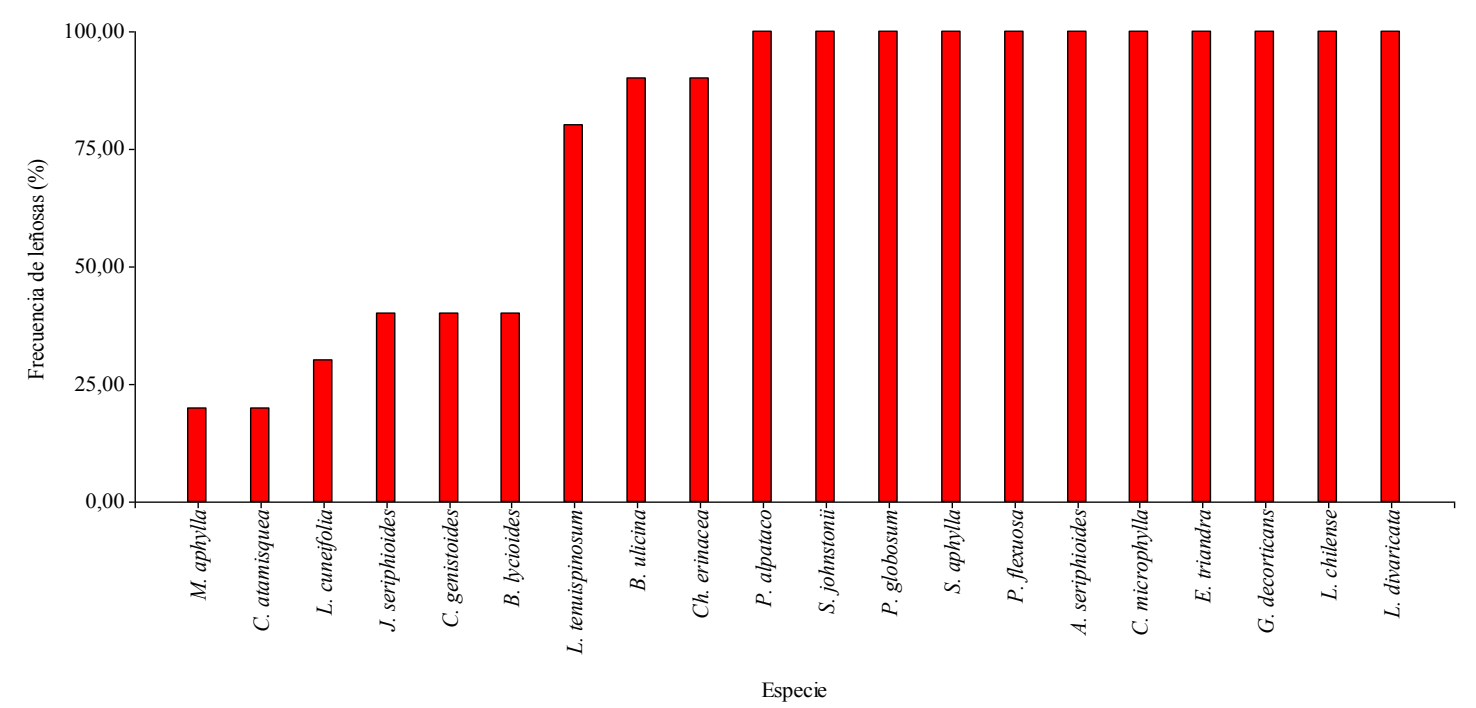

Figura 3.6. Frecuencia de especies leñosas, expresadas en porcentaje (\%) en la unidad geomorfológica Paleocanales.

- Frecuencia de especies herbáceas.

Las especies herbáceas más frecuentes en la Planicie aluvial fueron Nassella tenuis, Pappostipa speciosa y Poa ligularis, con porcentajes de frecuencia superior al $50 \%$ (Figura 3.7). 


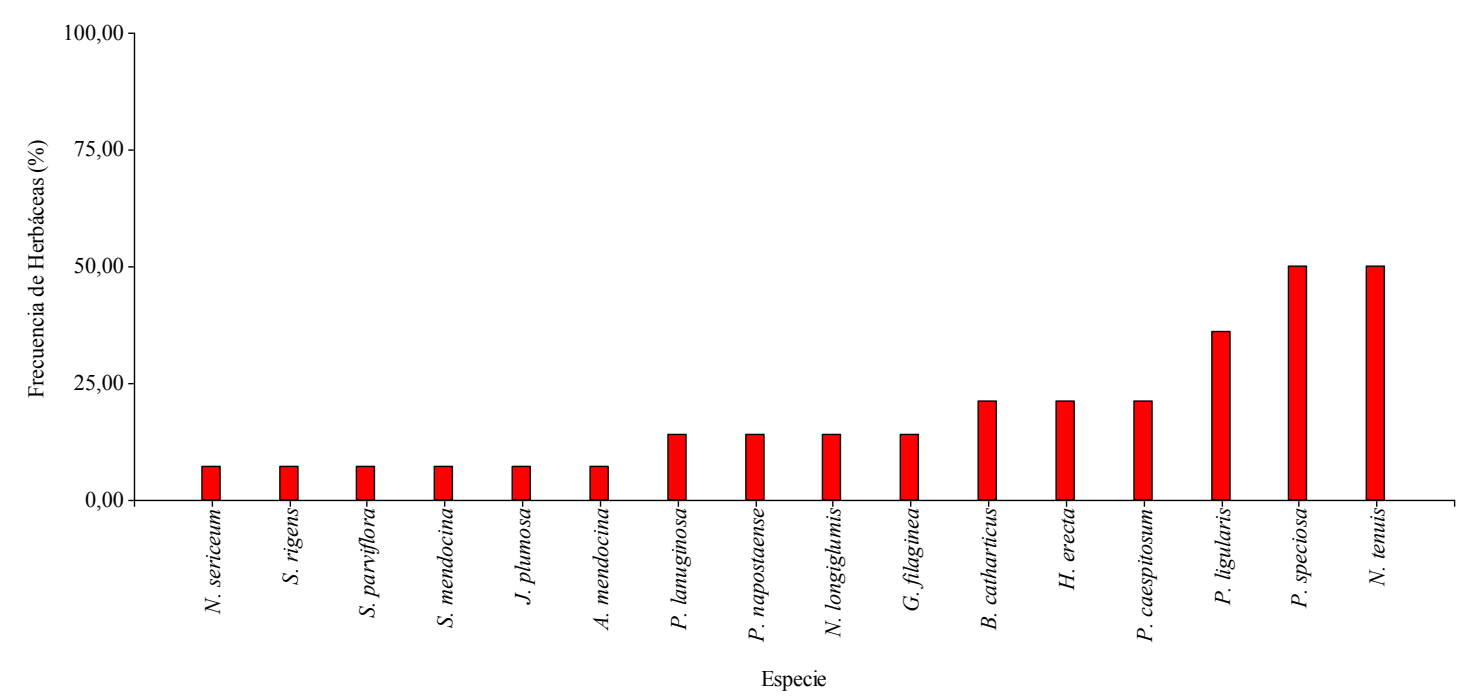

Figura 3.7. Frecuencia de especies herbáeas, expresadas en porcentaje (\%), en la unidad geomorfológica Planicie aluvial.

En la Planicie loéssica, Nassella tenuis, Pappostipa speciosa y Poa ligularis fueron las especies más frecuentes con porcentajes de $75 \%$. Nassella longiglumis y Bromus catharticus también fueron frecuentes, registraron valores cercanos al 50\% (Figura 3.8).

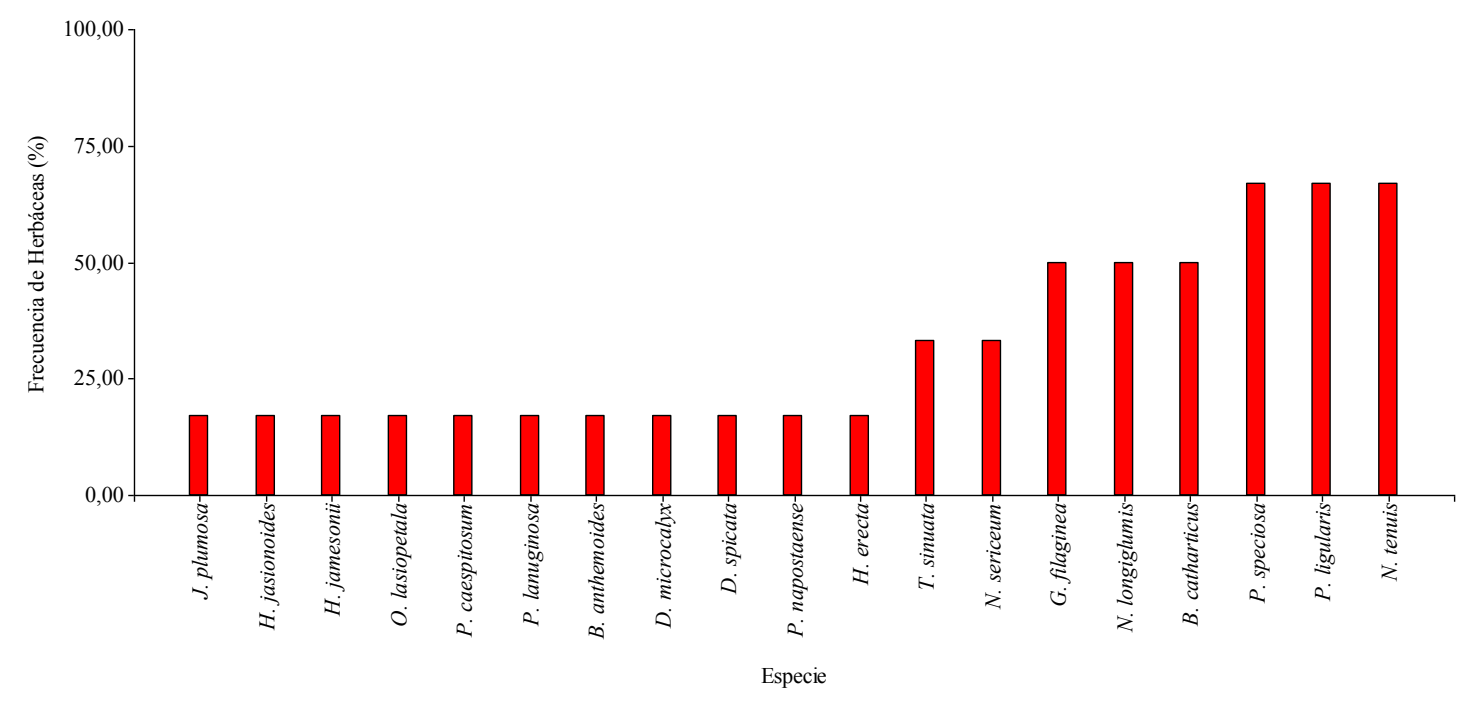

Figura 3.8. Frecuencia de especies herbáceas, expresadas en porcentaje (\%), en la unidad geomorfológica Planicie loéssica.

En los Paleocanales, la especie que aparecó con mayor frecuencia fué Poa ligularis (75\%) (Figura 3.9). 


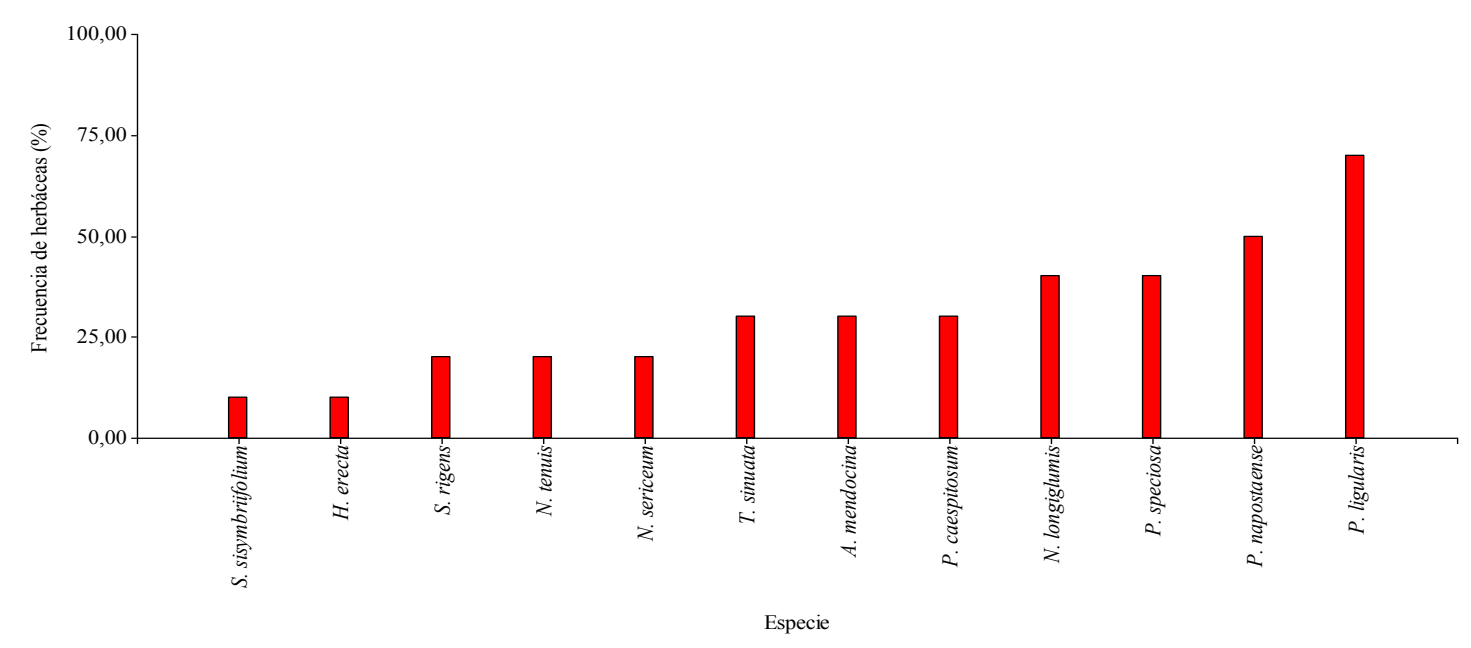

Figura 3.9. Frecuencia de especies herbáceas, expresadas en porcentaje (\%), en la unidad geomorfológica Paleocanales.

En la tabla 2 y 3 del anexo I se observa la frecuencia de las especie leñosas y herbáceas en cada uno de los sitios en los que se realizó el censo florístico.

- Origen de las especies registradas.

La totalidad de las especies registradas en las distintas unidades geomorfológicas estudiadas fueron nativas, excepto la especie herbácea graminiforme Aristida mendocina que presenta el status de adventicia.

- Especies forrajeras

Los porcentajes de especies forrajeras fueron similares entre unidades geomorfológicas (Planicie aluvial $90 \% \pm 73$, Planicie loéssica 64\% \pm 29 y Paleocanales $84 \% \pm 75, p=$ 0,55). Los rangos de variación también fueron similares (de 34 a $83 \%$ ) en los sitios de las tres unidades analizadas (Figura 3.10). 


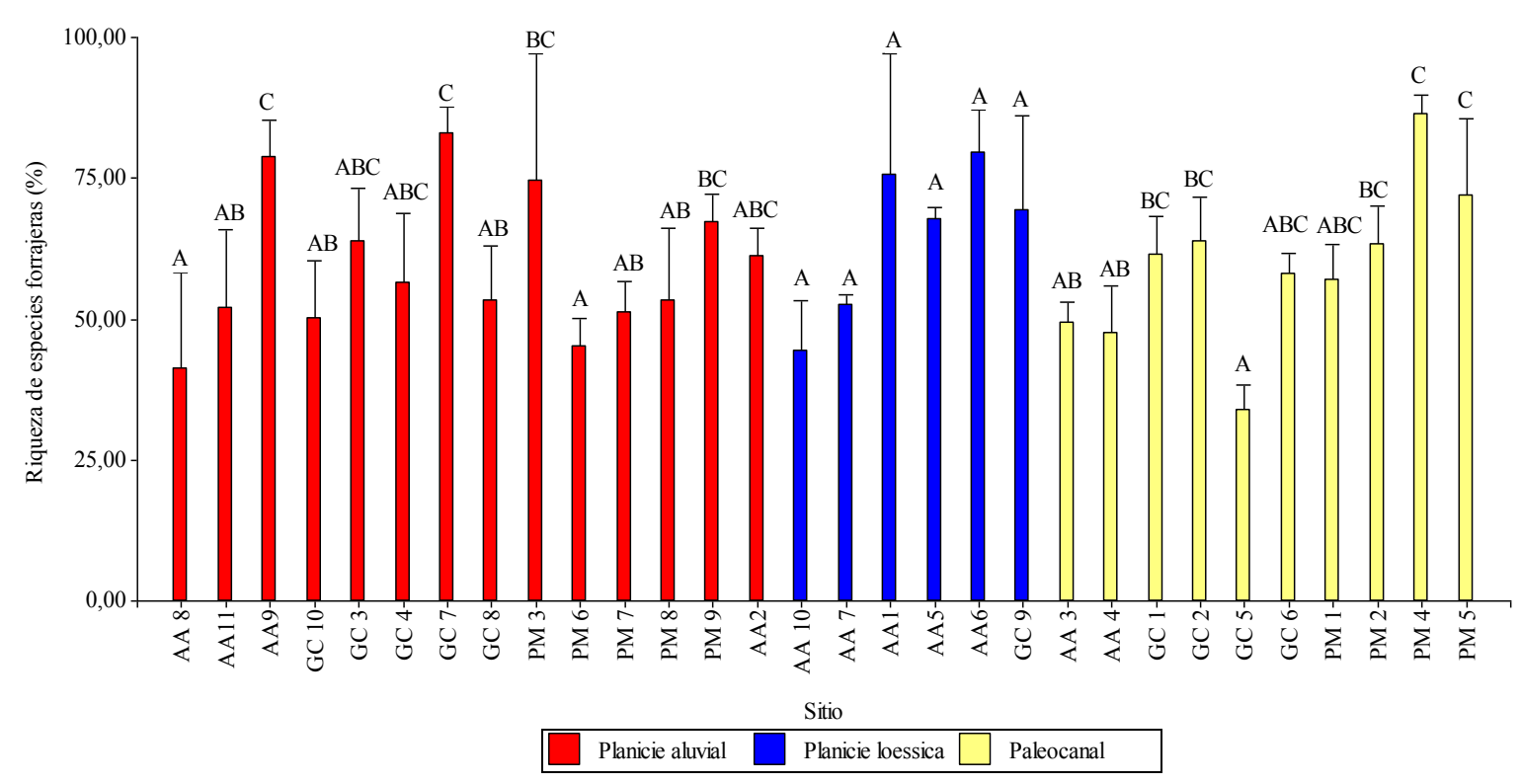

Figura 3.10. Riqueza de especies forrajeras expresadas como porcentajes del número total de especies en las unidades geomorfológicas. Medias con una letra diferente indican diferencias significativas $(\mathrm{p}<0,05)$.

- Estructura de la vegetación.

- Vegetación leñosa.

Las diferencias de cobertura del estrato arbóreo entre unidades geomorfológicas fueron marginalmente significativas (Planicie aluvial $6 \% \pm 12$, Planicie loéssica 10\% \pm 18 y Paleocanales $12 \% \pm 15, p=0,066)$. Se observa una tendencia de mayor cobertura de este estrato en los Paleocanales. Este estrato estuvo ausente en varios de los sitios muestreados y en aquellos en los que estuvo presente, su cobertura fue muy variable, entre $2 \%$ y $46 \%$, según el sitio y la unidad geomorfológica (Figura 3.11). 


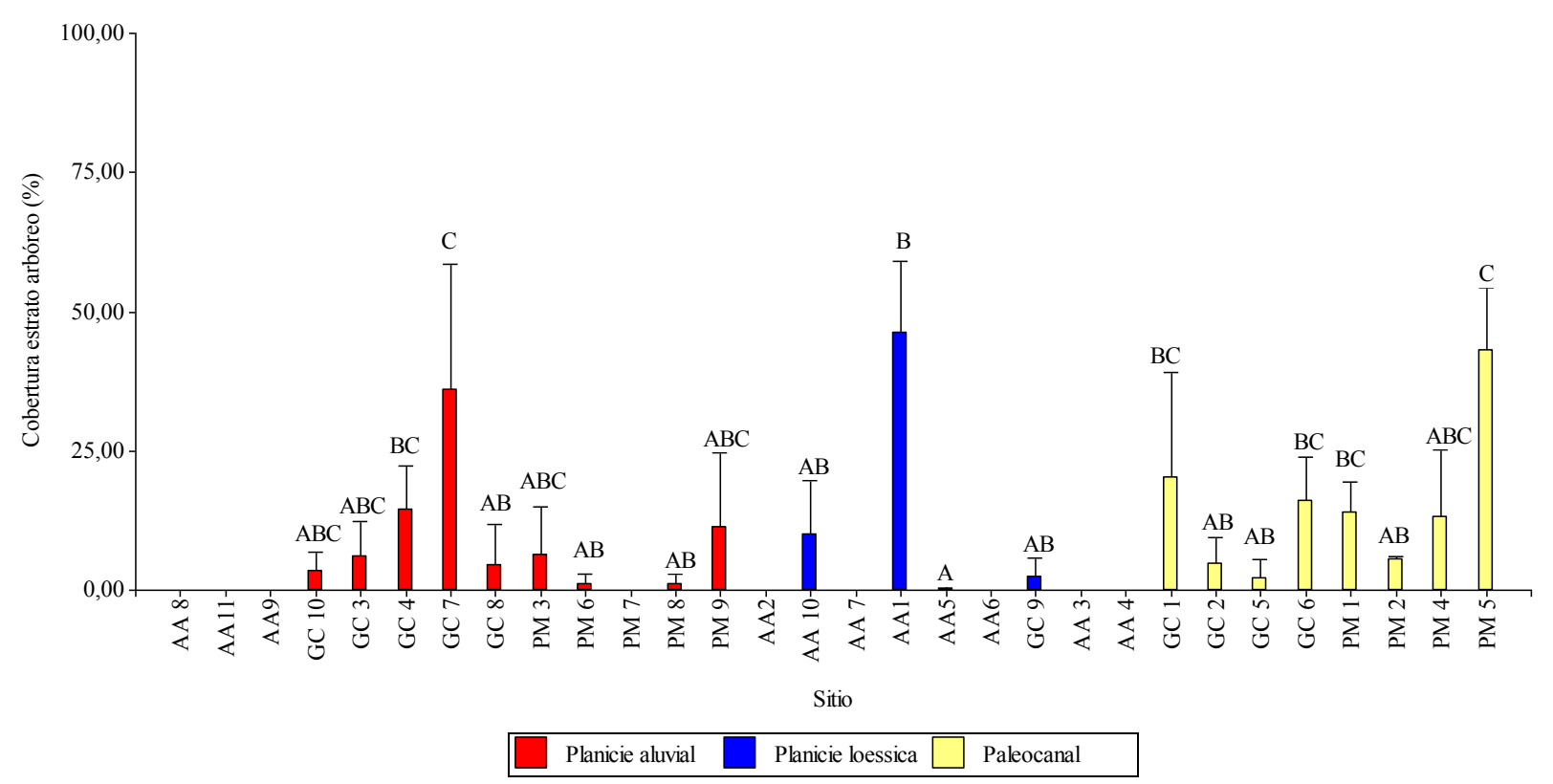

Figura 3.11. Cobertura (\%) del estrato arbóreo presente en las unidades geomorfológicas. Medias con una letra diferente indican diferencias significativas $(\mathrm{p}<0,05)$.

En promedio, la cobertura del estrato arbustivo alto fue similar entre unidades geomorfológicas (Planicie aluvial $27 \% \pm 17$, Planicie loéssica $25 \% \pm 8$ y Paleocanales $22 \% \pm 13, p=0,51)$. Aunque este estrato presentó rangos de variación amplios, fue el de mayor cobertura en la mayoría de los sitios muestreados y estuvo presente en todos ellos. La cobertura de este estrato fue relativamente más homogéneo entre sitios en la Planicie loéssica que en las otras dos unidades geomorfológicas, en las que se observaron diferencias significativas entre sitios (Figura 3.12).

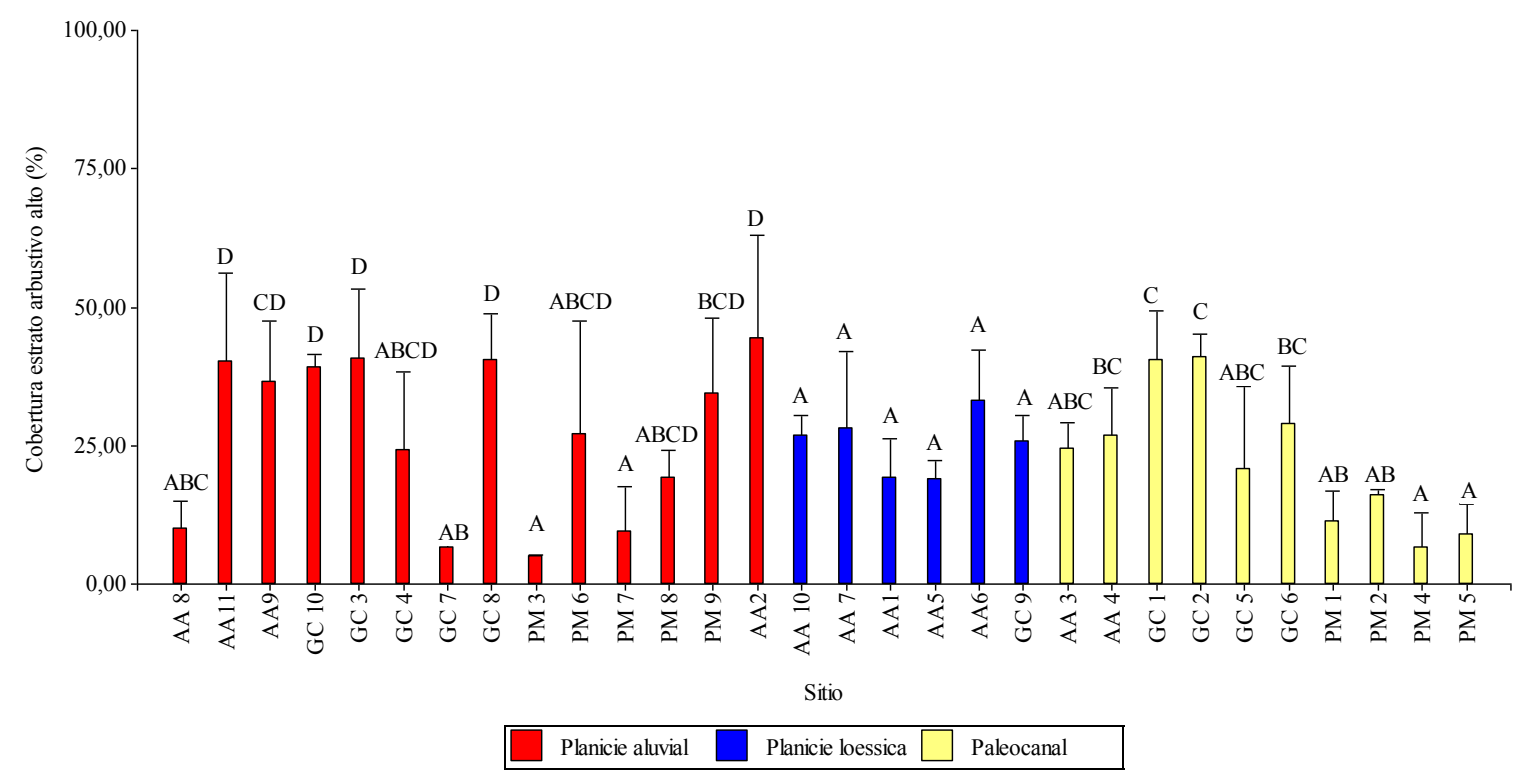

Figura 3.12. Cobertura del estrato arbustivo alto (\%) en las unidades geomorfológicas. Medias con una letra diferente indican diferencias significativas $(\mathrm{p}<0,05)$. 
El estrato arbustivo bajo presentó porcentajes de cobertura no significativamente diferentes entre unidades geomorfológicas (Planicie aluvial $17 \% \pm 16$, Planicie loéssica $10 \% \pm 9$ y Paleocanales $14 \% \pm 10, p=0,38)$. En la Planicie aluvial el rango de variación fue mayor (4\% a 60\%) que en las otras dos unidades (Planicie loéssica 7\% a $24 \%$ y Paleocanales $4 \%$ a 22\%). En relación con ello, la cobertura del estrato bajo fue significativamente diferente entre sitios sólo en la Planicie aluvial (Figura 3.13).

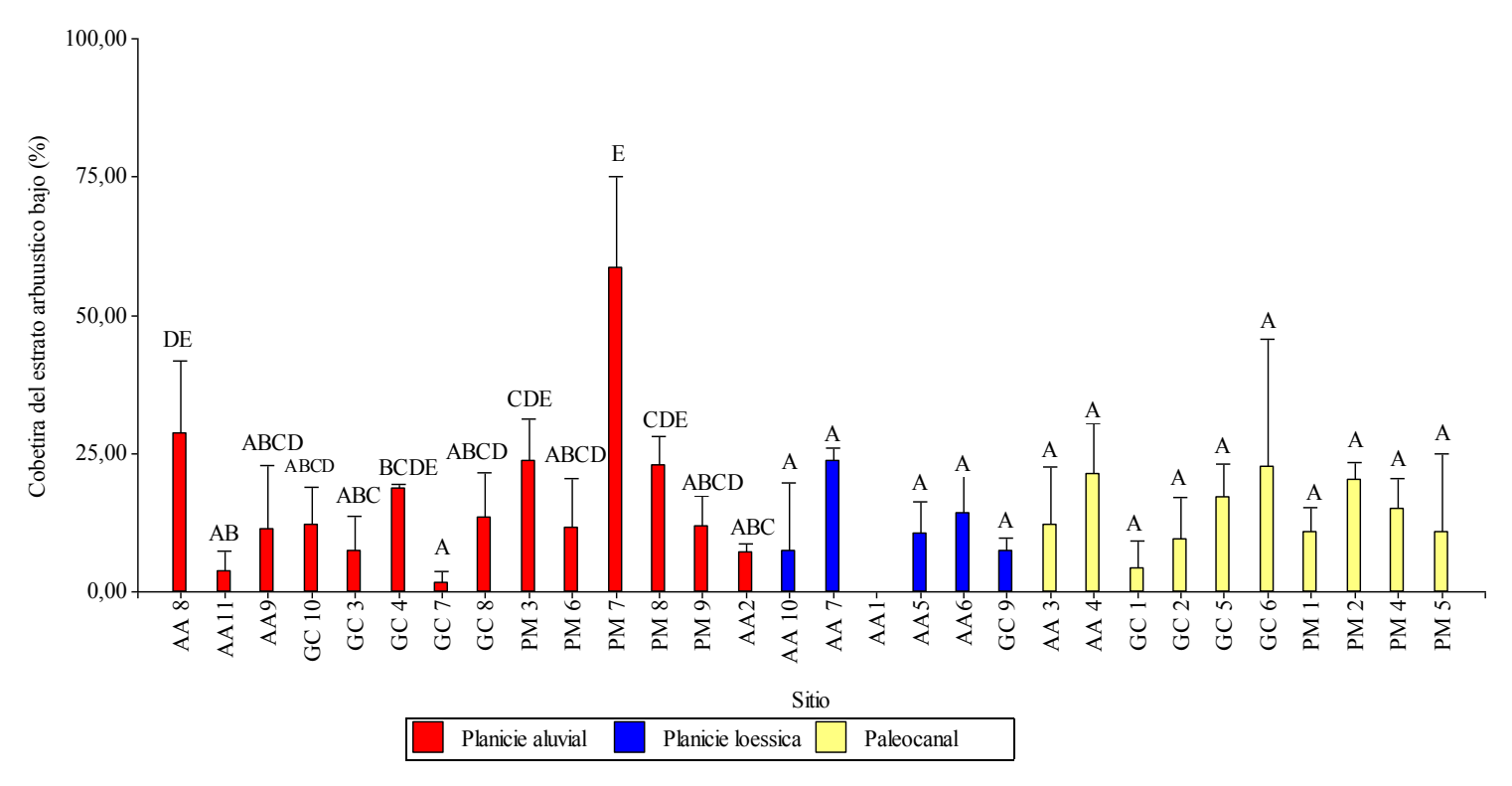

Figura 3.13. Cobertura del estrato arbustivo bajo (\%) en las unidades geomorfológicas. Medias con una letra diferente indican diferencias significativas $(\mathrm{p}<0,05)$.

La cobertura total de leñosas no difirió entre unidades geomorfológicas (Planicie aluvial $50 \% \pm 13$, Planicie loéssica $46 \% \pm 14$ y Paleocanal $49 \% \pm 16, p=0,42$ ). Dentro de cada unidad se observaron diferencias significativas entre sitios en la Planicie loéssica y en los Paleocanales (Figura 3.14). 

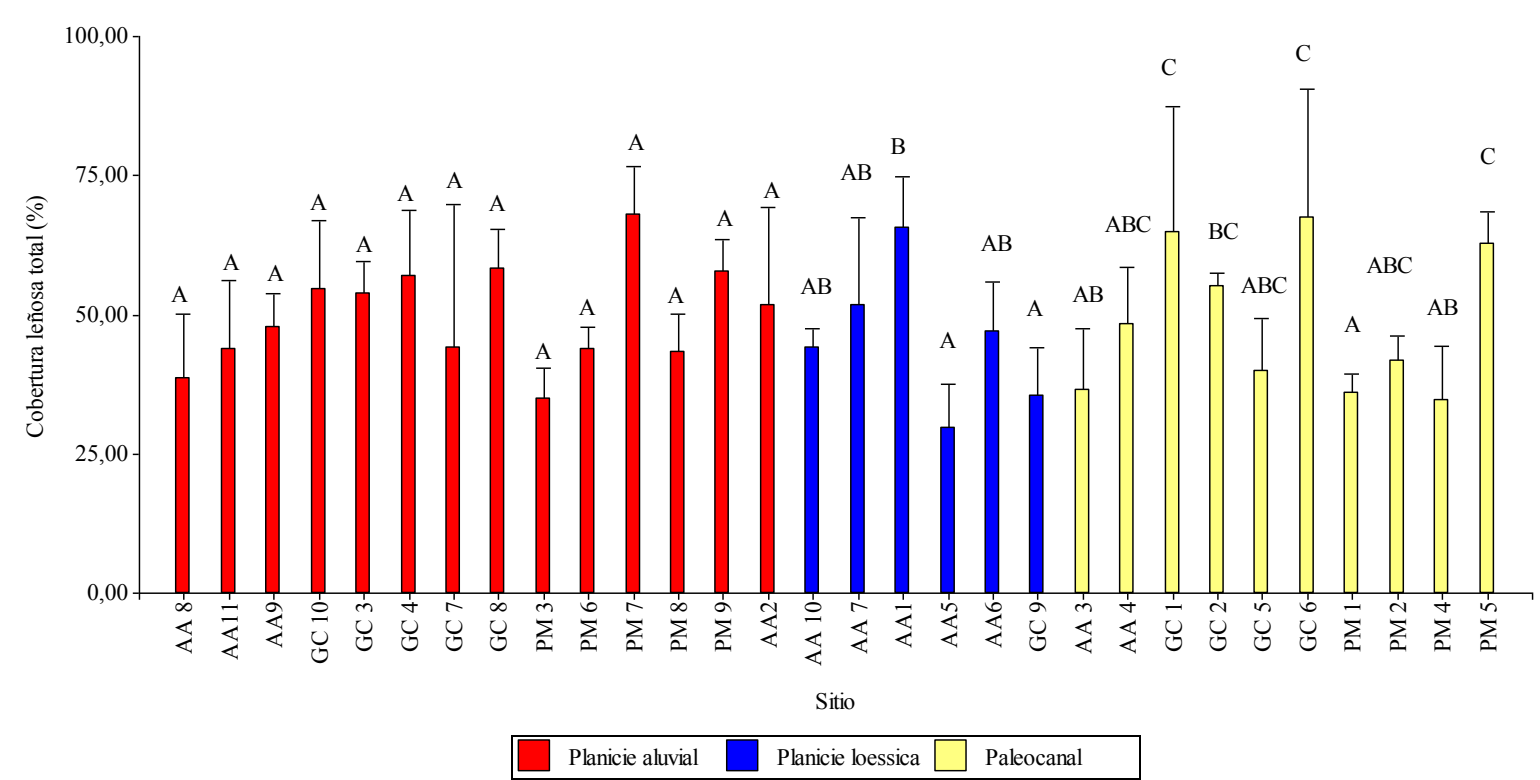

Figura 3.14. Cobertura total de especies leñosas (\%) en las unidades geomorfológicas. Medias con una letra diferente indican diferencias significativas $(\mathrm{p}<0,05)$.

El índice de diversidad de Shannon- Wiener fue significativamente diferente entre unidades geomorfológicas. La diversidad de leñosas fue similar en la Planicie aluvial y los Paleocanales $(1,73 \pm 0,52$ y $1,88 \pm 0,34$, respectivamente) y mayor respecto de la Planicie loéssica $(1,53 \pm 0,43, p=0,014)$. Los mayores rangos de variación en el índice de Shannon-Wiener entre los sitios muestreados se observaron en la Planicie aluvial y los menores en los Paleocanales (Figura 3.15).

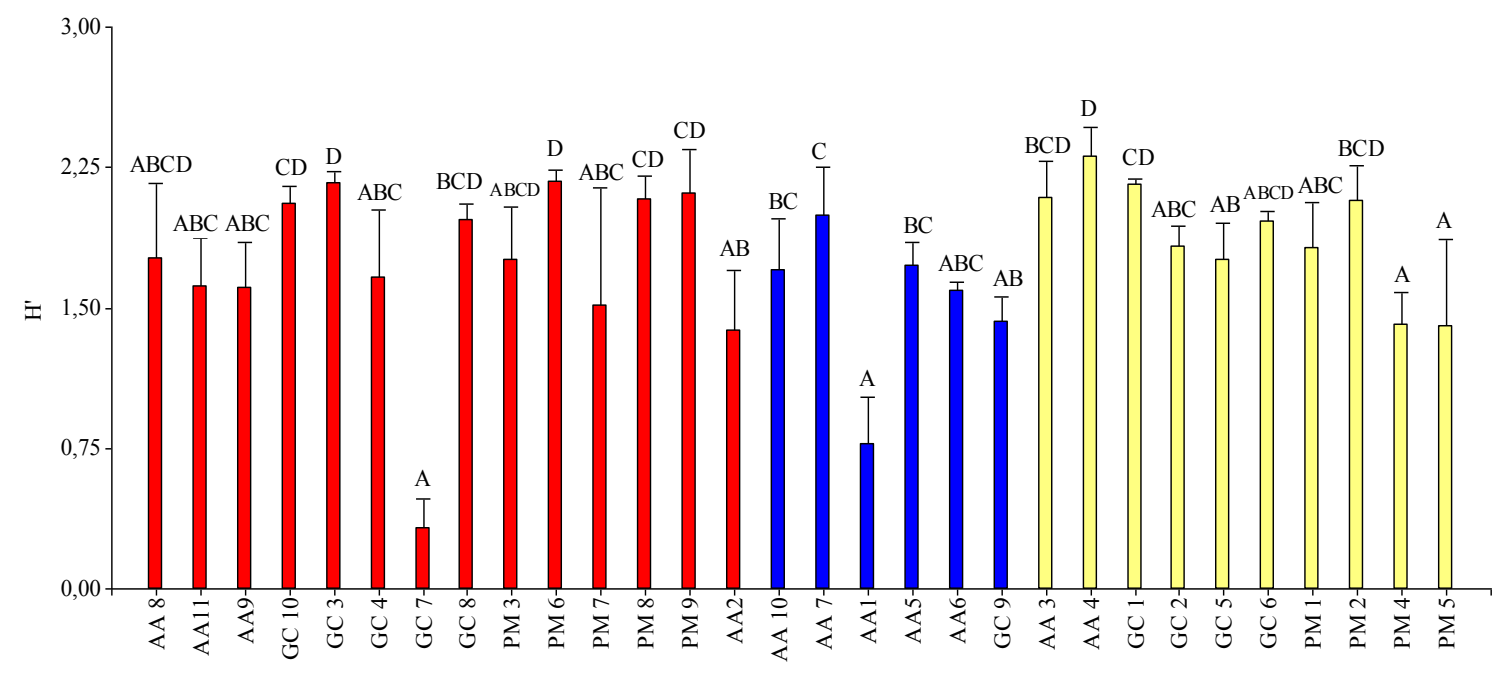

Sitio

Planicie aluvial

Planicie loessica $\square$ Paleocanal

Figura 3.15. Índice de diversidad de Shannon- Wiener ( $\left.\mathrm{H}^{\prime}\right)$ estimado para la vegetación leñosa presente en las unidades geomorfológicas. Medias con una letra diferente indican diferencias significativas $(p<0,05)$. 
- Vegetación herbácea.

La cobertura de las especies herbáceas perennes no difirió significativamente entre unidades geomorfológicas (Planicie aluvial 43\% $\pm 33,6 \%$, Planicie loéssica $42 \% \pm$ $24,2$ y Paleocanales $45 \% \pm 34,8, p=0,95)$, con rangos de variación amplios entre sitios en cada una de estas unidades (Figura 3.16).

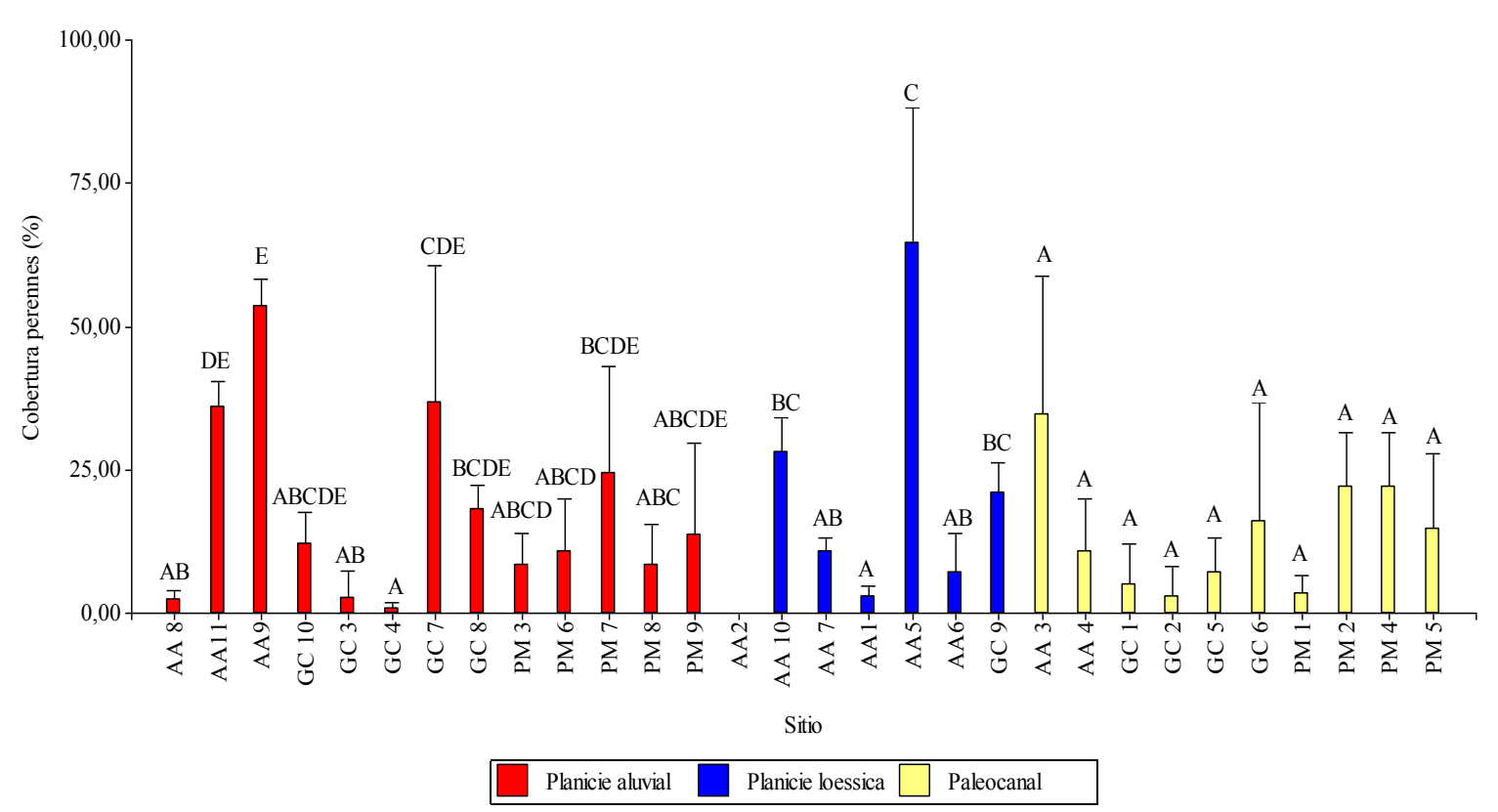

Figura 3.16. Cobertura total (\%) de especies herbáceas perennes en las unidades geomorfológicas. Medias con una letra diferente indican diferencias significativas $(\mathrm{p}<0,05)$.

\subsection{2- Suelos.}

- Composición granulométrica

En los suelos de los sitios muestreados predominó la fracción arena por sobre el limo y la arcilla. En todos los sitios se verificó un bajo porcentaje de la fracción fina (limo + arcilla), que no superó el 33 \% (Figura 3.17). En promedio, la proporción de arcilla + limo no difirió significativamente entre unidades geomorfológicas (Planicie aluvial 24 $\pm 9,1$; Planicie loéssica 22\% $\pm 9,7$; Paleocanales $23 \% \pm 9,7 ; p=0,094)$. 


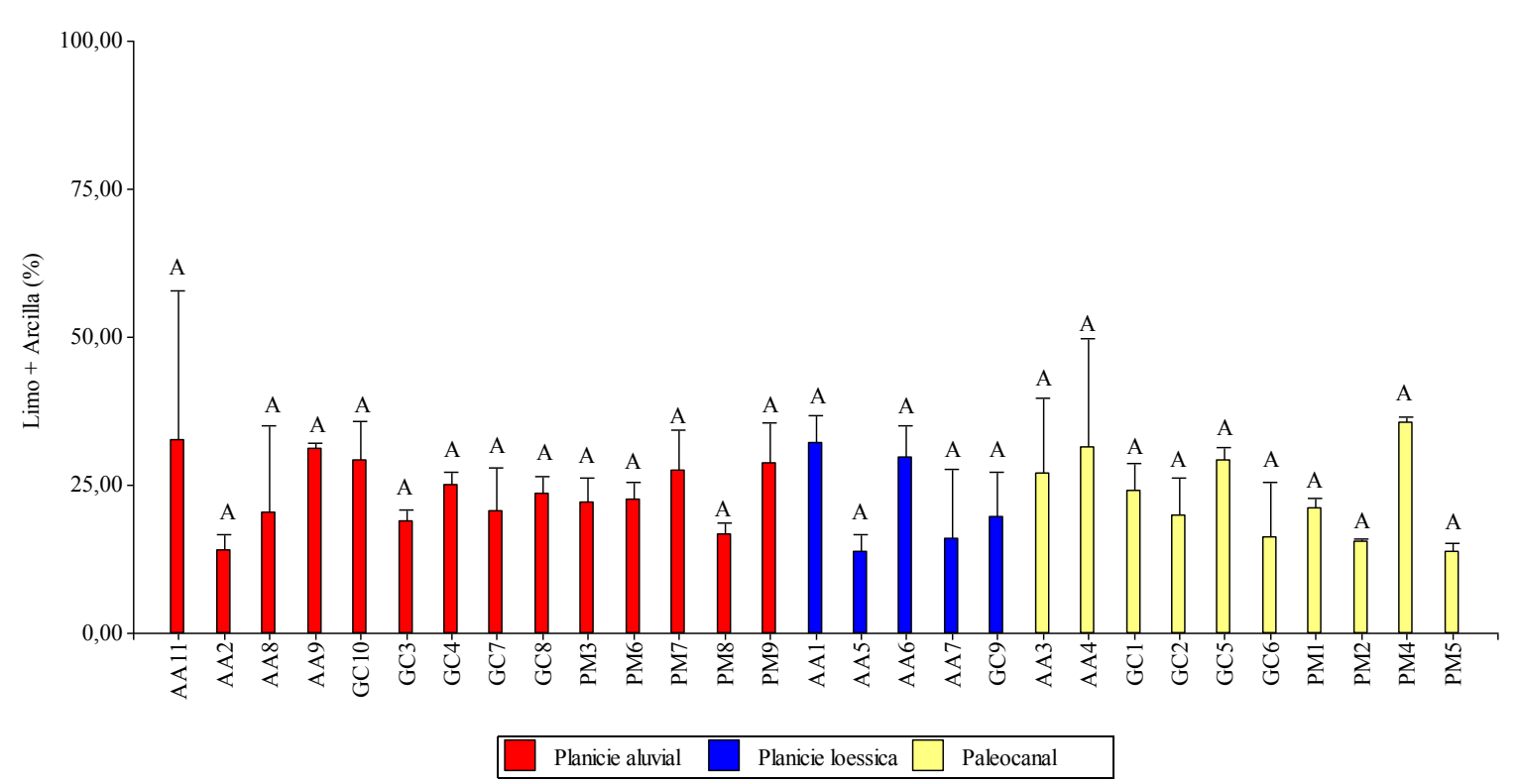

Figura 3.17. Porcentaje (\%) de limo + arcilla de los suelos de los sitios situados en las diferentes unidades geomorfológicas. Medias con una letra diferente indican diferencias significativas $(\mathrm{p}<0,05)$.

- $\mathrm{pH}$ y $\mathrm{Ce}^{-}$del suelo.

Los valores de $\mathrm{pH}$ no presentaron diferencias significativas entre distintas regiones geomorfológicas (Planicie aluvial 1,3 $\pm 2,4$; Planicie loéssica 2,4 4 4,1; Paleocanales $1,6 \pm 2, p=0,57)$. Las medias registradas en el área de estudio sitúan a los suelos de la región como levemente alcalinos con valores que varían entre 7,2 y 8,6, aunque algún sitio registró valores levemente ácidos $(\mathrm{pH}=6,24)$ (Anexo II, tabla 4).

Los valores medidos de $\mathrm{Ce}^{-}$mostraron diferencias significativas entre las diferentes unidades geomorfológicas analizadas (Planicie aluvial 1,3 $\pm 2,4$; Planicie loéssica 2,4 \pm 4,1; Paleocanales 1,6 $\pm 2, p=0,04)$. Algunos sitios presentaron valores de $\mathrm{Ce}^{-}$que corresponden a suelos ligeramente salinos a moderadamente salinos (4,6, a 2,2 mmhoms.cm ${ }^{-1}$ ). El resto de los sitios, que presentaron valores inferiores a 2 mmhoms.cm ${ }^{-1}$, poseen suelos no salinos (Figura 3.18). 


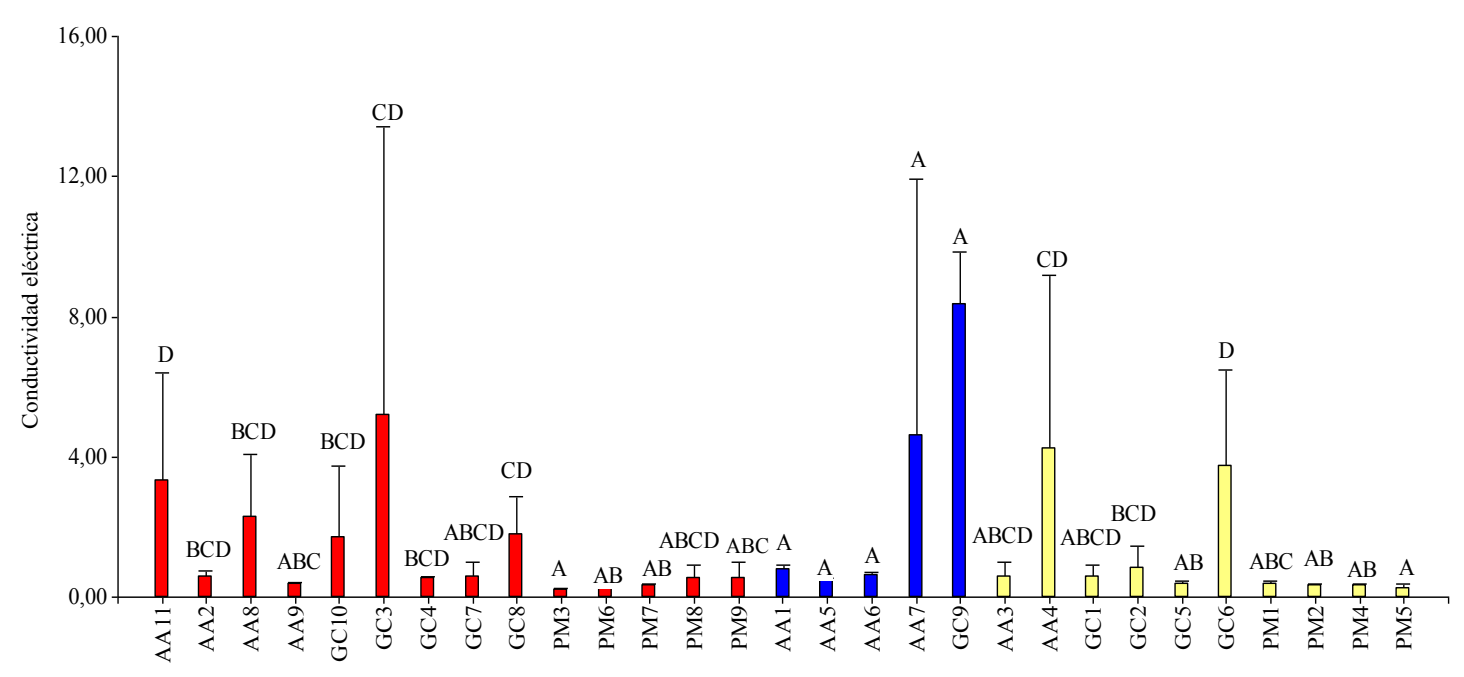

Sitio

$\square$ Planicie aluvial $\square$ Planicie loessica $\square$ Paleocanal

Figura 3.18. Conductividad eléctrica (mmhoms.cm-1) de los suelos de los sitios situados en las diferentes unidades geomorfológicas. Medias con una letra diferente indican diferencias significativas $(\mathrm{p}<0,05)$.

- Fertilidad del suelo.

El porcentaje de materia orgánica no difirió entre unidades geomorfológicas (Planicie aluvial $1,1 \% \pm 0,3$; Planicie loéssica $1,1 \% \pm 0,3$; Paleocanales $1,3 \% \pm 0,5, p=0,34$ ). Los valores fueron bajos en todos los sitios muestreados, aunque las variaciones entre sitios fueron más marcadas en la Planicie aluvial y Paleocanales, que en la Planicie loéssica (Figura 3.19). El nitrógeno tampoco difirió entre unidades geomorfológicas (Planicie aluvial $0,08 \% \pm 0,03$; Planicie loéssica $0,08 \% \pm 0,03$; Paleocanales $0,07 \% \pm$ $0,02, p=0,32)$ y mostró mayor variabilidad entre sitios en la Planicie aluvial y Paleocanales que en la Planicie loéssica (Figura 3.20).
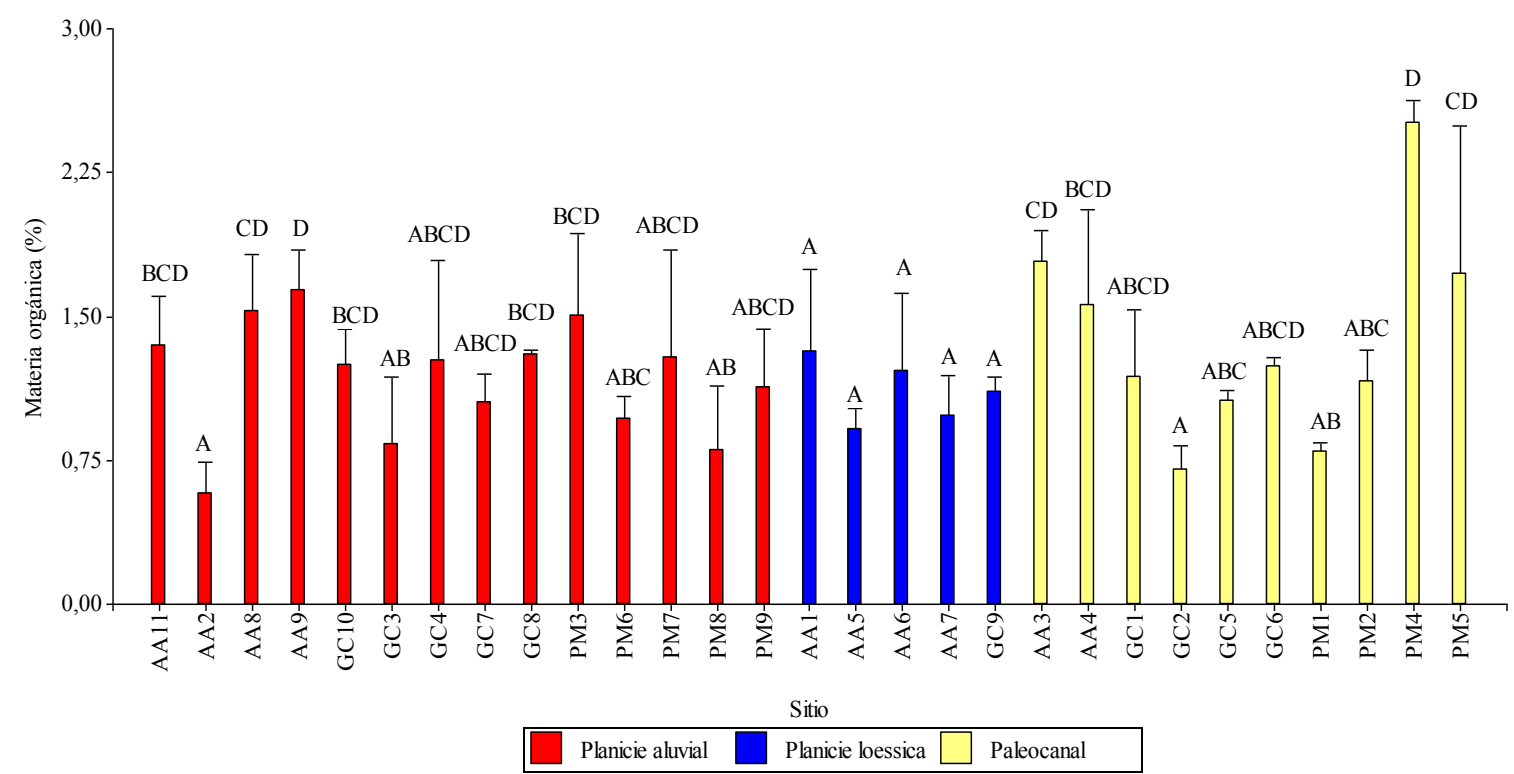

Figura 3.19. Contenido de Materia orgánica expresada en porcentaje (\%) de los suelos de los sitios situados en las diferentes unidades geomorfológicas. Medias con una letra diferente indican diferencias significativas $(\mathrm{p}<0,05)$. 


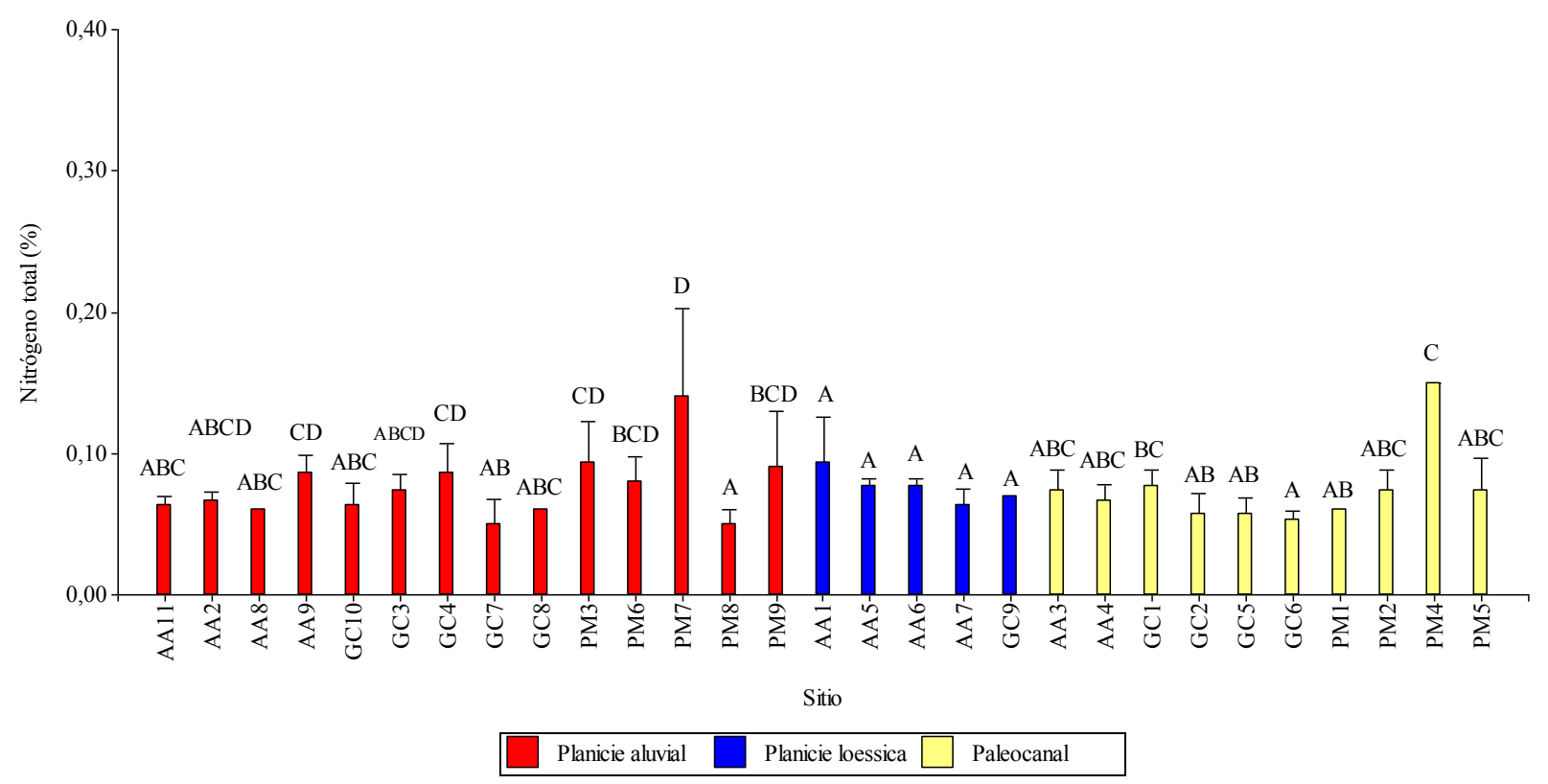

Figura 3.20. Contenido de Nitrógeno expresada en porcentaje (\%) de los suelos de los sitios situados en las diferentes unidades geomorfológicas. Medias con una letra diferente indican diferencias significativas $(\mathrm{p}<0,05)$.

La concentración de $\mathrm{P}$ fue mayor en los Paleocanales (12 ppm $\pm 8, p=0.04)$ que en la Planicie aluvial $(9 \mathrm{ppm} \pm 5)$ y en la Planicie loéssica $(9 \mathrm{ppm} \pm 12)$. Todos los sitios muestreados presentaron baja concentración de $\mathrm{P}$, cuya variación entre sitios fue mayor en la Planicie loéssica (1,5 a 29 ppm), que en las otras dos unidades geomorfológicas (Planicie aluvial 4 a 15 ppm y Paleocanales 6 a 22 ppm) (Figura 3.21).

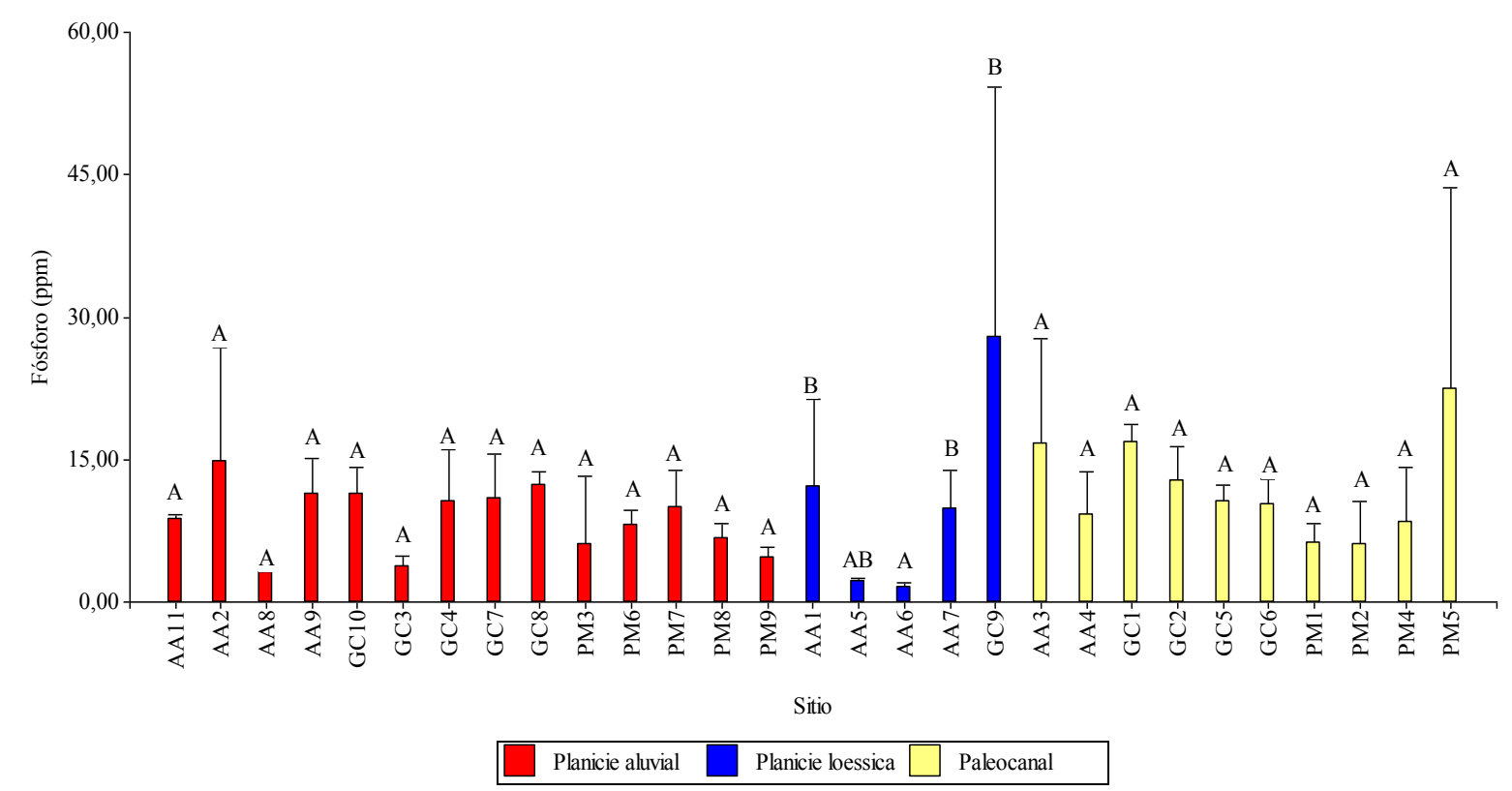

Figura 3.21. Contenido de Materia fósforo expresada en partes por millón (ppm) de los suelos de los sitios situados en las diferentes unidades geomorfológicas. Medias con una letra diferente indican diferencias significativas $(\mathrm{p}<0,05)$. 
- Compactación del suelo (densidad aparente).

La densidad aparente de los suelos no difirió significativamente entre unidades geomorfológicas (Planicie aluvial 1,35 gr/ $\mathrm{cm}^{3} \pm 0,3$; Planicie loéssica 1,34 gr/ $\mathrm{cm}^{3}$ $\pm 0,15$; Paleocanales $\left.1,2 \mathrm{gr} / \mathrm{cm}^{3} \pm 0,42, p=0,17\right)$ y varió en mayor medida entre sitios en la Planicie aluvial y en los Paleocanales $\left(0,4 \mathrm{gr} / \mathrm{cm}^{3}\right.$ y $1,6 \mathrm{gr} / \mathrm{cm}^{3}$ y $0,4 \mathrm{gr} / \mathrm{cm}^{3}$ y 1,5 $\mathrm{gr} / \mathrm{cm}^{3}$, respectivamente) que en la Planicie loéssica $\left(1 \mathrm{gr} / \mathrm{cm}^{3}\right.$ y $\left.1,5 \mathrm{gr} / \mathrm{cm}^{3}\right)$ (Figura $3.22)$.

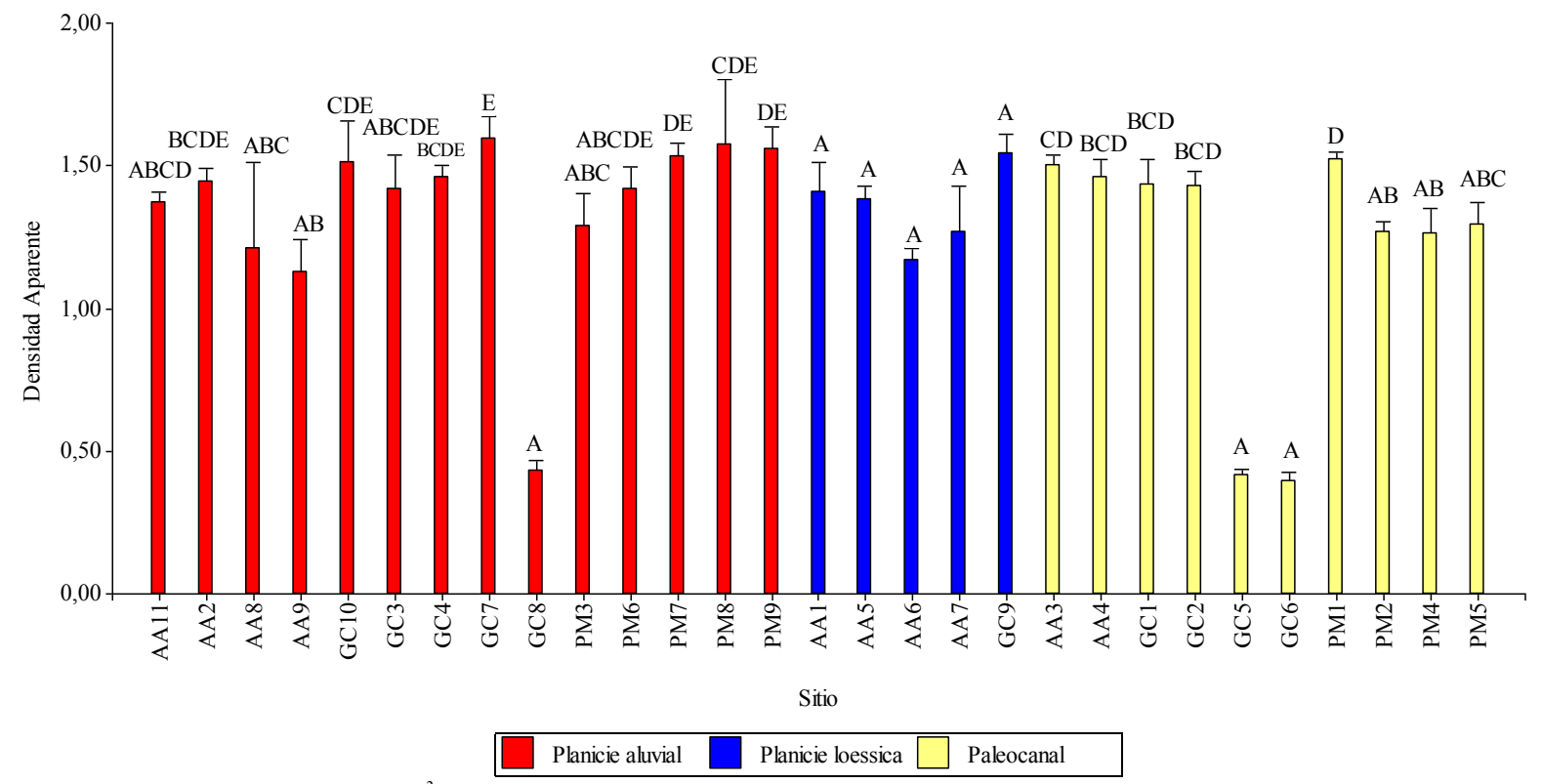

Figura 3.22. Densidad aparente $\left(\right.$ gr. $\left.\mathrm{cm}^{-3}\right)$ de los suelos de los sitios situados en las diferentes unidades geomorfológicas. Medias con una letra diferente indican diferencias significativas $(\mathrm{p}<0,05)$.

\subsection{3- Usos del suelo}

- Usos históricos del suelo.

Los usos de los suelos dominantes en el área, registrados en el año 1986, eran la ganadería extensiva de secano, seguida de la agricultura practicada en áreas bajo riego. La agricultura extensiva de secano se encontraba mucho menos difundida y sólo se localizaba en áreas específicas en el Este del departamento Adolfo Alsina y Este de General Conesa (Figura 3.23; Tabla 3.1). 


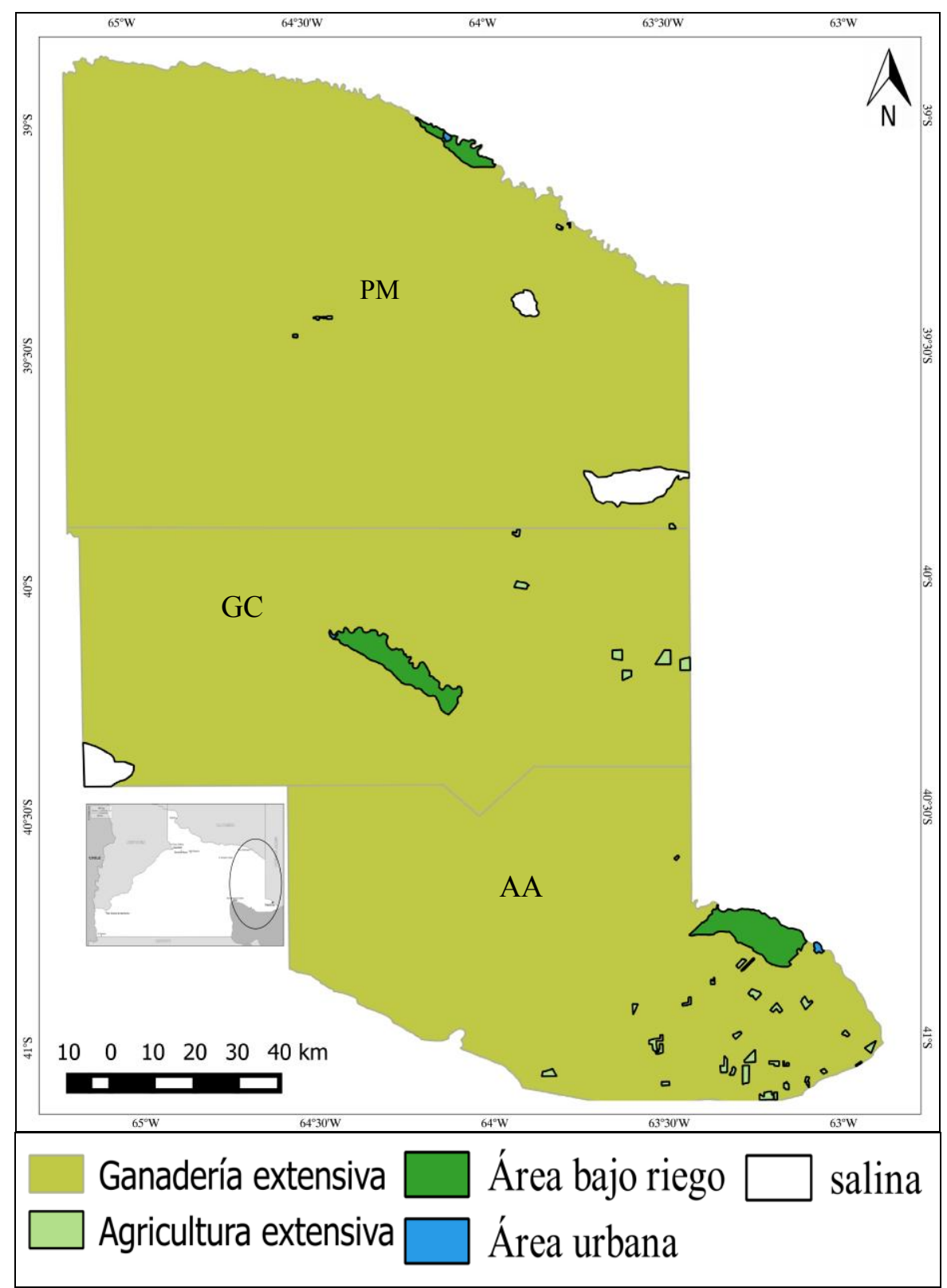

Figura 3.23. Usos del suelo año 1986 en los departamentos de Adolfo Alsina (AA), General Conesa (GC) y Pichi Mahuida (PM).

En el año 1992, las precipitaciones en el área de estudio estuvieron por encima de los registros históricos (311 mm/año), observándose medias anuales que duplicaban los registros medios históricos (654 mm/año) (De Berasategui 2004). Ello alentó a los productores, fundamentalmente del Este del departamento Adolfo Alsina, a sustituir la producción ganadera por la producción agrícola de secano (Figura 3.24). Para ello se despejaron grandes extensiones de tierra ocupadas por vegetación de monte y se implantaron monocultivos que venían siendo desplazados de otras áreas más productivas por cultivos de una rentabilidad superior (Pezzola y Winschel 2004; Zeberio 2012; Zeberio et al. 2015). Además, los métodos de preparación y labranza de la tierra empleados son los mismos que se usan en regiones más húmedas del país y no 
son los más adecuados para regiones semiáridas y áridas (Viglizzo et al. 2012).

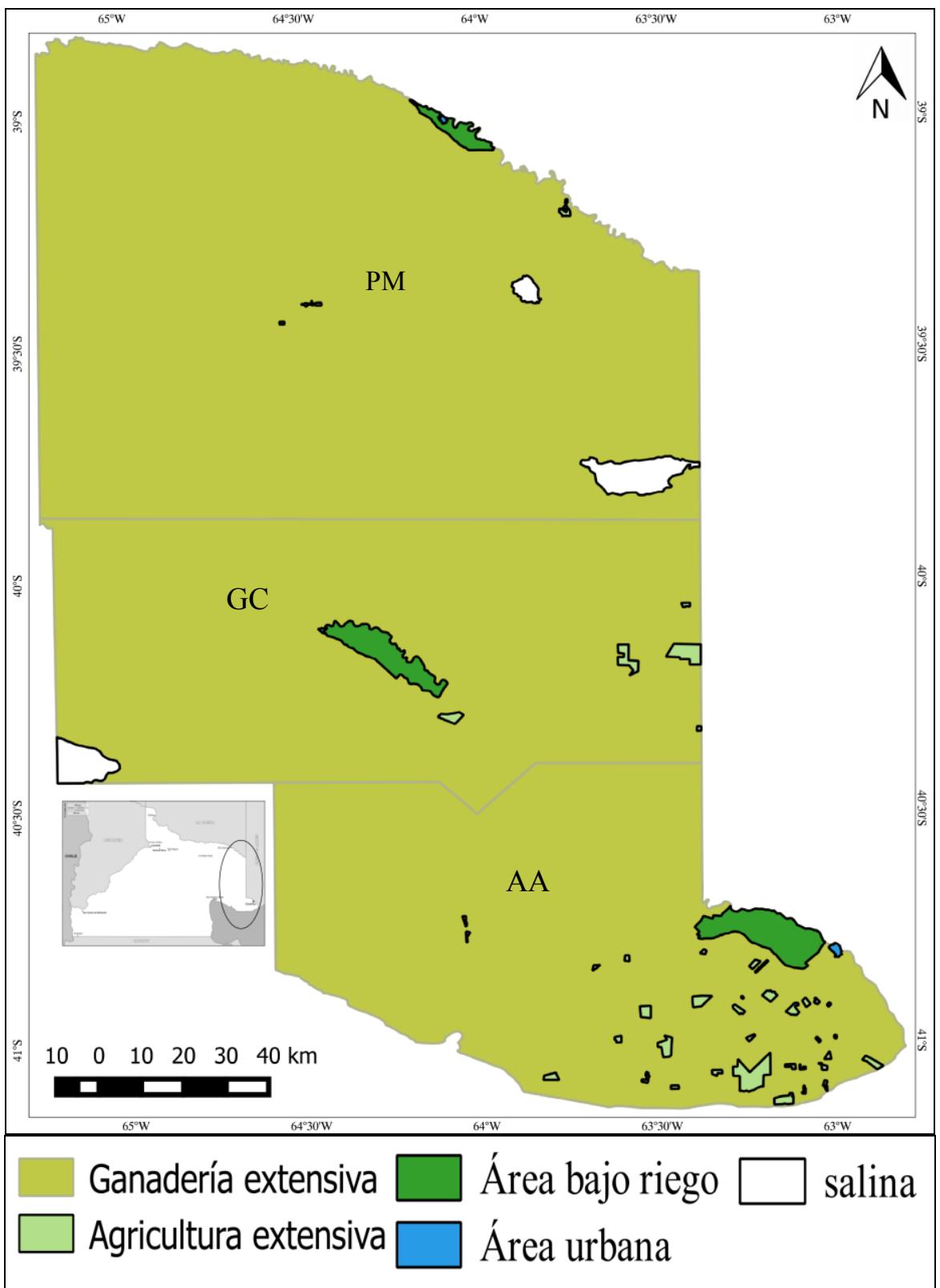

Figura 3.24. Usos del suelo año 1992 en los departamentos de Adolfo Alsina (AA), General Conesa (GC) y Pichi Mahuida (PM). 
Tabla 3.1. Superficie ocupada por uso del suelo en los años 1986, 1992 y 2015.

\begin{tabular}{l|ccc} 
& \multicolumn{3}{|c}{ Superficie (Ha.) } \\
Uso del suelo & 1986 & 1992 & 2015 \\
\hline Urbano & 955,62 & $1.020,78$ & $2.518,42$ \\
Salina & $28.691,01$ & $30.819,56$ & $32.965,39$ \\
Área bajo riego & $45.683,36$ & $45.956,40$ & $65.169,69$ \\
Agricultura extensiva & $12.017,53$ & $21.003,11$ & $109.559,65$ \\
Ganadería extensiva & $3.355 .945,50$ & $3.344 .493,17$ & $3.233 .079,87$ \\
\hline
\end{tabular}

- Usos actuales del suelo.

En la actualidad, el uso predominante de la tierra es la ganadería extensiva o ganadería de monte (Tabla 3.1). Sin embargo, en el Este del departamento Adolfo Alsina se observa un avance de la frontera agrícola, registrándose un marcado incremento de la superficie de tierras dedicada a los cultivos agrícolas de secano. También se detectó un incremento de este tipo de usos del suelo en el sector Este del departamento General Conesa, aunque no tan marcado como el anterior (Figura 3.25). En la actualidad, en comparación con años anteriores, la proporción de hectáreas ocupadas por el uso ganadero ha disminuido y se observa el incremento de áreas destinadas a la producción agrícola de secano y a la producción de cultivos en zonas con aporte de agua de riego (Tabla 3.1). Este último fenómeno se registra en áreas cercanas al valle del Río Negro donde, en los últimos años, se han desmontado y sistematizado para el riego grandes áreas (20.000 ha aproximadamente). 


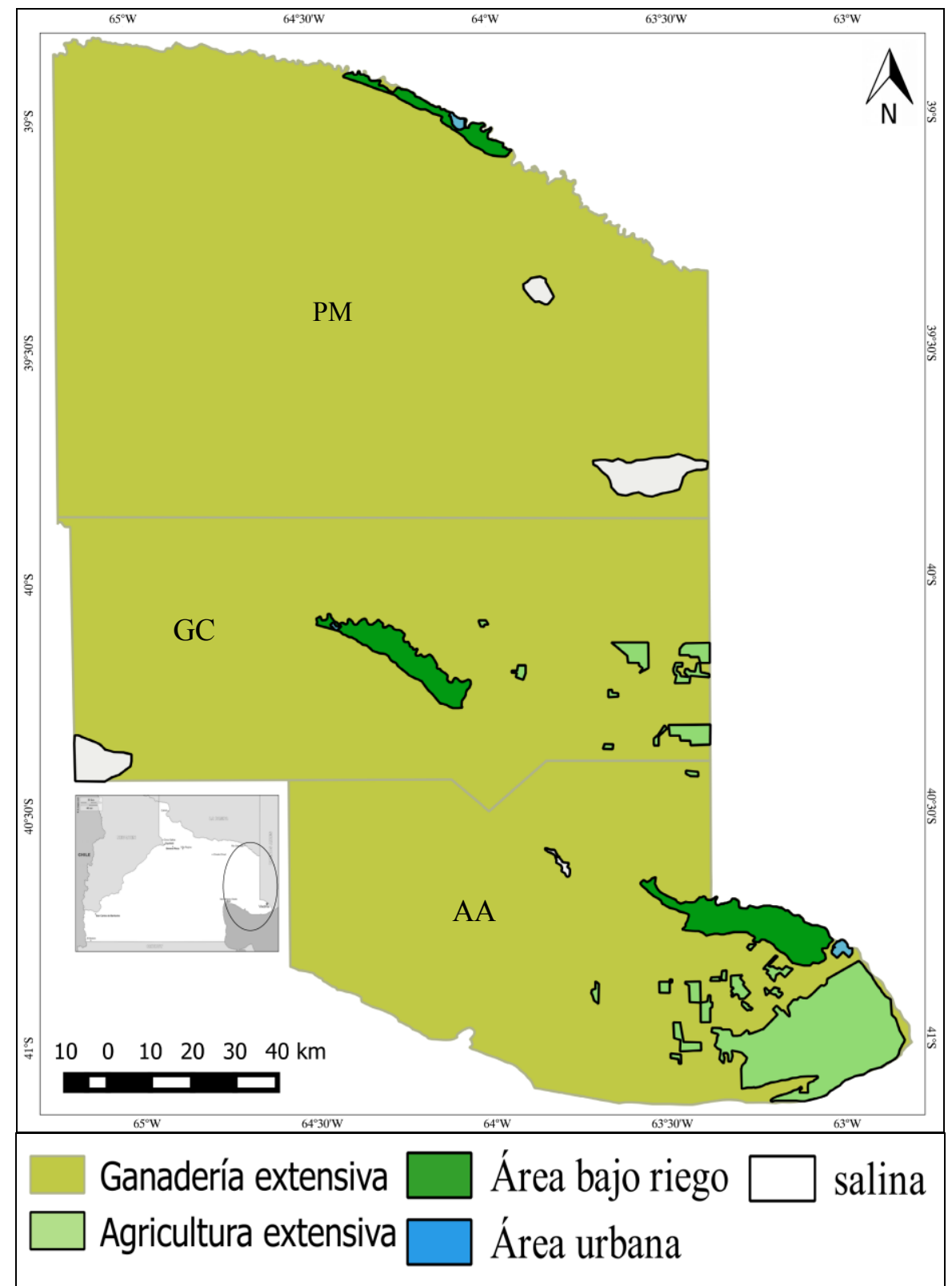

Figura 3.25. Usos del suelo año 2015 en los departamentos de Adolfo Alsina (AA), General Conesa (GC) y Pichi Mahuida (PM).

De la información obtenida en las encuestas a los productores en cuyas unidades productivas evaluamos la vegetación natural del monte, observamos que la actividad predominante es la ganadería extensiva o ganadería de monte $(73,7 \%)$ seguida de la actividad mixta (26,3\%) (Tabla 3.2). Cabe aclarar que la actividad mixta se refiere a la ganadería extensiva en campos naturales que es suplementada con verdeos o pasturas para reforzar la oferta forrajera en épocas desfavorables. Para llevar a cabo esta actividad se realiza el desmonte y luego se implantan cultivos extensivos de secano.

En la producción pecuaria, se efectúa un manejo de los recursos naturales del Monte que involucra rotaciones del ganado por los diferentes potreros. Este tipo de manejo tiene como propósito permitir la recuperación de los recursos forrajeros y es una 
práctica habitual. Sin embargo, el pastoreo continuo durante todo el año (año redondo) es casi tan practicado como las rotaciones. En los sitios de muestreo de este trabajo, según los resultados de las encuestas, no se practicó manejo de la cobertura leñosa por desmonte o fuegos, sin embargo, fueron bastante frecuentes los incendios que abarcaron grandes extensiones (Tabla 3.2).

Tabla 3.2. Tabla de frecuencias de variables nominales de uso de la tierra. Evaluación de RRNN: Evaluación de los recursos forrajeros para estimar la receptividad ganadera de los pastizales.

\begin{tabular}{|c|c|c|}
\hline & Frecuencia & Porcentaje \\
\hline & \multicolumn{2}{|c|}{ Régimen de tenencia } \\
\hline Arrendatario & 4 & 21,1 \\
\hline \multirow[t]{2}{*}{ Propietario } & 15 & 78,9 \\
\hline & \multicolumn{2}{|c|}{ Actividad desarrollada } \\
\hline Ganadera & 14 & 73,7 \\
\hline \multirow[t]{2}{*}{ Mixta } & 5 & 26,3 \\
\hline & \multicolumn{2}{|c|}{ RRNN involucrados } \\
\hline Monte nativo & 14 & 73,6 \\
\hline \multirow{3}{*}{$\begin{array}{l}\text { Pastura/cereale } \\
\mathrm{s}\end{array}$} & 5 & 26,4 \\
\hline & & \\
\hline & \multicolumn{2}{|c|}{ Evaluación de RRNN } \\
\hline No & 9 & 47,4 \\
\hline \multirow[t]{2}{*}{$\mathrm{Si}$} & 10 & 52,6 \\
\hline & \multicolumn{2}{|c|}{ Tipo de manejo } \\
\hline Año redondo & 9 & 47,4 \\
\hline \multirow[t]{2}{*}{ Rotación } & 10 & 52,6 \\
\hline & \multicolumn{2}{|c|}{$\begin{array}{c}\text { Manejo de la cobertura } \\
\text { leñosa }\end{array}$} \\
\hline \multirow[t]{2}{*}{ Sin manejo } & 19 & 100,0 \\
\hline & \multicolumn{2}{|c|}{ Ocurrencia de incendios } \\
\hline No & 10 & 52,6 \\
\hline $\mathrm{Si}$ & 9 & 47,4 \\
\hline
\end{tabular}

En el área dedicada a la ganadería extensiva la carga animal está determinada por la apreciación del contenido de forraje de los diferentes cuadros que tienen los encargados del manejo de la hacienda. Esta última es de dos tipo, ovina y bovina. La carga animal fue muy variable de una unidad productiva a otra (Tabla 3.3), indicando en algunos casos, la posibilidad de sobrepastoreo y deterioro de la vegetación y el suelo. Otro factor importante a considerar en la evaluación del estado de los recursos forrajeros es el número de las aguadas y el número y superficie de los cuadros de las unidades productivas. Generalmente, dos cuadros contiguos comparten una misma aguada, aunque existen casos en los que esto no se cumple y una misma aguada es utilizada para 
abastecer a tres o más cuadros. Además, la superficie de los campos de la zona, divididos en no más de 4 cuadros, indica potreros de grandes dimensiones con poca infraestructura para la provisión de agua y manejo de la hacienda (Tabla 3.3). Aguadas más abundantes y cuadros de menor superficie implican un aprovechamiento más uniforme de los pastos y hierbas de un potrero y evitan el sobre uso en las áreas cercanas a la aguada y el sub uso en las áreas más alejadas.

Tabla 3.3. Estadísticos de las variables escalares de uso del suelo.

\begin{tabular}{c|ccccc} 
& $\mathrm{N}$ & Mínimo & Máximo & Media & D.S. \\
\hline $\begin{array}{c}\text { Antigüedad } \\
\text { establecimiento } \\
\text { (años) }\end{array}$ & 19 & 10 & 95 & 47,63 & 24,89 \\
$\begin{array}{c}\text { Superficie } \\
\text { (hectáreas) }\end{array}$ & 19 & 600 & 10000 & 3845 & 2663,11 \\
$\mathrm{~N}^{\mathbf{0}}$ de cuadros & 19 & 2 & 16 & 4,89 & 3,34 \\
$\mathrm{~N}^{\text {o de aguadas }}$ & 19 & 1 & 6 & 2,32 & 1,37 \\
$\begin{array}{c}\text { Carga animal } \\
(\mathrm{EV} / \mathrm{ha})\end{array}$ & 19 & 50 & 2700 & 513,78 & 600,40 \\
\hline
\end{tabular}

\subsection{4- Estado de conservación del monte}

- Ordenamiento de los sitios en relación a la cobertura y la riqueza de la vegetación.

El ordenamiento de los sitios en función de la cobertura de la vegetación leñosa y herbácea y de la riqueza de los diferentes estratos presentes en los sitios de trabajo reunió el 75,6 \% de la varianza total acumulada en los tres primeros ejes. Hacia el extremo positivo del CP 1 fue posible identificar sitios en los que predominó la cobertura de los estratos arbustivos alto y bajo asociándose a elevada cobertura de estos estratos y mayor riqueza de especies de porte arbustivo. Hacia el extremo negativo del CP 1 se agruparon los sitios en los que la vegetación arbórea estuvo mejor expresada, con especies como P. flexuosa y G. decorticans. Asociado al extremo negativo del CP 2 se ubicaron los sitios que presentaron una mayor cobertura de especies herbáceas perennes (Figura 3.26). Hacia los valores positivos del CP 3 se ubicaron los sitios con mayor cobertura del estrato arbustivo alto y de las especies herbáceas perennes. Hacia los valores negativos de este eje se ubicaron los sitios con mayor cobertura y riqueza específica del estrato arbóreo y arbustivo bajo (Figura 3.27). 


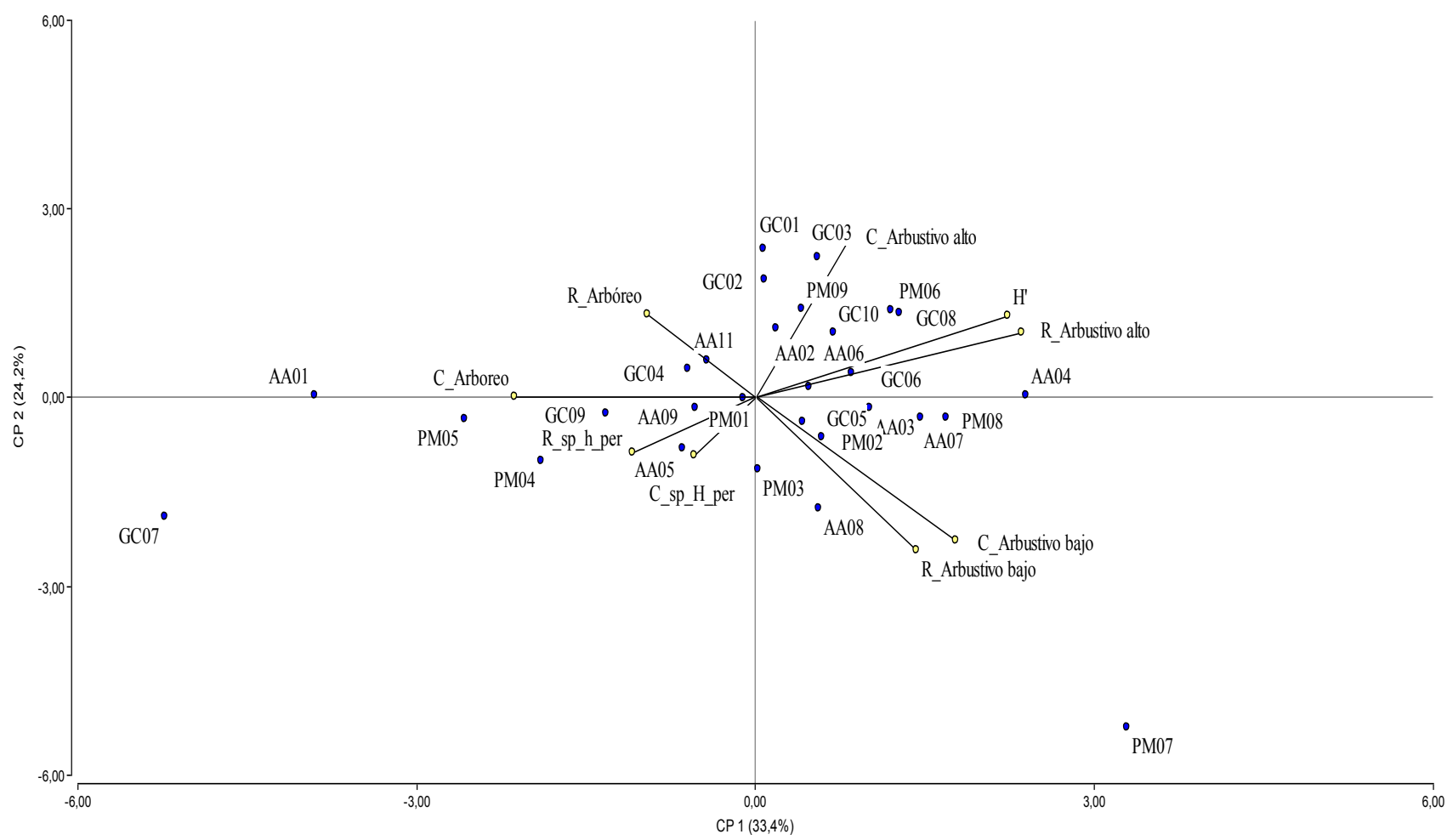

Figura 3.26. CP 1 y CP 2 del ordenamiento de los sitios en base a variables de estructura y composición de la vegetación leñosa y herbácea. C_Arbóreo= Cobertura del estrato arbóreo. C_Arbustivo alto $=$ Cobertura estrato arbustivo alto. C_Arbustivo bajo= cobertura del estrato arbustivo bajo. C_sp_H_per= cobertura del estrato herbáceo perenne. R_Arbóreo= riqueza del estrato arbóreo. R_Arbustivo alto= riqueza del estrato arbustivo alto. R_Arbustivo bajo= riqueza del estrato arbustivo bajo. R_sp_h_per= riqueza del estrato de especies herbáceas perennes. H’= Índice de Shannon.

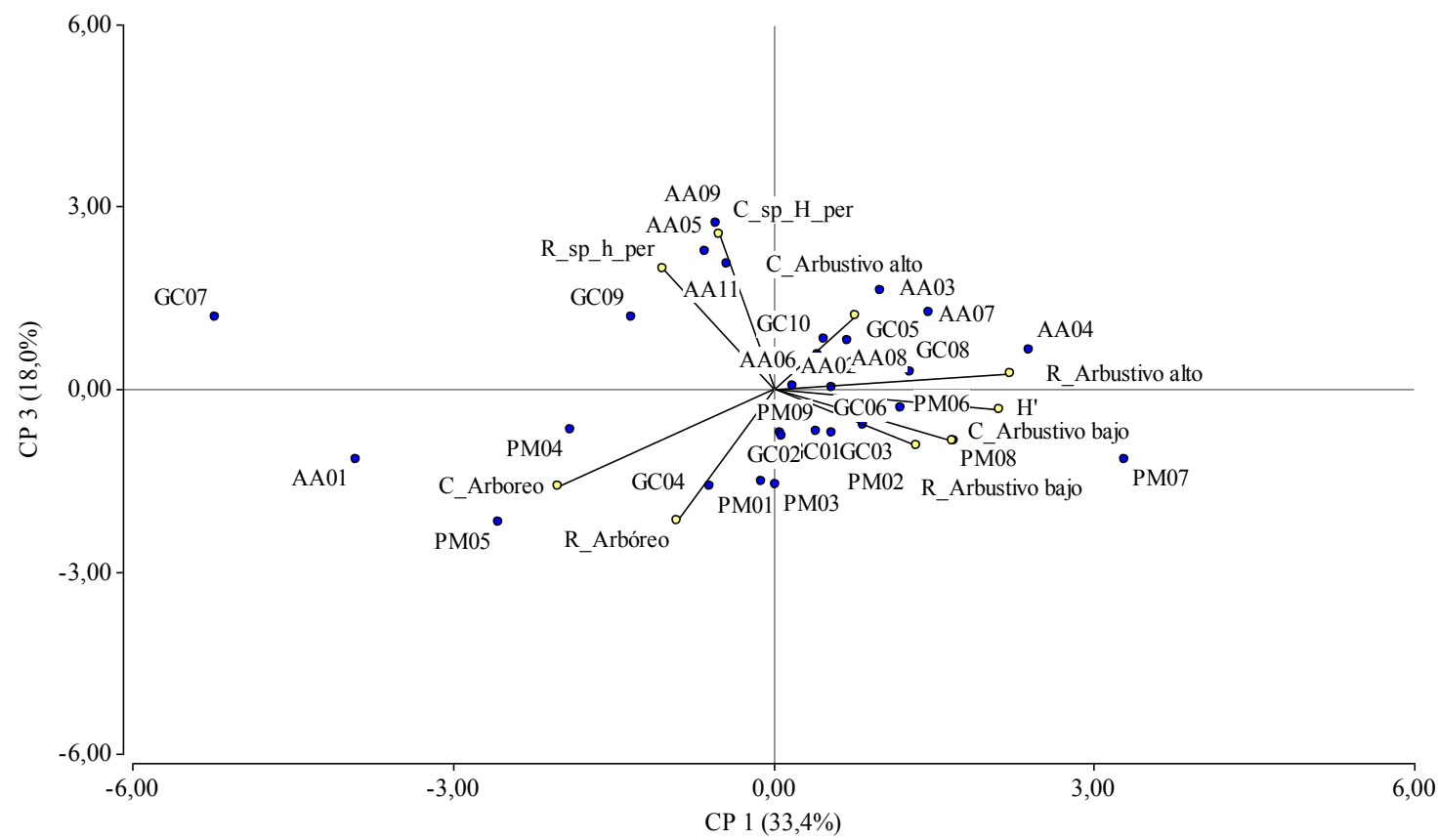

Figura 3.27. CP 1 y CP 3 del ordenamiento de los sitios en base a variables de estructura y composición de la vegetación leñosa y herbácea. C_Arbóreo $=$ Cobertura del estrato arbóreo. C_Arbustivo alto $=$ Cobertura estrato arbustivo alto. C_Arbustivo bajo $=$ cobertura del estrato arbustivo bajo. C_sp_H_per= cobertura del estrato herbáceo perenne. R_Arbóreo= riqueza del estrato arbóreo. $\mathrm{R} \_$Arbustivo alto $=$riqueza del estrato arbustivo alto. $\mathrm{R} \_$Arbustivo bajo= riqueza del estrato arbustivo bajo. $\mathrm{R} \_\mathrm{sp} \_\mathrm{h} \_$per $=$riqueza del estrato de especies herbáceas perennes. H’= Índice de Shannon. 
- Ordenamiento de los sitios en relación a las propiedades edáficas.

El ordenamiento de los sitios de acuerdo a las propiedades físicas y químicas del suelo explicó el 73,2 \% de la variabilidad total, acumulada en los tres primeros ejes.

En el extremo positivo de la CP 1 tendieron a asociarse los sitios con mayor \% de limo y arcilla, \% MO y \% Nt. Esto indicaría que los sitios asociados a estas variables presentan mejores condiciones de fertilidad que aquellos que se ubicaron hacia el extremo negativo de la CP 1. Estos últimos sitios se asocian a texturas dominadas por la fracción arena. Los sitios que presentaron suelos salinos sódicos, con alto contenido de RAS, pH y $\mathrm{Ce}^{-}$, se asociaron positivamente a la CP 2. (Figura 3.28). En el CP 3 se asociaron hacia los valores positivos de este eje los sitios que tuvieron una mayor concentración de calcio y carbonatos de calcio (Figura 3.29).

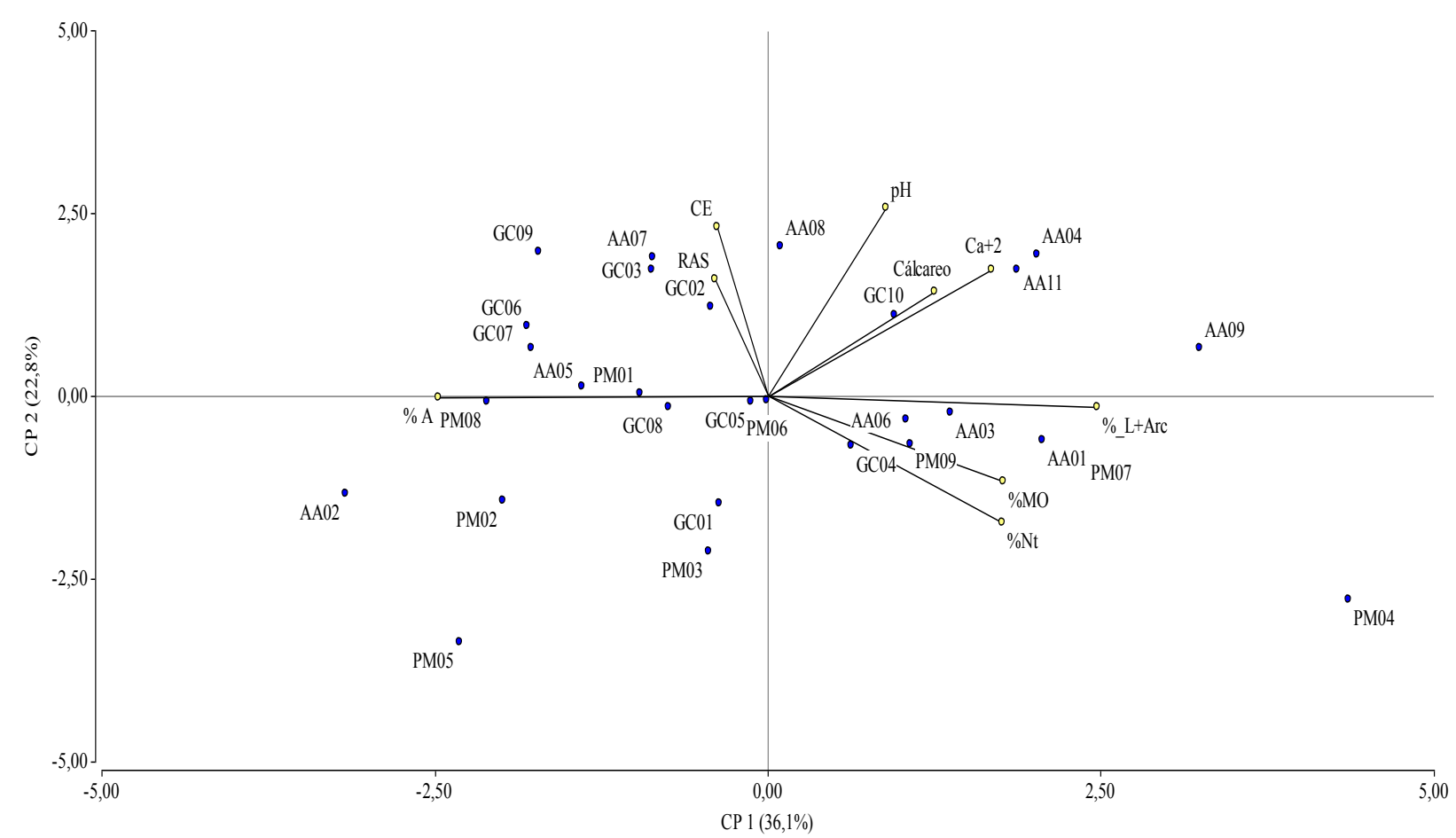

Figura 3.28. CP 1 y CP 2 del ordenamiento de los sitios en base a variables físicas y químicas de los suelos. CE= conductividad eléctrica. $\mathrm{RAS}=$ relación de adsorción de sodio. $\% \mathrm{MO}=$ porcentaje de materia orgánica. \% $\mathrm{Nt}=$ porcentaje de nitrógeno total. $\% \mathrm{~L}+\mathrm{Arc}=$ porcentaje de limo mas arcilla. $\mathrm{Ca}^{+2}=$ Cálcio. Calcáreo= carbonato de calcio presente en el suelo. 


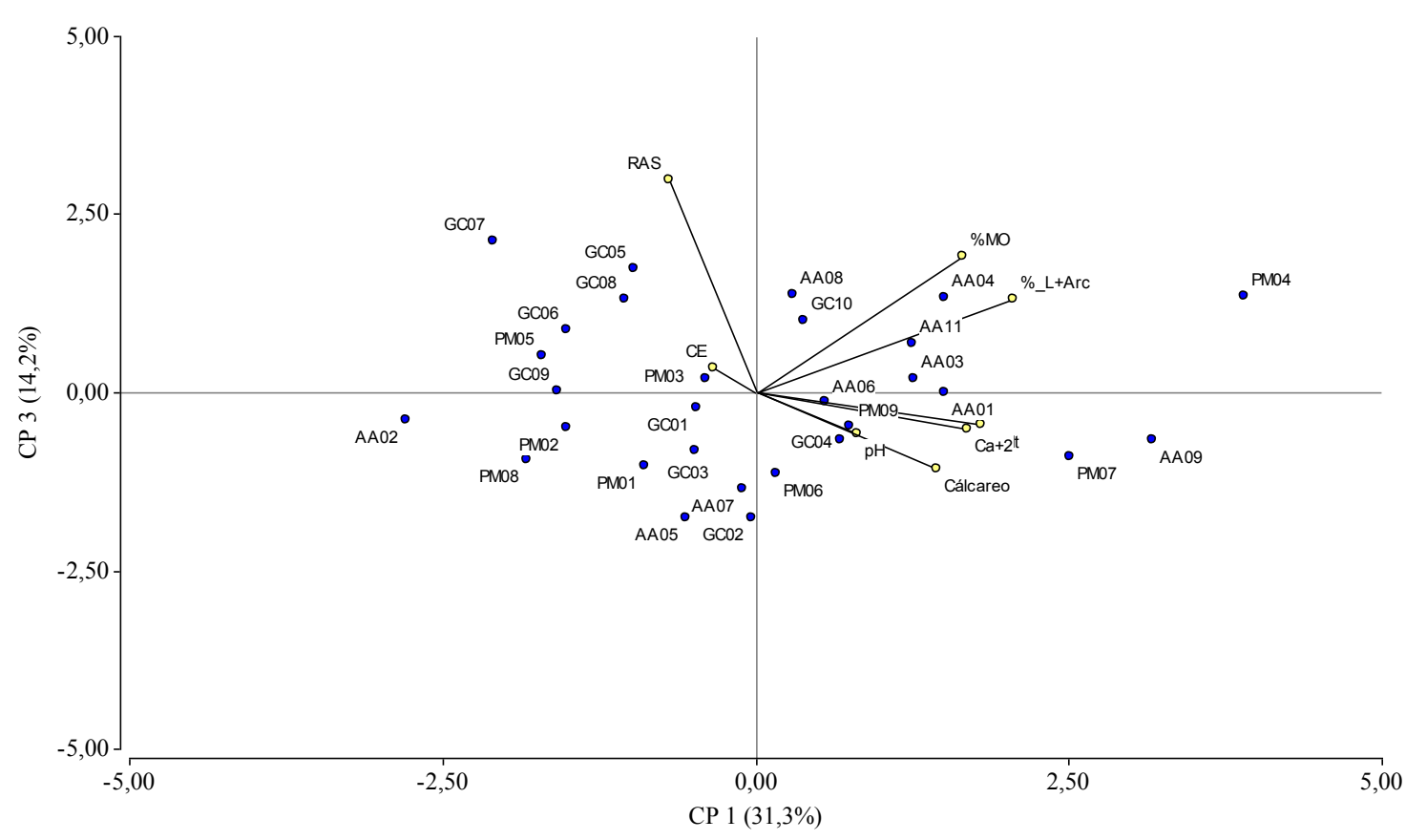

Figura 3.29. CP 1 y CP 3 del ordenamiento de los sitios en base a variables físicas y químicas de los suelos. CE= conductividad eléctrica. $\mathrm{RAS}=$ relación de adsorción de sodio. $\% \mathrm{MO}=$ porcentaje de materia orgánica. $\% \mathrm{Nt}=$ porcentaje de nitrógeno total. $\% \mathrm{~L}+\mathrm{Arc}=$ porcentaje de limo mas arcilla. $\mathrm{Ca}^{+2}=$ Cálcio. Calcáreo= carbonato de calcio presente en el suelo.

- Ordenamiento de los sitios según el uso de la tierra.

Las tres primeras componentes del ordenamiento de los sitios en relación al uso antrópico y a la ocurrencia de disturbios que se registraron en cada sitio, permitieron explicar el $74,4 \%$ de la varianza acumulada.

Hacia el extremo positivo de la CP 1 se ubicaron los sitios donde se desarrolla actividad ganadera y la utilización de rotaciones en el pastoreo (Pastoreo rotativo). La ocurrencia de incendios también se asoció al extremo positivo de este eje. A la parte negativa del CP 1 se asociaron los sitios con una baja intensidad de pastoreo (IP baja) y que tienen un mayor número de aguadas para abrevar el ganado. Al extremo negativo del CP 2 se ubicaron los sitios con pastoreo año redondo (Figura 3.30). El número de aguadas y la intensidad de pastoreo baja se asociaron con los valores positivos del CP 3 (Figura $3.31)$. 


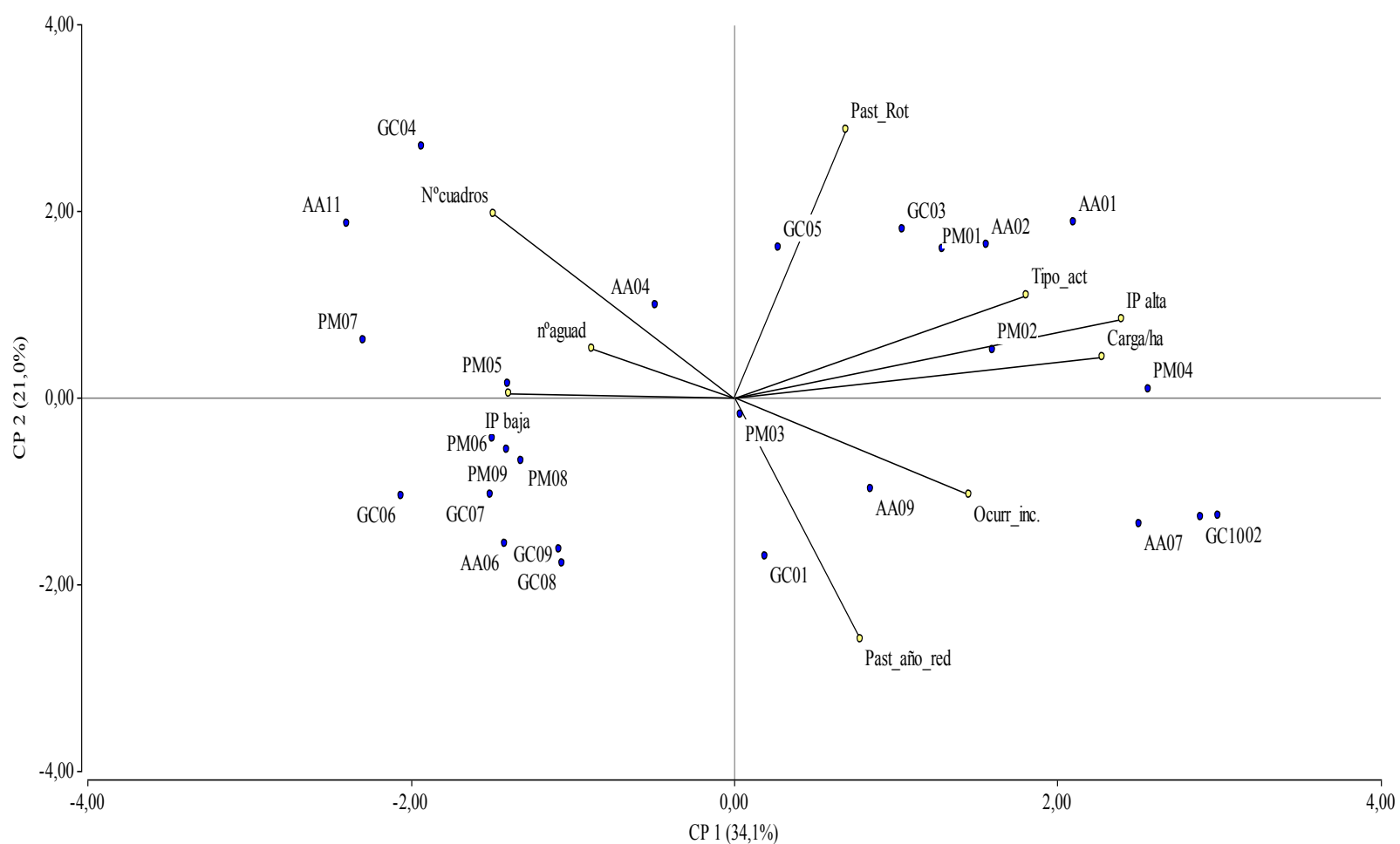

Figura 3.30. CP 1 y CP 2 del ordenamiento de los sitios en base a variables de uso del suelo evaluadas. $\mathrm{N}^{\circ}$ cuadros= número de cuadros en que se divide la unidad productiva. $\mathrm{N}^{\circ}$ aguadas= número de abrevaderos para el ganado. $\mathrm{IP}=$ intensidad de pastoreo. Past_año_red= pastoreo año redondo. Ocurr_inc $=$ ocurrencia de incendios. Carga/ha $=$ carga animal por hectárea. Past_rot= pastoreo rotativo.Tipo act: tipo de actividad desarrollada, ganadera o mixta.

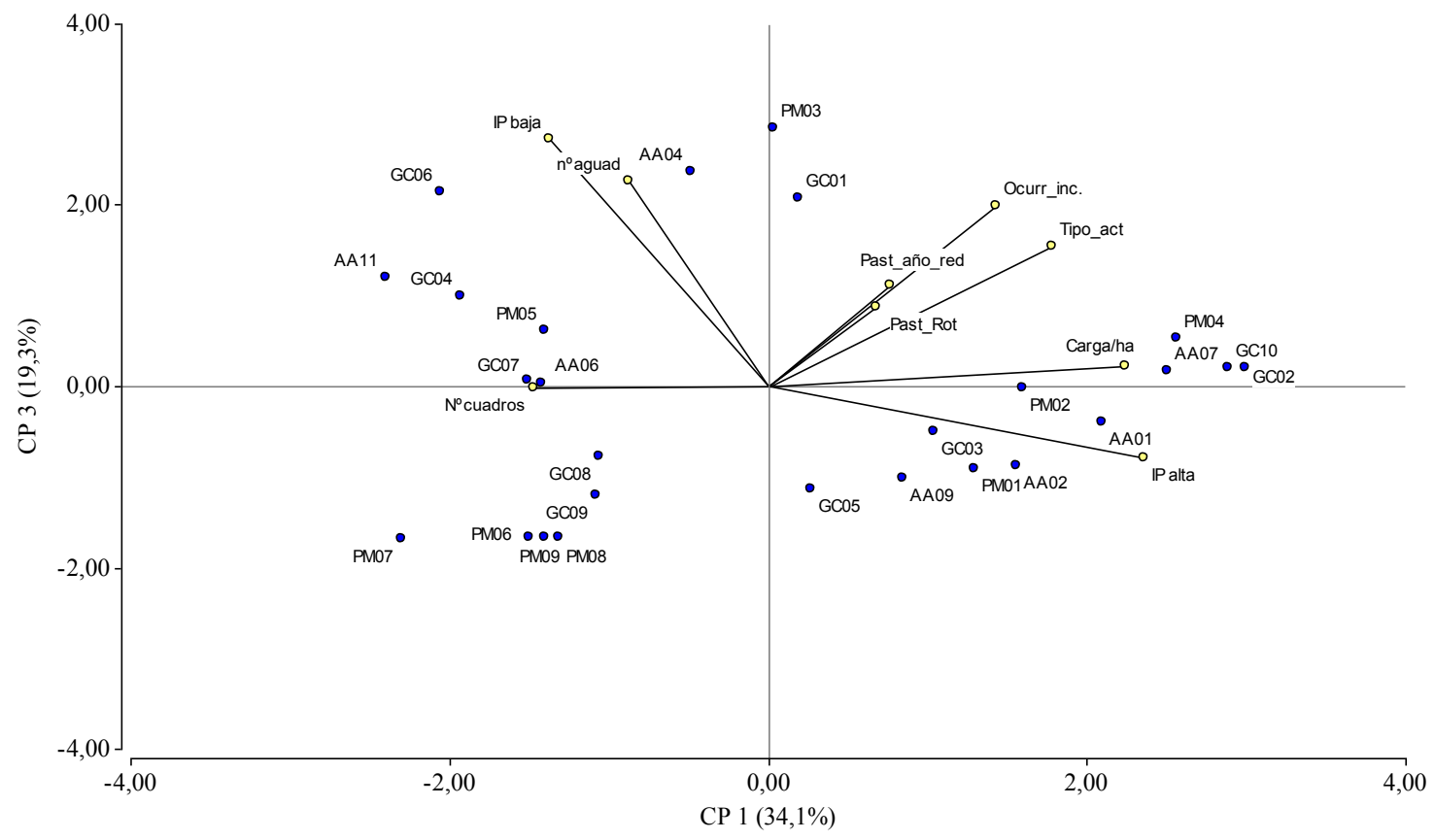

Figura 3.31. CP1 y CP 3 del ordenamiento de los sitios en base a variables de uso del suelo evaluadas. $\mathrm{N}^{\circ}$ cuadros= número de cuadros en que se divide la unidad productiva. $\mathrm{N}^{\circ}$ aguadas= número de abrevaderos para el ganado. $\mathrm{IP}=$ intensidad de pastoreo. Past_año_red= pastoreo año redondo. Ocurr_inc $=$ ocurrencia de incendios. Carga/ha $=$ carga animal por hectárea. Past_rot= pastoreo rotativo. Tipo act: tipo de actividad desarrollada, ganadera o mixta. 
- Relación entre las variables de uso del suelo, de las propiedades del suelo y la cobertura y riqueza de la vegetación nativa.

El análisis de correlación entre matrices de distancia euclídea, obtenidas a partir de los análisis de componentes principales (prueba de Mantel), indica la ausencia de asociación entre las variables de usos del suelo y de las propiedades físicas y químicas del suelo superficial. Estas últimas, tampoco guardaron relación con las variables evaluadas de cobertura y riqueza de la vegetación leñosa y herbácea. Sin embargo, al evaluar la asociación entre las matrices de distancia de las variables de usos del suelo y las variables de cobertura y riqueza de la vegetación nativa se observó una correlación positiva y significativa (Tabla 3.4 ).

Tabla 3.4. Coeficientes de correlación de Mantel entre conjuntos de variables. $p>0,05$ implica rechazo del supuesto de correlación entre las matrices de distancia euclídea.

\begin{tabular}{l|lcc} 
Matriz (A) & Matriz (B) & $\mathrm{r}(\mathrm{AB})$ & $\begin{array}{c}\text { p-valor } \\
\text { (bilateral) }\end{array}$ \\
\hline Usos del & Suelo & $-0,002$ & 0,973 \\
suelo & Cobertura y Riqueza & 0,255 & 0,032 \\
\hline Suelo & Cobertura y Riqueza & $-0,034$ & 0,756 \\
\hline
\end{tabular}

\subsection{5- Cobertura del suelo.}

A partir del análisis multitemporal de imágenes de los satélites Landsat 5 TM y Landsat 8 OLI, fue posible identificar la variación de las diferentes coberturas del suelo y detectar áreas que han sufrido una modificación de la vegetación nativa como así también detectar áreas con signos de avanzada degradación.

En el año 2001, la categoría monte denso ocupaba un $24 \%$ del área de estudio, porcentaje que fue decreciendo hasta el año 2014, en el que se registró $8 \%$ de monte con cobertura densa (Figura 3.32- 3.35; Tabla 3.5).

La categoría monte intermedio, muestra una tendencia inversa. Durante el período de tiempo analizado se evidenció un crecimiento en la superficie ocupada por esta clase, pasando de ocupar 11\% en 2001 a ocupar 23\% en 2007. En el año 2011, sin embargo, se observa una retracción, posiblemente relacionada a los eventos climáticos extremos que se registraron entre 2007 y 2010 en el área de estudio. En el año 2014 la superficie ocupada por esta clase volvió a incrementarse, llegando a ocupar el $29 \%$ de la superficie del área de estudio. 
El monte abierto mostró porcentajes de superficie decrecientes desde el año 2001 hasta el año 2014. En el comienzo del período de análisis este tipo de vegetación ocupaba el $48 \%$ de la superficie, registrándose una retracción en los años 2007 y 2011 que lo llevó a representar el 30\% y 17\% respectivamente. En el año 2014 ocupó un 29\% de la superficie del área de estudio (Figuras 3.32- 3.35; Tabla 3.5).

El porcentaje de suelo ocupado por la categoría pastizal mostró un comportamiento variable. Comenzó con un aumento de la superficie ocupada por pastizales naturales que llegó a alcanzar $23 \%$ en 2007. Esta tendencia continúo siendo creciente, ya que en el año 2011 ocupó $28 \%$ de la superficie del suelo, para, posteriormente, disminuir en el año 2014 hasta ocupar el 9\% de la superficie.

La categoría suelo desnudo, que en el año 2001 ocupaba el 10\% del área, mostró una disminución hacia el año 2007 (4\%) pero en los años posteriormente analizados mostró un fuerte crecimiento alcanzando valores de 19\% en 2011 y de 20\% en 2014 (Figuras 3.32- 3.35; Tabla 3.5).

En el período de tiempo analizado es posible observar una retracción de las zonas agrícolas. Estas se concentraron en el año 2001, casi exclusivamente, en las áreas bajo riego vinculadas a los valles de los ríos Negro y Colorado, aunque se observaron en el Este del departamento Adolfo Alsina varias parcelas ocupadas por este uso (Figuras 3.32-3.33; Tabla 3.5). En los años 2007 y 2011 el uso del suelo dedicado a la producción agrícola de secano fue mayor, identificándose varias parcelas en tierras que no poseían sistematización para el riego. Hacia el año 2014 volvieron a encontrarse las áreas cultivadas asociadas a las áreas regadas cercanas a los valles de los ríos principales de la región. Los porcentajes de territorio ocupadas por esta clase es muy bajo y está entre el 1\% para el año 2001 y 2\% del área en el año 2014 (Figuras 3.323.35; Tabla 3.5).

Los campos de dunas y las zonas de voladuras se hicieron más evidentes en el año 2011, donde alcanzaron $1 \%$ de la superficie. Para los demás años analizados estos porcentajes fueron menores.

Los bajos ocupados por concreciones salinas y el agua superficial mostró un comportamiento asociado a los pulsos de precipitaciones. Se aprecia en la tabla 7 que al disminuir la cobertura de las salinas crece la superficie cubierta por acumulación de 
agua en estos bajos, y viceversa.

La clasificación efectuada para cada uno de los años analizados presentó un coeficiente Kappa superior de 0,85 , lo que evidencia que las clasificaciones realizadas son aceptables (Tabla 3.5).

Tabla 3.5. Superficie ocupada por cada clase en los años 2001, 2007, 2011 y 2014 en el área de estudio.

\begin{tabular}{|c|c|c|c|c|c|c|c|c|}
\hline \multirow[b]{2}{*}{ Clase } & \multicolumn{2}{|c|}{2001} & \multicolumn{2}{|c|}{2007} & \multicolumn{2}{|c|}{2011} & \multicolumn{2}{|c|}{2014} \\
\hline & $\%$ & $\mathrm{~km}^{2}$ & $\%$ & $\mathrm{~km}^{2}$ & $\%$ & $\mathrm{~km}^{2}$ & $\%$ & $\mathrm{~km}^{2}$ \\
\hline Monte denso & 24,4 & 8375,8 & 15,0 & 5149,8 & 12,1 & 4148,5 & 8,1 & 2769,9 \\
\hline $\begin{array}{l}\text { Monte } \\
\text { intermedio }\end{array}$ & 10,8 & 3713,7 & 23,0 & 7913,6 & 17,3 & 5947,2 & 29,5 & 10119,8 \\
\hline Monte abierto & 48,5 & 16650 & 30,0 & 10299,5 & 20,1 & 6901,0 & 29,1 & 10008,8 \\
\hline Pastizal & 2,8 & 961,8 & 23,1 & 7941,3 & 27,7 & 9507,8 & 9,2 & 3175,9 \\
\hline Cultivos & 1,3 & 447,8 & 2,6 & 895,9 & 1,7 & 583,0 & 2,2 & 771,1 \\
\hline Suelo desnudo & 10,3 & 3546,3 & 4,0 & 1382,1 & 18,9 & 6502,9 & 19,9 & 6832,1 \\
\hline Salinas & 1,0 & 350,9 & 1,5 & 529,7 & 0,4 & 134,4 & 1,1 & 374,6 \\
\hline Médanos & 0,6 & 221,6 & 0,4 & 155,2 & 1,3 & 435,1 & 0,5 & 200,9 \\
\hline $\begin{array}{l}\text { Agua } \\
\text { superficial }\end{array}$ & 0,2 & 64,2 & 0,1 & 56,9 & 0,3 & 119,2 & 0,2 & 88,9 \\
\hline Coef. Kappa & & & & & & 399 & & 903 \\
\hline
\end{tabular}




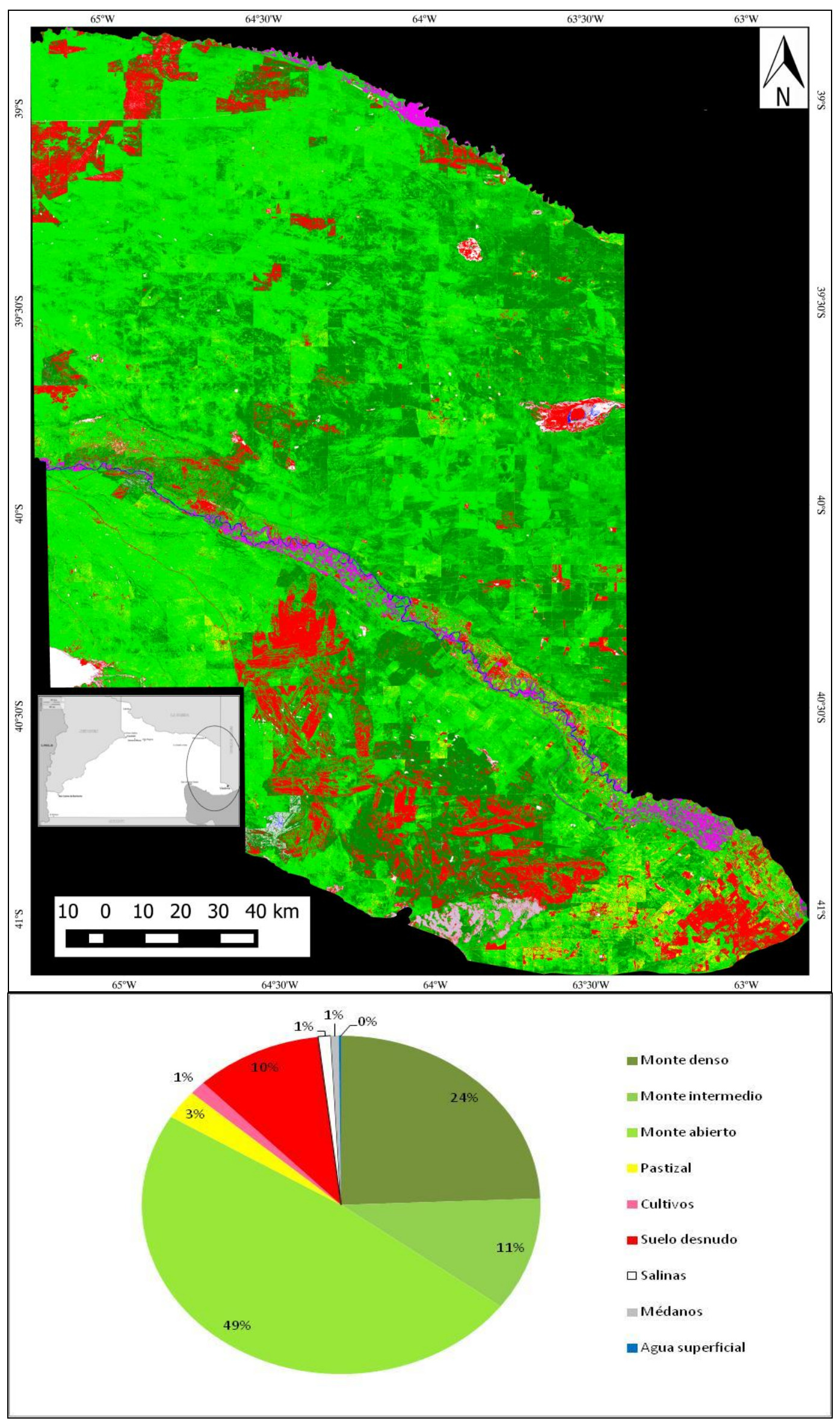

Figura 3.32. Clasificación supervisada del área de estudio del año 2001 y \% de cobertura por clases. 


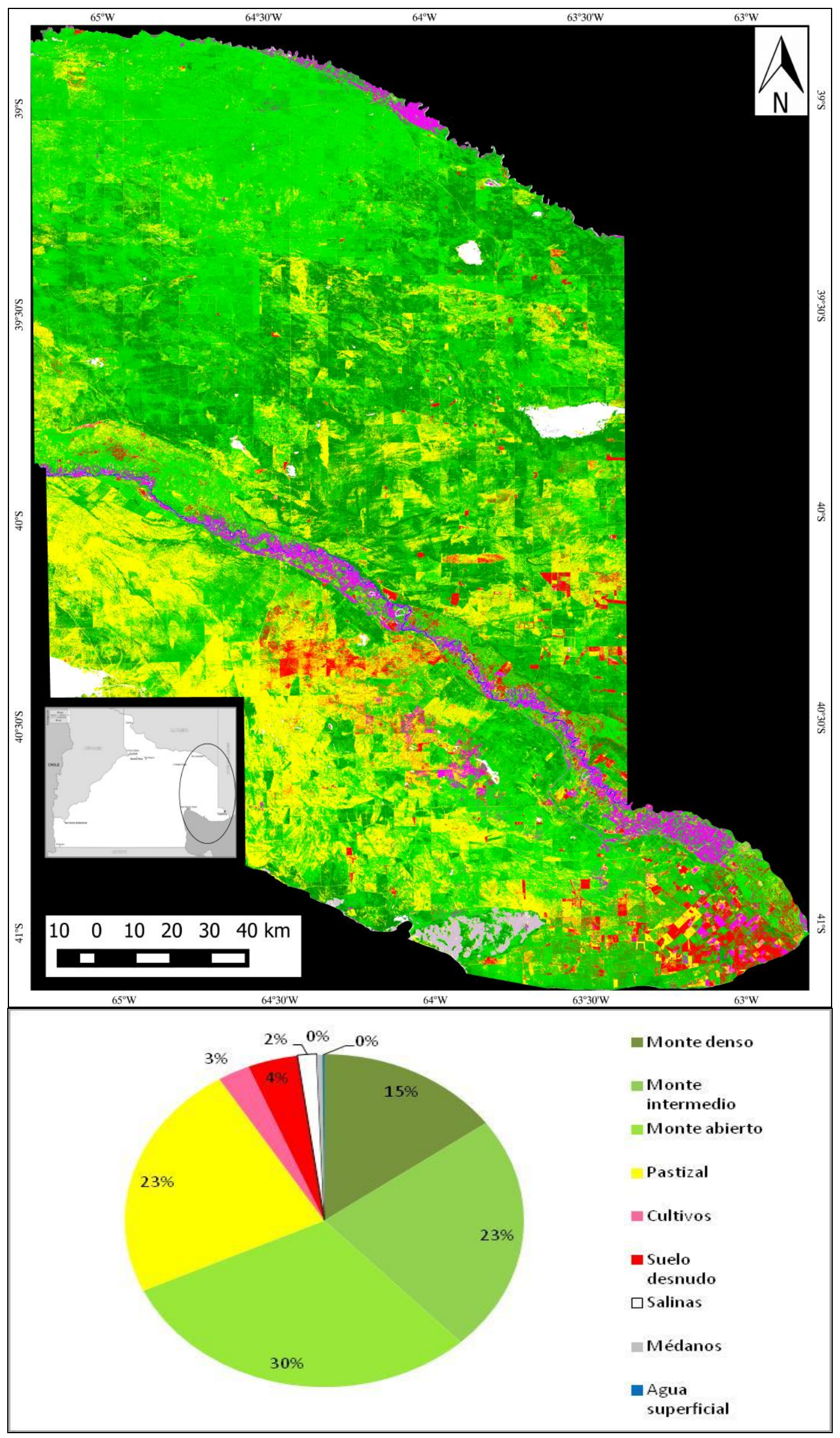

Figura 3.33. Clasificación supervisada del área de estudio del año 2007 y \% de cobertura por clases. 


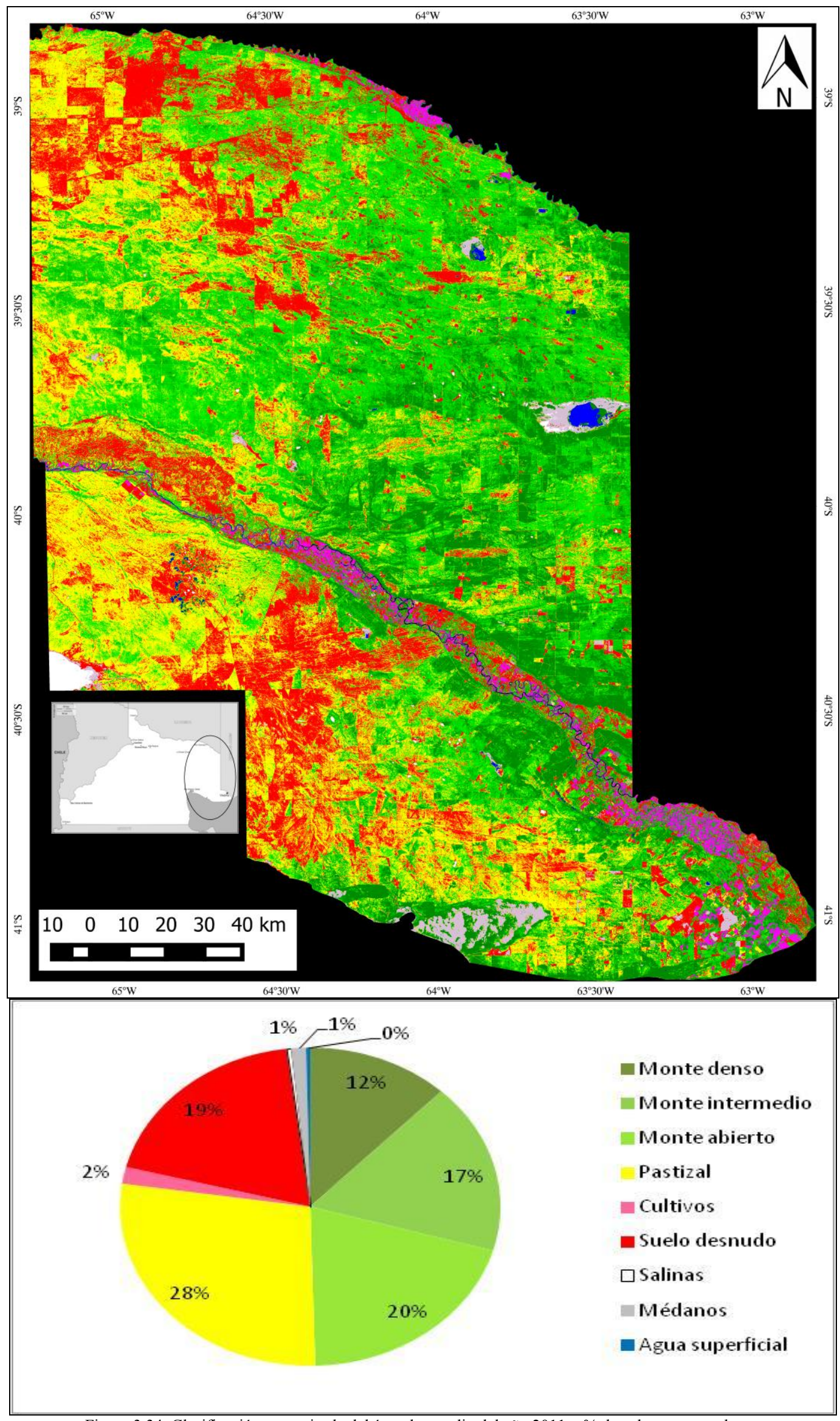

Figura 3.34. Clasificación supervisada del área de estudio del año 2011 y \% de cobertura por clases. 


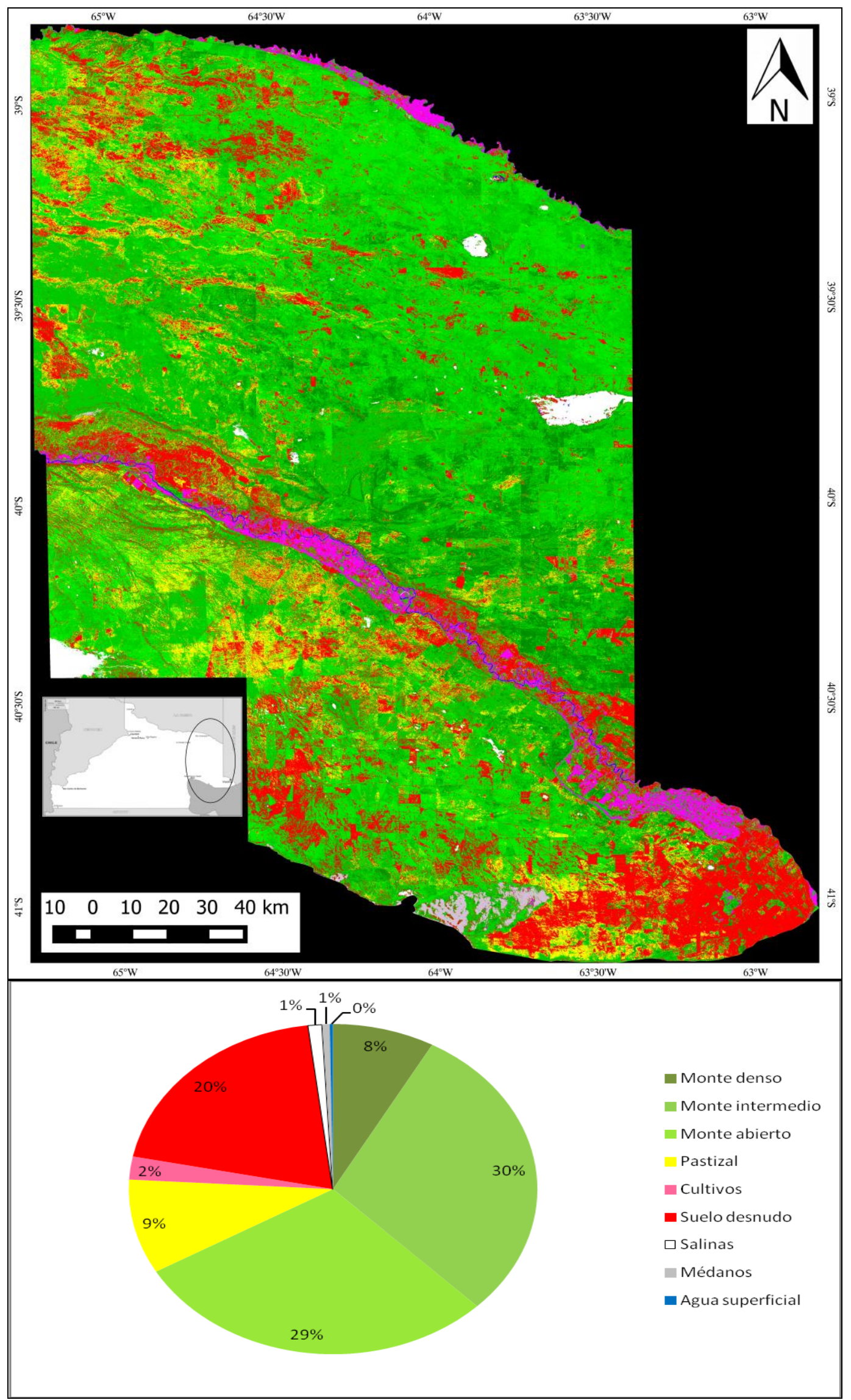

Figura 3.35. Clasificación supervisada del área de estudio del año 2014 y \% de cobertura por clases. 


\section{4- Discusión}

En el área de estudio todas las especies perennes registradas fueron nativas, excepto en el caso de A. mendocina que es una especie adventicia. La ausencia de especies exóticas podría relacionarse con la dificultad que los sistemas semiáridos ofrecen a estas especies para poder colonizar nuevas áreas y establecerse (Hobbs et al. 2006). Las condiciones ambientales de alta insolación, marcado estrés hídrico y suelos con escasez de nutrientes configuran una barrera abiótica para el ingreso de las exóticas, aún en los sitios con intensidades de pastoreo altas. Un reducido número de especies exóticas se ha observado sólo en áreas abandonadas luego de extensos períodos de cultivo extensivo, donde la vegetación nativa se encuentra ausente.

La vegetación del área de estudio presentó una amplia heterogeneidad espacial, relacionada con la variabilidad de las condiciones del ambiente físico y de uso. La vegetación leñosa de las unidades geomorfológicas estudiadas presentó diferencias menores en cuanto a su composición. Los especies arbóreas $P$. flexuosa y $G$. decorticans fueron registradas en las tres unidades geomorfológicas con elevada frecuencia, aunque el grado de desarrollo de los individuos presentes fue muy variable. Hacia el Noreste del área de estudio aumentó la frecuencia de individuos de P. caldenia, que se veían acompañados de especies arbustivas de porte bajo. Estos resultados concuerdan con los obtenidos por Torres Robles et al. (2015), quienes registraron un gradiente de composición O-E, expresado por la frecuencia de especies leñosas. Estos autores señalan que hacia el Este comienzan a aparecer especies arbóreas características del Espinal, tales como P. caldenia y G. decorticans y, hacia el Oeste, se destacan las comunidades vegetales que son características del Monte con especies tales como $M$. aphylla, L. divaricata, A. seriphioides y S. aphylla. En el presente trabajo, los sitios de muestreo abarcaron un área más acotada en ese gradiente, donde observamos que la variación de composición y estructura de la vegetación está asociada principalmente al uso del suelo.

La cobertura del estrato arbóreo mostró una tendencia a ser más alta en la Planicie loéssica y en los Paleocanales, con dominancia de P. flexuosa y G. decorticans. Posiblemente, la presencia de estas especies esté relacionada con la posición relativa en el paisaje que ocupan estas unidades geomorfológicas, que implican una mayor recepción de humedad y nutrientes proveniente de áreas subyacentes más elevadas. Sin 
embargo, la cobertura de este estrato no sólo responde a variables ambientales, sino también a prácticas de manejo. Los productores ganaderos locales, en general, consideran que la cobertura de las especies del estrato arbóreo dificulta la producción. Por este motivo es frecuente observar el manejo de su cobertura mediante el desmonte mecánico o el empleo del fuego, el cual, en reiteradas oportunidades, suele escapar al control de los productores y genera incendios de gran magnitud. Estos incendios reducen la cobertura de las leñosas y generan cambios en su estructura de edades (Villagra et al. 2009). En varios sectores que se vieron afectados por incendios en la temporada estival de los años 2000- 2001, fue registrada la especie G. decorticans. Los individuos de esta especie aparecían en forma de renovales, integrando matas junto a otras especies de porte arbustivo. El comportamiento de esta especie se debe a la forma de reproducción que posee, ya que al tener yemas gemíferas puede perder la parte aérea y posteriormente rebrotar. Solamente en el sitio AA1 y PM1 aparecen formando bosquetes de altura superior a los 3 metros tal cual lo describieron León et al. (1998) para el Monte Oriental. En las áreas con mayor presencia del estrato arbóreo se observó una disminución de la cobertura de especies herbáceas de ciclo de vida perenne, debida, principalmente, al uso pastoril sin la rotación de los rodeos y al sombreado del canopeo arbóreo.

Las áreas que presentaron mayor cobertura del estrato arbustivo alto no presentaron alta cobertura del estrato herbáceo, estando los pastos circunscriptos al interior de las matas de las leñosas, que le ofrecen protección contra la herbivoría (Bertiller 1999). Los sitios que presentaron elevada cobertura del estrato arbustivo alto, con elevada frecuencia de L. divaricata, P. globosum, S. johnstonii, C. microphylla, L. chilense y L. tenuispinosum, se asociaron con elevadas intensidades de pastoreo. Aunque los pastos y los arbustos compiten parcialmente por el agua del suelo, principalmente en la etapa de establecimiento de las leñosas (Ward et al. 2013), la ocurrencia de sobrepastoreo disminuye la cobertura de los pastos y aumenta la dominancia de las leñosas, causando un proceso de retroalimentación positiva, ya que los arbustos favorecen la recarga de humedad de las capas inferiores del suelo por medio del flujo de sus tallos. Este flujo es mayor a medida que crece la cobertura de especies leñosas, disminuyendo la disponibilidad de agua para las especies herbáceas (Bisigato y Bertiller 2004; Bisigato y Laphitz 2009; Whitford 2002). Este tipo de cobertura es considerado por Kröpfl et al. (2015) un estado degradado a causa del pastoreo moderado a intenso, presente durante 
períodos prolongados de tiempo sin realizar manejos de la hacienda y que no puede revertirse sólo con la supresión del pastoreo.

Los sectores que presentaron una cobertura dominante del estrato arbustivo bajo, en los cuales la frecuencia de $A$. seriphioides, $P$. alpataco, B. ulicina, Ch. erinacea y $S$. aphylla fue alta, se registró una cobertura elevada del estrato de especies herbáceas de ciclo de vida perenne. Estos sectores suelen tener una intensidad de pastoreo baja y la ausencia de rotaciones y períodos de descanso. Guevara et al. (2009) y Sabattini et al. (2002) observaron que el manejo de la hacienda y la rotación por los diferentes cuadros de las unidades productivas mejoran las condiciones de la vegetación herbácea, ofreciendo una mayor cobertura y productividad del estrato. Sin embargo, los resultados obtenidos aquí sugieren lo contrario. Posiblemente, la ausencia de rotaciones no sea el único factor causante de degradación en sí mismo, sino que lo sería, también, la inadecuada determinación de la carga animal. Con intensidades de pastoreo ajustadas a la oferta forrajera de cada temporada se evitaría el sobreuso de las especies herbáceas, permitiéndoles a los individuos de este estrato recuperar la biomasa removida y generar estructuras reproductivas. En numerosos trabajos se ha comprobado que el manejo de las cargas y los tiempos de permanencia en los distintos potreros mejoran la oferta forrajera (Bisigato y Bertiller 1997; Bisigato et al. 2005; Borrelli y Oliva 2001; Cingolani et al. 2005; Giorgetti et al. 1997; Golluscio et al. 1998; Kröpfl et al. 2011; Morici et al. 2006; Papanastasis 2009). En el presente estudio, las bajas cargas, aún con permanencia prolongada de los rodeos, estarían ejerciendo una baja presión de pastoreo, por lo cual en estos casos el sistema permanece con una diversidad y cobertura de las herbáceas perennes relativamente altas.

El pastoreo intenso genera un efecto de eliminación de la competencia entre los arbustos y las hierbas. La preferencia de las hierbas por parte del ganado respecto de los arbustos promueve la arbustificación del sistema y la consiguiente pérdida de receptividad ganadera del sitio. En aquellos sistemas dominados por pastos, disminuye la disponibilidad de micrositios aptos para la instalación y desarrollo de los arbustos. Debido a que la zona de mayor densidad de raíces de las especies herbáceas se desarrolla entre los 10 y $15 \mathrm{~cm}$ de profundidad, estas aprovechan de forma más efectiva la humedad aportada por las precipitaciones reduciendo la infiltración a las capas más profundas del suelo de las cuales se nutren las especies leñosas (Cingolani et al. 2008; Eldridge et al. 2016; Maestre et al. 2009; 2016; Whitford 2002). 
El efecto de pastoreo del ganado doméstico también se vio reflejado en el presente trabajo en la composición de las herbáceas perennes. La riqueza de especies preferidas por el ganado doméstico alcanzó valores superiores al 75\%, observándose solamente algunos sitios con valores inferiores a 50\%. Generalmente, las especies utilizadas como fuente de forraje son especies herbáceas graminoides y latifoliadas, aunque en épocas donde la oferta forrajera disminuye, son consumidas las especies leñosas que ofrecen frutos y brotes tiernos al ganado (observación personal). Los sitios con intensidades de pastoreo elevadas presentaron bajos porcentajes de riqueza de especies forrajeras. Villagra et al. (2009), observaron que en el Monte del Este de la provincia de Río Negro y Noreste de Chubut el pastoreo extensivo modificó la cobertura y la diversidad de especies leñosas y herbáceas, disminuyendo aquellas especies preferidas por el ganado y aumentando el porcentaje de suelo descubierto. Estos resultados guardan similitud con los aquí obtenidos, ya que aquellas áreas que mostraron intensidades de pastoreo elevadas se asociaron negativamente con aquellas que presentaron mayor riqueza de especies forrajeras. Además, la frecuencia de especies con valor forrajero disminuyó en áreas que presentan uso pastoril intenso, en particular fue baja la frecuencia de especies latifoliadas, siendo T. sinuata la única presente con importancia forrajera. El control del pastoreo posibilitaría una mejora de los estimadores de la diversidad de especies en los sistemas estudiados, ya que tanto intensidades de pastoreo altas como bajas pueden impactar negativamente sobre la riqueza de las comunidades vegetales (Díaz et al. 1999; Loydi et al. 2012; Loydi y Distel 2010). En ecosistemas de pastizales serranos, Loydi y Distel (2010), observaron una disminución de la riqueza de especies con valor forrajero a medida que aumentaba la presión de uso. Por un lado, con elevadas presiones de pastoreo, disminuye la riqueza de especies graminoides y latifoliadas debido al intenso uso del pastizal. Por otra parte, con bajas intensidades de pastoreo, las especies graminoides alcanzaban un elevado desarrollo, excluyendo a las especies latifoliadas que presentaban porte rastrero o arrosetado, y no hallaban micrositios propicios para poder establecerse y desarrollarse (Loydi y Distel 2010).

El fuego y el sobrepastoreo actúan en sentidos opuestos. Aquellos sectores que se asociaron positivamente con la ocurrencia de incendios en el área del presente estudio, mostraron una menor cobertura de especies leñosas y una mayor cobertura de especies herbáceas. Lo opuesto se verificó para sectores que se asociaron negativamente con la ocurrencia de incendios. En los ecosistemas áridos y semiáridos el fuego tiene un efecto 
modelador sobre la vegetación (Whitford 2002). Este factor causante de disturbio suele tener un efecto positivo sobre la regeneración y rebrote del estrato herbáceo y, por otra parte, actúa limitando el crecimiento del estrato leñoso evitando la arbustificación (Bran et al. 2007; Esterlich et al. 2005; Gibson 2009). El sobrepastoreo, en cambio, promueve la arbustificación, debido en gran parte al hábito selectivo de los animales. Éstos ejercen presión sobre un determinado pool de especies que, de no existir algún manejo tendiente a promover su preservación, comienzan a ser poco frecuentes en los pastizales y, en varias oportunidades, llegan a desaparecer (Bran et al. 2007; Kröpfl et al. 2007; 2015; Loydi et al. 2012). Esta simplificación de las comunidades vegetales implica una disminución de la capacidad forrajera de los sistemas productivos (Bertiller y Bisigato 1998; Borrelli y Oliva 2001; Cesa y Paruelo 2011; Golluscio et al. 1998) que se corrobora en el presente estudio. La pérdida de diversidad, a su vez, constituye una situación de mayor riesgo de degradación de un sistema, dado que afecta su capacidad de respuesta frente a cambios ambientales (Grime 1998; Whitford 2002).Por otra parte, el fuego, actúa en sentido opuesto ya que elimina la competencia con las especies leñosas y favorece el rebrote de las semillas contenidas en el banco repoblando el suelo. Este banco de semillas estará disponible siempre que el pastoreo permita a las especies herbáceas generar estructuras reproductivas para aportar propágulos al banco (Eldridge et al. 2011; Gaitán et al. 2014; Kröpfl et al. 2015; Maestre y Puche 2009; Ulrich et al. 2014). Gibson (2009), indica que la supresión y eliminación de los regímenes de fuego, tanto naturales como antrópicos, provocan un aumento de la heterogeneidad de la vegetación. En el presente estudio, en los sitios con baja o nula frecuencia de incendios y baja intensidad de pastoreo se observó una cobertura intermedia de los diferentes estratos leñosos arbustivos alto y arbustivo bajo que favorecerían la instalación y el mantenimiento de las especies herbáceas perennes. Tanto las especies leñosas como las herbáceas cumplen una destacada función en los ecosistemas áridos y semiáridos. Por un lado, son una fuente de forraje para los animales domésticos y silvestres, y por otro, en épocas de episodios climáticos extremos (como la escasez de precipitaciones acontecidas en el área entre 2005-2010) ofrecen cobertura al suelo protegiéndolo de los factores causantes de degradación.

En el área de estudio los mayores valores registrados de los parámetros de fertilidad del suelo (MO, Nt, $\mathrm{P}$, texturas más finas) se asociaron a sitios que presentaron un desarrollo de los estratos arbustivo bajo y herbáceo más abundante y con una menor intensidad de 
pastoreo. En ecosistemas áridos y semiáridos, el paisaje se estructura en islas de vegetación dominadas por arbustos, debajo de los cuales numerosos autores han reportado mayores concentraciones de MO y nutrientes y menores valores de densidad aparente del suelo respecto de los espacios de suelo desnudo o interparches (Maestre et al. 2015; English et al. 2005; Gómez et al. 2012; Mihoč et al. 2016; Miranda et al. 2004; Rabbi et al. 2015; Rostagno et al. 1991; del Valle 1998; Vourlitis y Fernandez 2012). Las especies herbáceas más frecuentes en estos sitios, al no ser defoliadas por los herbívoros, producen cantidades más elevadas de mantillo y un mayor aporte subsuperficial de su sistema subterráneo (Carrera et al. 2008). Las hojas de estas especies, al poseer un menor contenido de lignina, se degradaran e incorporan al suelo menor tiempo (Carrera et al. 2008; De Paz et al. 2013). Golluscio (2009) observaron en un área de la estepa patagónica una disminución del carbono y el nitrógeno del suelo a medida que aumentaba el pastoreo y se hacía más evidente la arbustificación del sistema, el cambio en la composición florística y la proliferación de parches de suelo desnudo. Este cambio en la comunidad altera, y en algunos casos inhibe, la mineralización del nitrógeno disminuyendo la productividad de esos sistemas (Carrera et al. 2008; Gollusio et al. 2009). Posteriormente a la disminución de los niveles de nitrógeno, los autores observaron una disminución de la materia orgánica que ingresa al suelo en forma de mantillo, reduciendo los niveles de carbono orgánico del suelo. En el presente estudio se registraron algunos sitios con altas coberturas del estrato arbustivo bajo y del estrato herbáceo que, sin embargo, mostraron bajos porcentajes de MO. Coincidentemente, estos sitios sufrieron fuertes incendios en la temporada estival de los años 2000-01 y registraron fuertes pérdidas de materia orgánica del suelo (Gaitán et al. 2007). Posiblemente estos sitios tenían una alta cobertura de leñosas antes del incendio. Se conoce que, a medida que la cobertura de la vegetación leñosa es más densa, es mayor la intensidad del fuego y la temperatura alcanzada durante el incendio (Bran et al. 2007). Este incremento en la temperatura provoca un aumento de los efectos negativos sobre la fertilidad de los suelos, ya que el carbono orgánico y el nitrógeno del suelo son volatilizados y se ven afectados los microorganismos del suelo (Gaitán et al. 2007; Gibson 2009).

En este estudio, el análisis multitemporal de las imágenes satelitales evidenció el avance de áreas desprovistas de vegetación. Éstas son causadas por la incorporación de tierras a la producción agrícola de secano y posteriormente abandonadas sin ningún tipo de 
cobertura ni manejo, debido a la pérdida de rentabilidad de la actividad. El avance de las áreas de suelo desnudo se intensificó en los períodos de sequía (Figura 2.4, Capítulo 2). La alteración de los regímenes pluviométricos afectó a la vegetación nativa y al normal desarrollo de las actividades productivas, que continuaron con prácticas habituales, aún bajo condiciones de sequía extraordinaria, como las que se registraron entre los años 2005 y 2010. Se observó la retracción del porcentaje de cobertura de la vegetación leñosa más densa y un aumento de las categorías de menor porcentaje de cobertura (intermedia y abierta). Este incremento de la vegetación abierta e intermedia fue en detrimento de la categoría monte denso. Por otra parte, el aumento de la clase pastizales durante los años de escasez de precipitaciones, está estrechamente vinculada a la colonización de áreas descubiertas y carentes de cualquier tipo de vegetación por especies adventicias como Salsola kali (Cardo ruso), Irschfeldia incana (Flor amarilla) y Diplotaxis tenuifolia (Mostacilla) que se encuentran ampliamente difundidas en el área de estudio y en la clasificación digital se comportan de forma similar a los pastizales naturales. Estas comunidades continúan ocupando grandes superficies del área de estudio. Aparecen como nuevos sistemas o sistemas emergentes, caracterizados por estar formados por especies adventicias (Hobbs et al. 2006). Estos sistemas están conformados por nuevas combinaciones de especies, causadas generalmente por disturbios antrópicos que desembocan en la extinción local de especies de animales, plantas y microorganismos que previamente se encontraban en la zona. Además, el uso agrícola de la tierra genera barreras a la dispersión de los organismos nativos (Hobbs et al. 2006). En el Monte, las tierras abandonadas por la agricultura extensiva de secano se ven repobladas por estas especies adventicias y la proliferación de estas comunidades se observa debido a la disminución de la complejidad biótica, quedando recursos disponibles para la colonización y establecimiento de especies exóticas. Sin embargo, estas comunidades tuvieron un efecto positivo sobre el suelo superficial, desprovisto de cobertura vegetal, disminuyendo los efectos de la erosión eólica y en algunos casos, actuaron como especies facilitadoras para el establecimiento de especies de gramíneas nativas (Valladares y Gianoli 2007; obs. pers.). Frente a la normalización de las condiciones pluviométricas en los años 2010 y 2011, y la ausencia de fuegos, se observó un decrecimiento de la categoría integrada por especies adventicias y un consecuente aumento de las coberturas leñosas abierta e intermedia. Este efecto podría ser causado por la colonización de espacios abiertos por comunidades leñosas adyacentes y su capacidad para adaptarse a condiciones de sequía. Este comportamiento 
en la vegetación leñosa de zonas áridas y semiáridas son observados por Scholes y Archer (1997) y por Kröpfl et al. (2015) y coinciden con los procesos de arbustificación observados en el área de estudio.

A modo de síntesis, el avance de la frontera agrícola en el Noreste de la provincia de Río Negro, y el consecuente desplazamiento de las actividades pecuarias a campos de monte, ha generado un fuerte proceso de degradación de los recursos naturales nativos del Monte. Además, la sequía registrada en la región profundizó el proceso de degradación. Este proceso se evidencia mediante la disminución la diversidad vegetal de los estratos leñosos y herbáceos y por los síntomas de degradación del suelo superficial, alcanzando en algunos casos la pérdida total de la capa superficial de suelo y la generación de pavimentos de desierto.

La degradación de los ecosistemas no impacta solamente sobre el suelo, las plantas vasculares, repercutiendo sobre las actividades económicas. Otros grupos de organismos también se ven afectados, tales como los que conforman las costras biológicas del suelo. Un estudio realizado en el departamento de Adolfo Alsina, evidenció que en los sitios más degradados, estas comunidades (constituidas fundamentalmente por musgos, y en menor meida líquenes y cianobacterias) presentan mayor tamaño, siendo más frecuentes en las proximidades de los arbustos que en las áreas adyacentes de suelo desnudo. El uso pastoril intensivo impediría el desarrollo de las costras en los interparches, mientras que los arbustos ofrecerían protección frente al pisoteo y ante el viento y la insolación, facilitando la formación de áreas con costras relativamente grandes. En áreas menos degradadas, las costras resultaron menos numerosas y de menor tamaño. Las costras biológicas son importantes en los ecosistemas semiáridos por su papel en el incremento de la estabilidad del suelo suprficial, la protección frente a la acción erosiva de la lluvia y el viento, y su aporte de carbono y nitrógeno. Además, en el Noreste de la Patagonia, cobran detacada importancia en la facilitación del establecimiento de especies arbustivas (Calabrese et al. 2013).

La degradación también afecta en gran medida a la fauna autóctona. El estado de conservación de un ecosistema se relaciona positivamente con su biodiversidad y provisión de servicios ecosistémicos, aunque los estudios que comparan diferentes mediciones de la biodiversidad (riqueza, diversidad o biomasa de especies) entre un sistema degradado y el de referencia, se han centrado en la cubierta vegetal, y en menor 
medida, en la fauna (Rey Benayas et al. 2009, Crouzeilles et al. 2015). La ecorregión del Monte alberga una rica fauna autóctona (Pol et al. 2005). La estrecha vinculación de la estructura de la vegetación y la abundancia y composición de aves ha dado lugar a diversos estudios en el Monte, en su mayoría realizados en la Reserva de la Biósfera de Nacuñán, en la provincia de Mendoza, que se ubica en la parte central de esta ecorregión. De estos estudios surge que la diversidad de especies de aves se correlacionó positivamente con la complejidad vertical, horizontal y florística del hábitat en temporada de cría (Marone 1991). En particular, Cueto et al. (2007) compararon la densidad de aves migratorias en dos tipos de vegetación característica del Monte, bosque abierto, con predominio de Prosopis flexuosa y Geoffrea decorticans en el estrato arbóreo, y el arbustal, dominado por Larrea divaricata. Claramente, durante la época de cría la densidad de aves migratorias fue superior en el bosque de P. flexuosa, en relación directa con una mayor oferta de sitios para nidificación y alimentación comparado con el arbustal. Estos autores advierten que la simplificación estructural del hábitat debido a actividades antrópicas conlleva un serio riesgo para la conservación de las aves migratorias australes del Neotrópico. A su vez, Milesi et al. (2002) compararon la riqueza de aves y la cobertura de la vegetación dentro de la Reserva de Ñacuñán y en zonas aledañas afectadas por fuego o pastoreo. Comparativamente, las áreas afectadas por los incendios, que presentaron mayor proporción de suelo desnudo y baja cobertura de leñosas y gramíneas, fueron las de menor diversidad de aves. Dentro de las áreas del Monte con dominancia de herbáceas, la diversidad y densidad poblacional de aves granívoras (Eemberizida) fue mayor en las áreas no pastoreadas que en las pastoreadas por ganado doméstico (Gonnet 2001). En cambio, estudios realizados para establecer la preferencia de hábitat de la mara (Dolichotis patagonum) en el Monte, mostraron que este roedor selecciona ambientes con predominio de vegetación herbácea abierta y alta proporción de suelo desnudo, mientras que su abundancia es baja en ambientes con alta cobertura de arbustos y hierbas, por lo que su densidad podría verse favorecida por el pastoreo (Kufner y Chambouleyron 1991; Alonso Roldán et al. 2017).

El cambio en el uso del suelo afecta de manera diferencial a las diferentes especies de un área determinada. El avance de la frontera agrícola y la urbanización suelen ser incompatibles con la conservación de la biodiversidad. Esto hace necesario efectuar evaluaciones de los recursos naturales que constituyen el hábitat de las especies de la fauna autóctona para planificar las actividades productivas, dirigir de manera adecuada 
los esfuerzos de conservación de hábitat y desarrollar proyectos de restauración ecológica en aquellas áreas degradadas. Las actividades productivas podrían ser compatibles con la conservación de la biodiversidad si se garantiza la diversificación de los distintos usos del suelo y el manejo adecuado.

\section{5- Conclusiones}

Este estudio ha permitido identificar la variación de las diferentes coberturas del suelo entre los años 2001 y 2014 y detectar áreas con signos de elevada degradación.

Las características de la vegetación del Monte en el Noreste de la provincia de Río Negro muestran que la categoría que mayores porcentajes de cobertura presenta es el monte intermedio, con una disminución del monte denso y del monte abierto. Esta última categoría se asoció con mayores valores de diversidad y cobertura de especies herbáceas.

La categoría monte intermedio es la que presenta un desarrollo y cobertura de los estratos arbustivos alto y bajo relativamente balanceada y muestra condiciones intermedias de cobertura de la vegetación herbácea, presentando mayores valores de riqueza de especies perennes.

Las mayores coberturas de especies con valor forrajero se encontraron en los sitios con mayor diversidad específica. Esta presencia de especies forrajeras ofrecería una mayor receptividad ganadera y una mayor productividad por unidad de superficie. Además, la mayor diversidad de especies leñosas y la presencia de diferentes estratos implican una mayor variedad de hábitats para la fauna silvestre.

El mantenimiento de la cobertura del estrato arbustivo alto junto al estrato arbustivo bajo es deseable ya que en épocas con episodios climáticos extremos ofrecen protección al suelo y actúan como especies facilitadoras para el establecimiento de especies herbáceas.

El uso del suelo afecta la cobertura y la riqueza de la vegetación nativa de forma diferencial de acuerdo a la intensidad y frecuencia de la ocurrencia de disturbios. El uso que se hace de la tierra, el tipo de intervención, la carga animal, la intensidad de pastoreo, el uso de rotaciones y la ocurrencia de incendios deben ser manejados 
cuidadosamente para evitar la pérdida de las especies deseables, la proliferación de las especies leñosas y la arbustificación del sistema.

El monte denso está relacionado, en gran medida, con el proceso de arbustificación. Si bien el aumento de la cobertura arbustiva ofrece servicios ecosistémicos relacionados al secuestro de carbono atmosférico en su biomasa, hábitat para diferentes especies de mamíferos y aves y protección al suelo superficial, no es considerado una situación deseable para la ganadería.

La arbustificación, desde el punto de vista de la conservación de la diversidad de la vegetación de un área determinada, supone una disminución de la misma y por ende estos sistemas presentarían menores valores de conservación.

El uso agrícola de la tierra es la actividad económica que causa el mayor grado de deterioro de la vegetación, ya que requiere de la tala rasa para la habilitación de tierras. A su vez, las áreas de cultivo abandonados fueron las que generaron grandes superficies descubiertas, que en algunos casos han dado lugar a la formación de sistemas noveles.

El análisis multitemporal con imágenes satelitales permitió obtener una visión sinóptica de los fenómenos de degradación y desertificación que se desarrollan en el territorio y son una herramienta de suma utilidad a la hora de tomar decisiones y seleccionar áreas y estrategias de intervención.

Sería deseable que aquellos sectores donde se registraron los valores óptimos de cobertura de los estratos leñosos y herbáceo, y que presentan mayor diversidad biológica, sean conservados como relictos naturales del ecosistema de Monte de transición, con planes de manejo y explotación que garanticen el aprovechamiento sustentable del mismo.

Asimismo, sería deseable delinear líneas de acción tendientes a recuperar aquellos sectores del área de estudio donde se observó la degradación o la eliminación de la cobertura vegetal y se registraron comunidades empobrecidas, con menores valores de conservación. En aquellas áreas que luego de eliminada la cobertura vegetal no recobraron su cobertura ni se desarrollaron sistemas emergentes, incluirlas en planes de restauración o rehabilitación ecológica. 
Anexo II. 
Tabla 1. Características de las especies registradas. Fuente: Zuloaga et al. 1994; Zuloaga y Morrone 1996; 1999; Kröpfl y Villasuso 2012.

\begin{tabular}{|c|c|c|c|c|c|c|c|}
\hline Especie & $\mathbf{L} / \mathbf{H}$ & Familia & Forma de Vida & Origen & $\begin{array}{c}\text { Hábito de } \\
\text { crecimiento }\end{array}$ & Fenología & Palatabilidad \\
\hline Acantholippia seriphioides (A. Gray) Moldenke & $\mathrm{L}$ & Verbenaceae & Arbusto & Nativo & rastrero & Primaveral & ramoneado \\
\hline Aloysia gratissima (Gillies \& Hook. ex Hook.) Tronc. var. Gratissima & $\mathrm{L}$ & Verbenaceae & Arbusto & Nativo & erecto & Primaveral & Toxica \\
\hline Aristida mendocina Phil. & $\mathrm{H}$ & Poaceae & Herbácea/Gramíneas & Adventicio & erecto & estival & Forrajera \\
\hline Baccharis crispa Spreng. & $\mathrm{L}$ & Asteraceae & Subarbusto & Nativo & erecto & estival & no posee \\
\hline Baccharis melanopotamica Speg. & $\mathrm{L}$ & Asteraceae & Subarbusto & Nativo & erecto & Primaveral & no posee \\
\hline Baccharis ulicina Hook \& Arn. & $\mathrm{L}$ & Asteraceae & Subarbusto & Nativo & erecto & estival & no posee \\
\hline Boopis anthemoides Juss. Var. Anthemoides & $\mathrm{H}$ & Calyceraceae & Herbácea/Dicotiledónea & Nativo & erecto & Primaveral & no posee \\
\hline Bougainvillea spinosa (Cam.) Heimert & $\mathrm{L}$ & Nyctaginaceae & Arbusto & Nativo & erecto & primaveral & no posee \\
\hline Brachyclados lycioides D. Don & $\mathrm{L}$ & Asteraceae & Arbusto & Nativo & erecto & primaveral & no posee \\
\hline Bredemeyera microphylla (Griseb.)Hieron. Var. Microphylla & $\mathrm{L}$ & Polygalaceae & Subarbusto & Nativo & erecto & Primaveral & ramoneado \\
\hline Bromus catharticus Vhal var. Rupestris (Speg) & $\mathrm{H}$ & Poaceae & Herbácea/Gramíneas & Nativo & erecto & primaveral & Forrajera \\
\hline Capparis atamisquea Kuntze & $\mathrm{L}$ & Capparaceae & Arbusto & Nativo & erecto & primaveral & ramoneado \\
\hline Cereus aethiops Haw. & $\mathrm{L}$ & Cactaceae & Arbusto & Nativo & erecto & estival & ramoneado \\
\hline Chuquiraga avellanedae Lorentz & $\mathrm{L}$ & Asteraceae & Arbusto & Nativo & erecto & estival & no posee \\
\hline Chuquiraga erinacea D. Don Erinacea & $\mathrm{L}$ & Asteraceae & Arbusto & Nativo & erecto & primaveral & no posee \\
\hline Chuquiraga rosulata Gaspar & $\mathrm{L}$ & Asteraceae & Arbusto & Nativo & rastrero & Primaveral & no posee \\
\hline Condalia microphylla Cav. & $\mathrm{L}$ & Rhamnaceae & Arbusto & Nativo & erecto & primaveral & ramoneado \\
\hline Cyclolepis genistoides D. Don & $\mathrm{L}$ & Asteraceae & Arbusto & Nativo & erecto & estival & ramoneado \\
\hline Dichondra microcalyx (Hallier f.) Fabris & $\mathrm{H}$ & Convolvulaceae & Herbácea/Dicotiledónea & Nativo & rastrero & primaveral & no posee \\
\hline Distichlis spicata (L.) Greene var. Spicata & $\mathrm{H}$ & Poaceae & Herbácea/Gramíneas & Nativo & erecto & primaveral & Forrajera \\
\hline Ephedra ochreata Miers & $\mathrm{L}$ & Ephedraceae & Arbusto & Nativo & erecto & Primaveral & Forrajera \\
\hline Ephedra triandra Tul. Emend. J. H. Hunz & $\mathrm{L}$ & Ephedraceae & Arbusto & Nativo & erecto & primaveral & Forrajera \\
\hline Gamochaeta filaginea (DC.) Cabrera & $\mathrm{H}$ & Asteraceae & Herbácea/Dicotiledónea & Nativo & erecto & primaveral & no posee \\
\hline Geoffroea decorticans (Guilies ex Hook. \& Arn) Burkart & $\mathrm{L}$ & Fabaceae & Árbol & Nativo & erecto & primaveral & Forrajera \\
\hline Habranthus jamesonii (Baker) Ravenna & $\mathrm{H}$ & Amaryllidaceae & Herbácea/Dicotiledónea & Nativo & erecto & estival & no posee \\
\hline Hoffmannseggia erecta Phil. & $\mathrm{H}$ & Fabaceae & Herbácea/Dicotiledónea & Nativo & erecto & primaveral & no posee \\
\hline Hysterionica jasionoides Willd. & $\mathrm{H}$ & Asteraceae & Herbácea/Dicotiledónea & Nativo & erecto & primaveral & no posee \\
\hline Jarava plumosa (Spreg.) S.W.L. Jacobs \& Everett & $\mathrm{H}$ & Poaceae & Herbácea/Gramíneas & Nativo & erecto & $\begin{array}{l}\text { primavero- } \\
\text { estival }\end{array}$ & Forrajera \\
\hline Junelia seriphioides (Gillies \& Hook. Ex Hook.) Moldenke & $\mathrm{L}$ & Verbenaceae & Arbusto & Nativo & erecto & estival & no posee \\
\hline
\end{tabular}




\begin{tabular}{|c|c|c|c|c|c|c|c|}
\hline Larrea cuneifolia Cav. & $\mathrm{L}$ & Zygophyllaceae & Arbusto & Nativo & erecto & primaveral & no posee \\
\hline Larrea divaricata Cav. & $\mathrm{L}$ & Zygophyllaceae & Arbusto & Nativo & erecto & primaveral & no posee \\
\hline Lycium chilense Miers ex Bertero & $\mathrm{L}$ & Solanaceae & Arbusto & Nativo & erecto & primaveral & ramoneado \\
\hline Lycium gillesianum Miers & $\mathrm{L}$ & Solanaceae & Arbusto & Nativo & erecto & primaveral & ramoneado \\
\hline Lycium tenuispinosum Miers & $\mathrm{L}$ & Solanaceae & Arbusto & Nativo & erecto & primaveral & ramoneado \\
\hline Margyricarpus pinnatus (Lam.) Kuntze & $\mathrm{L}$ & Rosaceae & Subarbusto & Nativo & erecto & primaveral & no posee \\
\hline Monttea aphylla (Miers) Benth. \& Hook. & $\mathrm{L}$ & Plantaginaceae & Arbusto & Nativo & erecto & primaveral & no posee \\
\hline Nassella hyalina (Nees) Barkworth & $\mathrm{H}$ & Poaceae & Herbácea/Gramíneas & Nativo & erecto & $\begin{array}{c}\text { primavero- } \\
\text { estival }\end{array}$ & no posee \\
\hline Nassella longiglumis (Phil.) Barkworth & $\mathrm{H}$ & Poaceae & Herbácea/Gramíneas & Nativo & erecto & primaveral & Forrajera \\
\hline Nassella tenuis (Phil.) Barkworth & $\mathrm{H}$ & Poaceae & Herbácea/Gramíneas & Nativo & erecto & primaveral & Forrajera \\
\hline Noticastrum sericeum (Less.) Less. Ex Phil. & $\mathrm{H}$ & Asteraceae & Herbácea/Dicotiledónea & Nativo & rastrero & estival & no posee \\
\hline Oxalis lasiopetala Zucc. & $\mathrm{H}$ & Oxalidaceae & Herbácea/Dicotiledónea & Nativo & erecto & primaveral & no posee \\
\hline Pappophorum caespitosum R.E. Fr. & $\mathrm{H}$ & Poaceae & Herbácea/Gramíneas & Nativo & erecto & $\begin{array}{c}\text { primavero- } \\
\text { estival }\end{array}$ & Forrajera \\
\hline Pappostipa speciosa (Trin. \& Rupr.) Romasch. & $\mathrm{H}$ & Poaceae & Herbácea/Gramíneas & Nativo & erecto & primaveral & Forrajera \\
\hline Piptochaetium napostaense (Speg.) Hack. & $\mathrm{H}$ & Poaceae & Herbácea/Gramíneas & Nativo & erecto & primaveral & Forrajera \\
\hline Poa lanuginosa Poir. & $\mathrm{H}$ & Poaceae & Herbácea/Gramíneas & Nativo & erecto & primaveral & Forrajera \\
\hline Poa ligularis Ness ex Steud. & $\mathrm{H}$ & Poaceae & Herbácea/Gramíneas & Nativo & erecto & primaveral & Forrajera \\
\hline Prosopidastrum globosum (Gillies ex Hook. \& Arn) Burkart & $\mathrm{L}$ & Fabaceae & Arbusto & Nativo & erecto & primaveral & no posee \\
\hline Prosopis alpataco Phil. F. alpataco & $\mathrm{L}$ & Fabaceae & Arbusto & Nativo & erecto & primaveral & no posee \\
\hline Prosopis caldenia Burkart & $\mathrm{L}$ & Fabaceae & Árbol & Nativo & erecto & Primaveral & ramoneado \\
\hline Prosopis flexuosa DC. Var. Depressa F.A. Roig & $\mathrm{L}$ & Fabaceae & Árbol & Nativo & erecto & primaveral & Forrajera \\
\hline Schinus jhonstonii F.A. Barkley & $\mathrm{L}$ & Anacardiaceae & Arbusto & Nativo & erecto & primaveral & Forrajera \\
\hline Senecio filaginoides DC. & $\mathrm{L}$ & Asteraceae & Subarbusto & Nativo & erecto & primaveral & no posee \\
\hline Senna aphylla (Cav.) H.S. Irwin \& Berneby & $\mathrm{L}$ & Fabaceae & Subarbusto & Nativo & rastrero & primaveral & no posee \\
\hline Setaria parviflora (Poir.) Kerguelen & $\mathrm{H}$ & Poaceae & Herbácea/Gramíneas & Nativo & erecto & primaveral & Forrajera \\
\hline Solanum sisymbriifolium Lam. & $\mathrm{L}$ & Solanaceae & Subarbusto & Nativo & erecto & estival & Toxica \\
\hline Sphaeralcea mendocina Phil. & $\mathrm{L}$ & Malvaceae & Subarbusto & Nativo & rastrero & primaveral & no posee \\
\hline Sporobolus rigens (Trin.) E. Desv. & $\mathrm{H}$ & Poaceae & Herbácea/Gramíneas & Nativo & erecto & estival & Forrajera \\
\hline Trichocline sinuata (D.Don) Cabrera & $\mathrm{H}$ & Asteraceae & Herbácea/Dicotiledónea & Nativo & rastrero & primaveral & no posee \\
\hline
\end{tabular}


Tabla 2. Frecuencia de especies leñosas por sitio.

\begin{tabular}{|c|c|c|c|c|c|c|c|c|c|c|c|c|c|c|c|c|c|c|c|c|c|c|c|c|c|c|c|c|c|c|}
\hline Especie & AA1 & $\mathbf{A A 2}$ & AA3 & AA4 & AA5 & AA6 & AA7 & AA8 & AA9 & $\begin{array}{c}\text { AA } \\
10 \\
\end{array}$ & \begin{tabular}{|c|} 
AA \\
11
\end{tabular} & GC1 & GC2 & GC3 & GC4 & GC5 & GC6 & GC7 & GC8 & GC9 & GC10 & PM1 & PM2 & PM3 & PM4 & PM5 & PM6 & PM7 & PM8 & PM9 \\
\hline Condalia microphylla Cav. & 2 & 3 & 3 & 3 & 3 & 3 & 2 & 3 & 3 & - & 3 & 3 & 3 & 3 & 2 & 3 & 3 & 3 & 3 & - & 2 & 2 & 3 & 3 & 3 & 3 & 3 & 3 & 2 & 2 \\
\hline Larrea divaricata Cav. & 2 & 3 & 3 & 3 & 3 & - & 2 & - & 3 & 3 & 3 & 3 & 3 & 3 & 3 & 3 & - & - & 3 & 3 & 3 & 3 & 3 & - & - & 3 & 2 & 2 & 2 & 3 \\
\hline Lycium chilense Miers ex Bertero & 3 & 3 & 3 & 3 & 2 & 3 & 3 & - & 3 & 3 & 2 & 3 & 3 & 3 & 2 & - & 3 & - & 2 & - & 2 & 3 & 2 & 2 & 2 & 2 & 3 & - & 3 & 3 \\
\hline $\begin{array}{l}\text { Chuquiraga erinacea D. Don } \\
\text { erinacea }\end{array}$ & - & 2 & 3 & 3 & 3 & 3 & 3 & 3 & 3 & - & - & 3 & 3 & 2 & 3 & - & 3 & - & 3 & - & 3 & 2 & 3 & 2 & - & - & 3 & 3 & 3 & 3 \\
\hline $\begin{array}{c}\text { Senna aphyla (Cav.) H.S. Irwin \& } \\
\text { Berneby }\end{array}$ & - & - & 3 & 3 & - & - & 3 & 3 & - & 2 & 3 & 3 & - & 3 & 3 & 3 & 3 & - & 2 & - & 2 & 2 & - & - & - & 2 & 3 & 3 & - & 3 \\
\hline Schinus johnstonii F.A Barkley & - & - & 3 & 3 & 3 & 3 & 3 & 2 & 3 & 2 & 2 & 3 & - & 3 & - & - & 2 & - & - & - & 3 & - & 2 & - & 2 & - & - & 2 & - & 2 \\
\hline $\begin{array}{l}\text { Geoffroea decorticans (Guilies ex } \\
\text { Hook. \& Arn) Burkart }\end{array}$ & 3 & - & - & - & 2 & - & - & - & - & 2 & - & 3 & 3 & 3 & 3 & 3 & 3 & 3 & 2 & 2 & 3 & - & - & - & - & 3 & - & - & - & 2 \\
\hline $\begin{array}{l}\text { Prosopisflexuosa DC. Var. Depressa } \\
\text { F.A. Roig }\end{array}$ & - & - & - & - & - & - & - & - & 2 & - & - & 3 & 3 & 3 & - & - & - & - & - & - & - & 3 & 3 & 3 & 3 & 3 & 3 & - & 3 & 3 \\
\hline Lycium tenuispinosum Miers & 2 & - & - & - & 3 & 3 & 3 & - & 3 & - & - & 2 & 3 & 2 & 2 & 3 & - & - & 3 & 3 & - & - & - & - & - & - & - & - & - & . \\
\hline Prosopis alpataco Phil. F. alpataco & - & - & 2 & 3 & - & - & 2 & 3 & - & 3 & 3 & - & - & - & - & 3 & 2 & - & 3 & - & 2 & - & - & - & - & - & - & 3 & 3 & - \\
\hline $\begin{array}{l}\text { Acantholippia seriphioides (A. Gray) } \\
\text { Moldenke }\end{array}$ & - & 2 & 2 & 2 & - & - & - & - & - & - & - & - & - & - & - & 2 & - & - & - & 3 & - & 3 & 3 & 2 & - & - & 2 & 3 & 2 & - \\
\hline $\begin{array}{l}\text { Prosopidastrum globosum (Gillies ex } \\
\text { Hook. \& Arn) Burkart }\end{array}$ & - & - & - & 2 & - & - & 3 & 3 & - & - & - & 3 & 2 & 2 & - & 3 & 2 & - & - & - & - & - & 2 & - & - & - & - & - & 2 & - \\
\hline $\begin{array}{c}\text { Ephedra triandra Tul. Eemend } \\
\text { J.H.Hunz }\end{array}$ & - & - & - & 3 & - & - & 3 & 2 & - & - & - & 3 & 3 & - & - & - & - & - & 2 & - & - & - & - & - & 2 & 2 & - & - & - & 2 \\
\hline Baccharis ulicina Hook \& Arn & - & - & 2 & 2 & - & - & 2 & 2 & - & - & - & - & - & - & - & 2 & 3 & - & 2 & - & 3 & - & - & - & - & - & - & - & 2 & - \\
\hline Larrea cuneifolia Cav. & - & - & - & - & - & - & - & - & - & 2 & - & - & - & - & - & 3 & - & - & - & - & 3 & - & - & - & - & - & 3 & 3 & - & - \\
\hline Brachyclados lycioides D. Don & - & - & 2 & - & - & - & - & - & - & - & - & - & - & - & - & - & - & - & - & - & - & - & 2 & 2 & - & - & 3 & - & 2 & - \\
\hline Cyclolepis genistoides D. Don & - & - & 2 & - & - & 2 & - & 2 & - & - & - & - & - & - & - & - & 2 & - & - & - & 3 & - & - & - & - & - & - & - & - & - \\
\hline $\begin{array}{c}\text { Monttea aphylla (Miers) Benth. \& } \\
\text { Hook }\end{array}$ & - & - & - & - & - & - & - & - & - & - & - & 2 & - & 3 & - & - & - & - & 2 & - & - & - & - & - & - & - & - & 2 & 2 & - \\
\hline Ephedra ochreata Miers & - & - & - & - & - & 3 & - & - & - & - & - & - & - & - & - & - & - & - & - & - & - & - & - & 2 & - & - & - & - & 2 & - \\
\hline Capparis atamisquea Kuntze & - & - & - & - & - & - & - & - & - & - & - & - & - & - & - & - & 2 & - & 2 & - & - & - & - & - & - & - & - & - & - & - \\
\hline $\begin{array}{l}\text { Junellia seriphioides (Gillies \& } \\
\text { Hook. Ex Hook.) Moldenke }\end{array}$ & - & - & - & - & - & - & - & - & - & - & - & - & - & - & - & - & - & - & - & - & - & 2 & 2 & - & - & - & - & - & - & - \\
\hline Baccharis melanopotamica Speg & - & - & - & - & - & - & - & - & - & - & - & - & - & - & - & - & 3 & - & - & - & - & - & - & - & - & - & - & - & - & - \\
\hline Chuquiraga avellanedae Lorentz & - & - & - & 3 & - & - & - & - & - & - & - & - & - & - & - & - & - & - & - & - & - & - & - & - & - & - & - & - & - & - \\
\hline $\begin{array}{c}\text { Bredemeyera microphylla (Griseb.) } \\
\text { Hieron. var. Microphylla }\end{array}$ & - & - & - & - & - & - & - & 2 & - & - & - & - & - & - & - & - & - & - & - & - & - & - & - & - & - & - & - & - & - & - \\
\hline Lycium gillesianum Miers & - & 2 & - & - & - & - & - & - & - & - & - & - & - & - & - & - & - & - & - & - & - & - & - & - & - & - & - & - & - & - \\
\hline $\begin{array}{c}\text { Margyricarpus pinnatus (Lam.) } \\
\text { Kuntze }\end{array}$ & - & - & - & - & - & - & - & 2 & - & - & - & - & - & - & - & - & - & - & - & - & - & - & - & - & - & - & - & - & - & - \\
\hline Prosopis caldenia Burkart & - & - & - & - & - & - & - & - & - & - & - & - & - & - & - & - & - & - & - & - & - & - & - & - & 2 & - & - & - & - & - \\
\hline
\end{tabular}




\begin{tabular}{|c|c|c|c|c|c|c|c|c|c|c|c|c|c|c|c|c|c|c|c|c|c|c|c|c|c|c|c|c|c|c|}
\hline & AA & $\overline{\mathbf{A A}}$ & $\overline{A A}$ & AA & $\overline{\mathbf{A A}}$ & AA & $\overline{\mathrm{AA}}$ & $\overline{\mathrm{AA}}$ & AA & AA1 & AA1 & GC & GC & GC & GC & GC & GC & $\mathbf{G C}$ & GC & GC & GCI & PM & PM & PM & PM & PM & PM & PM & PM & PM \\
\hline Especie & 1 & 2 & 3 & 4 & 5 & 6 & 7 & 8 & 9 & $\mathbf{0}$ & 1 & 1 & 2 & 3 & 4 & 5 & 6 & 7 & 8 & 9 & 0 & 1 & 2 & 3 & 4 & 5 & 6 & 7 & 8 & 9 \\
\hline Nassella tenuis (Phil.) Barkworth & 2 & - & - & - & - & 1 & - & - & 3 & - & 3 & - & - & - & - & 1 & 3 & 2 & 3 & 3 & 2 & - & - & - & - & - & - & 3 & 2 & 2 \\
\hline Poa ligularis Nessex Steud. & - & - & 2 & 1 & - & - & 3 & - & 3 & 2 & - & 1 & 1 & 1 & - & 1 & 2 & 3 & 1 & 3 & 3 & 2 & - & 1 & - & - & - & - & - & - \\
\hline $\begin{array}{l}\text { Pappostipa speciosa (Trin. \& Rupr.) } \\
\text { Romasch }\end{array}$ & - & - & - & 1 & 1 & 3 & 2 & 1 & 1 & - & 1 & - & - & - & 1 & - & 1 & 1 & - & - & - & - & - & - & - & 2 & 1 & 2 & 1 & 1 \\
\hline Pappophorum caespitosum R.E.Fr. & - & - & - & - & 3 & - & - & - & - & - & - & - & - & 1 & - & - & - & 3 & - & - & - & - & 2 & - & 2 & - & - & 1 & 2 & 1 \\
\hline Piptochaetium napostaense (Speg.) Hack & 1 & - & - & - & - & - & - & - & 2 & - & - & - & - & 1 & - & - & - & - & - & - & $=$ & 1 & 2 & 3 & 2 & 2 & - & - & - & - \\
\hline Nassella longiglumis (Phil.) Barkworth & - & - & 1 & 1 & - & - & - & - & 2 & 1 & - & 1 & 1 & 1 & - & - & - & 1 & - & - & 1 & - & - & - & - & - & - & - & - & - \\
\hline Trichocline sinuata (D.Don) Cabrera & - & - & 2 & 3 & - & - & - & - & - & 1 & - & - & - & - & - & 2 & - & - & - & - & 1 & - & - & - & - & - & - & - & - & - \\
\hline Aristida mendocina Phil. & - & - & - & - & - & - & - & - & - & - & - & 1 & - & - & - & - & - & - & - & - & - & - & 2 & 2 & 2 & - & - & - & - & - \\
\hline $\begin{array}{c}\text { Bromus catharticus Vhal var. } \\
\text { Rupestris(Speg) }\end{array}$ & - & - & - & - & 1 & - & - & - & 1 & 1 & - & - & - & - & - & - & - & 1 & - & 1 & - & - & - & - & - & - & - & - & 1 & - \\
\hline Gamochaeta filaginea (DC.) Cabrera & 1 & - & - & - & - & - & 1 & 1 & - & 2 & - & - & 1 & - & - & - & - & - & - & - & - & - & - & - & - & - & - & - & - & - \\
\hline Hoffmannseggia erecta Phil. & - & - & - & - & - & - & - & 1 & - & - & - & - & - & - & - & 2 & - & 1 & - & - & - & - & - & 1 & - & - & 1 & - & - & - \\
\hline Noticastrum sericeum (Less.) Less. Ex Phil & - & - & 1 & - & - & - & 1 & - & - & - & - & - & - & - & - & - & - & 1 & - & - & - & - & - & - & - & 1 & 1 & - & - & - \\
\hline Poa lanuginosa Poir & - & - & - & - & - & 1 & - & - & 2 & - & - & - & - & - & - & - & - & - & - & 2 & - & - & - & - & - & - & - & - & - & - \\
\hline Sporobolus rigens (Trin.) E. Desv. & - & - & - & - & - & - & - & - & - & - & - & - & - & - & - & - & - & - & - & - & - & - & 2 & 1 & 2 & - & - & - & - & - \\
\hline $\begin{array}{c}\text { Jarava plumosa (Spreg.) S.W.L. Jacobs \& } \\
\text { Everett }\end{array}$ & - & - & - & - & 3 & - & - & - & - & - & 1 & - & - & - & - & - & - & - & - & - & - & - & - & - & - & - & - & - & - & - \\
\hline Nassella hialina (Nees) Barkworth & - & - & - & - & 3 & - & - & - & - & - & - & - & - & - & - & - & - & - & - & - & - & - & - & - & - & - & - & - & - & - \\
\hline Setaria parviflora (Poir.) Kerguelen & - & - & - & - & - & - & - & - & - & - & - & - & - & - & - & - & - & - & - & - & - & - & - & - & - & - & - & - & - & 2 \\
\hline Solanum sisymbriifolium Lam. & - & - & - & - & - & - & - & - & - & - & - & - & - & - & - & - & - & - & - & - & - & - & - & - & 2 & - & - & - & - & - \\
\hline Boopis anthemoides Juss. Var. Anthemoides & - & - & - & - & - & - & - & - & - & - & - & - & - & - & - & - & - & - & - & - & 1 & - & - & - & - & - & - & - & - & - \\
\hline Dichondra microcalyx (Hallier f.) Fabris & - & - & - & - & 1 & - & - & - & - & - & - & - & - & - & - & - & - & - & - & - & - & - & - & - & - & - & - & - & - & - \\
\hline Distichlis spicata (L.) Greene var. Spicata & - & & - & - & - & 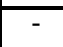 & & - & 7 & - & - & - & - & - & - & - & - & 1 & - & - & & & - & - & & - & - & - & - & \\
\hline Habranthus jamesonii (Baker) Ravenna & - & & 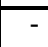 & - & - & & & - & 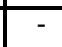 & 1 & 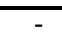 & 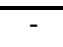 & - & - & & - & - & - & - & - & & & - & 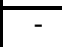 & & - & & - & - & \\
\hline Hysterionica jasionoides Willd. & - & & 7 & - & - & 1 & & - & 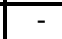 & & 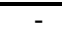 & 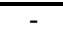 & - & - & & - & - & - & $\begin{array}{ll}- \\
-\end{array}$ & - & & & & & & - & & & & \\
\hline Oxalis lasiopetala Zucc. & 1 & & 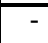 & - & - & & & - & & & - & 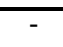 & - & - & & - & - & - & - & - & & & & & & - & & & & \\
\hline Sphaeralcea mendocina Phil. & & & & & & & & & & & & & 1 & & & & & & & & & & & & & & & & & \\
\hline
\end{tabular}




\begin{tabular}{|c|c|c|c|c|c|c|c|c|c|c|c|c|c|c|c|c|c|c|c|c|c|c|c|c|c|c|c|c|c|}
\hline & \multicolumn{14}{|c|}{ Planicie Aluvial } & \multicolumn{5}{|c|}{ Planicie loéssica } & \multicolumn{10}{|c|}{ Paleocanales } \\
\hline & AA11 & AA2 & AA8 & AA9 & GC10 & GC3 & GC4 & GC7 & GC8 & PM3 & PM6 & PM7 & PM8 & PM9 & AA1 & AA5 & AA6 & AA7 & GC9 & AA3 & AA4 & GC1 & GC2 & GC5 & GC6 & PM1 & PM2 & PM4 & PM5 \\
\hline \%A & 67,4 & 86,0 & 79,8 & 68,9 & 70,8 & 81,1 & 75,0 & 79,4 & 76,6 & 77,9 & 77,5 & 72,6 & 83,4 & 71,4 & 67,8 & 86,2 & $\mid 70,4$ & 84,0 & 80,4 & 73,0 & 68,7 & 76,0 & 80,2 & 70,9 & 83,8 & 79,0 & 84,6 & 64,5 & 86,2 \\
\hline D.E. & 25,3 & 2,8 & 14,9 & 1,0 & 6,6 & 1,8 & 2,2 & 7,4 & 3,0 & 4,1 & 2,9 & 6,9 & 2,1 & 6,8 & 4,5 & 2,8 & 5,4 & 11,7 & 7,6 & 12,8 & 18,5 & 4,8 & 6,3 & 2,3 & 9,3 & 1,7 & 0,5 & 0,9 & 1,3 \\
\hline pH & 8,4 & 7,2 & 8,6 & 8,4 & 8,4 & 8,2 & 8,0 & 8,2 & 7,9 & 7,6 & 8,3 & 8,3 & 8,3 & 8,1 & 7,9 & 8,5 & 8,5 & 8,1 & 8,3 & 8,3 & 8,4 & 7,6 & 8,4 & 8,0 & 7,9 & 8,3 & 7,7 & 7,6 & 6,2 \\
\hline D.E. & 0,3 & 0,3 & 0,1 & 0,3 & 0,4 & 0,4 & 0,4 & 1,1 & 0,2 & 0,1 & 0,1 & 0,1 & 0,2 & 0,1 & 0,1 & 0,1 & 0,2 & 0,1 & 0,1 & 0,2 & 0,2 & 0,4 & 0,3 & 0,7 & 0,3 & 0,2 & 0,2 & 0,1 & 0,5 \\
\hline $\mathrm{Ce}$ & 3,3 & 0,6 & 2,3 & 0,4 & 1,7 & 5,2 & 0,6 & 0,6 & 1,8 & 0,2 & 0,3 & 0,3 & 0,6 & 0,6 & 0,8 & 0,5 & 0,6 & 4,6 & 8,4 & 0,6 & 4,2 & 0,6 & 0,8 & 0,4 & 3,8 & 0,4 & 0,3 & 0,3 & 0,3 \\
\hline D.E. & 3,1 & 0,1 & 1,8 & 0,1 & 2,0 & 8,2 & 0,1 & 0,4 & 1,1 & 0,1 & 0,0 & 0,1 & 0,4 & 0,5 & 0,1 & 0,1 & 0,1 & 7,3 & 1,5 & 0,4 & 5,0 & 0,3 & 0,6 & 0,1 & 2,7 & 0,1 & 0,1 & 0,0 & 0,1 \\
\hline RAS & 11,7 & 8,5 & 22,3 & 1,3 & 13,9 & 6,3 & 1,7 & \begin{tabular}{|l|}
27,9 \\
\end{tabular} & 13,9 & 1,7 & 1,0 & 1,3 & 0,8 & 0,7 & 0,3 & 0,0 & 2,0 & 2,3 & 9,3 & 2,3 & 16,0 & 1,0 & 1,0 & 18,9 & 14,3 & 0,7 & 1,2 & 1,6 & 1,6 \\
\hline D.E. & 11,6 & 10,7 & 20,6 & 0,6 & 7,5 & 7,5 & 0,6 & 10,0 & 6,9 & 0,2 & 0,5 & 0,5 & 0,1 & 0,2 & 0,6 & 0,0 & 1,0 & 2,3 & 0,7 & 2,3 & 10,5 & 0,0 & 0,0 & 9,3 & 8,1 & 0,1 & 0,1 & 0,6 & 0,1 \\
\hline $\mathrm{CaCO}^{3}$ & 5,4 & 2,2 & 4,3 & 6,5 & 2,7 & 4,5 & 5,2 & 2,2 & 1,7 & 2,6 & 4,1 & 3,7 & 1,3 & 2,9 & 1,5 & 4,1 & 2,6 & 5,0 & 2,9 & 4,2 & 4,8 & 2,5 & 4,3 & 1,5 & 2,0 & 2,1 & 2,0 & 3,3 & 2,5 \\
\hline D.E. & 1,2 & 0,6 & 1,9 & 0,9 & 1,1 & 0,7 & 3,0 & 0,9 & 1,1 & 0,5 & 1,6 & 2,4 & 0,2 & 0,6 & 0,3 & 1,0 & 1,1 & 1,1 & 2,8 & 1,1 & 2,1 & 0,5 & 2,1 &, 4 & ,2 & 0,6 & 0,2 & 1,0 & 0,2 \\
\hline \%М.O & 1,4 & 0,6 & 1,5 & 1,6 & 1,3 & 0,8 & 1,3 & 1,1 & 1,3 & 1,5 & 1,0 & 1,3 & 0,8 & 1,1 & 1,3 & 0,9 & 1,2 & 1,0 & 1,1 & 1,8 & 1,6 & 1,2 & 0,7 & 1,1 & 1,2 & 0,8 & 1,2 & 2,5 & 1,7 \\
\hline D.E. & 0,3 & 0,2 & 0,3 & 0,2 & 0,2 & 0,4 & 0,5 & 0,2 & 0,0 & 0,4 & 0,1 & 0,6 & 0,3 & 0,3 & 0,4 & 0,1 & 0,4 & 0,2 & 0,1 & 0,2 & 0,5 & 0,4 & 0,1 & 0,1 & 0,1 & 0,1 & 0,2 & 0,1 & 0,8 \\
\hline$\% \mathrm{Nt}$ & 0,1 & 0,1 & 0,1 & 0,1 & 0,1 & 0,1 & 0,1 & 0,1 & 0,1 & 0,1 & 0,1 & 0,1 & 0,1 & 0,1 & 0,1 & 0,1 & 0,1 & 0,1 & 0,1 & 0,1 & 0,1 & 0,1 & 0,1 & 0,1 & 0,1 & 0,1 & 0,1 & 0,2 & 0,1 \\
\hline D.E. & 0,0 & 0,0 & 0,0 & 0,0 & 0,0 & 0,0 & 0,0 & 0,0 & 0,0 & 0,0 & 0,0 & 0,1 & 0,0 & 0,0 & 0,0 & 0,0 & 0,0 & 0,0 & 0,0 & 0,0 & 0,0 & 0,0 & 0,0 & 0,0 & 0,0 & 0,0 & 0,0 & 0,0 & 0,0 \\
\hline $\mathbf{P}(\mathbf{p p m})$ & 8,8 & 14,9 & 3,2 & 11,4 & 11,4 & 3,8 & \begin{tabular}{|l|}
10,6 \\
\end{tabular} & 11,0 & 12,3 & 6,1 & 8,1 & 9,9 & 6,8 & 4,6 & 12,1 & 2,2 & 1,5 & 9,8 & 27,9 & 16,6 & 9,3 & 16,8 & 12,7 & 10,6 & 10,3 & 6,2 & 6,0 & 8,5 & 22,4 \\
\hline D.E. & 0,4 & 12,0 & 0,1 & 3,7 & 2,8 & 1,0 & \begin{tabular}{|l|}
5,4 \\
\end{tabular} & \begin{tabular}{|l|}
4,6 \\
\end{tabular} & 1,5 & 7,1 & 1,5 & 4,0 & 1,5 & 1,2 & 9,3 & 0,4 & 0,5 & 4,0 & 26,3 & 11,1 & 4,5 & \begin{tabular}{|l|}
1,8 \\
\end{tabular} & 3,6 & 1,6 & 2,7 & 2,2 & 4,7 & 5,8 & 21,2 \\
\hline $\mathrm{Ca}$ & 8,6 & 3,3 & 9,7 & 11,6 & 9,7 & 8,2 & 4,7 & 3,8 & 6,3 & 3,0 & 6,7 & 10,4 & 6,4 & 7,7 & \begin{tabular}{|l|}
12,1 \\
\end{tabular} & 6,3 & 6,4 & 10,7 & 5,8 & 7,5 & 10,0 & 5,3 & 10,3 & 5,8 & 8,3 & 7,8 & 4,8 & 8,5 & 3,6 \\
\hline D.E. & 3,3 & 0,3 & 2,9 & 2,9 & 3,5 & 1,4 & 2,5 & 0,6 & 3,1 & 0,9 & 0,3 & 0,8 & 0,5 & 1,3 & 9,3 & 1,3 & 1,5 & 2,0 & 4,6 & 1,9 & 1,2 & 0,7 & 2,5 & 1,6 & 1,4 & 0,2 & 1,5 & 1,3 & 1,2 \\
\hline D. Ap. & 1,4 & 1,5 & 1,2 & 1,1 & 1,5 & 1,4 & 1,5 & 1,6 & 0,4 & 1,3 & 1,4 & 1,5 & 1,6 & 1,6 & 1,4 & 1,4 & 1,2 & 1,3 & 1,6 & 1,5 & 1,5 & 1,4 & 1,4 & 0,4 & 0,4 & 1,5 & 1,3 & 1,3 & 1,3 \\
\hline D.E. & 0,0 & 0,1 & 0,3 & 0,1 & 0,2 & 0,1 & 0,0 & 0,1 & 0,0 & 0,1 & 0,1 & 0,1 & 0,2 & 0,1 & 0,1 & 0,1 & 0,1 & 0,2 & 0,1 & 0,0 & 0,1 & 0,1 & 0,1 & 0,0 & 0,0 & 0,0 & 0,0 & 0,1 & 0,1 \\
\hline$\% \mathbf{L}+\mathbf{A}$ & 32,6 & 14,0 & 20,3 & 31,1 & 29,2 & 18,9 & 25,0 & 20,6 & 23,5 & 22,2 & 22,6 & 27,4 & 16,6 & 28,6 & 32,2 & 13,8 & 29,6 & 16,0 & 19,7 & 27,0 & 31,3 & 24,0 & 19,8 & 29,1 & 16,2 & 21,0 & 15,4 & 35,5 & 13,8 \\
\hline D.E. & 25,3 & 2,8 & 14,9 & $\mid 1,0$ & 6,6 & 1,8 & 2,2 & 7,4 & 3,0 & 4,1 & 2,9 & 6,9 & 2,1 & 6,8 & 4,5 & 2,8 & 5,4 & 11,7 & 7,6 & 12,8 & 18,5 & 4,8 & 6,3 & 2,3 & 9,3 & 1,7 & 0,5 & 0,9 & 1,3 \\
\hline
\end{tabular}




\section{Capítulo IV \\ Rehabilitación ecológica}

\section{1- Introducción}

La degradación de las tierras secas es un fenómeno registrado en numerosas regiones de nuestro planeta. La mayor parte de estos fenómenos están asociados al uso productivo que el hombre hace de estos ecosistemas (Cortina et al. 2011; Vallejo et al. 2009). Esta degradación se manifiesta por la pérdida total o parcial de la cobertura de la vegetación, la degradación física y química de los suelos, la erosión de la capa superficial y la consecuente pérdida de funcionalidad de los ecosistemas de regiones áridas, semiáridas y sub húmedas secas (Abraham et al. 2009). En estos casos es deseable llevar a cabo acciones para la remediación de los efectos negativos causados por las actividades productivas. Se intenta alcanzar la recuperación de algunos atributos perdidos de los sistemas naturales, siendo la restauración y rehabilitación ecológica opciones a considerar (Aronson et al. 1993; Delgado-Baquerizo et al. 2013; Maestre et al. 2001).

Existe una sutil diferencia entre el significado de rehabilitación y restauración sensu stricto. Esta última propone recuperar y mantener el ecosistema en estado prístino y sin ningún tipo de intervención del hombre, considera el ambiente como un "museo vivo" de relictos de la vegetación originaria de un lugar. En cambio, la rehabilitación ecológica propone la recuperación de algunos atributos de los sistemas naturales para devolverles la productividad perdida (Aronson et al. 1993; Fraterrigo y Rusak 2008).

Dentro de la disciplina de la rehabilitación ecológica es posible identificar dos variantes, rehabilitación activa y pasiva (Aronson et al. 1993; Hobbs y Cramer 2008). Por una parte la rehabilitación ecológica activa, consiste en realizar tareas deliberadas sobre un sistema natural con el objeto de devolverle los atributos estructurales y funcionales perdidos. Estas acciones tendientes a la recuperación consisten en la eliminación del disturbio causante de la degradación y la reintroducción de organismos vegetales para colonizar áreas descubiertas. Esta reintroducción puede ser tanto de propágulos, semillas, renovales de especies nativas o exóticas (Dalmasso 2010; Landi y Renison 2010; Mcadoo et al. 2016; Meli et al. 2013; Soteras et al. 2014; Torres et al. 2015), como así también la aplicación de enmiendas al suelo para modificar sus características físicas y químicas (Delgado-Baquerizo et al. 2013; Milgrom 2008; Neri y Sánchez 2010; Novák y Prach 2003), o la roturación de la superficie (Gasch et al. 2014). 
Las especies leñosas seleccionadas para ser empleadas en proyectos de rehabilitación ecológica son comúnmente denominadas árboles o arbustos multipropósito (Alvarez y Villagra 2009). Algunos de ellos son de la familia de las leguminosas y poseen un rol ecológico destacado debido a que son fijadoras de nitrógeno atmosférico a través de la asociación simbiótica con bacterias del género Rhizobium (López Lauenstein et al. 2012; Pece et al. 2014; Villagra et al. 2011). Otras especies generan grandes cantidades de mantillo o actúan como fuente de forraje para animales silvestres y domésticos que consumen sus hojas y sus frutos. Además, estas especies ofrecen refugio a las aves y a los mamíferos de menor tamaño que actúan como dispersores de semillas y colaboran en la difusión de las especies deseadas (Bertiller et al. 2009; Busso et al. 2016; Guevara et al. 2009; Loydi y Distel 2010; Villagra et al. 2011).

Es necesario conocer aspectos relacionados a la reproducción de las especies nativas del área a intervenir y poseer una referencia de la comunidad vegetal nativa de un área determinada (Aronson et al. 1993; Moore et al. 1999). Siempre que se inician prácticas de rehabilitación ecológica activa, es deseable emplear material genético del área a intervenir, ya que supone que los genotipos estarán adaptados a las condiciones ambientales de la región. Además, efectuar tratamientos pregerminativos, permite obtener un plantel de individuos con un grado de desarrollo similar facilitando el manejo durante las diferentes etapas de crecimiento y desarrollo en el invernadero (Cortina y Del Campo 2006). Esta información de base permite identificar las especies más deseables para utilizar en los ensayos de rehabilitación ecológica y los pasos a seguir a la hora de la producción de ejemplares destinados a repoblar las zonas a rehabilitar (Aronson et al. 1993; Bradshaw 1996; Clewell y Aronson 2007; Moore et al. 1999; Perrow y Davy 2002; Wang 2009).

Por otra parte, la rehabilitación pasiva, consiste en una intervención no deliberada sobre el ecosistema. Mediante la identificación del factor causante del disturbio y la supresión o eliminación del mismo, se espera que el sistema recupere los atributos estructurales y funcionales perdidos a causa de la degradación. Sin embargo, esta recuperación se hace más lenta y costosa cuanto más umbrales de degradación han sido superados (Aronson et al. 2007; Clewell y Aronson 2007; Fraterrigo y Rusak 2008).

Si bien nuestro país presenta una amplia zona cubierta de tierras áridas, semiáridas y sub húmedas secas, no hay cuantiosos trabajos de rehabilitación sobre áreas degradadas. 
Quiroga et al. (2009) realizaron una experiencia de rehabilitación en el Chaco árido, más precisamente en áreas degradadas del ecotono entre el Chaco árido y el Monte. Se realizaron clausuras donde se implantaron diferentes tratamientos para repoblar la zona de pastos nativos. La hipótesis de trabajo fue que en ambientes sobrepastoreados la compactación, la falta de semillas en el banco, la competencia con los arbustos, y la falta de mantillo son factores que limitan el establecimiento de gramíneas forrajeras nativas, concluyendo que el agregado de semillas es una intervención clave en los intentos de recuperar la capacidad forrajera en ambientes sobrepastoreados del Chaco árido.

En la provincia de Neuquén se llevaron a cabo ensayos de rehabilitación de la vegetación nativa en Aguada Pichana. Uno de ellos consistió en rehabilitar canteras a partir de trasplante directo de individuos adultos de especies nativas que crecían en zonas aledañas al área a rehabilitar. Se observó la supervivencia de las especies, como así también la producción de estructuras reproductivas bajo diferentes tratamientos (Nittmann 2010). Otro de los ensayos consistió en observar la supervivencia de plantines de Cercidium praecox de diferentes tamaños, con y sin protección antiherbivoría y con y sin hidrogel, plantados en dos épocas del año diferentes, obteniendo los plantines de vivero a partir de semillas de procedencia local (Altamirano y Pérez 2010). La tercera de las experiencias realizadas se basó en el análisis de la supervivencia temprana de Senna aphylla plantada de forma aislada y asociada a un sub-arbusto nativo (González 2010). Quezada y Pérez (2010) evaluaron el establecimiento inicial de Prosopis flexuosa var. depressa en diferentes tipos de suelo.

En la provincia de Río Negro no se han realizado experiencias de este tipo, a pesar de que las dos terceras partes de la superficie provincial corresponden a zona semiárida ocupada por el Monte (Godagnone y Bran 2009). El alto grado de degradación de los ecosistemas de monte y pastizales en el área de Viedma y Carmen de Patagones es conocido (Abraham et al. 2016; Zeberio 2012). Estos ecosistemas están dedicados a la producción agropecuaria, la cual se ha intensificado sobre los campos ocupados por vegetación nativa de monte $\mathrm{y}$, en algunos casos, la vegetación fue reemplazada por cultivos extensivos de secano. Estos cultivos posteriormente fueron abandonados debido a la pérdida de rentabilidad a causa de la sequía. En el área de estudio, estas tierras, ocupan aproximadamente $6.800 \mathrm{~km}^{2}$ (20\% de la superficie), y evidencian síntomas de degradación edáfica y pérdida de la cobertura de especies de ciclo de vida 
perenne (Cap. III de esta tesis; Pezzola y Winschel 2004; Zeberio 2012). Con el manejo adecuado y la implementación de acciones tendientes a la recuperación, tales como la reintroducción de especies, se propone investigar si es posible generar una mejora sustancial de las áreas degradadas del Monte, favoreciendo su rehabilitación.

El objetivo fue evaluar los efectos de la rehabilitación ecológica sobre campos antes poblados por vegetación nativa de Monte que fueron afectados a la explotación agropecuaria y luego abandonadas sin medidas o planes de recuperación. Particularmente, se evaluó cuáles son los tratamientos pregerminativos más adecuados para la producción de individuos de especies nativas a usar en ensayos de rehabilitación activa y se registraron los niveles de supervivencia y crecimiento de los individuos trasplantados. También se estimó la recuperación de la cobertura en ensayos de rehabilitación pasiva. Finalmente se analizaron los efectos que la rehabilitación, tanto activa como pasiva, tuvieron sobre el sistema intervenido.

\section{2- Materiales y métodos.}

\subsection{1- Selección de sitios}

La selección de los sitios para el desarrollo de ensayos de rehabilitación se llevó a cabo en base al análisis multitemporal de las imágenes Landsat 5 TM del año 2011, Landsat 8 OLI del año 2014, de los resultados obtenidos por Zeberio (2012), tipos de suelos y actividades productivas. Los criterios de selección fueron: áreas con signos de degradación avanzados, una historia de uso similar y características ambientales diferentes. El cumplimiento de estos criterios y la posibilidad de obtener los permisos necesarios para acceder a los sitios y realizar los ensayos condujo a que uno de ellos estuviera emplazado en el partido de Patagones, provincia de Buenos Aires. Este sitio presenta similitudes ecológicas y de usos con otros ubicados en la provincia de Río Negro a los que no se pudo acceder por falta de autorización. En cada uno de ellos se realizaron ensayos de rehabilitación activa y pasiva que se contrastaron con una situación testigo.

Se seleccionaron tres sitios que presentaran diferencias edáficas y climáticas, y que poseían áreas cubiertas por monte nativo el cual fue eliminado mediante tala rasa para desarrollar actividades productivas extensivas de secano. Los parámetros del suelo evaluados fueron conductividad eléctrica $\left(\mathrm{Ce}^{-}\right)$, relación de adsorción de sodio (RAS), Calcáreo $\left(\mathrm{CaCO}_{3} \%\right)$, materia orgánica (\%M.O.), nitrógeno total $(\% \mathrm{Nt})$, fósforo $(\mathrm{P}$ 


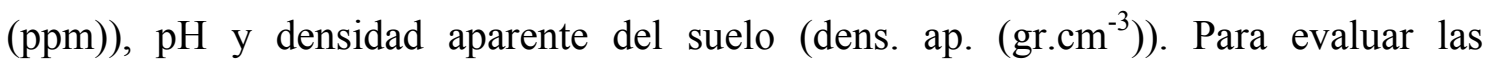
propiedades de los suelos de los distintos sitios se utilizaron las mismas metodologías que las descriptas en el capítulo 3. La variable del clima que se tuvo en cuenta fue la precipitación media, debido a la amplia variabilidad que presenta. Los datos de las precipitaciones ocurridas durante el período de mediciones (2013-2015) fueron extraídos del satélite TRMM Giovanni (https://giovanni.gsfc.nasa.gov) y de estaciones meteorológicas colocadas en los sitios de trabajo.

Con estos criterios fueron identificados tres sectores sin cobertura vegetal nativa y con una distancia creciente del litoral marítimo. El sitio Bosero está ubicado en un plano elevado, con alta exposición a los vientos. De los sitios seleccionados es el que presentó menor profundidad de los suelos, que varió entre los 10 y $20 \mathrm{~cm}$ hasta el contacto lítico. Estos rasgos indican la ocurrencia de voladura del suelo superficial. En este sitio, además de los síntomas de erosión eólica, se observan síntomas de erosión hídrica, tales como las cárcavas producidas por el escurrimiento superficial. En cambio, el sitio Iturburu, ubicado en la planicie loéssica, presenta un relieve vasto y plano con una suave pendiente con dirección hacia el Este. Este sitio posee suelos francos y se observa un encostramiento superficial que dificulta la infiltración del agua de lluvia y el enterramiento de las semillas de las especies presentes. El sitio Erripa, por su proximidad al litoral marítimo, presenta suelos arenosos, profundos y algo excesivamente drenados, con escaso porcentaje de materia orgánica, ocasionando que la retención de la humedad aportada por las precipitaciones sea baja y exista baja disponibilidad de agua para las plantas. Este sitio se encuentra reparado de los vientos predominantes del área por una cadena de médanos fijos situada en las inmediaciones que reduce las necesidades evapotranspirativas de las plantas, atemperando las condiciones para su establecimiento y desarrollo.

\subsection{2- Selección de especies y tratamientos pregerminativos.}

En la primavera del año 2011 comenzó la colecta de semillas de las especies nativas de la región. Para conocer cuál es el período de reproducción de las especies nativas del monte se consultó bibliografía específica (Kröpfl y Villasuso 2008).

Se seleccionaron aquellas especies que ofrecen algún servicio ecosistémico, como puede ser generar altos porcentajes de cobertura del suelo, proveer de forraje a los 
animales silvestres y domésticos, aportar mantillo y materia orgánica al suelo, fijar nitrógeno atmosférico al suelo y mejorar las condiciones de fertilidad del mismo.

Las especies seleccionadas fueron:

Leñosas: Condalia microphylla, Prosopis flexuosa, Prosopis alpataco, Prosopis caldenia, Prosopis denudans, Geoffroea decorticans, Schinus johnstoni, Brachyclados lycioides, Cyclolepis genistoides, Senna aphylla, Grindelia chiloensis, Baccaris ulicina, Senecio filaginoides, Prosopidastrum globosum.

Herbáceas: Pappophorum caespitosum, Nassella longiglumis, Nassella tenuis, Piptochaetium napostaense, Jarava plumosa, Poa ligularis.

Posteriormente, y siguiendo los lineamientos más difundidos, se identificaron plantas semilleras. Generalmente, son aquellas que en épocas desfavorables presentan un estado sanitario saludable, producen estructuras reproductivas con regularidad y, de ser un atributo buscado, muestran ciertas características morfológicas de interés, como un fuste erecto o un dosel muy estratificado (Gallo L. com. pers.).

La colecta del material genético se realizó manualmente, depositando las semillas y frutos recolectados en bolsas plásticas que posteriormente fueron transportadas al laboratorio. Una vez en el laboratorio, las semillas fueron procesadas para ser conservadas hasta el momento de aplicación de los tratamientos pregerminativos. Para ello fueron eliminadas aquellas partes de la semilla que no son útiles, como el mesófilo de las semillas de Condalia mycrophylla, Geoffroea decorticans y Schinus jonsthonii y las vainas dehiscentes de Prosopis flexuosa.

Las especies leñosas Brachyclados lycioides, Cyclolepis genistoides, Grindelia chiloensis, Baccaris ulicina, Senecio filaginoides y Prosopidastrum globosum pertenecientes a la familia Asteraceae, presentan aquenios vulgarmente llamados semillas (Valla 2011). En este trabajo denominaremos a estas especies como compuestas leñosas.

Las semillas de las especies herbáceas seleccionadas pertenecen a la familia Poaceae y las denominaremos gramíneas. Estas semillas fueron secadas al aire durante 48 horas, sobre papel de diario, y posteriormente, separadas de los restos de hojas y tallos de la 
planta. Una vez limpias fueron depositadas en bolsas de papel y colocadas en sectores secos y desprovistos de luz natural para ser almacenadas.

Ensayos preliminares realizados en laboratorio sobre semillas de especies nativas del monte indicaron que sería necesario realizar algún tipo de tratamiento previo a la germinación para romper la latencia o dormición del embrión en aquellas semillas que mostraban un pericarpio duro e impermeable o una cutícula seminal impermeable. Las semillas con estas características pertenecen a las especies C. microphylla, $G$. decorticans, Prosopis sp. y Schinus johnstonii y las denominaremos leñosas con semillas con dormición.

Los tratamientos pregerminativos llevados a cabo fueron medios de escarificación física y tratamientos de escarificación química. Los tratamientos físicos consistieron en el raspado de la cubierta seminal con una lija de calibre 100 (lija al agua) para debilitar el tejido y permitir el intercambio de agua y oxígeno entre el exterior y el embrión. Posteriormente, las semillas lijadas fueron remojadas durante 24 horas en agua previamente calentada hasta $80^{\circ} \mathrm{c}$ y dejada enfriar hasta temperatura ambiente. Los tratamientos químicos consistieron en emplear ácidos fuertes para degradar la cubierta seminal. Para ello las semillas fueron sumergidas en ácido sulfúrico $\left(\mathrm{H}_{2} \mathrm{SO}_{4} 98 \% \mathrm{P} / \mathrm{V}\right)$ y agitadas con un mezclador manual a intervalos de tiempo regulares. Los tiempos de exposición de las semillas al ácido sulfúrico fueron de 32 minutos y 64 minutos. Posteriormente fueron retiradas del medio ácido y enjuagadas con peróxido de hidrógeno para retirar los restos de materia orgánica y ácido adheridos a las semillas y se colocaron en un recipiente para la imbibición con agua corriente durante 24 horas. Para el análisis de la germinación de las semillas de las especies con dormición se aplicó un diseño experimental completamente aleatorizado con tres tratamientos (ácido sulfúrico 64' y 32' y escarificación física) y un grupo testigo. Se efectuaron tres réplicas por tratamiento y tres réplicas para el grupo testigo. Cada una de las repeticiones contenía 20 semillas. En total fueron usadas 80 semillas por cada uno de los tratamientos y un total de 560 semillas en todo el ensayo.

Las semillas tratadas fueron colocadas en bandejas plásticas, de $48 \mathrm{~cm}$ de largo y 36 centímetros de ancho, con un sustrato conformado por 50\% de arena y $50 \%$ de turba. Fueron sembradas a una profundidad de 5 milímetros $( \pm 2 \mathrm{~mm})$ y se registró la emergencia de la plántula una vez cada cuatro días durante un período de 28 días. 
En las semillas de las gramíneas y de las compuestas leñosas no fue necesario aplicar tratamientos para degradar su cubierta seminal y permitir la germinación. Las semillas de estas especies fueron colocadas en cajas de Petri, recubiertas con algodón y papel secante, y llevadas a una cámara de germinación con temperatura y contenido de humedad constante. La temperatura utilizada fue de $20^{\circ} \mathrm{C}$ y el tiempo de exposición fue de ocho días. El control y registro de la emergencia de la radícula se efectuó diariamente.

Posteriormente, y para evaluar si las semillas de las gramíneas necesitaban acumular horas de frío para activarse y germinar, realizamos un tratamiento de estratificación fría. Se esterilizó arena en autoclave $\mathrm{y}$, posteriormente, fue colocada en bandejas de polipropileno que fueron llevadas a heladera, a una temperatura constante de $7^{\circ} \mathrm{C}$ durante 20 días. Luego fueron retiradas y llevadas a cámara de germinación, con temperatura constante a $20^{\circ} \mathrm{C}$ y humedad controlada. Fue evaluada diariamente la germinación a lo largo de ocho días.

Para el análisis de la germinación de las compuestas leñosas y de las gramíneas se usaron tres réplicas por especies, con 20 semillas cada una. En el caso de las leñosas compuestas se utilizaron un total de 420 semillas en todo el ensayo. Para la evaluación de la germinación de las gramíneas se usaron un total de 360 en todo el ensayo.

Los resultados obtenidos fueron analizados con ANOVA y la comparación de medias realizadas con el test de LSD de Fisher con un nivel de significancia inferior al 5\%.

\subsection{3- Rehabilitación activa.}

Para los tratamientos de rehabilitación activa, fueron seleccionadas aquellas especies más frecuentes en los sitios de referencia en las áreas a rehabilitar. Como criterio complementario se eligieron especies, entre aquellas utilizadas en los ensayos de los tratamientos pregerminativos, de acuerdo a los criterios ya mencionados (forrajeras, fijadoras de suelo, etc.), pero que además por su porte, pueden favorecer procesos de facilitación para otros ejemplares de la misma u otra especie (Tabla 4.1). Las especies leñosas seleccionadas fueron las siguientes: Prosopis flexuosa, Condalia microphylla, Geoffroea decorticans, Schinus johnstonii. Las especies herbáceas seleccionadas fueron: Nassella tenuis, Nassella longiglumis, Piptochaetium napostaense y Pappophorum caespitosum. 
Tabla 4.1. Características de las especies leñosas ponderadas para el tratamiento de rehabilitación activa. Fuente: Zuloaga et al. 1994; Zuloaga y Morrone 1996; 1999; Kröpfl y Villasuso 2012.

\begin{tabular}{|l|c|c|c|c|c|}
\hline & $\begin{array}{c}\text { Fijadora } \\
\mathbf{N}_{\mathbf{2}}\end{array}$ & Follaje & $\begin{array}{c}\text { Uso } \\
\text { forrajero }\end{array}$ & Dormición & Porte \\
\hline C. microphylla & No & Caducifolio & No & Sí & Arbustivo \\
\hline G. decorticans & Sí & Caducifolio & Sí & Sí & Arbóreo \\
\hline S. jonsthonii & No & Perennifolio & No & No & Arbustivo \\
\hline P. flexuosa & Sí & Caducifolio & Sí & Si & Arbóreo \\
\hline P. alpataco & Sí & Caducifolio & Sí & Si & Arbustivo \\
\hline P. caldenia & Sí & Caducifolio & Sí & Si & Arbóreo \\
\hline P. denudans & Sí & Caducifolio & No & Si & Arbustivo \\
\hline B. ulicina & no & Perennifolio & No & No & Subarbustivo \\
\hline B. lycioides & No & Perennifolio & Sí & No & Arbustivo \\
\hline C. genistoides & No & Caducifolio & No & No & Arbustivo \\
\hline G. chiloensis & No & Perennifolio & No & No & Subarbustivo \\
\hline$P$. globosum & Sí & Caducifolio & No & No & Arbustivo \\
\hline S. aphylla & Sí & Perennifolio & No & No & Subarbustivo \\
\hline S. filaginoides & no & Perennifolio & No & No & Arbustivo \\
\hline
\end{tabular}

La información relativa a las características de las especies empleadas en los tratamientos de rehabilitación activa fue obtenida del Catálogo de Plantas Vasculares de la República Argentina (Zuloaga et al. 1994; Zuloaga y Morrone 1996; 1999a; 1999b) y de la Guía para el Reconocimiento de Especies de los Pastizales del Monte Oriental de la Patagonia (Kröpfl y Villasuso 2012).

- Prosopis flexuosa: árbol de 1 a 3 metros de altura, caducifolio y de ramas arqueadas y semipéndulas. Sus flores son pequeñas y aparecen en racimos de cerca de 200 inflorescencias. Su fruto es una legumbre indehiscente, levemente encorvada, con pulpa dulce de escaso desarrollo, color amarillo-pajiza con manchas violáceas. Esta especie florece a mediados de primavera. Tiene valor forrajero ya que la hacienda come sus hojas y legumbres. Esta especie, en épocas en que als precipitaciones son escasas, actúa como facilitadora ya que ofrece sombra, menores temperaturas y menor evaporación a las especies que se desarrollan bajo su copa. Esta especie, además, es fijadora de nitrógeno atmosférico mediante la asociación con bacterias del género Rhizobium.

- Geoffroea decorticans: árbol caducifolio de 1,5 a 4 metros de altura, con raíces gemíferas. Su fuste principal y las ramas más importantes poseen una corteza 
que cae en largas placas y franjas longitudinales secas, quedando al descubierto su lustrosa cubierta verde. Posee una flor amarilla con estrías rojizas y su fruto es una drupa globosa, rojiza, sin pelos, con pulpa dulzona, carozo grande y semillas blandas oleaginosas. El fruto de esta especie es comestible y forrajero, pero además, los ovinos ramonean sus brotes tiernos. Esta especie, cuando alcanza elevado grado de desarrollo, ofrece sombra al ganado y, en ocasiones, permite el establecimiento de especies herbáceas.

-Condalia microphylla: arbusto caducifolio, de hasta 2 metros de altura, con gran cantidad de ramas verde oscuras, rígidas y espinescentes y abundantes hojas. Flores amarillentas, pequeñas, pedunculadas y dispuestas en fascículos de 2 a 5 flores. Su fruto es una drupa elipsoidea, roja, amarilla o naranja. Los ovinos y caprinos consumen sus frutos y los brotes tiernos. Posee una madera de alta densidad

- Schinus johnstonii: arbusto achaparrado de entre 0,5 y 1,5 metros de altura. Flores amarillas en fascículos plurifloros que aparecen en primavera. Su fruto es una drupa azul oscuro o violácea. Su valor forrajero radica en el consumo, por parte del ganado ovino y caprino, de sus brotes tiernos y sus frutos.

Entre las herbáceas se seleccionaron:

- Nassella longiglumis: pasto perenne, cespitoso, con tallos erectos de 30-80 centímetros de altura, con macollos intravaginales. Sus hojas son vainas de margen ciliado y lígula membranosa. Láminas planas o lineales, pilosas en la cara superior y sin pelos en la cara inferior. Sus flores son panojas erectas, laxas y pacifloras. Su fruto es un cariopse castaño, de 6-7 milímetros. Esta especie es de ciclo invernal, teniendo su mayor crecimiento en primavera. Florece a finales de septiembre y sus semillas maduran para diciembre. Es una gramínea de alta preferencia por parte del ganado. Sus valores de digestibilidad varían entre el $55 \%$ y el $62 \%$ y el contenido de proteína bruta entre $8-10 \%$.

- Nassella tenuis: pasto perenne, de entre 15 y 40 centímetros de alto, pilosa debajo de los nudos. Sus hojas son amarillo pajiza, y las basales algo violáceas. Posee lígulas basales muy cortas y las superiores largas. Sus flores son panículas enmarañadas, con espiguillas verdosas a violáceas. Su fruto es un cariopse 
translúcido, elíptico, alargado, de 4 milímetros. Es una gramínea de ciclo invernal, con máximo crecimiento y floración en primavera. Sus frutos maduran para los meses de noviembre- diciembre. Es la principal especies forrajera de la región por su disponibilidad. Su valor de preferencia por parte del ganado es moderado. Es muy resistente al pastoreo.

-Pappophorum caespitosum: pasto perenne, cespitoso, de 6-80 centímetros de alto. Sus hojas son vainas sin pelos, con láminas lineares rígidas, convolutas, punzantes, sin pelos en la cara abaxial y pilosa en la cara adaxial. Presenta una panoja densa, espiciforme, normalmente incluida en la vaina foliar. Sus frutos son cariopses de alrededor de 2 milímetros. Es una especie heliófila, común en barrancos y faldeos. Son pastos de ciclo estival, rebrotan en septiembre y permanecen vegetando hasta fines de mayo, cuando entran en reposo y toman una coloración violácea. Su etapa reproductiva comienza a finales de octubre, extendiéndose hasta febrero. Es una buena forrajera hasta la maduración de sus frutos. El contenido de proteína varía entre 6 y 9,5\% y su digestibilidad entre 52 y $65 \%$.

- Piptochaetium napostaense: pasto perenne cespitoso con cañas comúnmente de 60 a 80 centímetros de alto. Sus hojas tienen forma de una vaina sin pelos, con una lígula membranosa de hasta 1 milímetro. Sus flores aparecen en formas de panoja laxa, de 10 a 24 centímetros. Su fruto es un cariopse cilíndrico, de 4 a 4,5 milímetros, castaño oscuro o casi negro. Es una especie invernal que florece a principios de octubre y sus semillas maduran hacia finales de noviembre. Es una especie forrajera de preferencia media. Su digestibilidad varía entre 53\% y $63 \%$ y el contenido de proteína entre 6,5\% a 10\%. Es más susceptible al pastoreo que la flechilla común, por lo que en campos sobrepastoreados tiende a desaparecer.

En cada uno de los sitios seleccionados se establecieron tres parcelas de 100 metros cuadrados cada una y distanciadas, unas de otras, al menos 75 metros. Las parcelas fueron construidas en alambre liso, de cuatro hilos, colocados a los 20, 40, 80 y 1,2 metros cada uno. En la parte inferior del alambrado se colocó una malla plástica protectora de 60 centímetros de alto para evitar el ingreso de animales silvestres que podrían ocasionar daños a los individuos plantados.

\subsubsection{1- Preparación de los individuos.}


Las semillas de las especies empleadas en este trabajo se sembraron en el invernadero de la Estación Experimental Agropecuaria de INTA Valle Inferior entre los meses de mayo y julio del año 2012.

Se aplicaron los tratamientos pregerminativos que mejor se ajustaron a cada especie de acuerdo al ensayo previamente realizado y se sembraron en bandejas plásticas de 60 centímetros de largo por 48 centímetros de ancho por 15 centímetros de profundidad. Estas bandejas contenían sustrato para el repique, constituido por partes iguales de arena y turba para facilitar el retiro de la plántula sin fracturar la raíz y para luego colocarla en un contenedor individual para que continúe su ciclo de crecimiento una vez que había emergido y mostrado sus primeras hojas verdaderas.

El contenedor individual donde se alojó el individuo contenía sustrato preparado con $50 \%$ de material extraído del sitio de plantación, $25 \%$ de lombricompuesto comercial y $25 \%$ de turba. La adición de estos dos materiales fue para evitar la fertilización durante la etapa de crecimiento y aportar nutrientes y estructura al sustrato del contenedor plástico.

Teniendo en cuenta las consideraciones de Cortina y Del Campo (2006) se efectuaron procesos de rustificación antes de llevar el material vegetal a campo. Éstos suponen una adaptación paulatina de los individuos a las condiciones ambientales naturales. Para ello, durante la primera semana del mes de diciembre del año 2012, fueron dispuestos todos los individuos de las especies leñosas y herbáceas al aire libre y sin ningún tipo de protección contra el viento o el sol. El suministro de riego se mantuvo constante durante los primeros quince días fuera del invernadero. Transcurrido ese período se redujo a tres veces por semana para los 15 días siguientes y, hasta el trasplante a campo, fueron regados una vez a la semana.

\subsubsection{2- Diseño experimental.}

Las especies leñosas fueron trasplantadas en el los meses de Abril y Mayo. Fueron dispuestas en hileras (Figura 4.1), a razón de dos hileras por cada especie, a excepción de Condalia microphylla, la cual se plantó en una sola hilera. Esto fue debido a la falta de ejemplares por la alta mortalidad de los individuos de esta especie en la fase de rustificación. Los individuos de cada especie poseían una separación aproximada de 2 metros con su ejemplar contiguo. Los hoyos de plantación fueron hechos con pala de 
punta, con un diámetro aproximado de 15 centímetros y una profundidad de 20 centímetros. El fondo del pozo fue acondicionado para eliminar la posible compactación. Se adicionaron $1200 \mathrm{~cm}^{3}$ de lombricompuesto comercial y se colocó el individuo con el pan de tierra extraído de la maceta. Se rellenó el espacio sobrante con tierra extraída al cavar el hoyo de plantación y se compactó manualmente. A efectos de mejorar la captación de la humedad, se dejó una cuenca que rodea al individuo, a un nivel inferior que el del resto de la parcela, para que capte y conserve la humedad natural. A todos los individuos se les asignaron dos riegos. El primero de ellos inmediatamente después de trasplantado y el siguiente transcurridos quince días. Cada uno de los riegos fue de $1500 \mathrm{~cm}^{3}$.

En los espacios entre individuos de la misma especie y de forma transversal a la dirección seguida en la disposición de los ejemplares de especies leñosas, se colocaron las especies herbáceas. Se trasplantaron en hileras de once individuos cada una, según se indica en la figura 4.1. Los hoyos de plantación fueron de 10 centímetros de profundidad por 12 centímetros de diámetro aproximadamente. El fondo del hoyo fue acondicionado para eliminar la compactación. Posteriormente se colocaron $400 \mathrm{~cm}^{3} \mathrm{de}$ lombricompuesto comercial en el hoyo de plantación y se colocó el individuo. Se cubrieron los espacios sobrantes con material extraído en la construcción del hoyo y se compactó manualmente, dejando una pequeña cuenca alrededor para mejorar la captación de humedad. Se suministraron dos riegos, uno al momento inmediato del trasplante y el siguiente quince días después. El volumen aportado en cada riego fue de $750 \mathrm{~cm}^{3}$.

En los meses de enero y febrero de la temporada estival 2013-2014, luego de un período de establecimiento de los individuos de las distintas especies, y transcurridos siete meses desde el momento de plantación, se efectuó el monitoreo para evaluar la supervivencia temprana. Posteriormente, en los meses de enero y febrero de la temporada de verano 2015- 2016, se efectuó un monitoreo para evaluar la supervivencia, luego de casi tres años de trasplantados los individuos. Se obtuvo información acerca de la supervivencia y del crecimiento (variación de la altura y del diámetro basal para las especies leñosas, y de la superficie proyectada por la mata en especies herbáceas). Para obtener los datos referidos al diámetro basal de los individuos de especies leñosas se empleó un calibre mecánico convencional. Para la obtención de 
la medida de la proyección de la cobertura de la mata de las especies herbáceas, como así también para obtener la altura de las especies leñosas, se usó metro plegable.

Además, se evaluó la recuperación de la cobertura en el interior de la parcela a partir del establecimiento espontáneo de diferentes especies. Para ello se instalaron tres transectas dentro de cada una de las parcelas ( 9 en cada sitio y 27 en total), de 10 metros de longitud y separadas unas de otras 2,5 metros. Utilizando el método de puntos de intercepción (Moreno 2001) se efectuó un toque cada $10 \mathrm{~cm}$ y se midió la proyección horizontal de la parte aérea del individuo que interceptaban la transecta. Además de registrar la presencia o ausencia de individuos espontáneos, se identificó su especie y se lo clasificó de acuerdo a su ciclo de vida y valor forrajero. Para la obtención de las medidas de cobertura de suelo se usó una cinta métrica.

Para la evaluación de la supervivencia y crecimiento de los ejemplares de las especies plantadas se emplearon modelos lineales generales de medidas repetidas con asunción de distribución binomial y normal de los datos, respectivamente. Como variable predictora fue utilizado el sitio y la especie. Además se estimaron las interacciones sitioespecie para evaluar la posible existencia de un comportamiento diferencial de las especies en los diferentes sitios. Los datos fueron analizados con el software Infostat versión 2014 (Di Rienzo et al. 2008).

Para el análisis estadístico de los datos de cobertura del suelo, cobertura de especies de ciclo de vida perenne y cobertura de especies de ciclo de vida perenne con valor forrajero se efectuó ANOVA no paramétrico. Se empleó el test de Kruskal- Wallis debido al incumplimiento de normalidad de los datos. El test de comparación de medias usado fue LSD de Fisher con un nivel de significancia inferior al 5\%. Los datos fueron analizados con el software Infostat versión 2014 (Di Rienzo et al. 2008). 


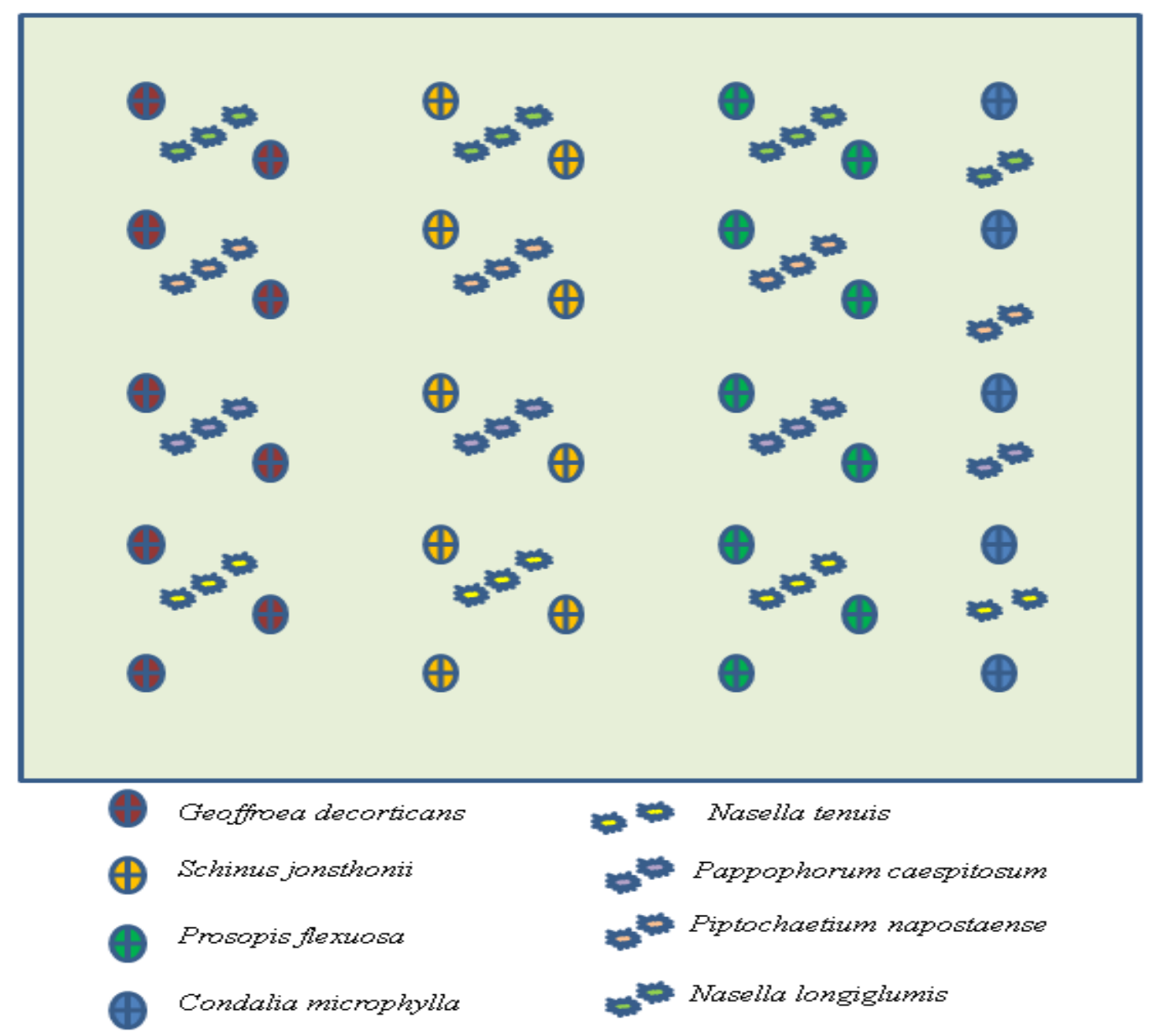

Figura 4.1. Diagrama del diseño experimental empleado en la reintroducción de especies nativas a campo en parcelas de $10 \times 10$ metros.

\subsubsection{3- Efecto de los individuos trasplantados sobre el reclutamiento}

Para evaluar si los individuos de las especies trasplantadas sobrevivientes actuaron como facilitadoras para el establecimiento de ejemplares de esa misma u otra especie, contabilizamos el número de ejemplares de diferentes especies establecidos en el área circundante al ejemplar plantado. Se empleó un marco de $50 \mathrm{~cm}$ por $50 \mathrm{~cm}$ y, dejando el individuo trasplantado al centro, se evaluó el número de plantas que colonizaron el área y la especie a la cual pertenecían. Se estimó la abundancia, entendida como el número total de ejemplares presentes en el área y la riqueza específica, como el número de especies de los individuos reclutados.

Para efectuar la comparación de medias y, debido a que los datos de abundancia no cumplían con los supuestos de normalidad estimados con el test de Shapiro- Wilks se 
llevó a cabo un ANOVA no paramétrico, empleando el test de Kruskal- Walis, con un nivel de significancia menor a $5 \%(p<0,05)$.

\subsection{4- Rehabilitación pasiva}

En todos los sitios en los que se realizaron ensayos de rehabilitación activa, se establecieron además clausuras de $100 \mathrm{~m}^{2}(10 \times 10 \mathrm{~m})$ con el objeto de evaluar la capacidad de estos ecosistemas de recuperar atributos tras un episodio de degradación intensa una vez eliminado el disturbio. Las clausuras fueron cercadas con alambre tejido romboidal para evitar el ingreso de ganado doméstico y animales silvestres. En ellas se establecieron tres transectas de 10 metros de longitud, distanciadas una de otra 2,5 metros y a 1,25 metros del borde de la parcela. Se empleó la metodología de los puntos de intercepción (Moreno 2001). Se realizó un toque cada 10 centímetros y se identificó la especie presente. Esta evaluación se efectuó en el período comprendido entre los meses de marzo del año 2012 y noviembre del año 2014, realizándose un monitoreo en cada una de las estaciones del año. Posteriormente, en la temporada estival del año 2015-16, se repitieron las medidas para evaluar el estado de esos ecosistemas transcurridos cuatro años de la clausura.

Para comparar entre las diferentes estaciones del año la cobertura de especies perennes, la variación de la riqueza específica y la cobertura de especies de ciclo de vida perenne con valor de uso forrajero se realizó un ANOVA no paramétrico y se empleó el test de comparación de medias LSD de Fisher con un valor de significancia inferior al 5\% ( $p$ $<0,05$ ). Se utilizó el software Infostat versión 2014 (Di Rienzo et al. 2008).

\subsection{5- Evaluación de los efectos de la rehabilitación}

Para evaluar el efecto que los tratamientos de rehabilitación activa y pasiva tuvieron sobre los sistemas naturales intervenidos, se efectuaron comparaciones entre las parcelas clausuradas en las que se introdujeron especies nativas, las que no recibieron ningún tratamiento y se observó la sucesión natural, y áreas no clausuradas (testigo) lindantes a los ensayos con clausuras, en las que no fue removido el agente de disturbio (pastoreo).

En el exterior de las parcelas donde fueron aplicados los diferentes tratamientos se instalaron tres transectas, de 10 metros de longitud, a modo de testigo o control, para 
evaluar la evolución de la cobertura vegetal cuando permanece el factor causante de disturbio. Se usó el método de los puntos de intercepción (Moreno 2001) y se efectuó un toque cada 10 centímetros, donde se registró la especie, se midió la proyección horizontal de la parte aérea del individuo que interceptaban la transecta y el ciclo de vida (anual o perenne) de la especie presente.

Se compararon las coberturas medias en los sitios con rehabilitación activa, rehabilitación pasiva y control. Se aplicó el test de Kruskal- Wallis, de ANOVA no paramétrico, debido a la falta de normalidad y homocedasticidad de los datos. Para analizar el nivel de significancia de las medias se empleó el test de comparación de medias LSD de Fisher con un valor de significancia estadística inferior a 5\% $(p<0,05)$. El software utilizado fue Infostat (Di Rienzo et al. 2008).

\subsection{6- Relación entre variables ambientales y los efectos de la rehabilitación}

Se realizó un análisis de componentes principales a fin de explorar el grado de relación entre variables ambientales y variables de la vegetación, relevadas en la evaluación del reclutamiento de nuevos individuos en las parcelas de rehabilitación activa y pasiva. Fueron tenidos en cuenta parámetros del clima (temperatura media y precipitación media), propiedades físicas y químicas de los suelos ( $\mathrm{Ce}^{-}, \mathrm{RAS}$, Calcáreo $\left(\% \mathrm{CaCO}^{3}\right)$, \%M.O., \%N.t., P(ppm), pH y densidad aparente del suelo $\left.\left(\mathrm{gr.cm}^{-3}\right)\right)$, y variables de la vegetación que se estableció en forma espontánea en los sitios seleccionados (cobertura de especies leñosas y herbáceas, riqueza total, riqueza de especies forrajeras, riqueza de especies perennes y abundancia de especies perennes). El software usado fue Infostat, versión 2014 (Di Rienzo et al. 2008).

\section{3- Resultados}

\subsection{1- Características de los sitios seleccionados}

Los sitios seleccionados fueron denominados por el nombre de los propietarios de la tierra. Dos de estos sitios están ubicados en el departamento Adolfo Alsina, provincia de Río Negro y el tercero en el partido de Patagones, en la provincia de Buenos Aires (Figura 4.2; Tabla 4.2). 


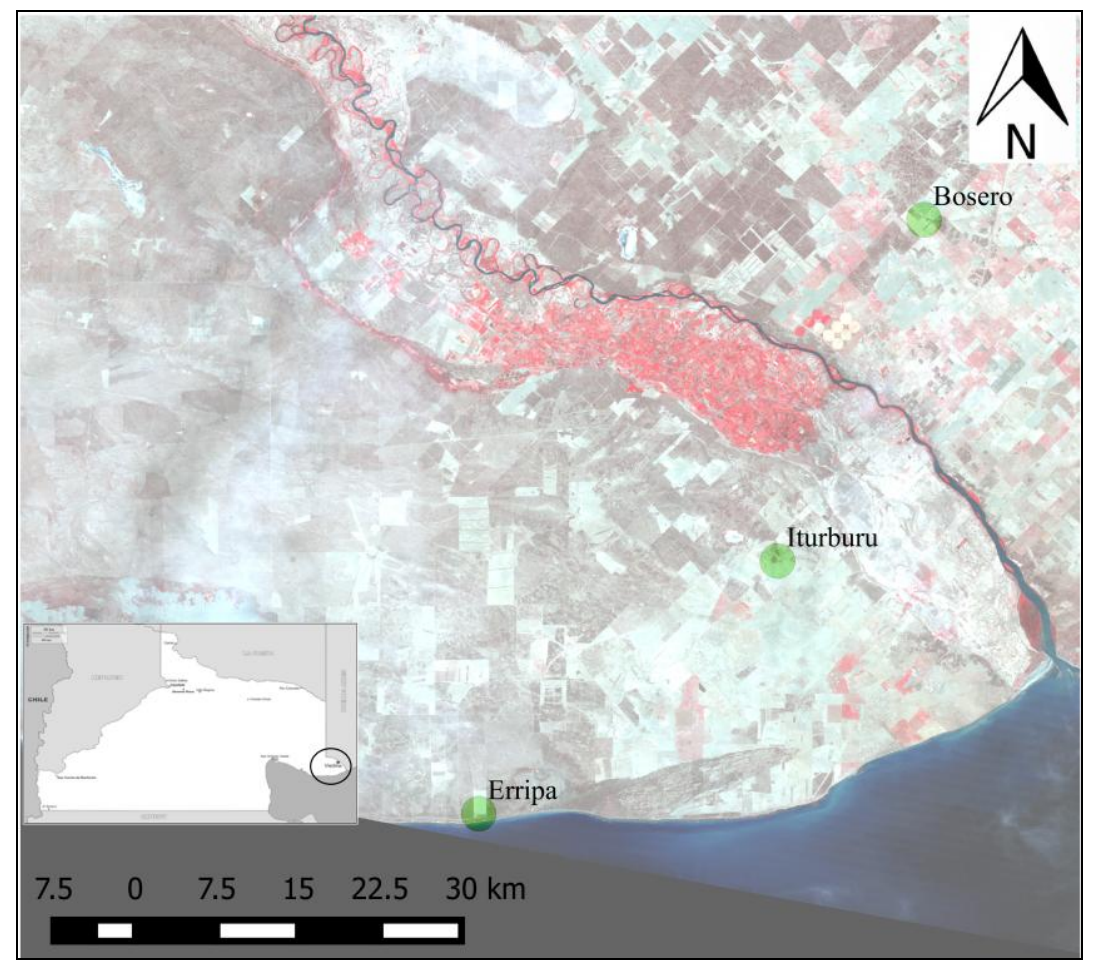

Figura 4.2. Sitios seleccionados.

Tabla 4.2. Coordenadas geográficas de los sitios de ensayo seleccionados.

\begin{tabular}{|l|c|c|}
\hline \multicolumn{1}{|c|}{ Sitio } & Latitud & Longitud \\
\hline Erripa & $41^{\circ} 9^{\prime} 11,86^{\prime \prime} \mathrm{S}$ & $63^{\circ} 25^{\prime} 19,01^{\prime \prime} \mathrm{O}$ \\
\hline Iturburu & $41^{\circ} 1^{\prime} 4,01 " \mathrm{~S}$ & $63^{\circ} 1^{\prime} 40,36^{\prime \prime} \mathrm{O}$ \\
\hline Bosero & $40^{\circ} 39^{\prime} 30,38^{\prime \prime} \mathrm{S}$ & $62^{\circ} 52^{\prime} 0,16^{\prime \prime} \mathrm{O}$ \\
\hline
\end{tabular}

En el año 1996, en el sitio Bosero, se eliminó la cobertura vegetal nativa para ser reemplazada por cultivos extensivos de secano (Bosero com. pers.). En este sitio la erosión eólica ha generado una importante pérdida de la capa superficial del suelo, teniendo al momento de la toma de muestras e instalación de ensayos una profundidad de 15 centímetros hasta el contacto lítico (capa potente y homogénea de $\mathrm{CaCO}_{3}$ ). Los suelos de este sitio son Calciortides típicos, con un contenido de materia orgánica y nitrógeno muy bajos (Tabla 4.3). La textura del suelo es franco arenosa. El sitio está situado en la región geomorfológica planicies interfluviales mesetiformes y se ubica en un plano alto dentro de un sector levemente ondulado (Godagnone y Bran 2009). Actualmente, en este sitio, no se desarrolla ninguna actividad productiva.

El sitio Erripa, situado en proximidades de la costa atlántica, se halla ubicado en la región geomorfológica de la planicie loéssica (Godagnone y Bran 2009). Presenta un 
suelo de textura arenosa, con valores de materia orgánica, nitrógeno y fósforo muy bajos (Tabla 4.3). Los suelos de este sitio son profundos, de escaso desarrollo y excesivamente drenados. La actividad productiva desarrollada fue la agricultura extensiva de secano. En el año 1994 se realizaron desmontes a tala rasa y, desde ese entonces hasta el advenimiento de la sequía en el año 2007, se cultivó trigo (Erripa com. pers.). Luego fue abandonado sin ningún tipo de manejo. Actualmente, se desarrollan prácticas de ganadería ovina extensiva con baja carga. En este sitio se observan tropillas de guanacos (Lama guanicoe) que constituyen otro factor de presión de pastoreo.

El sitio Iturburu está situado en la planicie loéssica, y se diferencia del sitio Erripa por la distancia al mar, que es de $12 \mathrm{~km}$. La actividad desarrollada es la ganadería extensiva de monte. Para favorecer el rebrote de los pastos y hierbas se realizaron prácticas de clareo del monte, quedando unos pocos ejemplares de especies leñosas muy dispersos. Con la sobrecarga animal se alcanzaron estados de degradación muy avanzados. Los suelos de este sitio son de textura arenosa franca, con valores de materia orgánica, nitrógeno y fósforo más elevados respecto de los otros sitios analizados (Tabla 4.3).

Tabla 4.3. Propiedades físicas y químicas del suelo de los sitios seleccionados. Ce: Conductividad eléctrica. RAS: Relación de adsorción de sodio. \%M.O.: Porcentaje de materia orgánica. \%Nt: Porcentaje de nitrógeno total. P (ppm): Concentración de fósforo. Dens. Ap.: Densidad aparente del suelo.

\begin{tabular}{|l|l|c|c|c|c|c|c|c|c|}
\hline \multicolumn{1}{|c|}{ Sitio } & \multicolumn{1}{|c|}{ Textura } & pH & CE & RAS & Cálcareo & \%MO & \%Nt & P ppm & $\begin{array}{l}\text { Densidad } \\
\text { Ap }\end{array}$ \\
\hline Erripa & Arenoso & 8,20 & 0,58 & 3,42 & 1,77 & 0,53 & 0,06 & 8,93 & 1,27 \\
\hline Iturburu & Arenoso Franco & 8,21 & 0,54 & 3,69 & 4,75 & 1,06 & 0,09 & 8,77 & 1,41 \\
\hline Bosero & Franco Arenoso & 7,86 & 1,78 & 13,86 & 1,67 & 0,30 & 0,03 & 2,31 & 0,43 \\
\hline
\end{tabular}

Además de las diferencias edáficas y fisiográficas fueron observadas diferencias en las precipitaciones ocurridas durante los años de estudios en los sitios evaluados. Las precipitaciones medias mensuales para el período 2013-2016 en los tres sitios de trabajo presentaron un comportamiento bimodal, con dos máximos, uno en el mes de abril y otro en el mes de septiembre en Bosero y en el mes de octubre en Erripa e Iturburu (Figura 4.3).

Las precipitaciones acumuladas en los sitios Bosero, Iturburu y Erripa fueron de $1329,24 \mathrm{~mm}, 1381,25 \mathrm{~mm}$ y $1365,93 \mathrm{~mm}$, respectivamente.

En el sitio Iturburu las precipitaciones acumuladas a lo largo del año fueron menores respecto de los sitios Bosero y Erripa. En los meses de otoño e invierno se observó un 
mayor registro pluviométrico en el sitio Bosero, seguido del sitio Erripa. En los meses de primavera y verano esta tendencia se ve modificada, registrándose mayores precipitaciones en el sitio Erripa, más cercano a la zona costera. (Figura 4.3).

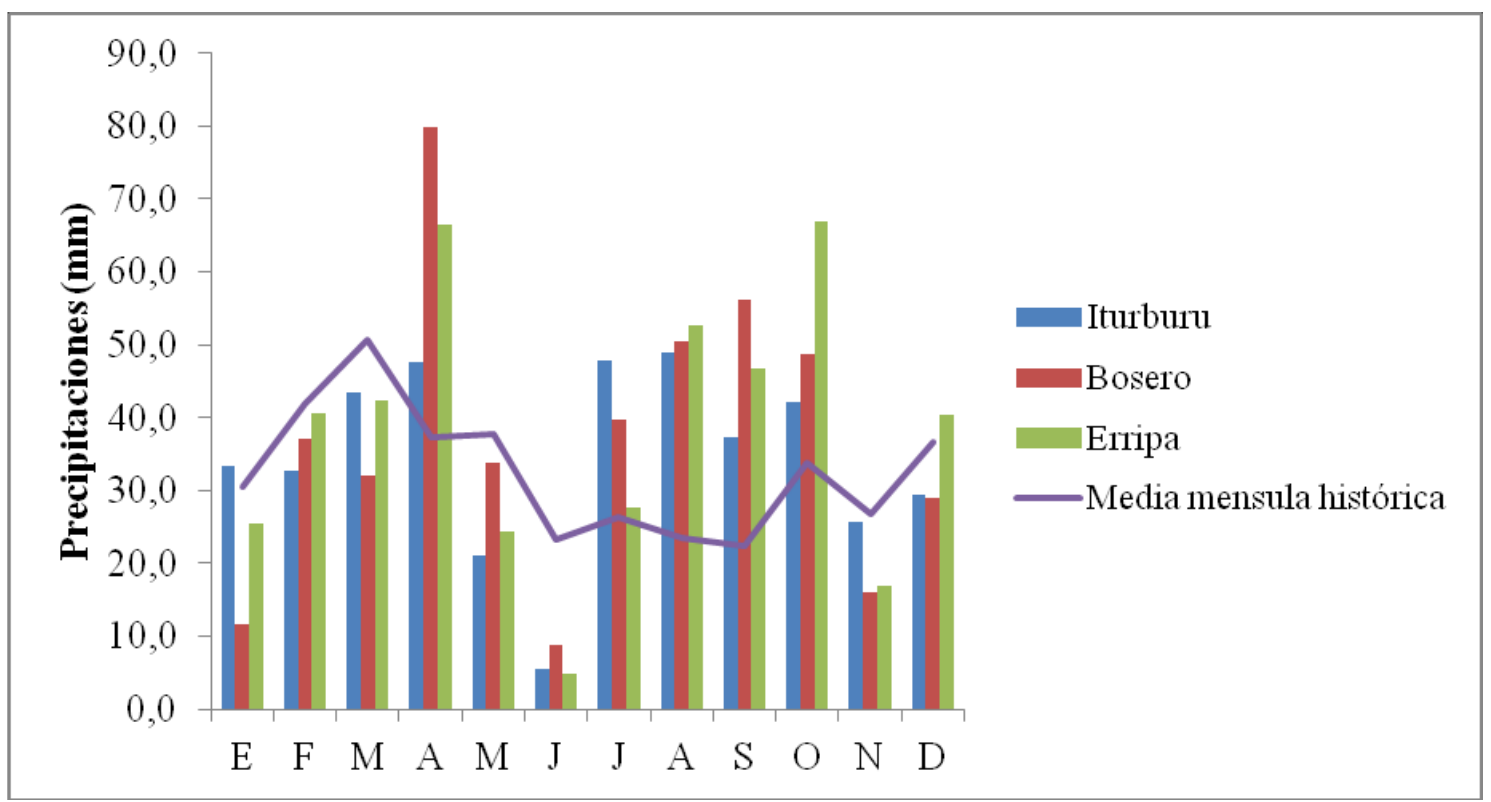

Figura 4.3. Precipitación media mensual por sitio para los años 2013-2016 (Fuente: https://giovanni.gsfc.nasa.gov) y media mensual histórica estimada en la EEA Valle Inferior para el período 1960-2004 (Fuente: De Berasategui 2004).

\subsection{2- Tratamientos pre germinativos.}

La especie Condalia microphylla mostró diferencias altamente significativas $(p<0,01)$ en los porcentajes de germinación entre los distintos tratamientos. Estos valores están por debajo de $33 \%$, siendo los tratamientos con ácido sulfúrico, ya sea con un tiempo de exposición de 32' o 64', los que mejor se ajustaron para esta especie. Las semillas tratadas con escarificación mecánica no mostraron respuesta y el grupo testigo arrojó un porcentaje de germinación muy bajo (Tabla 4.4).

Para la especie Geoffroea decorticans las diferencias entre medias fueron significativas $(p<0,05)$, siendo el tratamiento con ácido sulfúrico durante 32' el que mejores resultados arrojó, con 58 \% de germinación (Tabla 4.4).

Aunque Schinus johnstonii no mostró diferencias significativas $(p>0,05)$ entre los distintos tratamientos, se observó una tendencia en la que el grupo testigo fue el que mejor resultados mostró, seguido de la escarificación mecánica y por último los tratamientos con ácidos fuertes (Tabla 4.4). 
Las especies del género Prosopis mostraron una mejor respuesta a la exposición al ácido sulfúrico durante 32 minutos $(p<0,01)$, a excepción de $P$. denudans. Para esta especie el tratamiento que mejores resultados mostró fue el $\mathrm{H}_{2} \mathrm{SO}_{4}$ durante 64' alcanzando porcentajes de germinación de $43 \%$. P. flexuosa, tratado con $\mathrm{H}_{2} \mathrm{SO}_{4}$ durante 64' también mostró un elevado índice de germinación. La escarificación mecánica mostró respuesta solo en $P$. flexuosa y $P$. denudans, aunque con porcentajes inferiores al 10\% (Tabla 4.4).

Tabla 4.4. Porcentaje (\%) de germinación de especies nativas leñosas con semillas que poseen dormición física. Medias con una letra diferente indican diferencias significativas entre tratamientos $(p<0,05)$. Ac. 32 min= Inmersión en ácido sulfúrico durante 32 minutos. Ac. 64 min= Inmersión en ácido sulfúrico durante 64 minutos. Esc. Mec.= Escarificación mecánica.

\begin{tabular}{|c|c|c|c|c|c|c|c|c|c|c|c|c|c|c|}
\hline & \multicolumn{2}{|c|}{$\begin{array}{c}C . \\
\text { microphylla }\end{array}$} & \multicolumn{2}{|c|}{$\begin{array}{c}G . \\
\text { decorticans }\end{array}$} & \multicolumn{2}{|c|}{$\begin{array}{c}S . \\
\text { johnstonii }\end{array}$} & \multicolumn{2}{|c|}{ P. flexuosa } & \multicolumn{2}{|c|}{ P. alpataco } & \multicolumn{2}{|c|}{ P. caldenia } & \multicolumn{2}{|c|}{ P. denudans } \\
\hline & Media & D.E. & Media & D.E. & Media & D.E. & Media & D.E. & Media & D.E. & Media & D.E. & Media & D.E. \\
\hline Tratamiento & & & & & & & & & & & & & & \\
\hline Ac. $32 \mathrm{~min}$ & $33,3^{\mathrm{c}}$ & 11,37 & $58,3^{\mathrm{b}}$ & 17,56 & $25,33^{\mathrm{a}}$ & 8,33 & $94,33^{\mathrm{c}}$ & 1,53 & $80^{c}$ & 10 & $43,32^{\mathrm{c}}$ & 5,77 & $36,6^{\mathrm{b}}$ & 11,55 \\
\hline Ac. $64 \mathrm{~min}$ & $21,3^{b c}$ & 9,02 & $43,3^{\mathrm{ab}}$ & 7,64 & $25,33^{\mathrm{a}}$ & 20,5 & $91^{\mathrm{c}}$ & 4,36 & $40^{\mathrm{b}}$ & 10 & $30^{\mathrm{b}}$ & 0 & $43,3^{\mathrm{b}}$ & 5,77 \\
\hline Esc. Mec. & $0^{\mathrm{a}}$ & 0 & $25^{\mathrm{ab}}$ & 17,32 & $30,67^{\mathrm{a}}$ & 2,31 & $8,33^{\mathrm{b}}$ & 1,53 & $0^{\mathrm{a}}$ & 0 & $0^{\mathrm{a}}$ & 0 & $63,3^{\mathrm{c}}$ & 0,58 \\
\hline Testigo & $14^{\mathrm{ab}}$ & 2 & $18,33^{\mathrm{a}}$ & 14,43 & $34,67^{\mathrm{a}}$ & 6,11 & $1^{\mathrm{a}}$ & 1 & $0^{\mathrm{a}}$ & 0 & $0^{\mathrm{a}}$ & 0 & $0^{\mathrm{a}}$ & 0 \\
\hline$p$-valor & 0,0 & & 0,03 & & 0,7 & & $<0,00$ & 01 & $<0,0$ & & $<0,00$ & & $<0,0$ & 001 \\
\hline
\end{tabular}

Entre las especies leñosas que no poseen dormición física, Cyclolepis genistoides, con $43 \%$ de germinación, fue la única que mostró una respuesta más favorable y evidenció diferencias estadísticamente significativas con el resto. En general, el resto de las especies presentaron porcentajes de germinación fueron bajos, menores al $9 \%$ (Tabla 4.5).

Tabla 4.5. Porcentaje (\%) de germinación de especies nativas leñosas que requieren tratamientos pregerminativos. Medias con una letra diferente indican diferencias significativas entre tratamientos $(p<0,05)$.

\begin{tabular}{l|cc} 
Especie & Media & D.E. \\
\hline Baccaris ulicina & 1,33 a & 0,58 \\
Brachyclados lycioides & 2,67 a & 0,58 \\
Cyclolepis genistoides & $43,33 \mathrm{~b}$ & 12,58 \\
Grindelia chiloensis & 4,33 a & 2,08 \\
Prosopidastrum globosum & $4 \mathrm{a}$ & 1,73 \\
Senna aphylla & $8,33^{\mathrm{a}}$ & 2,89 \\
Seneciofilaginoides & $13^{\mathrm{a}}$ & 2 \\
\hline p-valor & $<0,0001$ &
\end{tabular}


La estratificación fría no mostró respuesta de las semillas de las diferentes especies, que presentaron tasas de germinación similares a las del testigo.

Las especies pertenecientes al género Nassella fueron las que presentaron porcentajes de germinación más altos respecto del resto de las gramíneas. Por su parte, Jarava plumosa, especie que se encuentra ampliamente difundida en la región, también evidenció porcentajes de germinación elevados respecto de las demás especies observadas. Poa ligularis, especie muy apreciada por el valor forrajero que posee, no respondió a las condiciones de humedad y temperatura a la que fue expuesta y su germinación fue nula (Tabla 4.6).

Tabla 4.6. Porcentaje (\%) de germinación de especies nativas herbáceas. Medias con una letra diferente indican diferencias significativas entre tratamientos $(p<0,05)$.

\begin{tabular}{l|cc}
\multicolumn{1}{c|}{ Especie } & Media & D.E. \\
\hline Nassella longiglumis & $78,33 \mathrm{de}$ & 10,41 \\
Nassella tenuis & $91,67 \mathrm{e}$ & 2,89 \\
Pappophorum caespitosum & $46,67 \mathrm{c}$ & 2,89 \\
Jarava plumosa & $75 \mathrm{~d}$ & 13,23 \\
Poa ligularis & $0 \mathrm{a}$ & 0 \\
Piptochaetium napostaense & $30 \mathrm{~b}$ & 8,66 \\
\hline p-valor & $<0,0001$
\end{tabular}

\subsection{3- Rehabilitación activa}

4.3.3.1-Supervivencia de especies leñosas.

- Supervivencia temprana de especies leñosas.

Luego de transcurrido el período de establecimiento y el comienzo de la etapa de crecimiento, el cual fue de siete meses, las especies leñosas trasplantadas mostraron elevados niveles de supervivencia, los cuales fueron cercanos al $100 \%$, a excepción de C. microphylla. Esta fue la especie que menores porcentajes de supervivencia presentó ( $p<0,01)$, respecto de P. flexuosa, G. decorticans y S. johnstonii (Figura 4.4). 


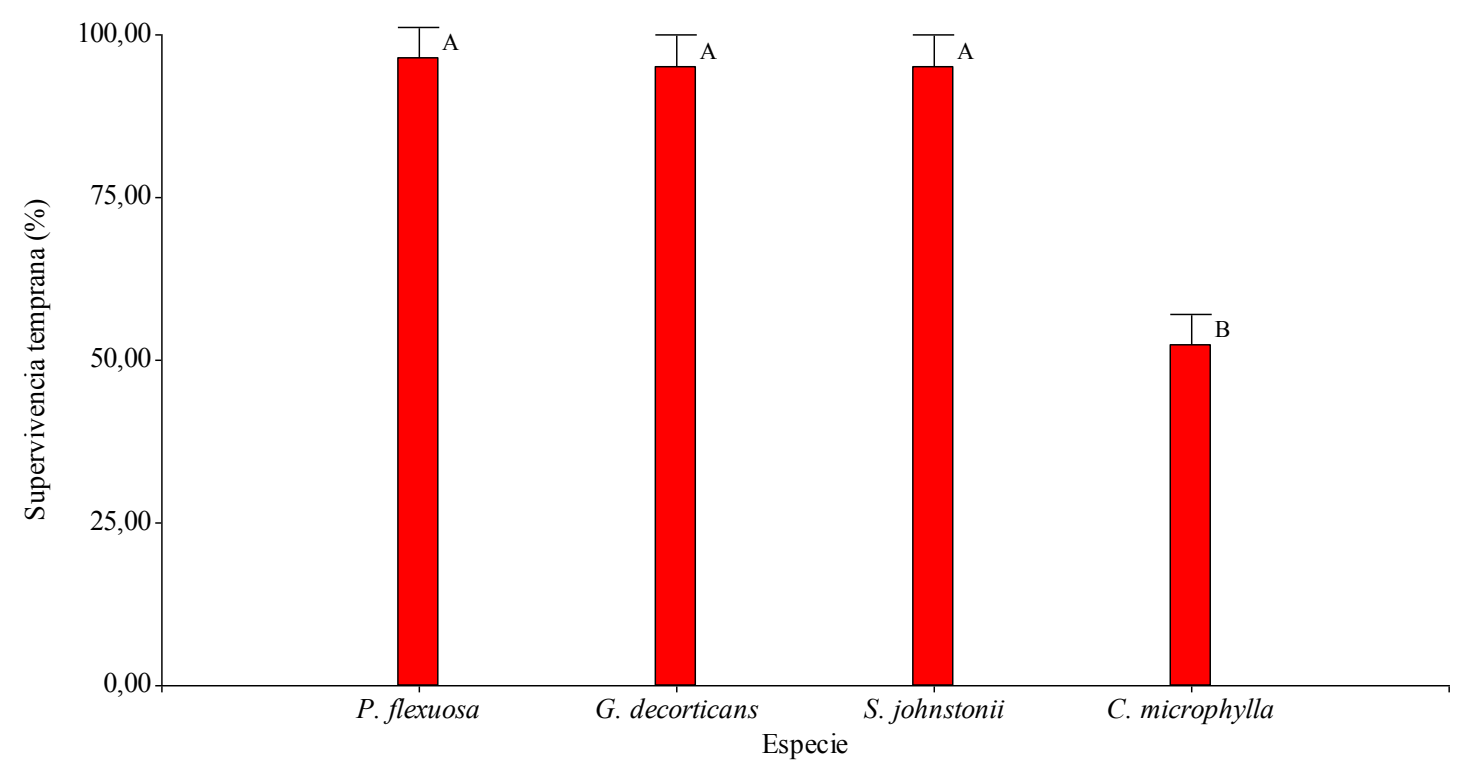

Figura 4.4. Supervivencia temprana de especies leñosas registrada en enero de 2013 ( 7 meses desde su plantación a campo). Medias con una letra diferente indican diferencias significativas entre $\%$ de supervivencia para cada especie $(p<0,05)$

La interacción especie* sitio fue altamente significativa $(p=0,0090)$ en el porcentaje de supervivencia. La especie C. microphylla, presentó elevados niveles de supervivencia en el sitio Erripa, y porcentajes significativamente inferiores en los sitios Bosero e Iturburu. Las especies $G$. decorticans, P. flexuosa y $S$. johnstonii no presentan diferencias significativas en los porcentajes de supervivencia entre sitios (Figura 4.5).

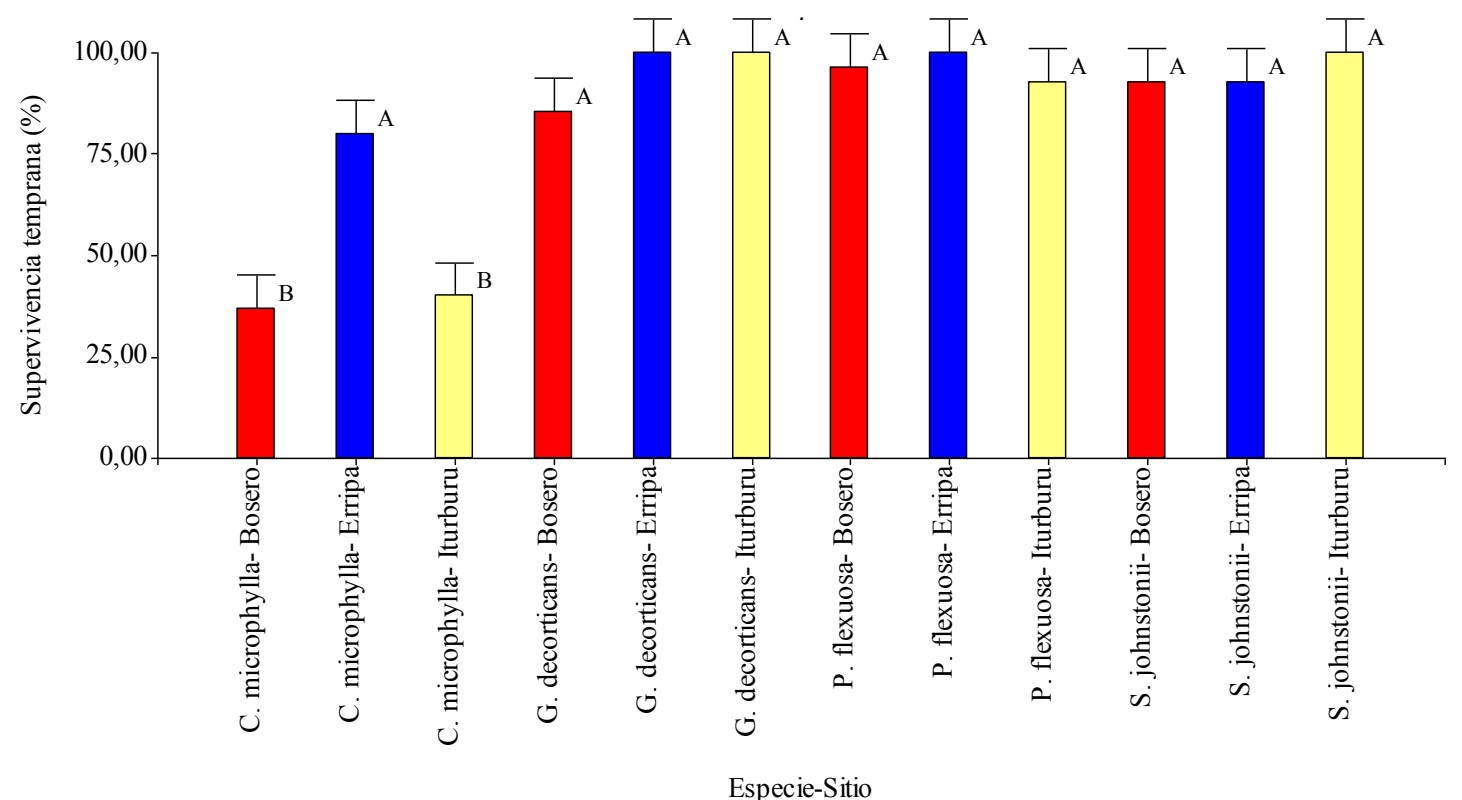

Figura 4.5. Supervivencia temprana de especies leñosas en los sitios Bosero, Erripa e Iturburu registrada en enero de 2013 (7 meses desde su plantación a campo). Medias con una letra diferente indican diferencias significativas entre sitios $(p<0,05)$. 
- Supervivencia tardía de especies leñosas.

La supervivencia de las especies leñosas, transcurridos casi tres años desde el trasplante, registra en la temporada estival de los años 2015-2016 valores inferiores a los observados en los años 2013-2014. Las supervivencia mostró diferencias altamente significativas $(p=0,0003)$ entre las diferentes especies. C. microphylla y G. decorticans presentaron las menores supervivencias, las cuales fueron inferiores al 30\% (Figura 4.6).

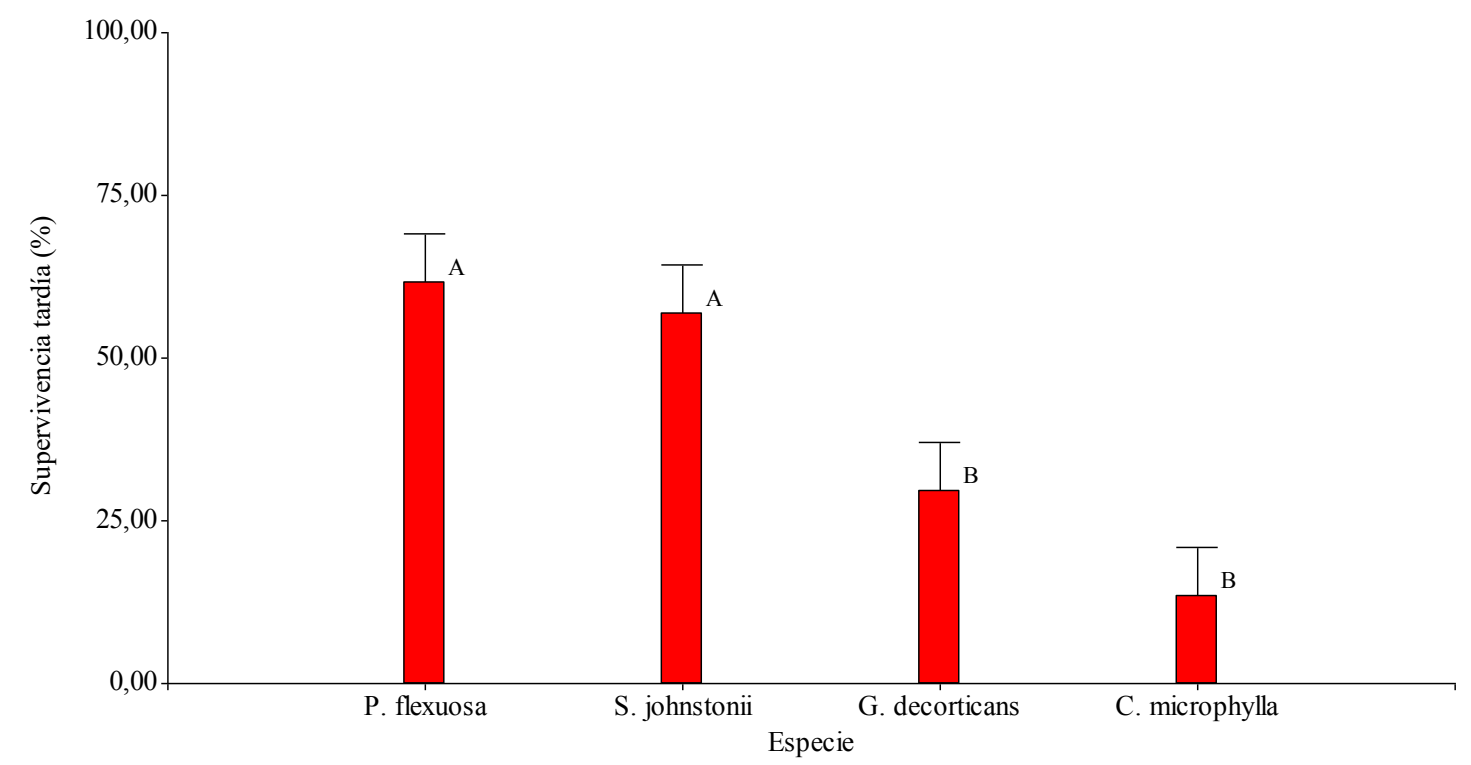

Figura 4.6. Supervivencia tardía de especies leñosas registrada en enero de 2016 (31 meses desde su plantación a campo). Medias con una letra diferente indican diferencias significativas entre $\%$ de supervivencia para cada especie $(p<0,05)$.

La interacción especie*sitio no fue significativas $(p=0,1862)$. Pese a ello se observaron algunas tendencias. P. flexuosa presentó porcentajes de supervivencia cercanos al 55\% en los sitios Bosero y Erripa, mientras que en el sitio Iturburu alcanzó valores próximos al $83 \%$. S. johnstonii, en los sitios Bosero y Erripa, presentó valores inferiores al 50\% de supervivencia, mientras que en Iturburu el porcentaje de supervivencia fue del $90 \%$ (Figura 4.7). 


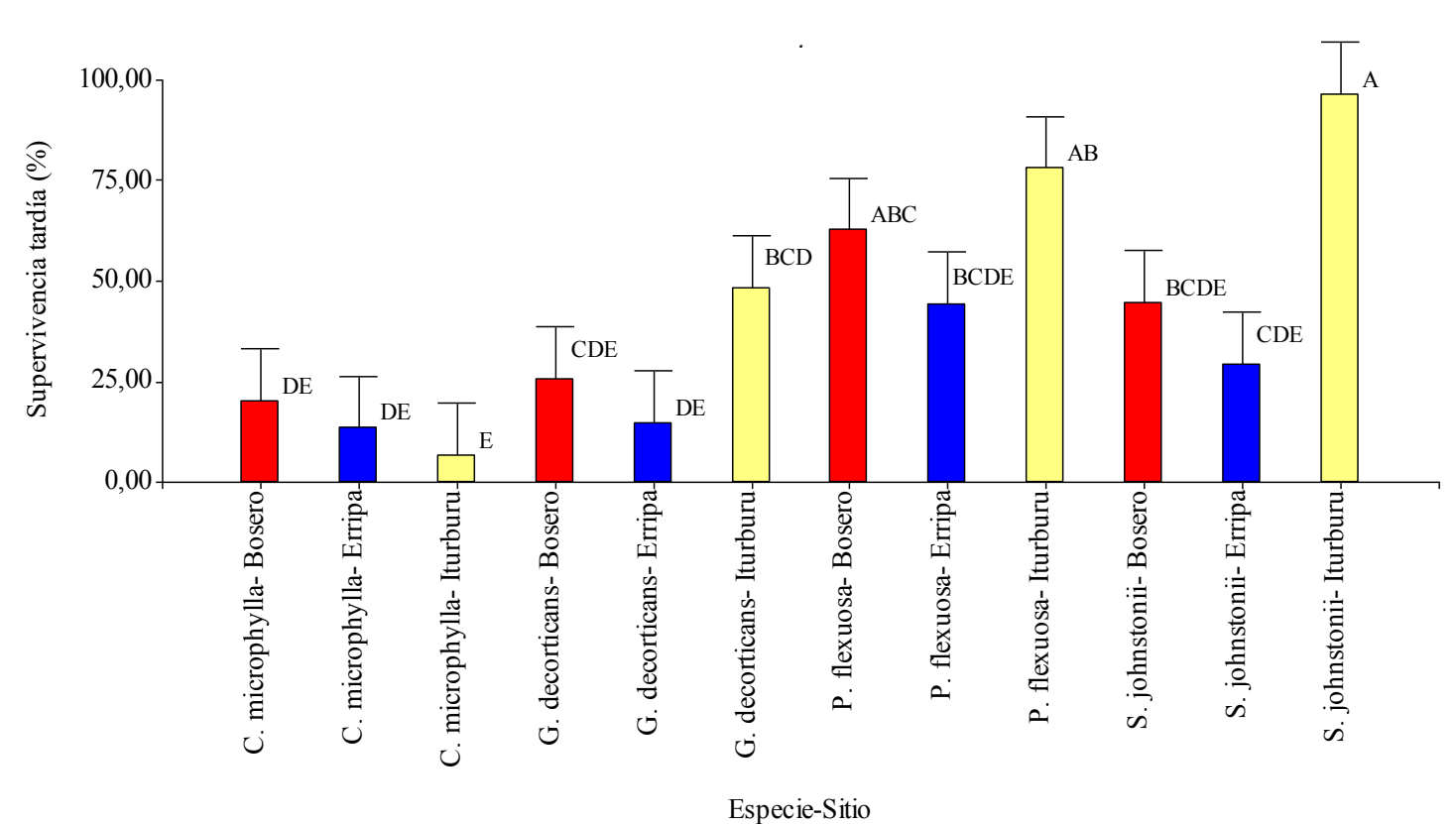

Figura 4.7. Supervivencia tardía de especies leñosas en los sitios Bosero, Erripa e Iturburu registrada en enero de 2016 (31 meses desde su plantación a campo). Medias con una letra diferente indican diferencias significativas entre sitios $(p<0,05)$

- Incremento de la altura y el diámetro del cuello de especies leñosas.

La altura media alcanzada por las especies leñosas varió entre 25,5 cm (C. microphylla) y $38,54 \mathrm{~cm}$ (S. johnstonii).

El incremento de altura de las especies leñosas en el período analizado presentó diferencias significativas entre especies $(p=0,0002)$. P. flexuosa y S. johnstonii presentaron los mayores incrementos de altura, los cuales fueron de 9,76 cm y 9,58 cm, respectivamente. $G$. decorticans, con un incremento en altura de $5,99 \mathrm{~cm}$, se diferenció de las especies P. flexuosa y C. microphylla, siendo esta última especie la que menores incrementos de altura presentó, con 1,04 cm en todo el período (Figura 4.8). 


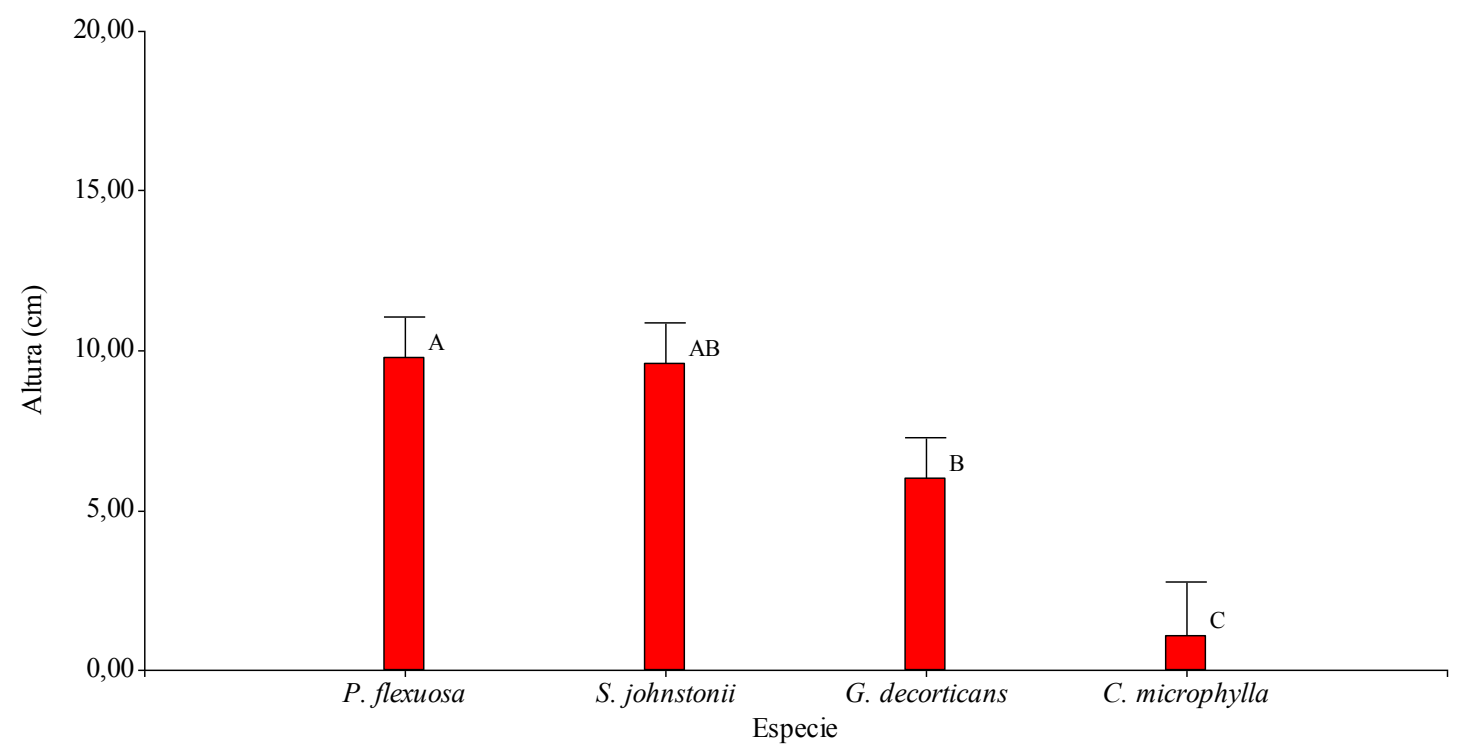

Figura 4.8.Incremento de la altura $(\mathrm{cm})$ de especies leñosas entre los años 2013 y 2016. Medias con una letra diferente indican diferencias significativas $(p<0,05)$.

La interacción entre sitio y especie fue significativa $(p=0,0471)$. $G$. decorticans presentó mayores incrementos en altura en el sitio Iturburu que en los sitios Bosero y Erripa, entre los cuales no evidenció diferencias en el crecimiento en altura. $C$. microphylla mostró los menores valores de crecimiento sin evidenciar diferencias significativas entre sitios. P. flexuosa no presentó diferencias significativas entre sitios. S. johnstonii presentó diferencias estadísticamente significativas entre sitios, destacándose el incremento de la altura de los individuos de esta especie en el sitio Iturburu (Figura 4.9).

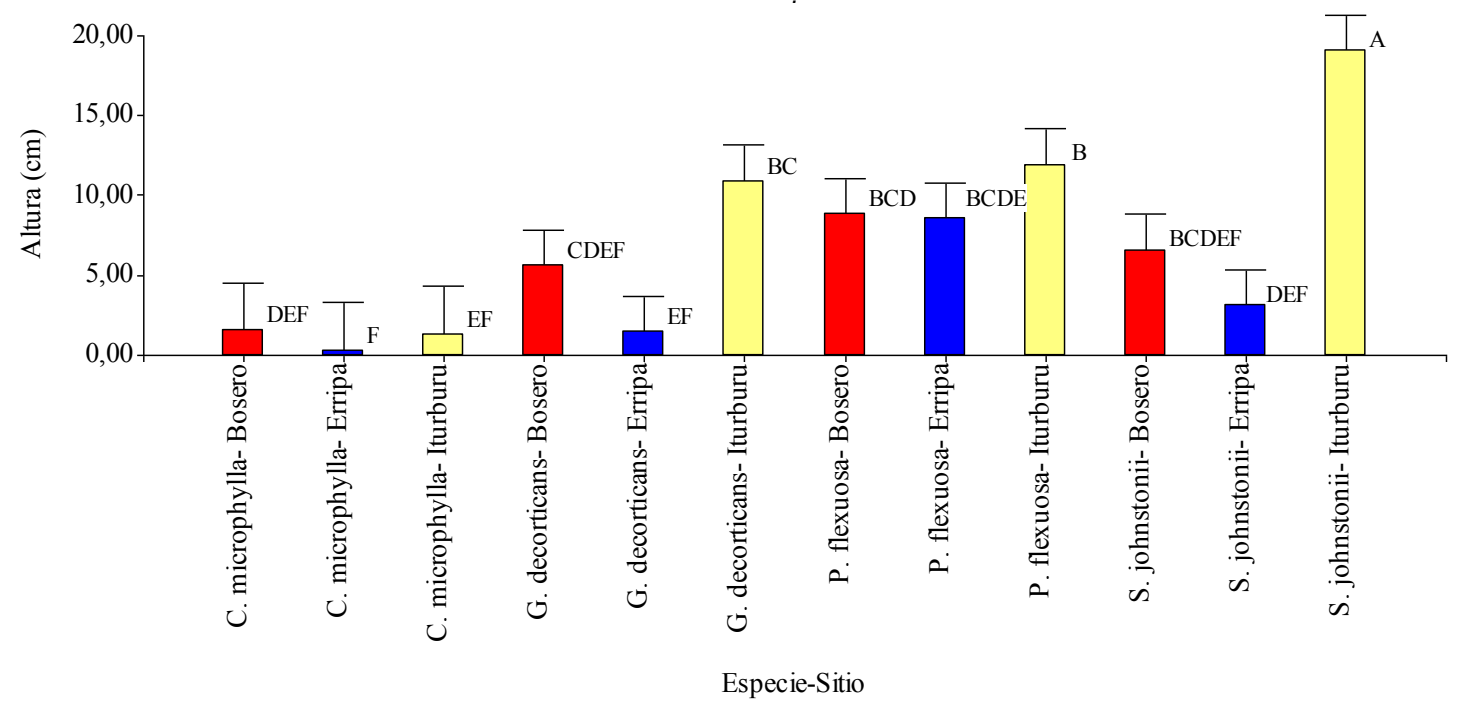

Figura 4.9. Incremento de la altura (cm) de las especies leñosas en los sitios Bosero, Erripa e Iturburu entre los 2013 y 2016. Medias con una letra diferente indican diferencias significativas $(p<0,05)$ 
El diámetro del cuello varió entre $0,47 \mathrm{~cm}(G$. decorticans) y $0,96 \mathrm{~cm}(S$. johnstonii $)$.

El incremento del diámetro del cuello de los individuos o diámetro basal, presentó diferencias altamente significativas entre especies $(p<0,001)$. S. johnstonii y P. flexuosa fueron las especies que mayor incremento del diámetro del tallo mostraron, sin presentar diferencias significativas entre ellas (Figura 4.10).

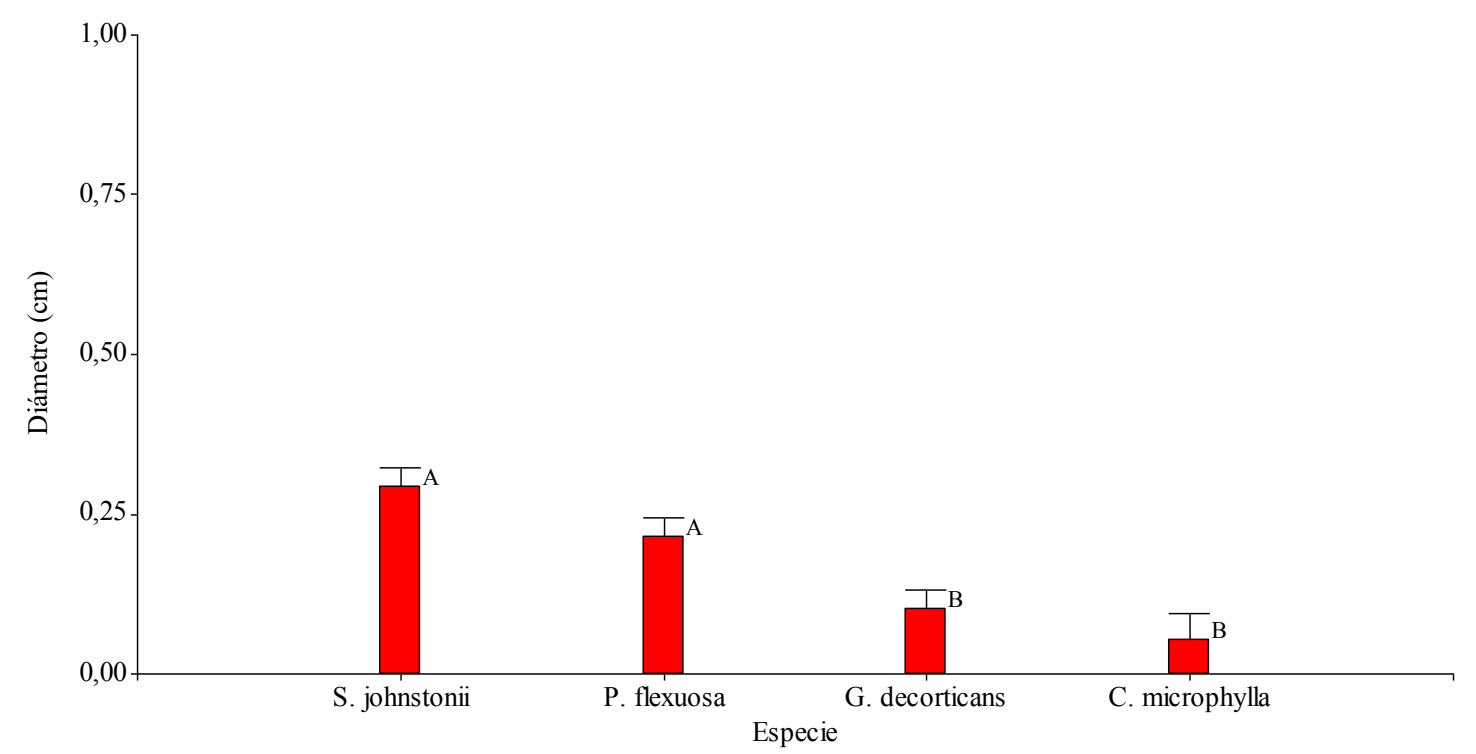

Figura 4.10. Incremento del diámetro basal $(\mathrm{cm})$ de las especies leñosas entre los años 2013 y 2016. Medias con una letra diferente indican diferencias significativas $(p<0,05)$.

La interacción entre especie y sitio fue altamente significativa $(p<0,0001)$. S. johnstonii presentó valores elevados de incremento del diámetro basal en el sitio Iturburu. Las especies C. microphylla, G. decorticans y P. flexuosa no presentaron diferencias significativas entre sitios (Figura 4.11).

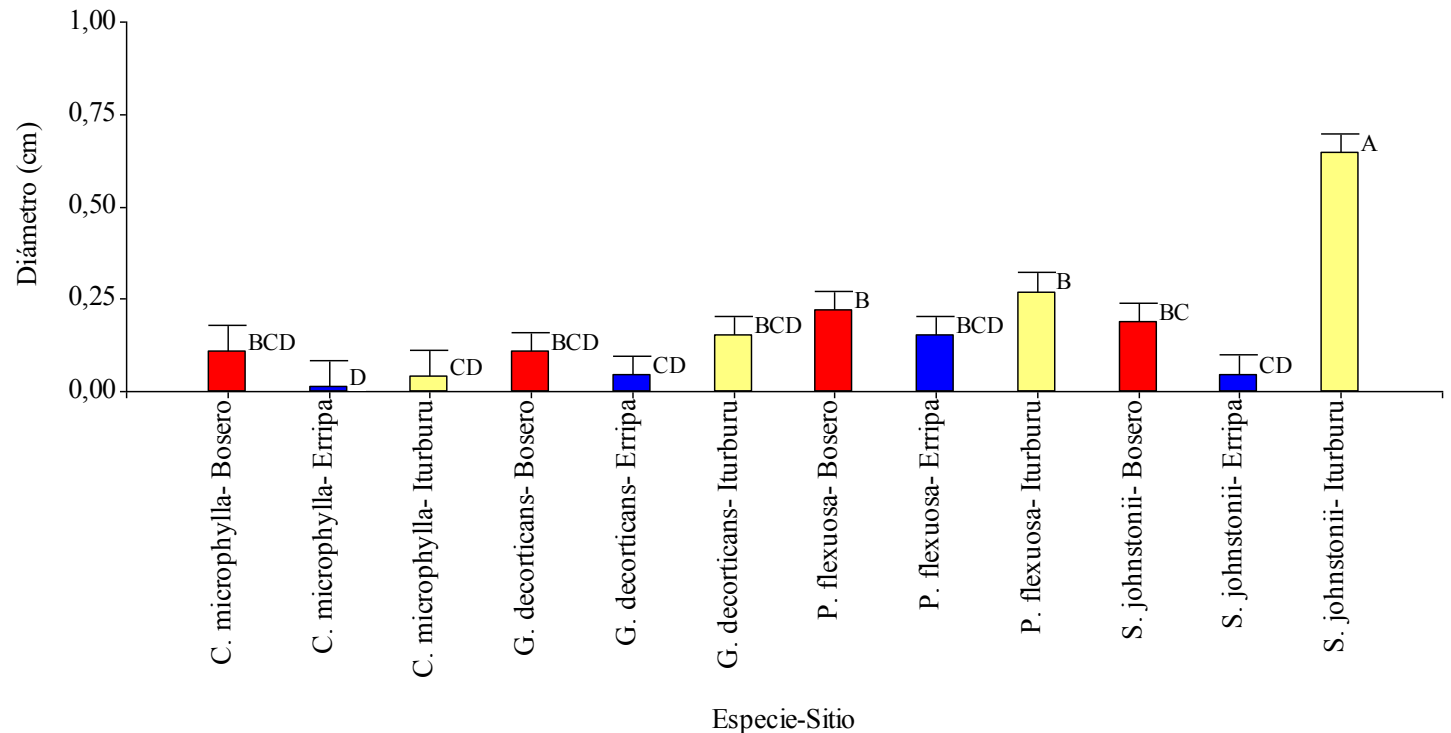

Figura 4.11. Incremento del diámetro del cuello $(\mathrm{cm})$ de las especies leñosas en los sitios Bosero, Erripa e Iturburu entre los años 2013 y 2016. Medias con una letra diferente indican diferencias significativas $(p<0,05)$. 
- 4.3.3.2- Supervivencia de gramíneas

- Supervivencia temprana de gramíneas.

La supervivencia temprana de las gramíneas mostró diferencias significativas entre especies $(p<0,05)$. N. longiglumis y $P$. napostaense fueron las especies que presentaron mayor porcentaje de supervivencia, alcanzando $100 \%$ y $95 \%$ respectivamente. $N$. tenuis y $P$. caespitosum presentaron porcentajes de supervivencia temprana inferiores respecto de las especies anteriores, aunque estas también fueron elevadas, $89 \%$ y $85 \%$, respectivamente (Figura 4.12).

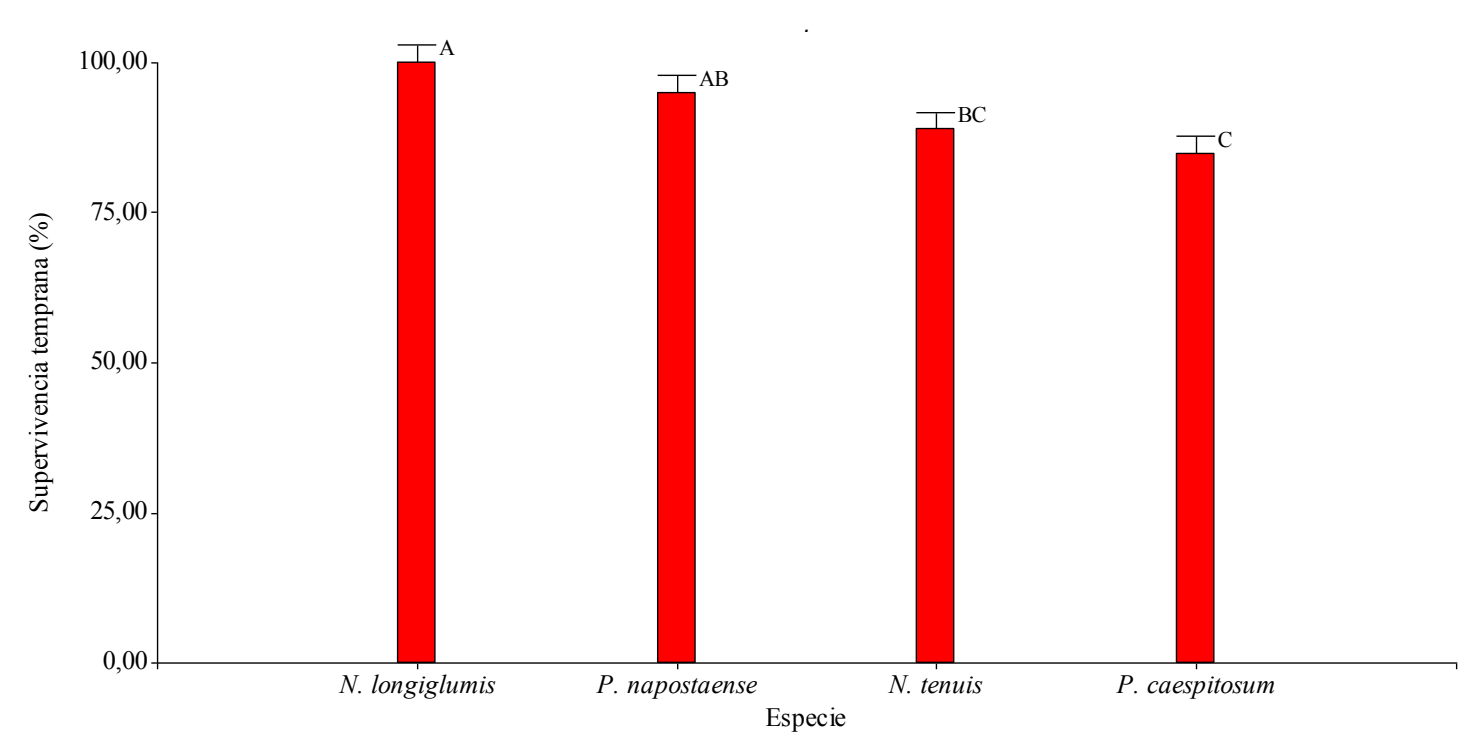

Figura 4.12. Supervivencia temprana de especies herbáceas registrada en enero de 2013 (7 meses desde su plantación a campo). Medias con una letra diferente indican diferencias significativas entre $\%$ de supervivencia para cada especie $(p<0,05)$.

La interacción especie*sitio no presentó diferencias significativa $(p=0,8684)$ en la supervivencia de las distintas especies (Figura 4.13). 


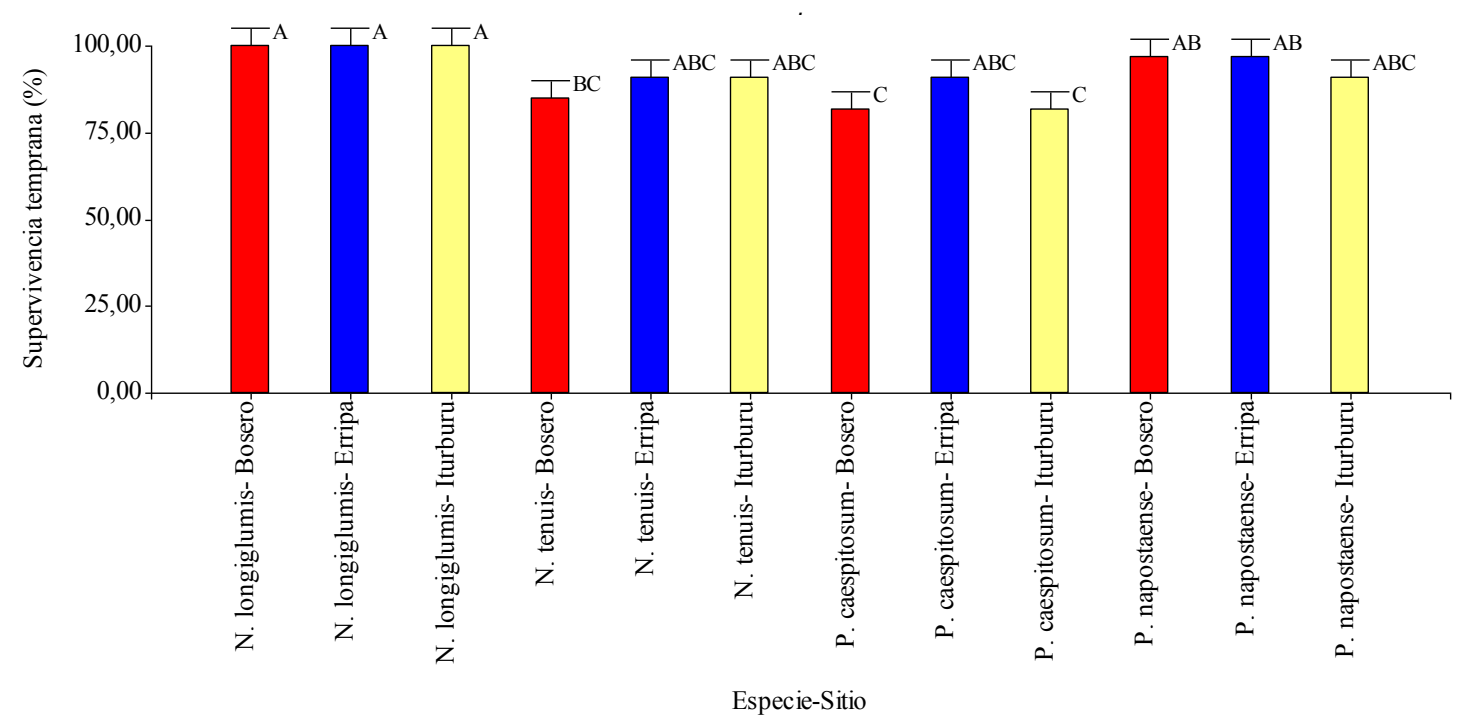

Figura 4.13. Supervivencia temprana de especies herbáceas en los sitios Bosero, Erripa e Iturburu registrada en enero de 2013 (7 meses desde su plantación a campo). Medias con una letra diferente indican diferencias significativas $(p<0,05)$

- Supervivencia tardía de gramíneas.

Los ejemplares de gramíneas, al cabo de tres años de trasplantadas, no se diferenciaron significativamente en los porcentajes de supervivencia, con valores próximos al 50\% (Figura 4.14).

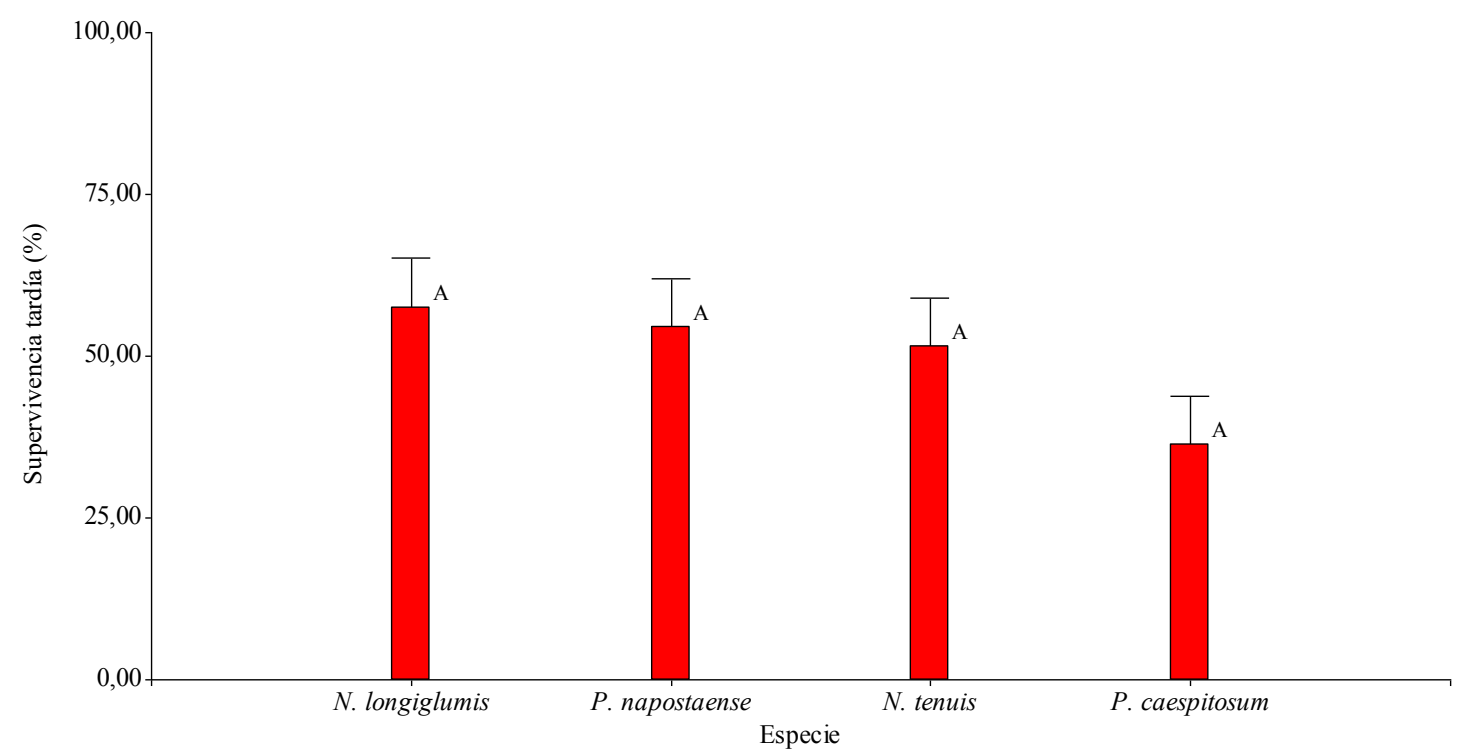

Figura 4.14. Supervivencia tardía de especies herbáceas registrada en enero de 2016 (31 meses desde su plantación a campo). Medias con una letra diferente indican diferencias significativas entre $\%$ de supervivencia para cada especie $(p<0,05)$.

La interacción especie* sitio no fue significativa ( $p=0,2892$, Figura 4.15). 


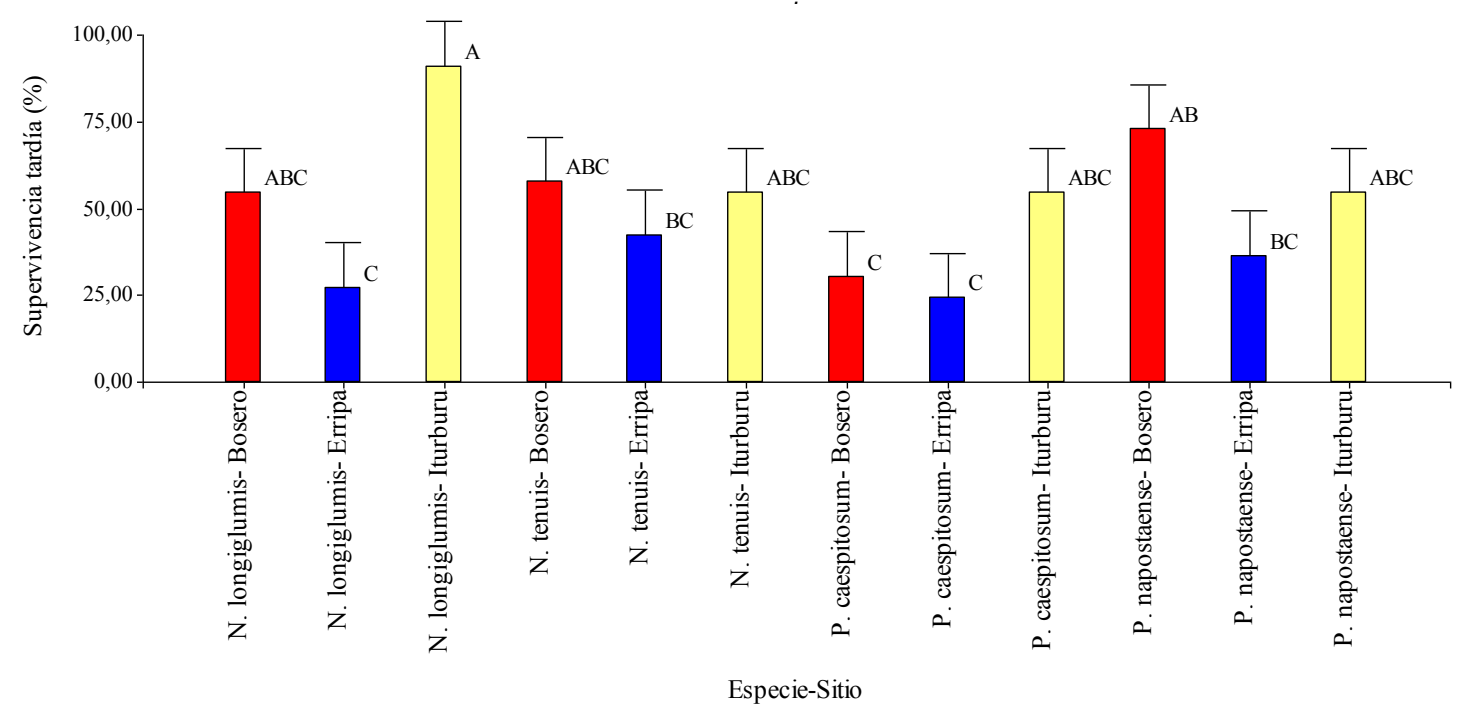

Figura 4.15. Supervivencia tardía de especies herbáceas en las especies Bosero, Erripa e Iturburu registrada en enero de 2016 (31 meses desde su plantación a campo). Medias con una letra diferente indican diferencias significativas $(p<0,05)$.

- Incremento de la altura y el diámetro de las gramíneas.

La altura de las especies de gramíneas varió entre los 40 y los $50 \mathrm{~cm}$, dependiendo del porte de cada especie.

El incremento de la altura de las matas presentó diferencias altamente significativas entre especies $(p=0,0001)$. El mayor incremento lo mostró $P$. napostaense $(8,19 \mathrm{~cm})$, que se diferenció de $N$. tenuis y $P$. caespitosum $(5,63$ y 4,61 cm, respectivamente). El menor incremento fue hallado en $N$. longiglumis con 3,29 $\mathrm{cm}$ de incremento de la altura (Figura 4.16).

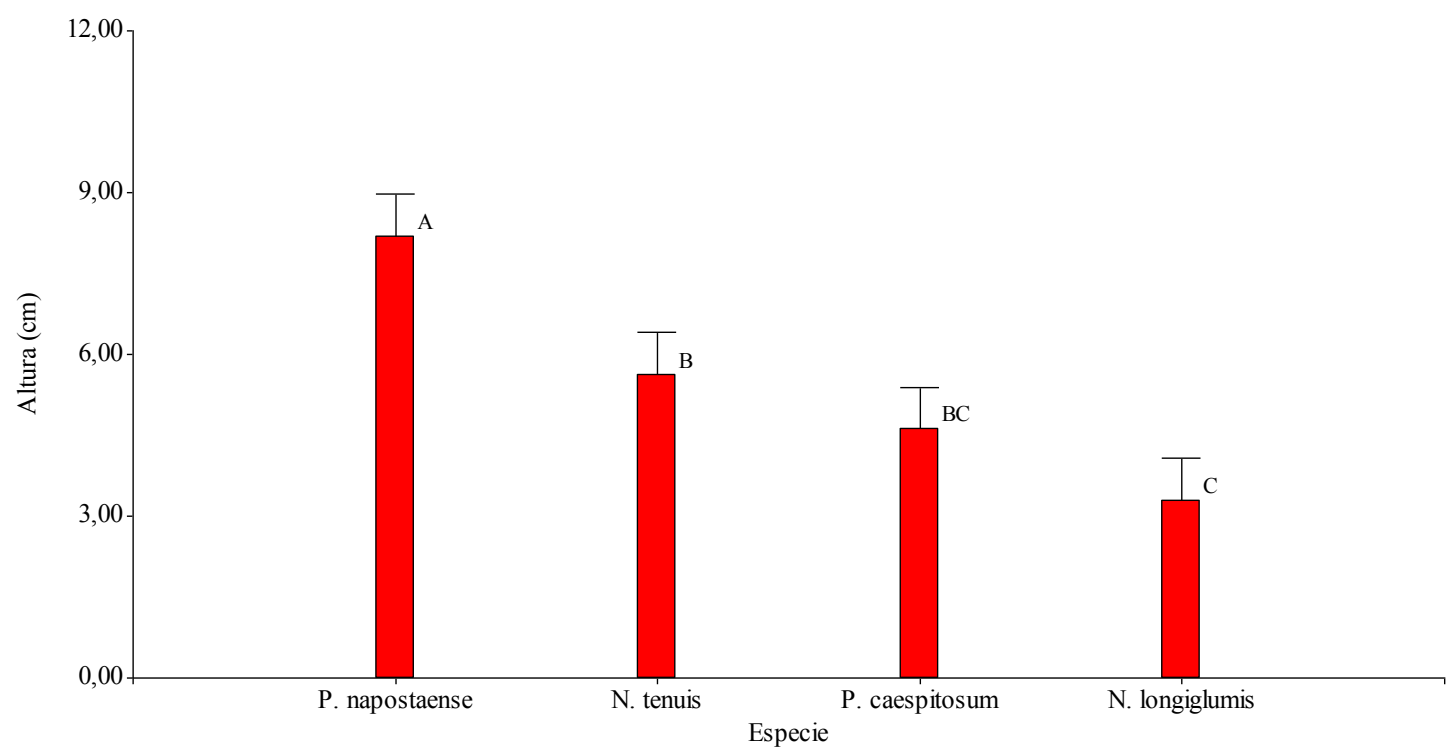

Figura 4.16. Incremento de la altura $(\mathrm{cm})$ de las especies herbáceas entre los años 2013 y 2016. Medias con una letra diferente indican diferencias significativas $(p<0,05)$ 
La interacción entre especie y sitio no presentó diferencias significativas $(p=0,2206)$ (Figura 4.17).

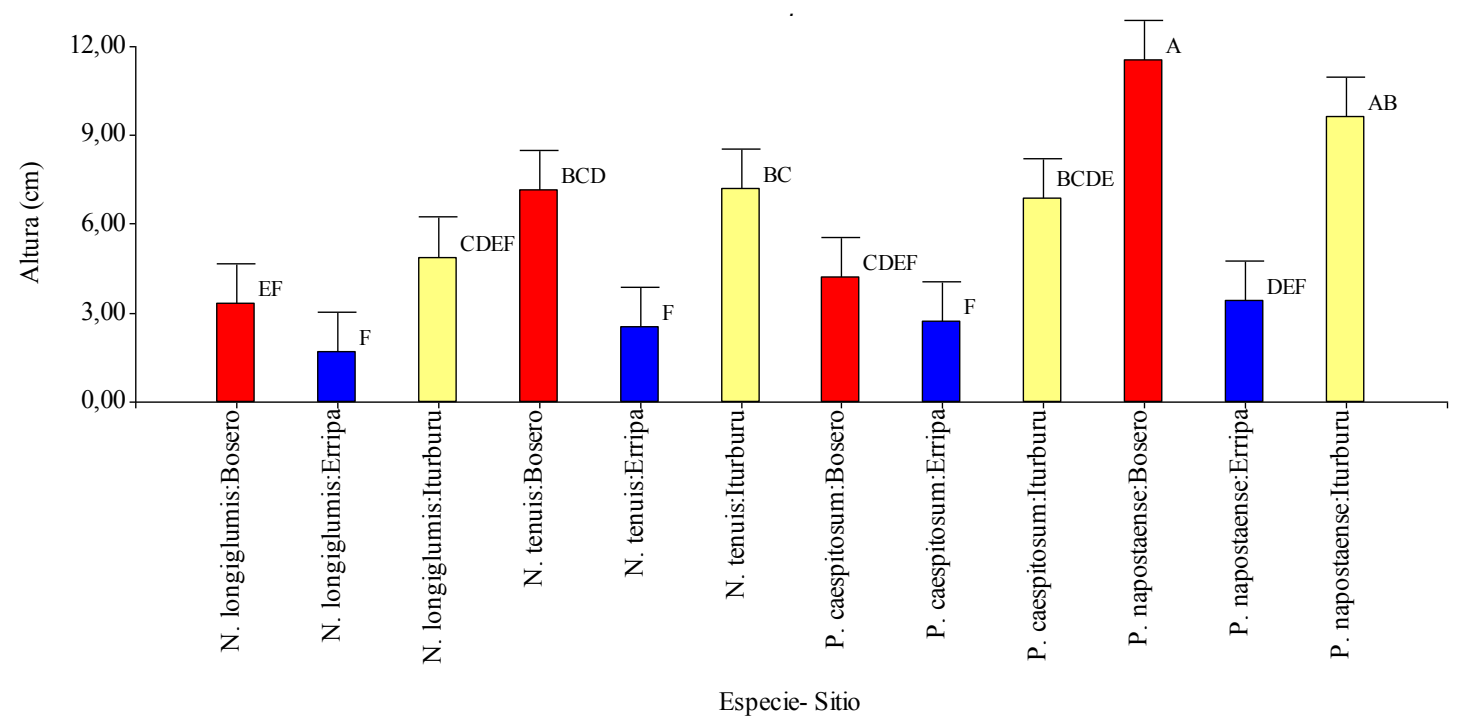

Figura 4.17. Incremento de la altura de las especies herbáceas en los sitios Bosero, Erripa e Iturburu entre los años 2013 y 2016. Medias con una letra diferente indican diferencias significativas $(p<0,05)$.

La superficie de las matas presentó valores entre $0,16 \mathrm{~cm}^{2}$ y $1,30 \mathrm{~cm}^{2}$. Al analizar los valores medios de los incrementos de la superficie de la mata de las gramíneas no se observaron diferencias significativas entre las distintas especies $(p=0,2315)$ (Figura 4.18) y la interacción especies*sitio fue no significativa $(p=0,2445)$ (Figura 4.19).

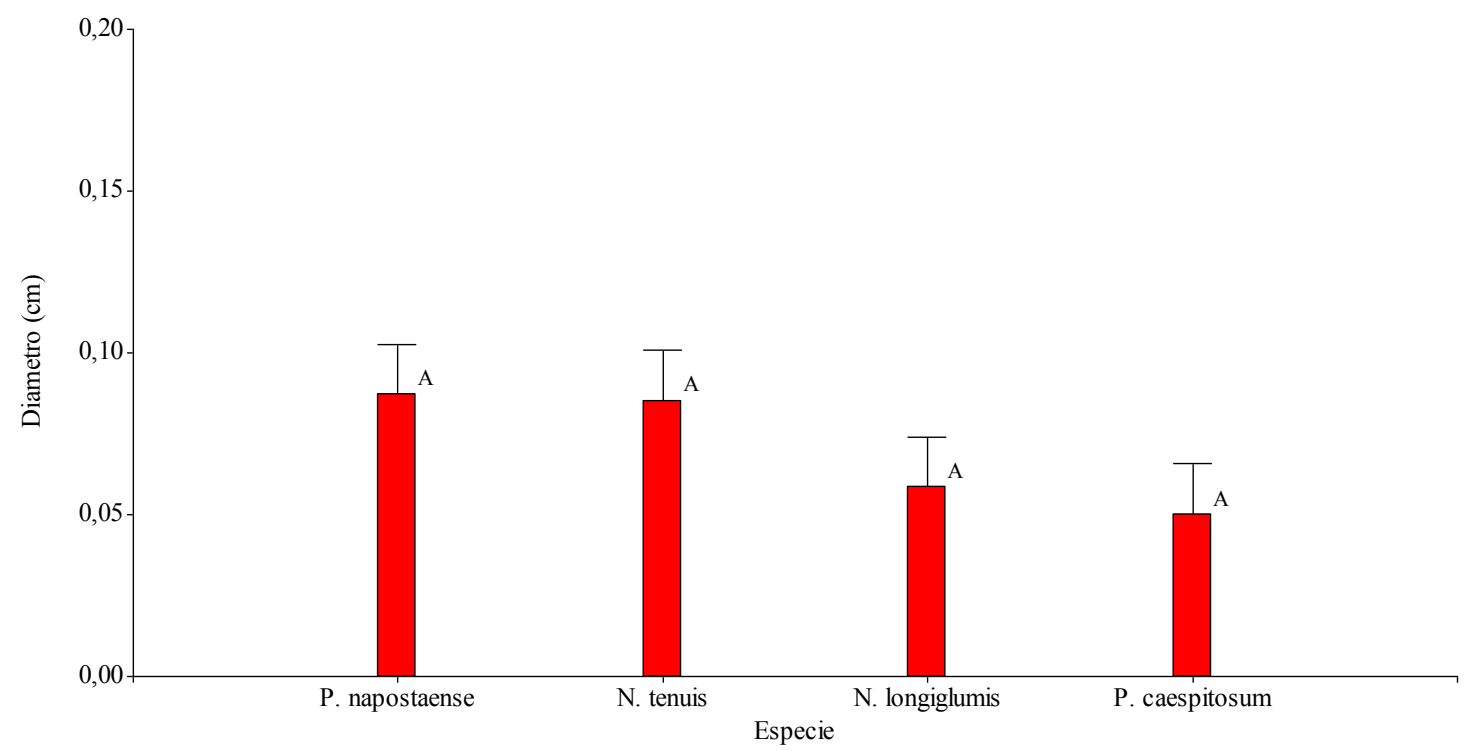

Figura 4.18. Incremento del diámetro $(\mathrm{cm})$ de la macolla de las especies herbáceas entre los años 2013 y 2016. Medias con una letra diferente indican diferencias significativas $(p<0,05)$. 


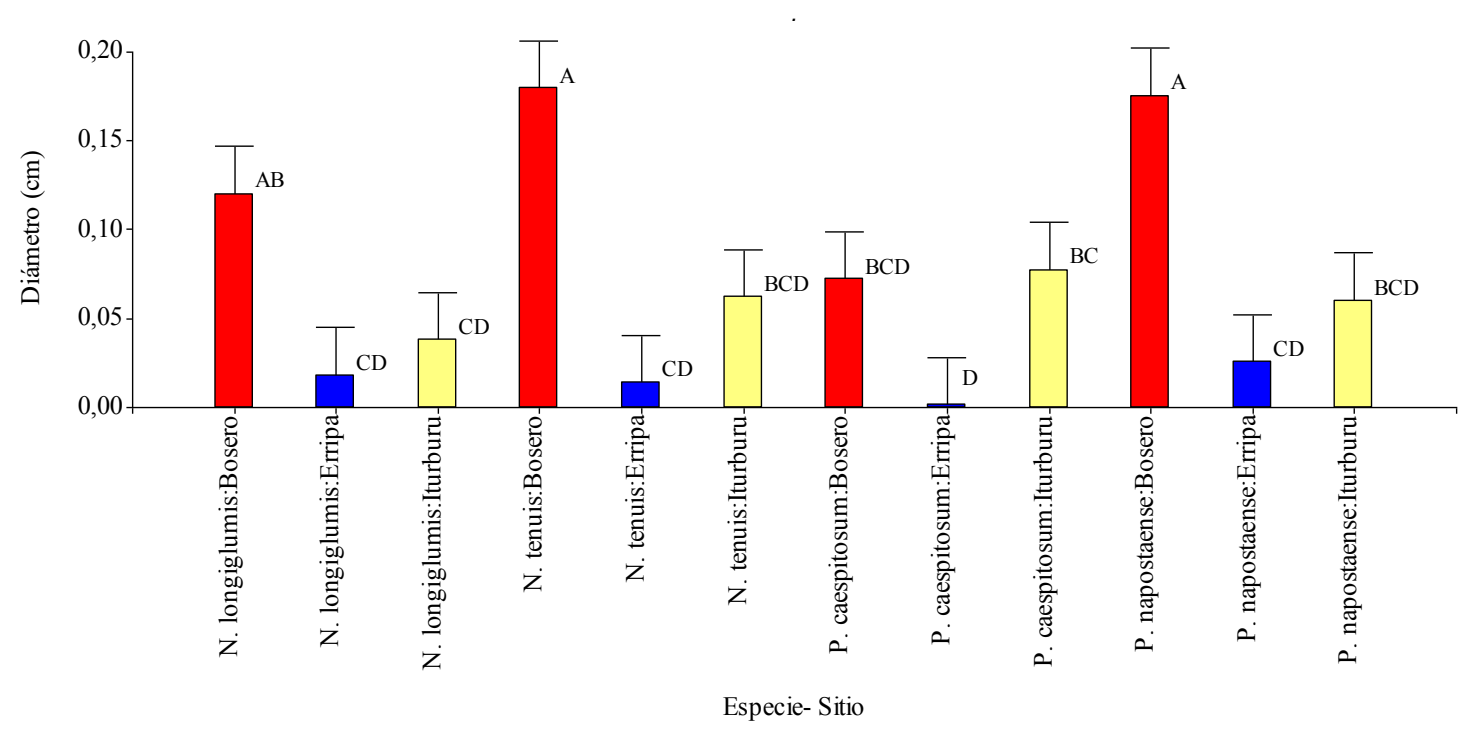

Figura 4.19. Incremento del diámetro de la macolla de las especies herbáceas en los sitios Bosero, Erripa e Iturburu entre los años 2013 y 2016. Medias con una letra diferente indican diferencias significativas $(p<0,05)$.

4.3.3.3- Efecto de los individuos trasplantados sobre el reclutamiento

Las especies reclutadas fueron todas herbáceas, no se registró el reclutamiento de leñosas durante el período de mediciones. Las especies anuales más frecuentes fueron Medicago mínima, Erodium cicutarium, Plantago patagónica, Schismus barbatus y Salsola Kali. En cambio, dentro de las perennes sólo se registraron individuos de las mismas especies que las transplantadas.

En el sitio Bosero, las especies trasplantadas no mostraron diferencias significativas ( $p$ $=0,77$ ) respecto del número de individuos reclutados (abundancia), que varió entre 6 (S. johnstonii) y 19 (P. flexuosa) (Figura 4.20). 


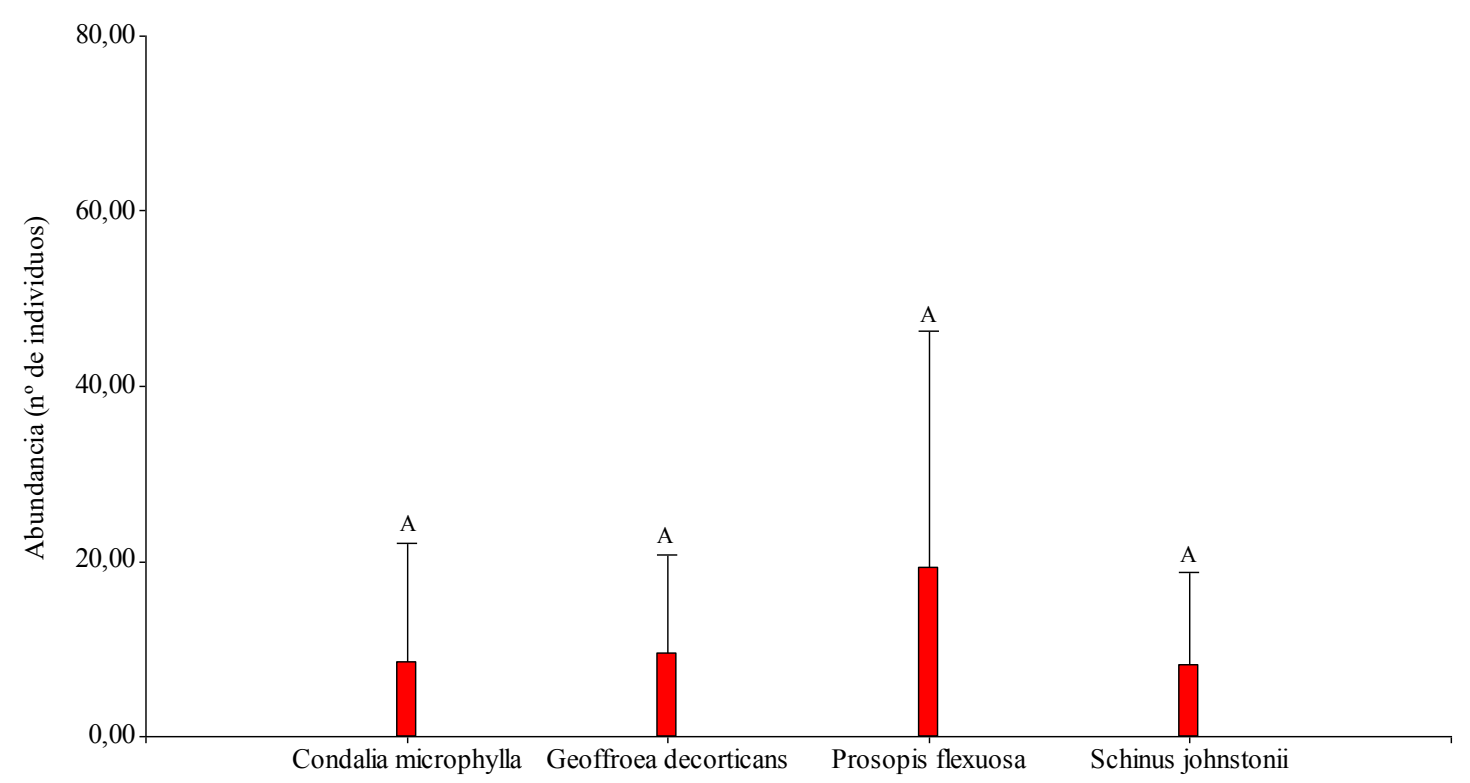

Figura 4.20. Sitio Bosero. Abundancia de individuos reclutados por especies leñosas trasplantadas. Medias con una letra diferente indican diferencias significativas $(p<0,05)$.

La riqueza específica de los individuos que colonizaron el área circundante a los ejemplares trasplantados sobrevivientes fue mayor en el caso de $S$. johnstonii y $P$. flexuosa, con 11 y 10 especies, respectivamente, comparados con C. microphylla y $G$. decorticans, que presentaron valores de 6 y 8 especies reclutadas, respectivamente (Figura 4.21).

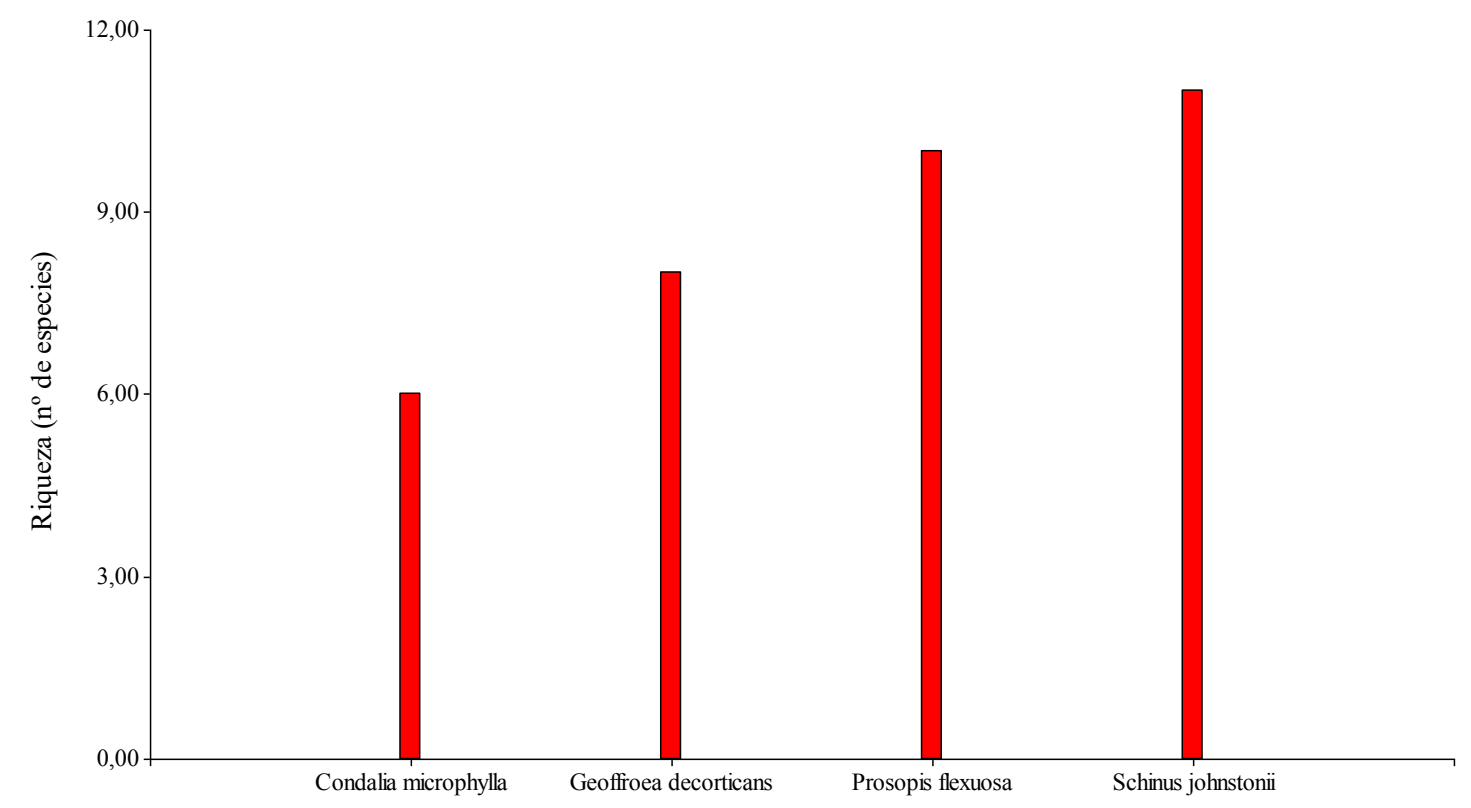

Figura 4.21. Sitio Bosero. Riqueza de especies reclutadas por especies leñosas trasplantadas.

En el sitio Erripa no se observaron diferencias significativas entre las especies trasplantadas $(p=0,722)$ en la abundancia de individuos reclutados, con valores entre 
los 4 y 14 individuos reclutados por especie (Figura 4.22).

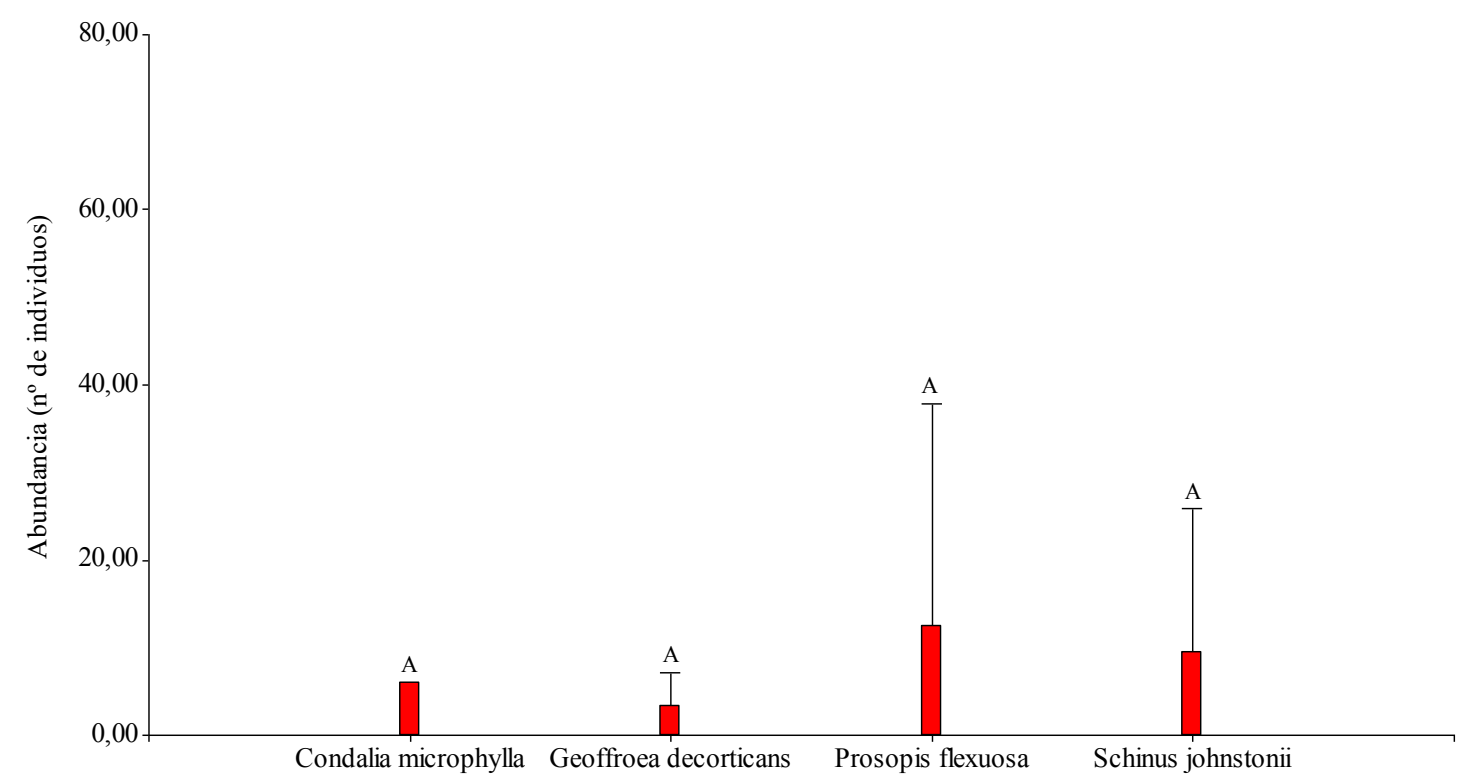

Figura 4.22. Sitio Erripa. Abundancia de individuos reclutados por especies leñosas trasplantadas. Medias con una letra diferente indican diferencias significativas $(p<0,05)$.

La riqueza específica de especies espontáneas fue mayor en las cercanía de $G$. decorticans, P. flexuosa y $S$. johnstonii, con 4,5 y 4 especies, respecto de $C$. microphylla que solo reclutó una especie (Figura 4.23).

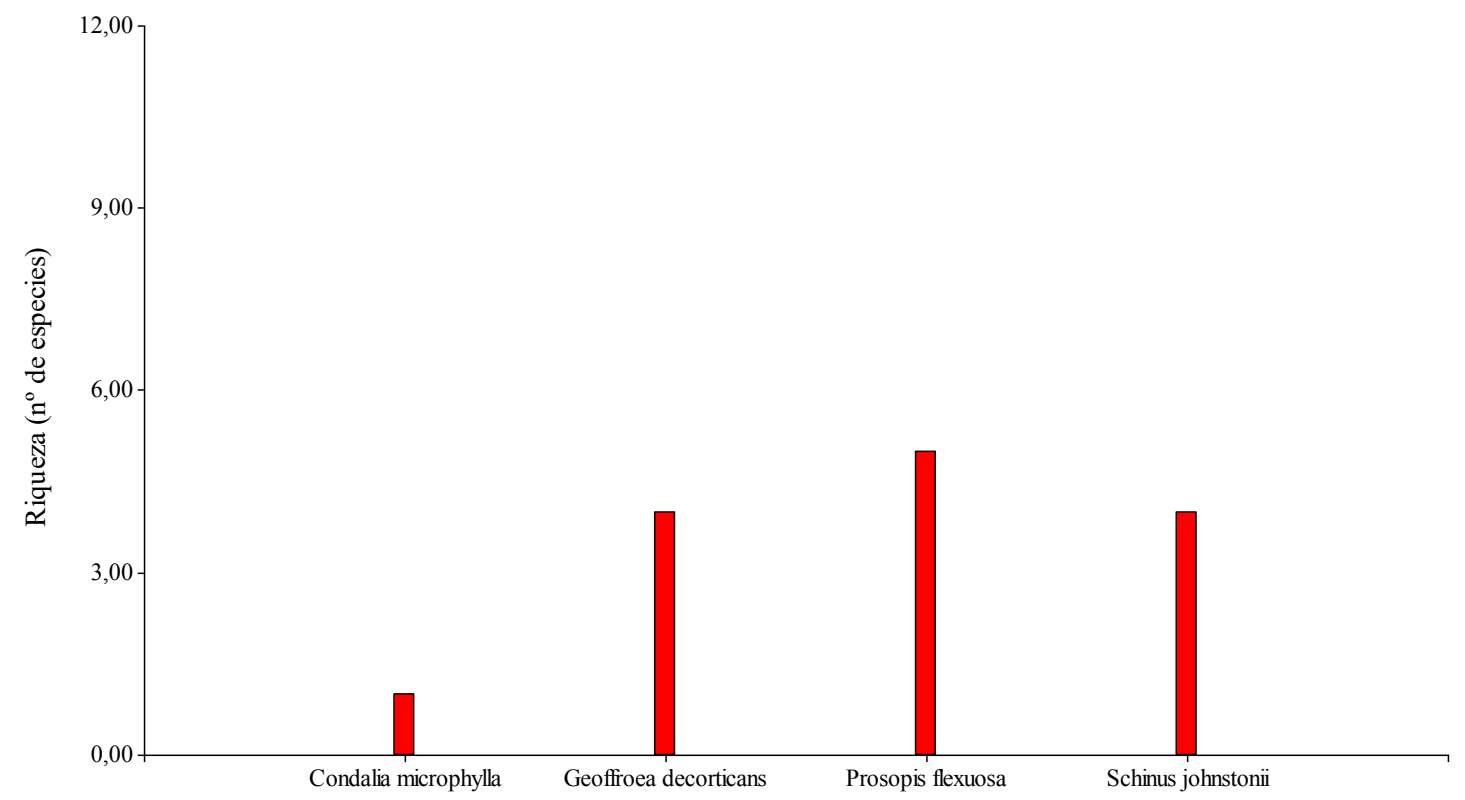

Figura 4.23. Sitio Erripa. Riqueza de especies reclutadas por especies leñosas trasplantadas. 
En el sitio Iturburu no se observaron diferencias significativas en la abundancia del reclutamiento entre especies plantadas, registrándose 26 y 29 individuos en el área de influencia de $P$. flexuosa y $S$. johnstonii, respectivamente. G. decorticans y $C$. microphylla, presentaron valores de abundancia de 21 y 4 individuos, respectivamente (Figura 4.24).

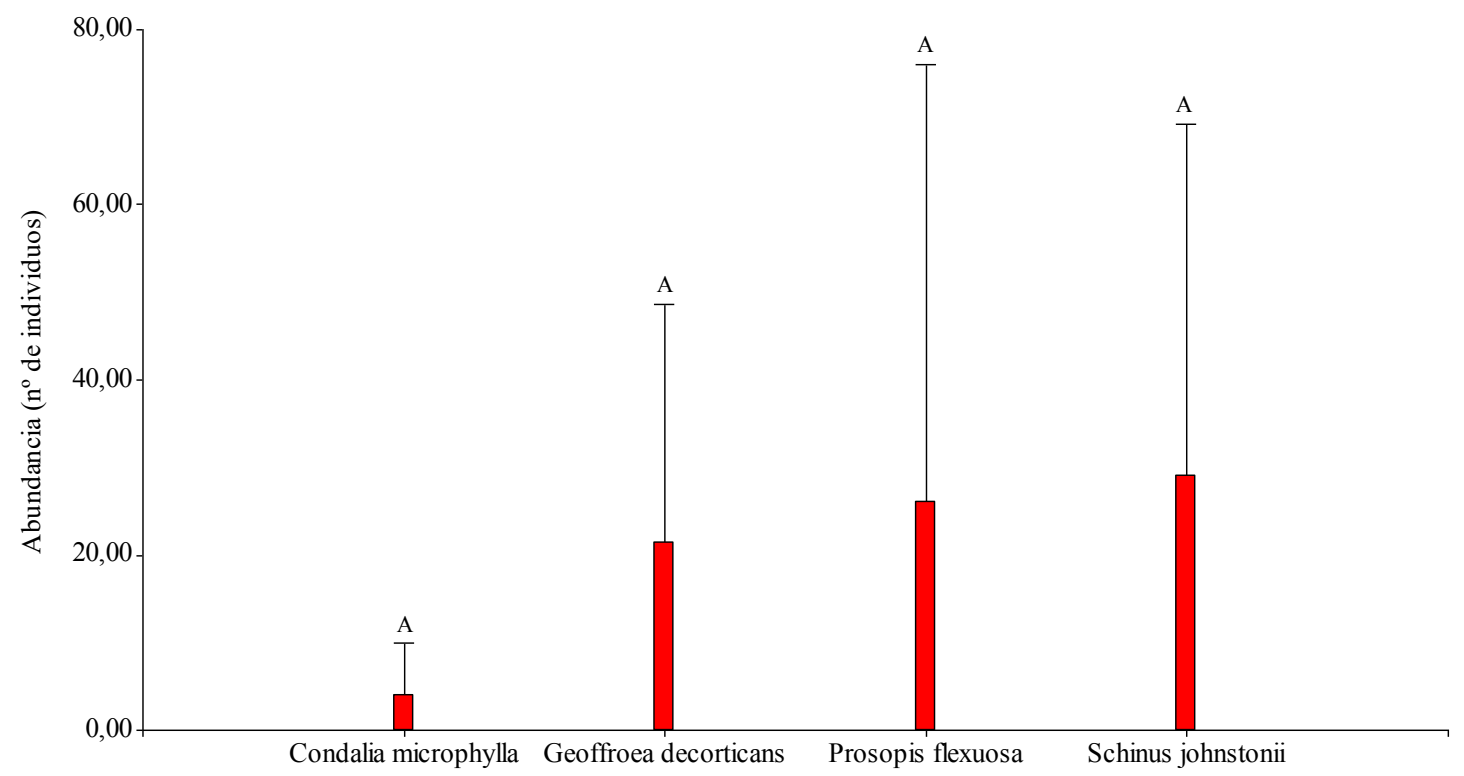

Figura 4.24. Sitio Iturburu. Abundancia de individuos reclutados por especies leñosas trasplantadas. Medias con una letra diferente indican diferencias significativas $(p<0,05)$

La riqueza de especies reclutadas fue mayor alrededor de $P$. flexuosa y S. johnstonii, con 9 y 8 especies, respectivamente. Las especies C. microphylla y $G$. decorticans presenta valores de 4 y 5 especies (Figura 4.25).

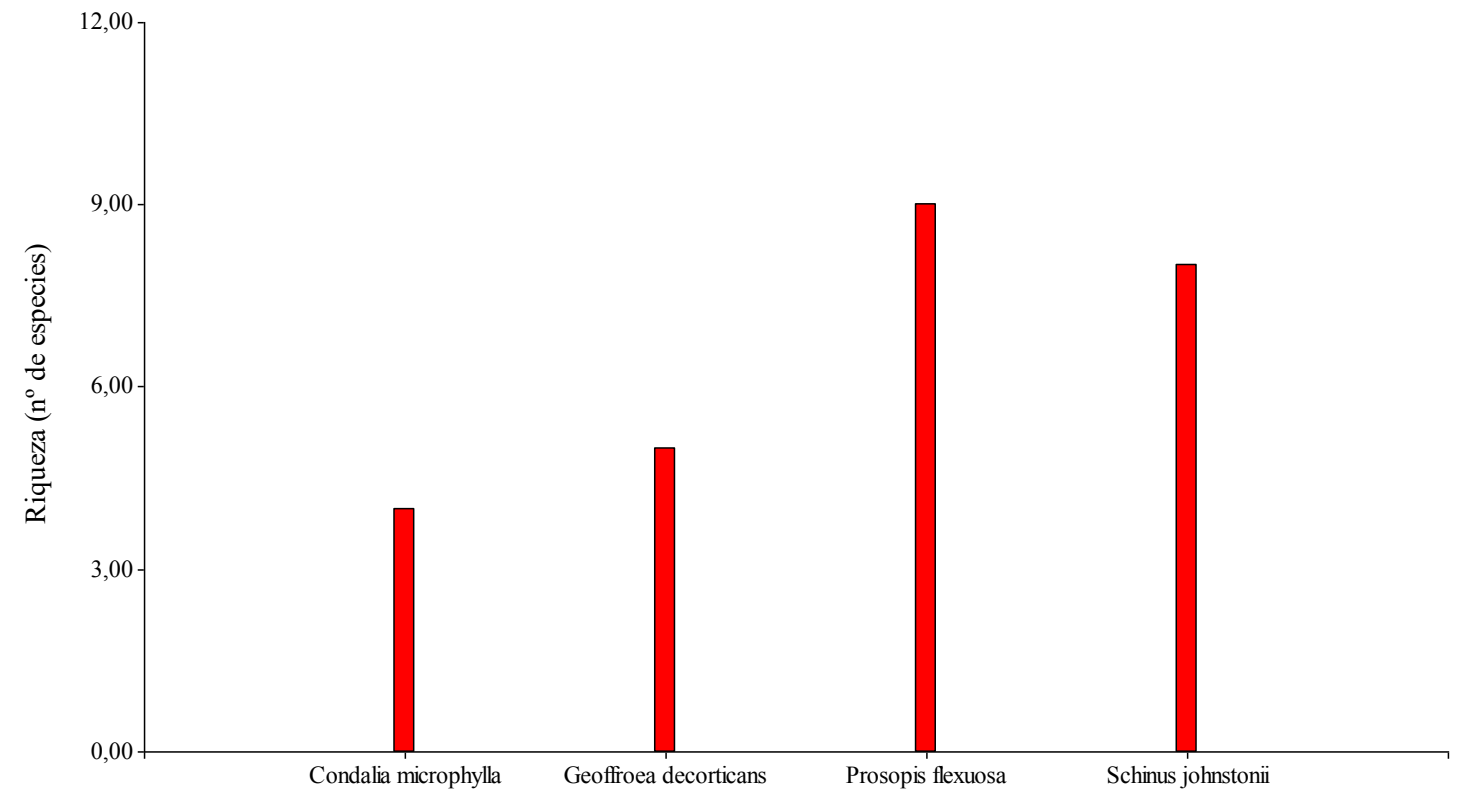

Figura 4.25. Sitio Iturburu. Riqueza de especies reclutadas para especies leñosas trasplantadas. 
La abundancia de especies reclutadas en el área circundante de las especies herbáceas en el sitio Bosero no presentó diferencias significativas $(p=0,355)$. Los valores de abundancia variaron entre 3 y 19 individuos (Figura 4.26).

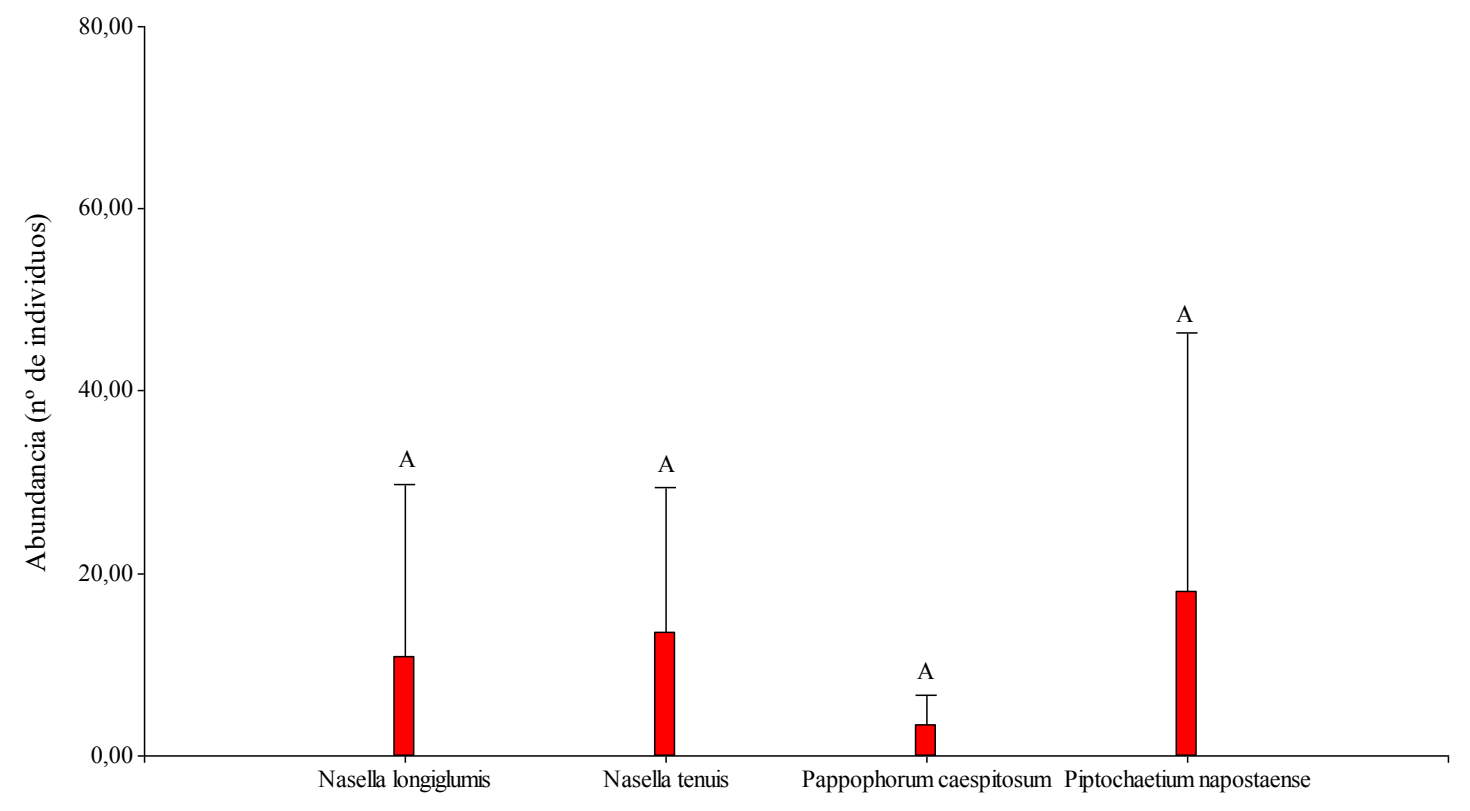

Figura 4.26. Sitio Bosero. Abundancia de individuos reclutados por especies herbáceas trasplantadas. Medias con una letra diferente indican diferencias significativas $(p<0,05)$.

La riqueza de especies reclutadas presentó valores de 12, 7, 6 y 9 especies para $N$. longiglumis, N. tenuis, P. caespitosum y P. napostaense, respectivamente (Figura 4.27).

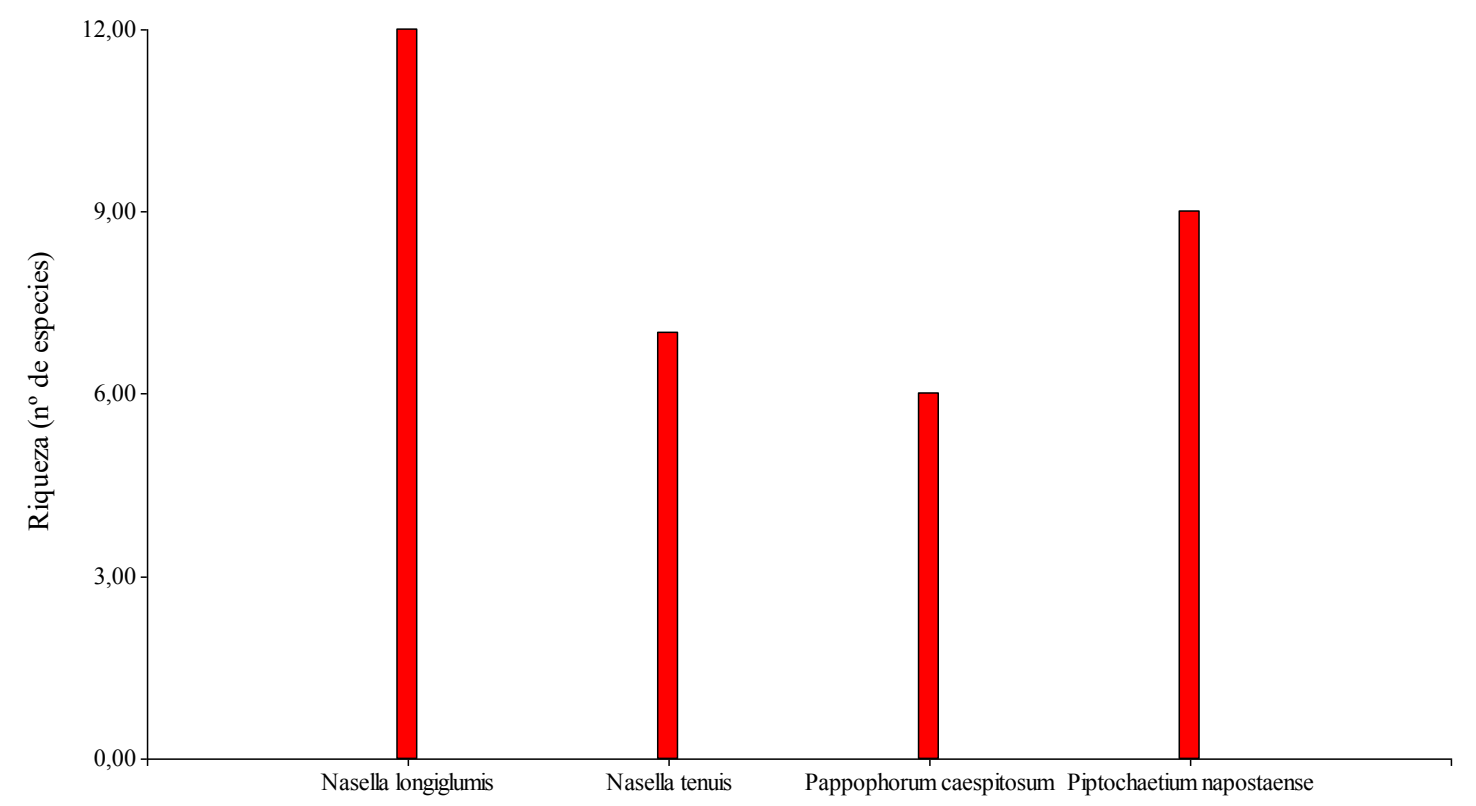

Figura 4.27. Sitio Bosero. Riqueza de especies reclutadas para las especies herbáceas trasplantadas. 
En el sitio Erripa no se observaron diferencias significativas en la abundancia de individuos reclutados por las especies trasplantadas $(p=0,989)$, registrándose valores de abundancia entre 6 y 9 individuos reclutados por especie (Figura 4.28).

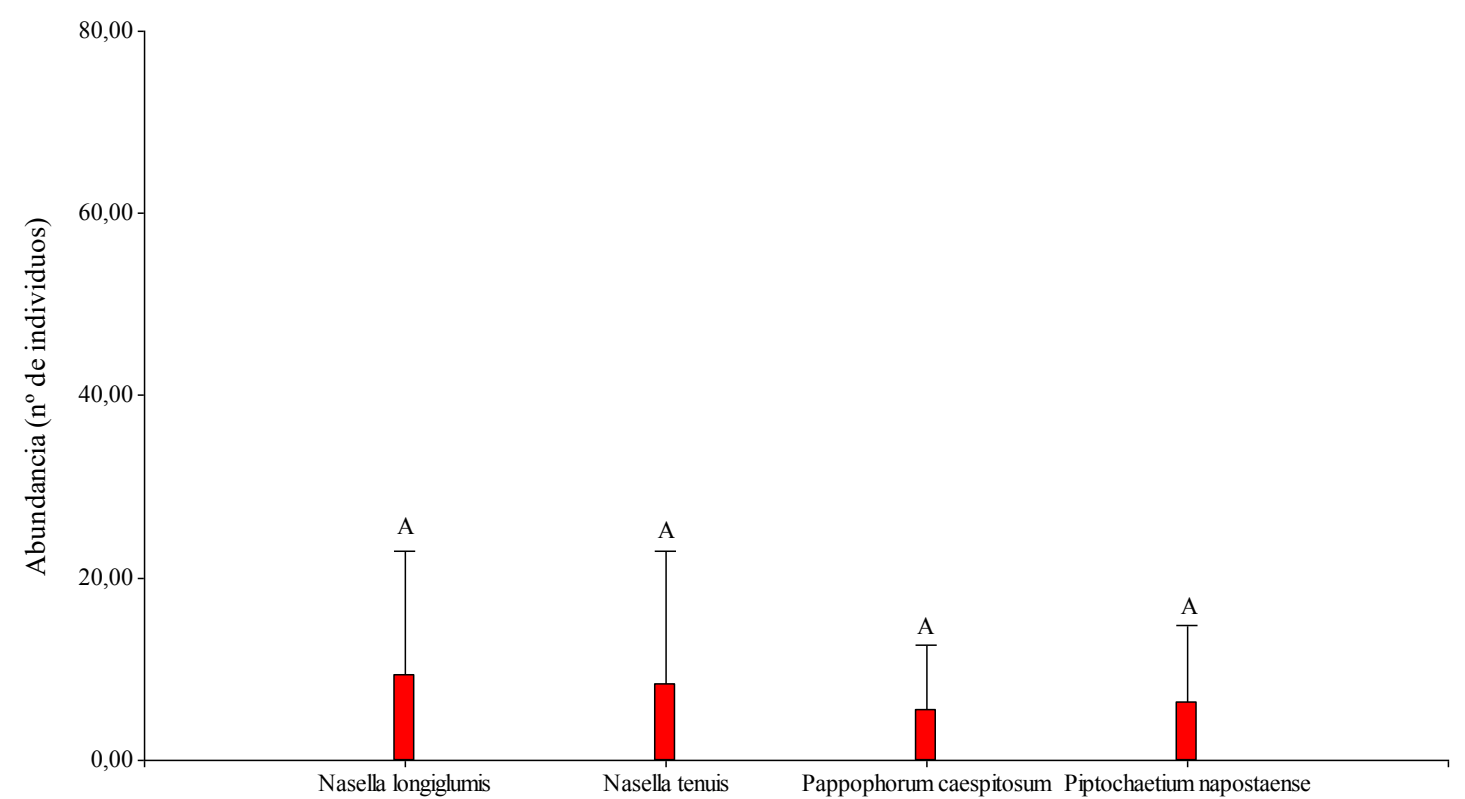

Figura 4.28. Sitio Erripa. Abundancia de individuos reclutados por especies herbáceas trasplantadas. Medias con una letra diferente indican diferencias significativas $(p<0,05)$.

Los valores de riqueza variaron entre 3 y 6 especies reclutadas en el área circundante de de las gramíneas trasplantadas (Figura 4.29).

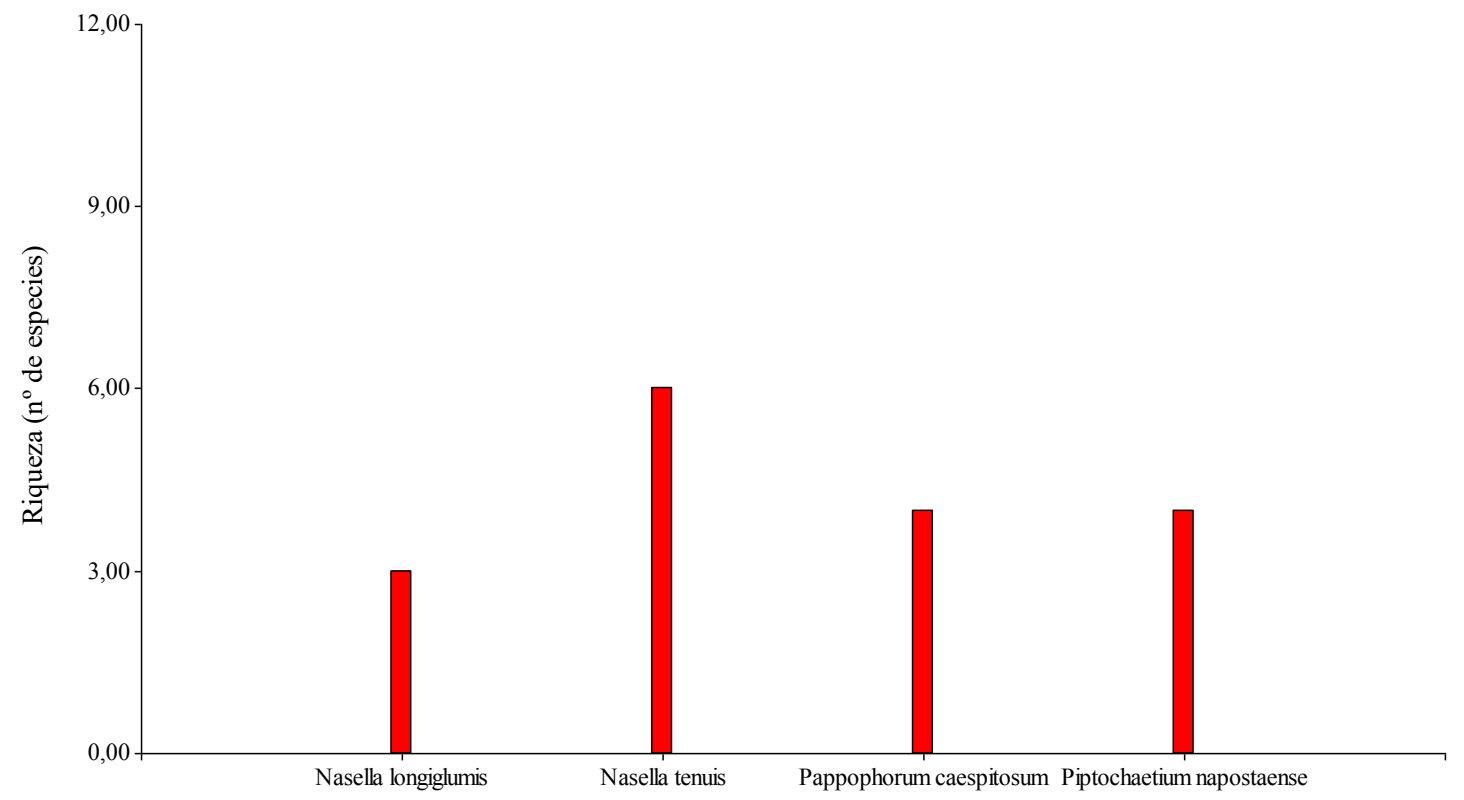

Figura 4.29. Sitio Erripa. Riqueza de especies reclutadas por especies herbáceas trasplantadas. 
La abundancia de individuos reclutados en el sitio Iturburu en cercanías de las distintas gramíneas trasplantadas no presentó diferencias significativas $(p=0,660)$, con valores medios que variaron entre 6 y 19 individuos por especie (Figura 4.30).

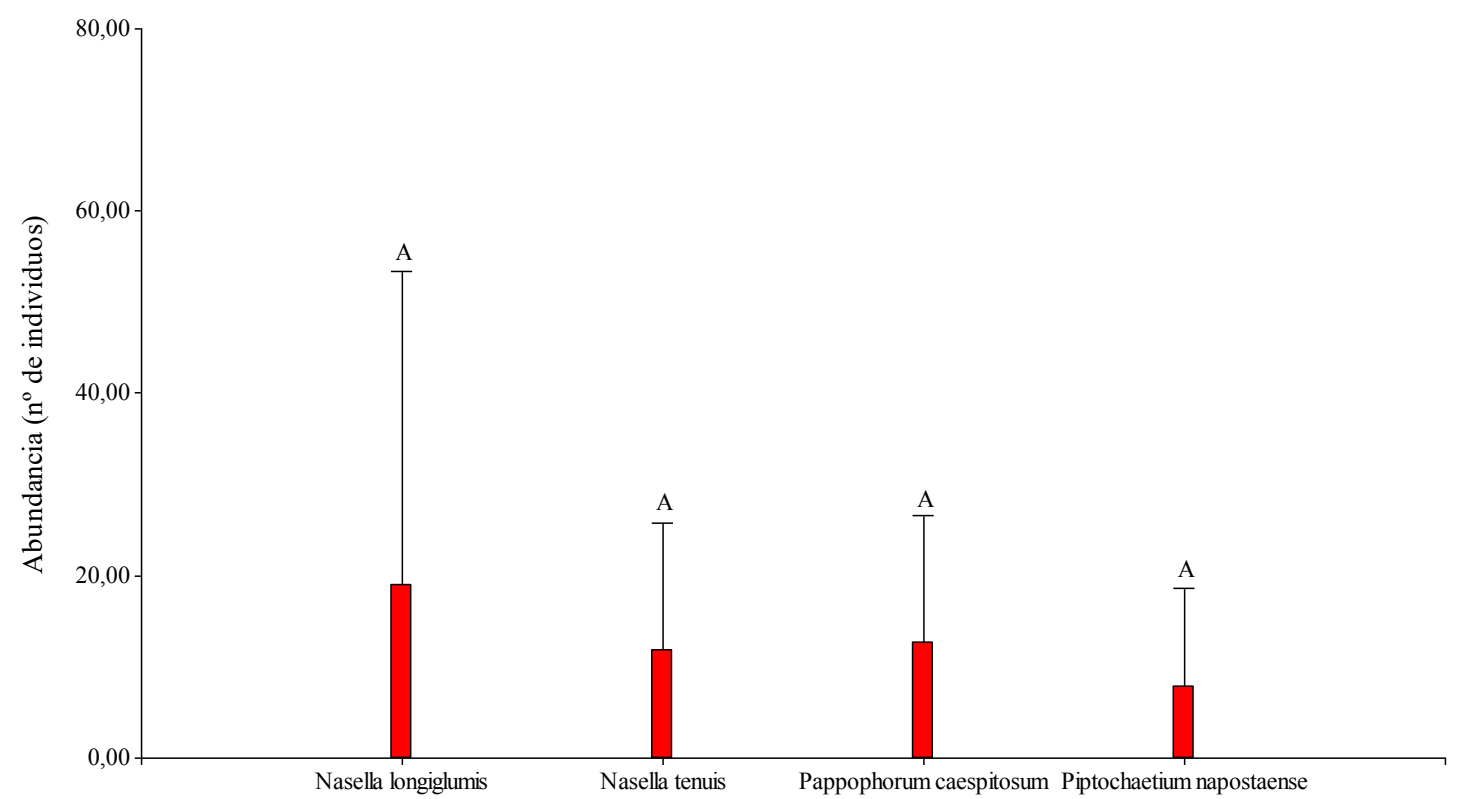

Figura 4.30. Sitio Iturburu. Abundancia de individuos reclutados por especies herbáceas trasplantadas. Medias con una letra diferente indican diferencias significativas $(p<0,05)$.

La riqueza de especies reclutadas en el área de influencia de las especies $N$. longiglumis, $N$. tenuis, $P$. caespitosum y P. napostaense fue de 10, 6, 7 y 7, respectivamente (Figura 4.31).

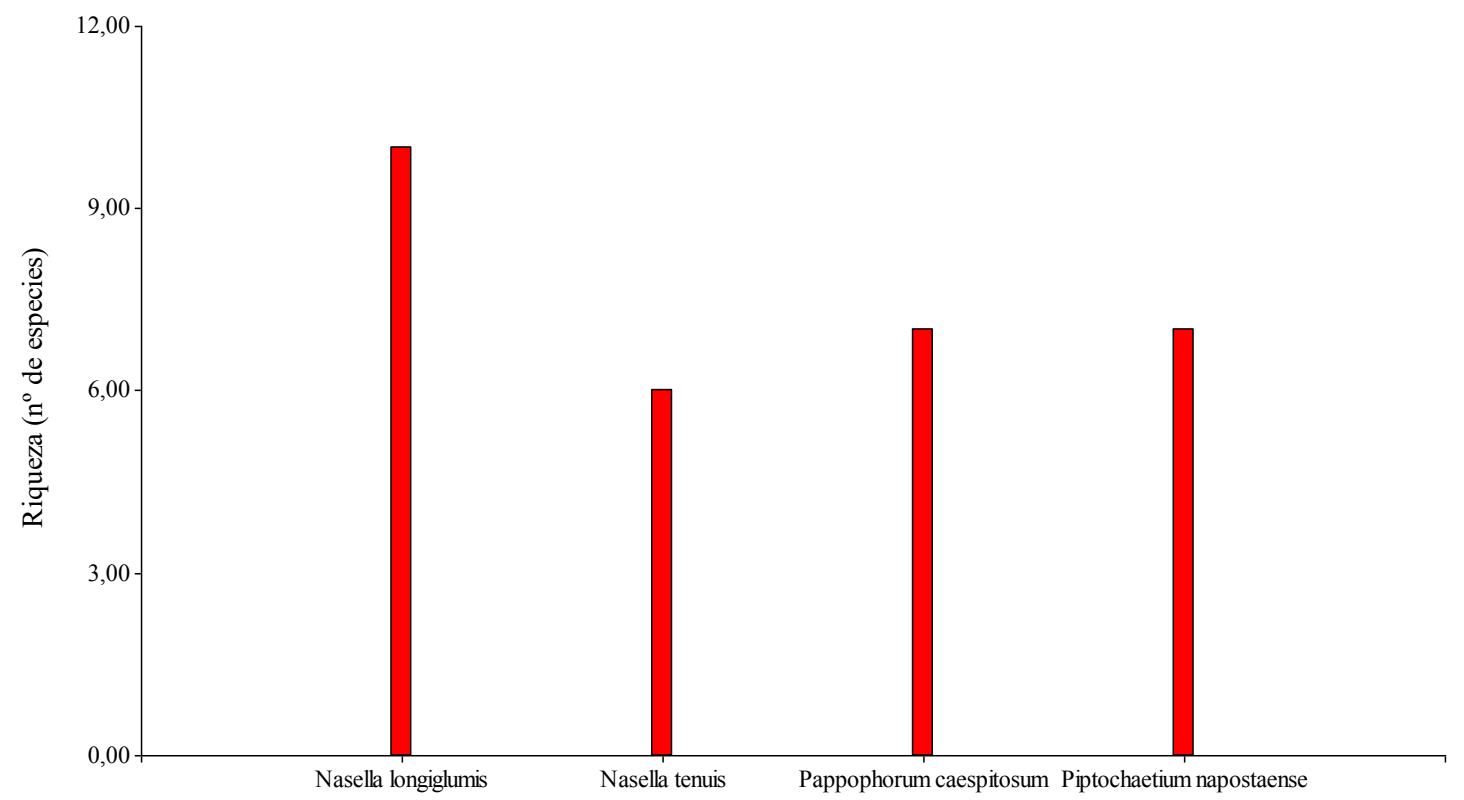

Figura 4.31. Sitio Iturburu. Riqueza de especies reclutadas por especies herbáceas trasplantadas. 


\subsubsection{4- Recuperación de la cobertura.}

La cobertura de especies espontáneas en los diferentes sitios no presentó diferencias significativas $(p=0,4071)$, siendo los valores de cobertura para los sitios Bosero, Erripa e Iturburu de $81 \%, 78 \%$ y $88 \%$, respectivamente (Figura 4.32 ).

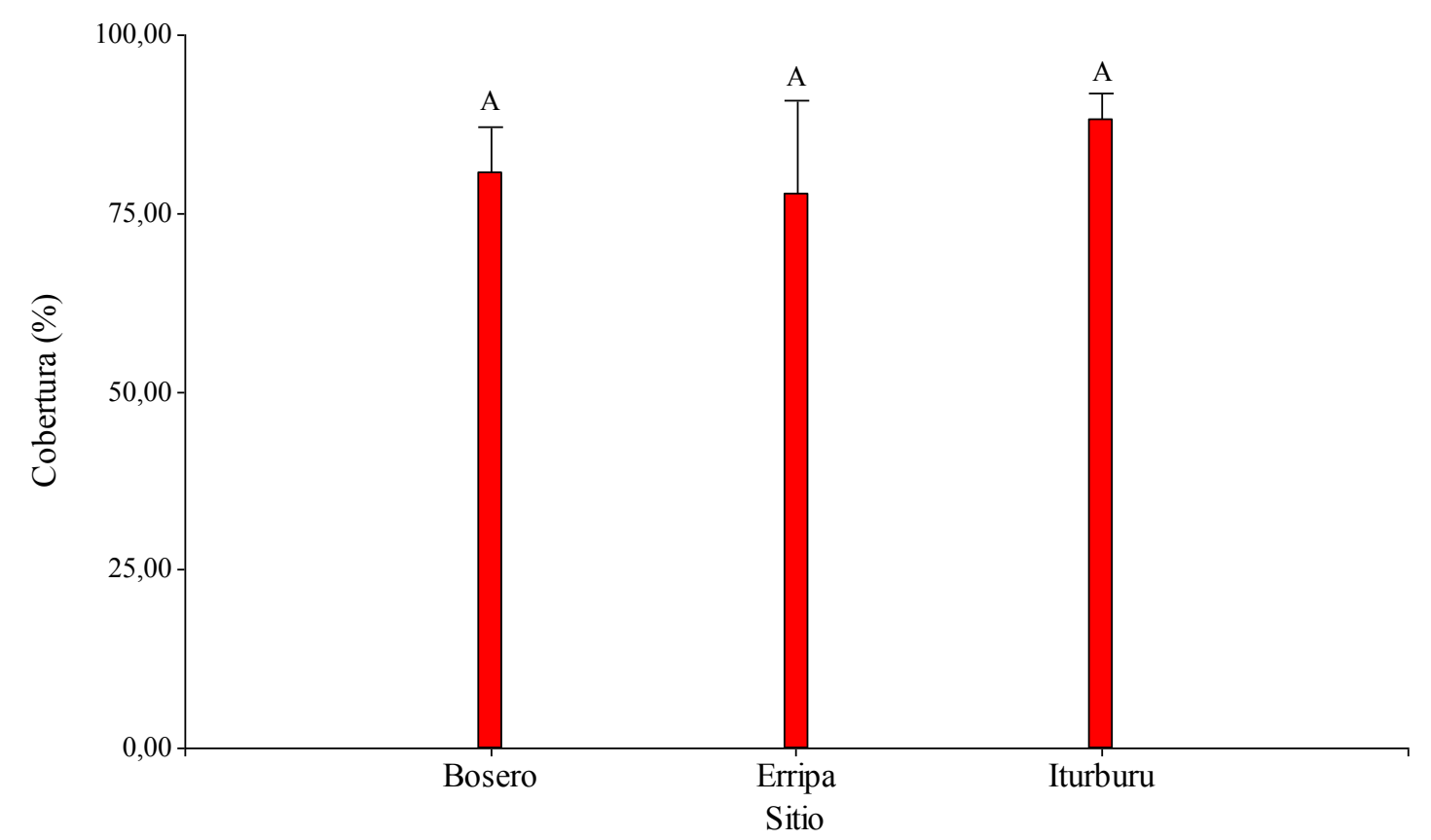

Figura 4.32. Porcentaje (\%) de cobertura del suelo en 2016. Medias con una letra diferente indican diferencias significativas $(p$ $<0,05)$.

La cobertura de especies de ciclo de vida perenne en los diferentes sitios no presentó diferencias significativas $(p=0,0679)$ (Figura 4.33).

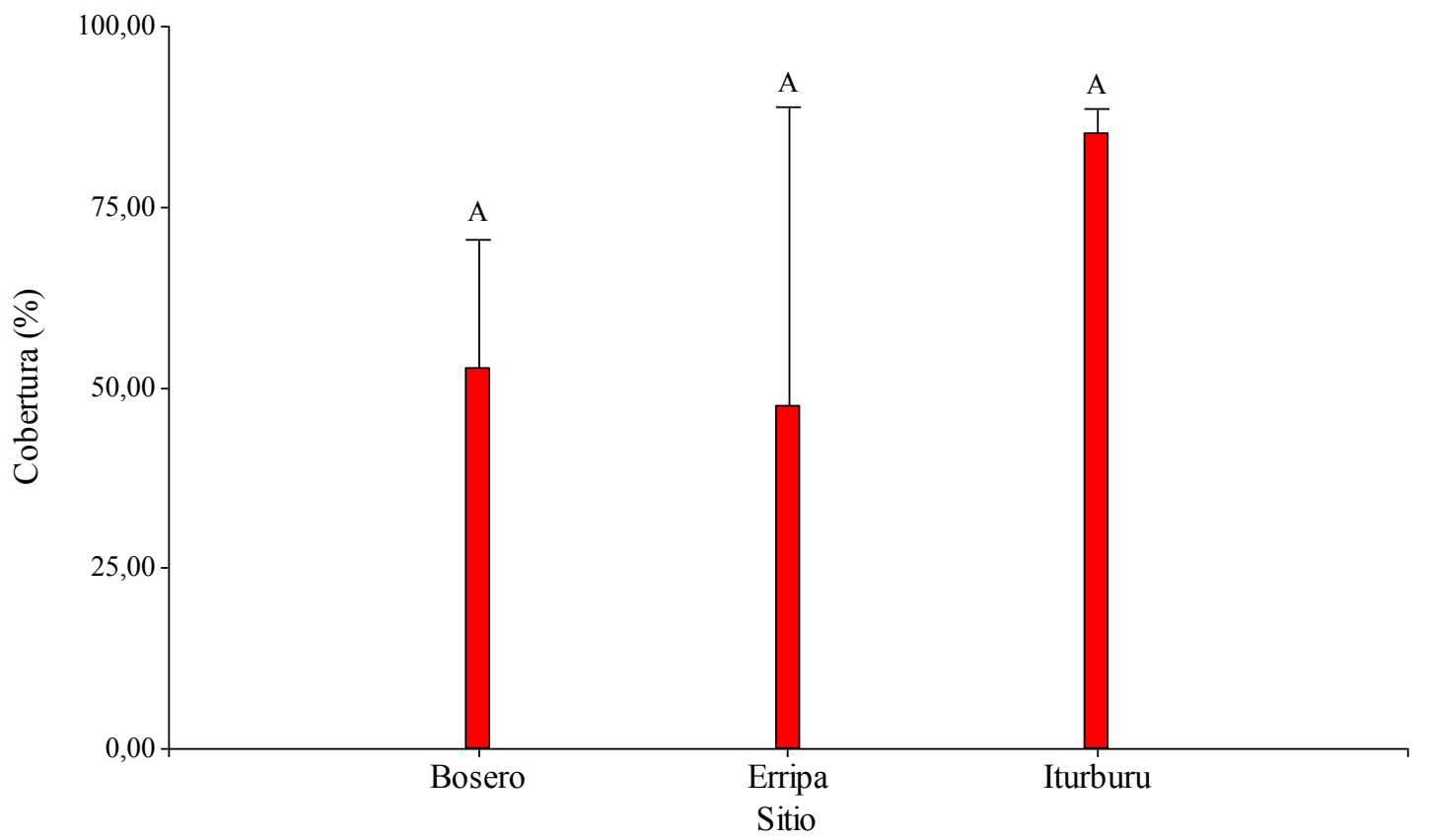

Figura 4.33. Porcentaje (\%) de cobertura del suelo de especies perennes en 2016. Medias con una letra diferente indican diferencias significativas $(p<0,05)$. 
La cobertura de especies de ciclo de vida perenne con valor de uso forrajero no presentó diferencias significativas entre sitios $(p=0,3607)$, con valores para los sitios Bosero, Erripa e Iturburu de 28\%, 41\% y 56\% respectivamente (Figura 4.34).

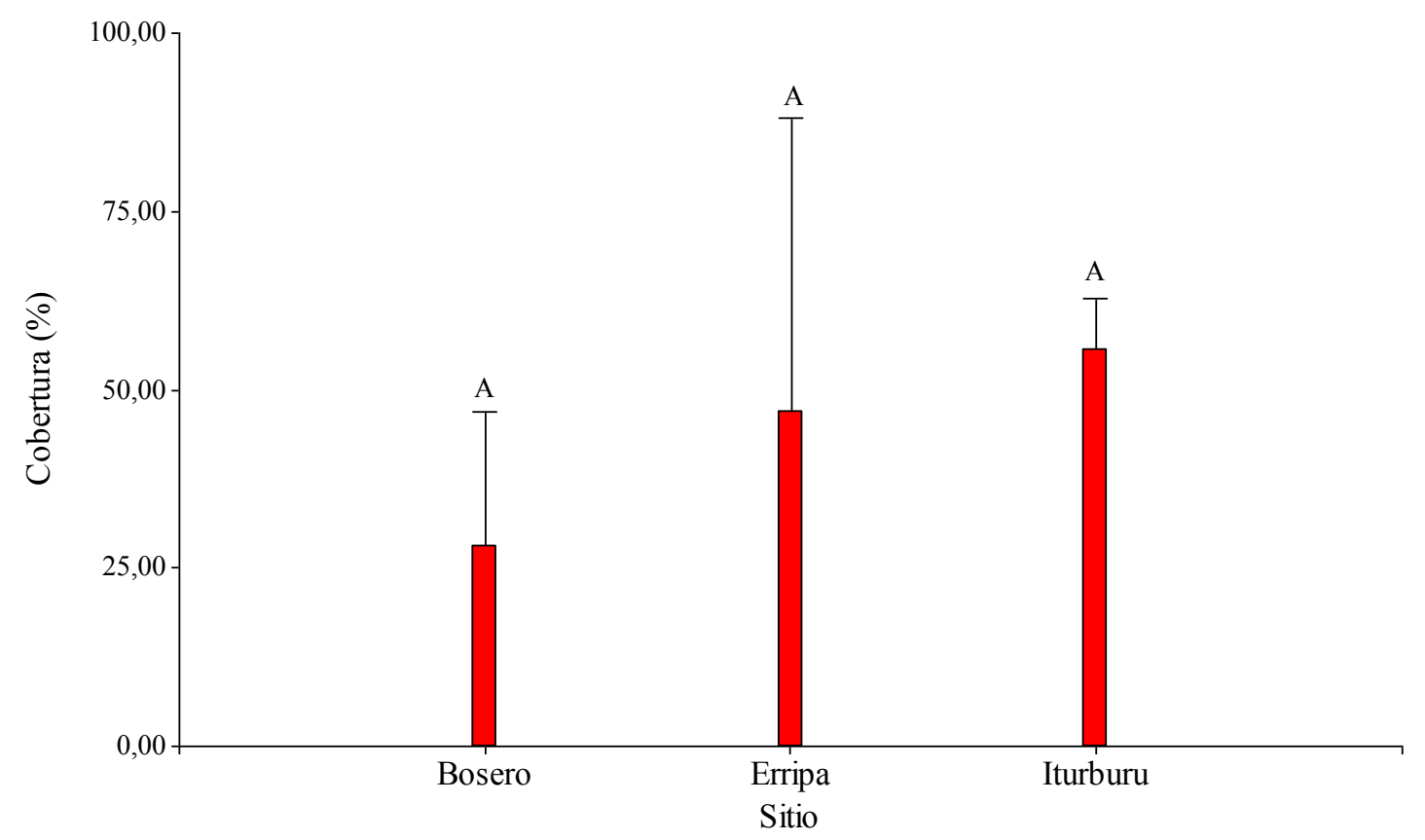

Figura 4.34. Porcentaje (\%) de cobertura del suelo de especies con valor forrajero en 2016. Medias con una letra diferente indican diferencias significativas $(p<0,05)$.

\subsection{4- Rehabilitación pasiva.}

Para evaluar los efectos de los ensayos de rehabilitación pasiva sobre la recuperación de la cobertura del suelo se registraron sólo las especies de ciclo de vida perenne. Las especies anuales poseen importancia relativa en los proyectos de rehabilitación ecológica, debido a su amplia variabilidad inter e intra anual, sujeta a los pulsos de precipitaciones, su breve ciclo de vida y al bajo volumen de forraje que ofrecen, lo cual dificulta las estimaciones.

Sitio Bosero. En este sitio se observó la recuperación de la cobertura vegetal a través de las diferentes estaciones del período analizado, evidenciándose diferencias significativas entre estaciones $(p=0,02)$. En otoño del año 2012, momento del primer censo de vegetación, la cobertura registrada fue de $39 \%$. La cobertura disminuyó marcadamente en el período estival 2013/14 (15\%). En los censos siguientes se observó una recomposición de la cobertura, alcanzando valores entre $29 \%$ y $32 \%$ hasta llegar al verano de 2016 donde fue registrada la mayor cobertura vegetal (63\%) (Figura 4.35). 


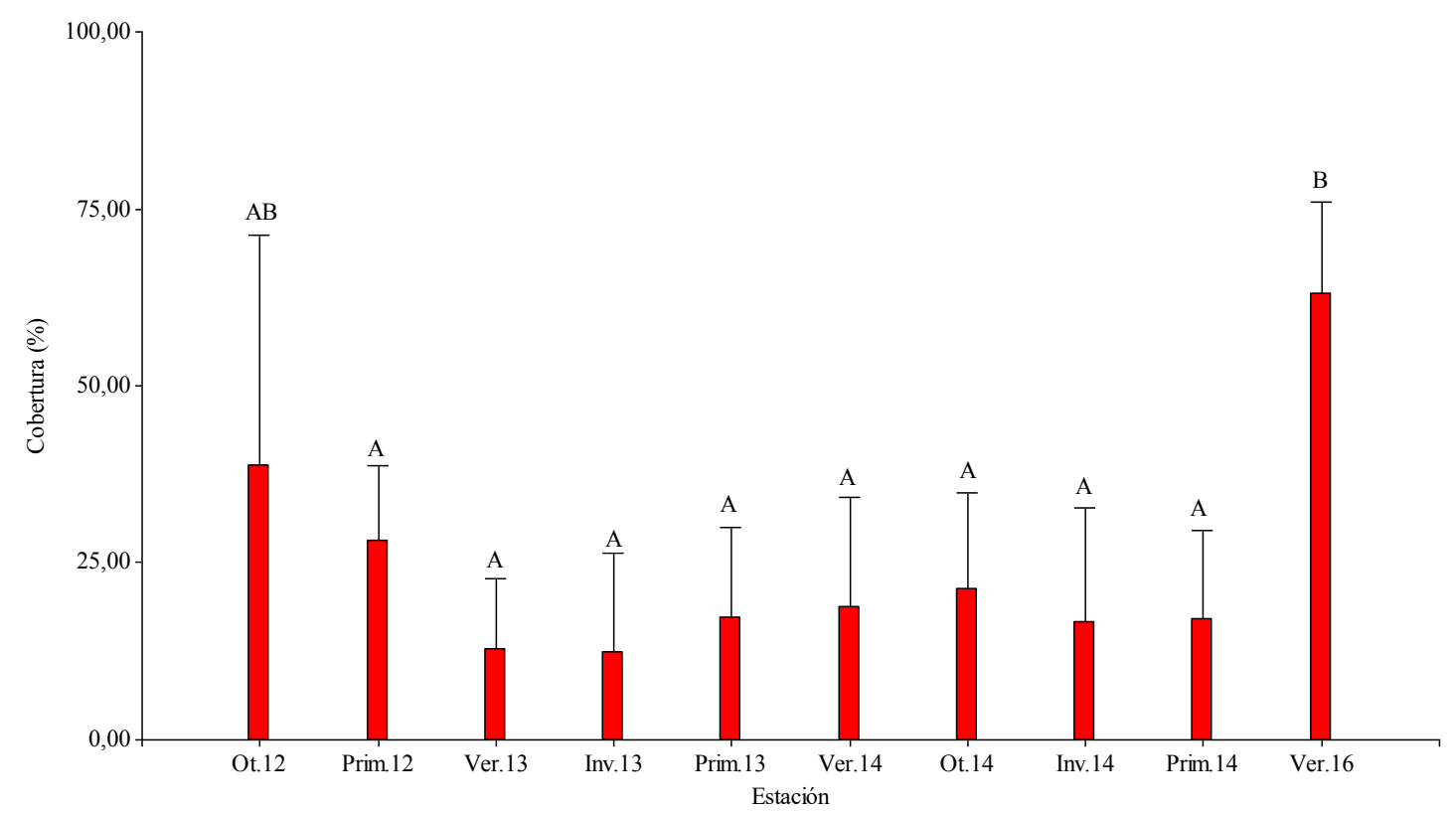

Figura 4.35. Porcentaje (\%) de cobertura del suelo en el sitio Bosero en otoño (ot), primavera (Prim) y verano (Ver) del período 2012-2016. Medias con una letra diferente indican diferencias significativas $(p<0,05)$.

La riqueza específica mostró un comportamiento variable, sin mostrar diferencias estadísticamente significativas entre fechas de muestreo. La riqueza varió entre 3 y 6 especies a lo largo del período analizado (Figura 4.36).

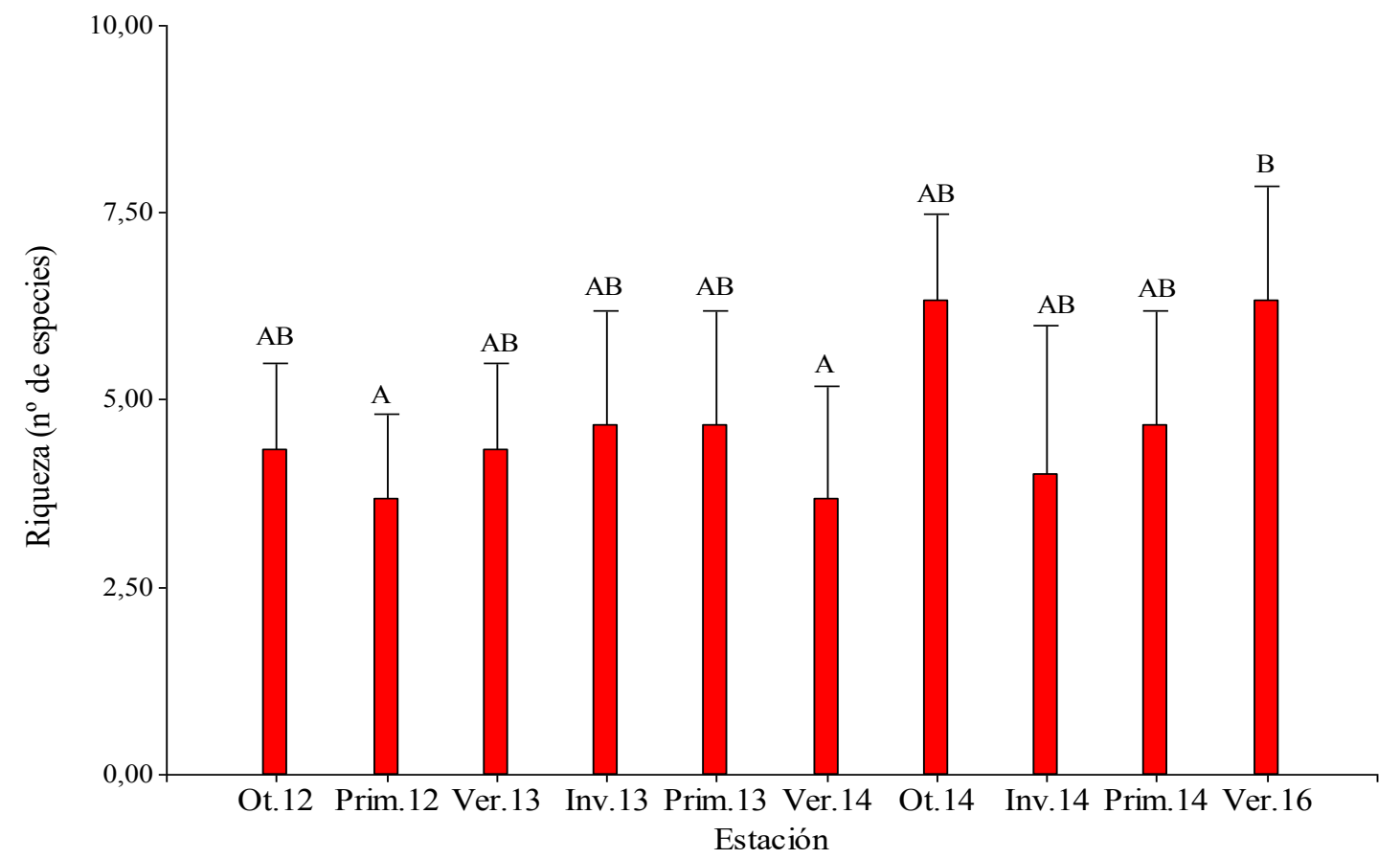

Figura 4.36. Riqueza específica en el sitio Bosero en otoño (ot), primavera (Prim) y verano (Ver) del período 2012-2016. Medias con una letra diferente indican diferencias significativas $(p<0,05)$.

El porcentaje de cobertura de especies perennes con valor forrajero respecto de la cobertura total fue muy variable entre estaciones. La cobertura de especies con valor 
forrajero difirió significativamente entre fechas de muestreo $(p=0,01)$. Los porcentajes más elevados se registraron en otoño de 2014 (82\%) y primavera de 2013 y 2014 (82\% y 84\%, respectivamente). En verano de 2014 la cobertura de especies con valor forrajero también fue elevada, llegando a alcanzar $80 \%$. En verano de 2012 y otoño de 2013 no se registró cobertura de estas especies (Figura 4.37).

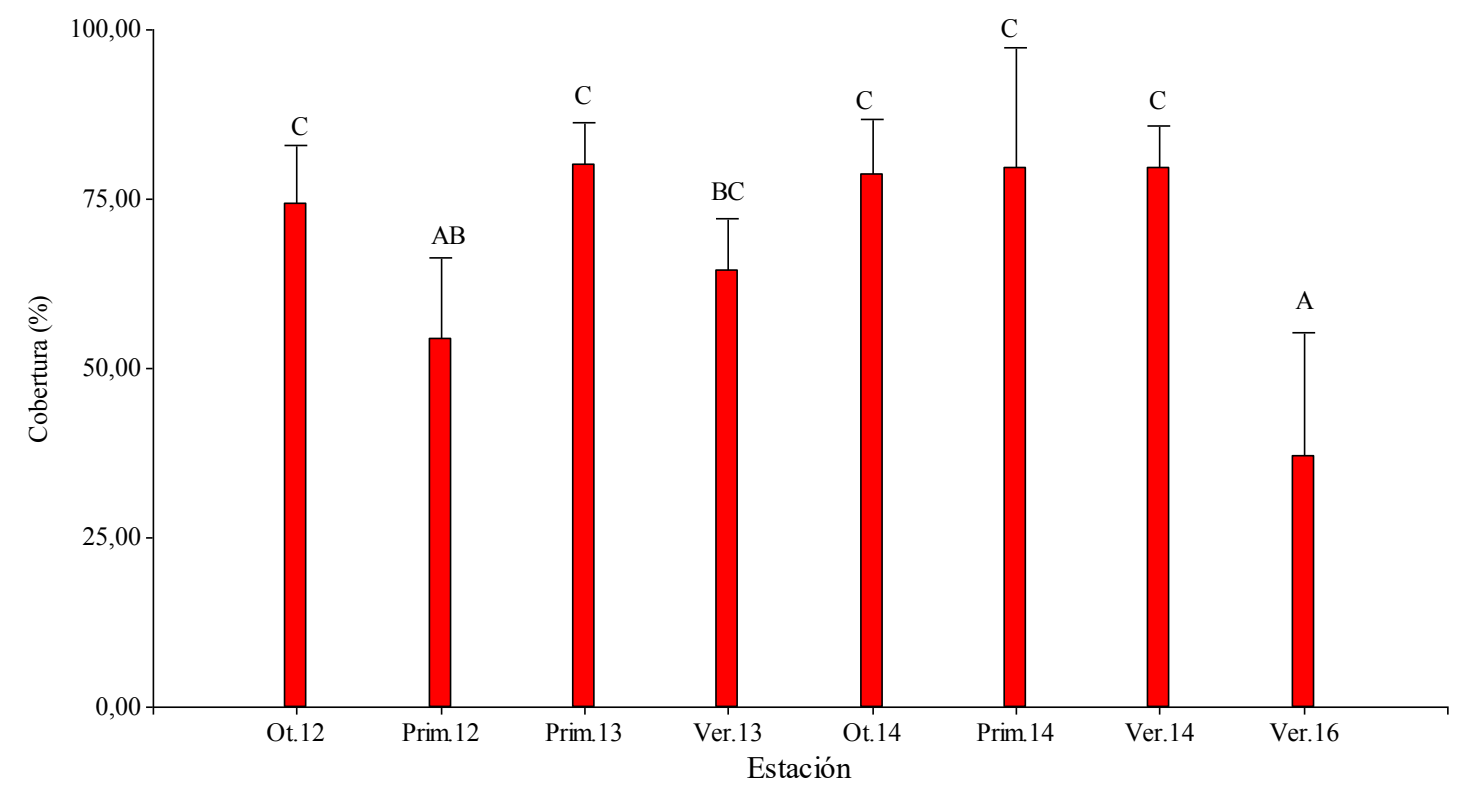

Figura 4.37. Porcentaje (\%) de cobertura de especies con valor forrajero en el sitio Bosero. Medias con una letra común no son significativamente diferentes $(\mathrm{p}>0,05)$.

Sitio Erripa. En este sitio se observaron diferencias altamente significativas $(p<0,01)$ en la cobertura del suelo entre los períodos de tiempo considerados. Desde la primavera del año 2012 hasta el invierno de 2013 se detectaron bajos porcentajes de cobertura del suelo, (entre $28 \%$ y 32 \%). En el período estival del año 2016, se observó una disminución muy marcada de la cobertura de la vegetación, la cual alcanzó solo el 53\% de la superficie del suelo (Figura 4.38). 


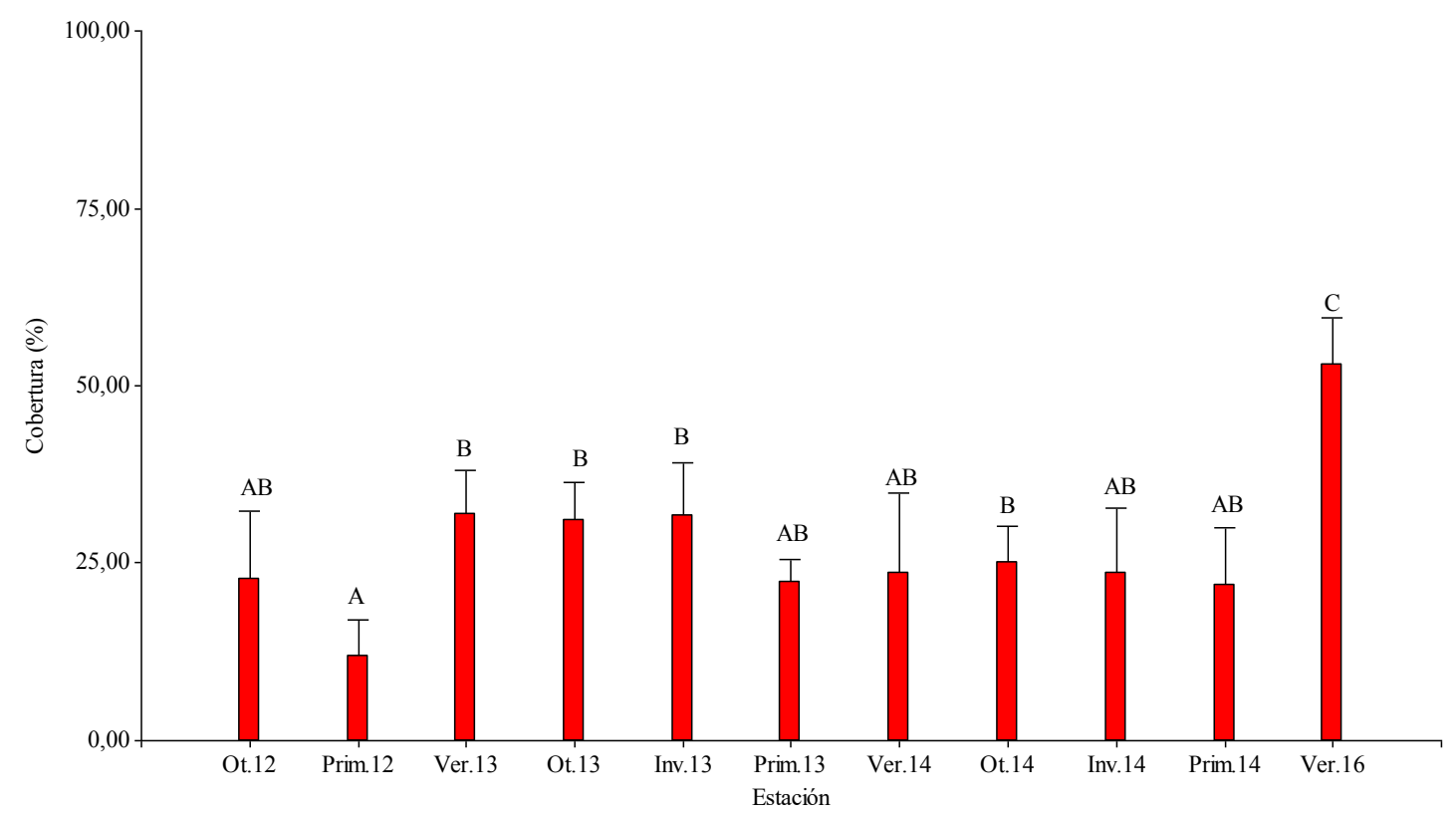

Figura 4.38. Porcentaje (\%) de cobertura del suelo en el sitio Erripa en otoño (ot), primavera (Prim) y verano (Ver) del período 2012-2016. Medias con una letra diferente indican diferencias significativas $(p<0,05)$.

La riqueza de especies no presentó diferencias significativas entre las diferentes estaciones del año analizadas, variando entre 4 y 6 especies por fecha de muestreos. (Figura 4.39).

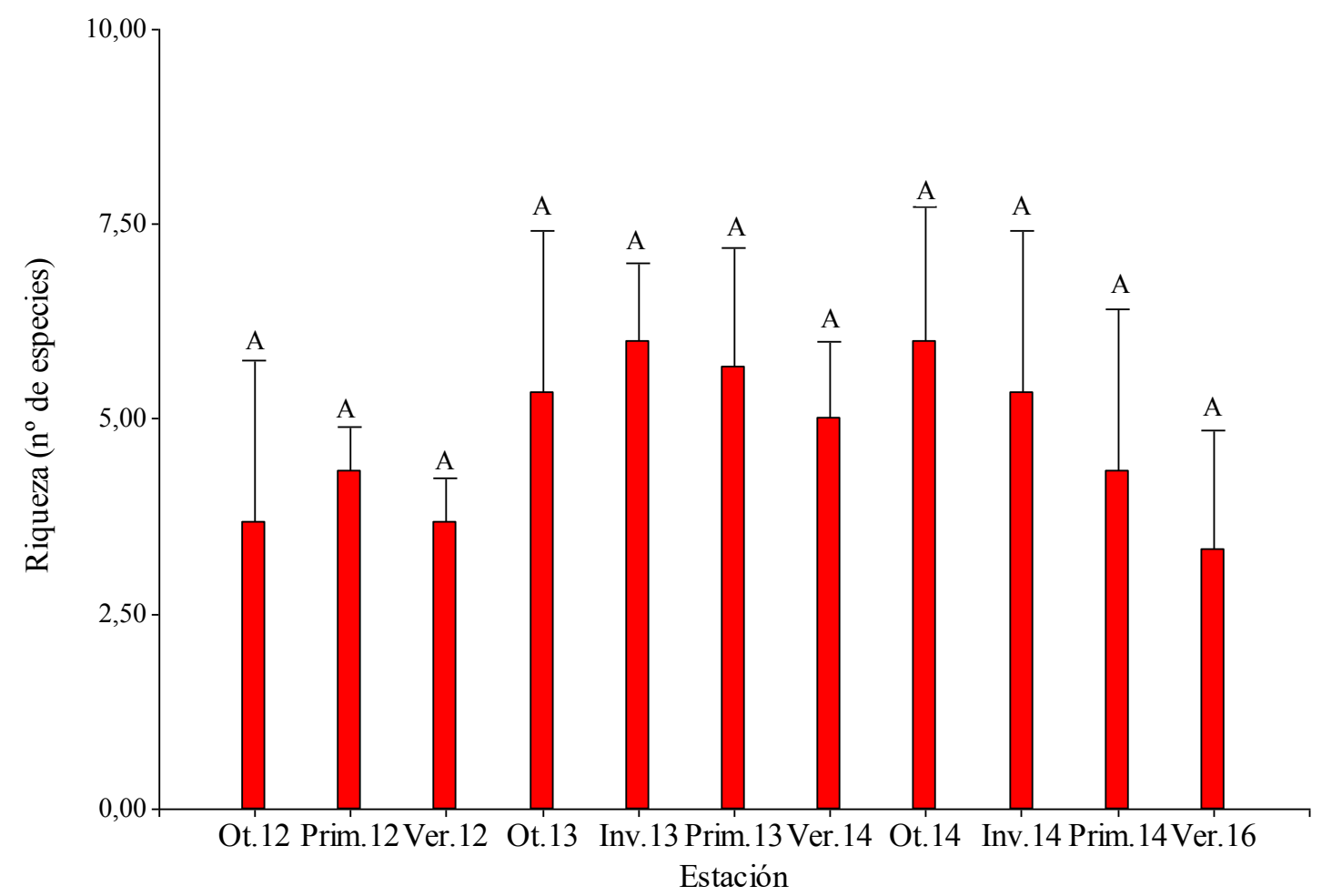

Figura 4.39. Riqueza específica en el sitio Erripa en otoño (ot), primavera (Prim) y verano (Ver) del período 2012-2016. Medias con una letra diferente indican diferencias significativas $(p<0,05)$.

La cobertura de las especies con valor forrajero mostró diferencias altamente 
significativas entre fechas $(p<0,001)$. Los mayores porcentajes de cobertura fueron registrados en verano y otoño, con valores que variaron entre $53 \%$ y $85 \%$ (Figura 4.40 ).

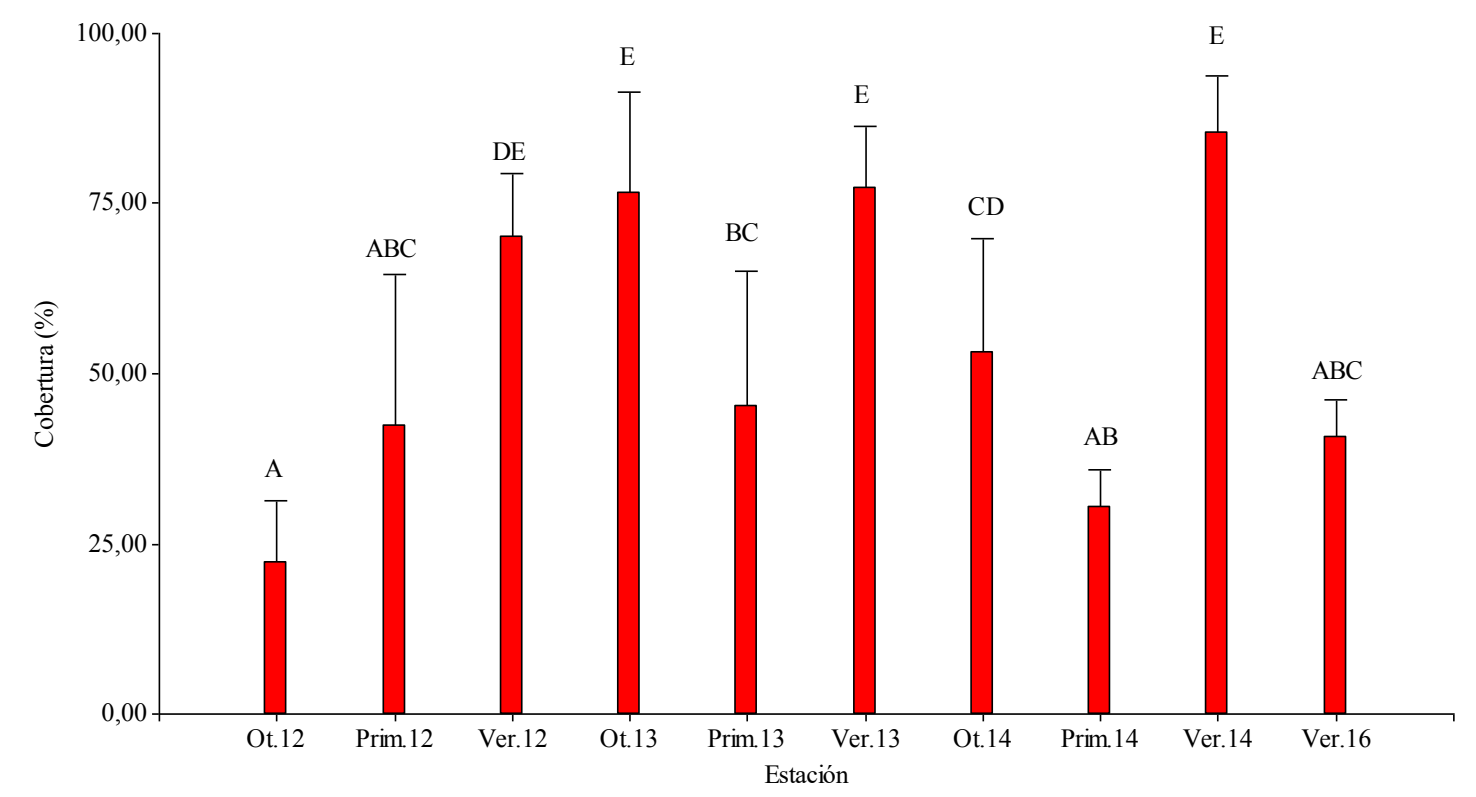

Figura 4.40. Porcentaje (\%) de cobertura de especies con valor forrajero en el sitio Erripa. Medias con una letra común no son significativamente diferentes $(\mathrm{p}>0,05)$.

Sitio Iturburu. En el sitio Iturburu, en otoño de 2012, se registró una cobertura del suelo de $14 \%$. Este valor, en la primavera de ese mismo año, mostró valores superiores al 20 $\%$, dejando una importante superficie de suelo desnudo. La cobertura de la vegetación perenne no presento signos de recuperación en el área clausurada hasta la temporada estival del año 2016. En el verano del año 2016 el porcentaje de cobertura del suelo alcanzó un $14 \%$. Las diferencias detectadas en cuanto a la cobertura en las diferentes estaciones del período analizado fueron altamente significativas $(p<0,01)$ (Figura 4.41). 


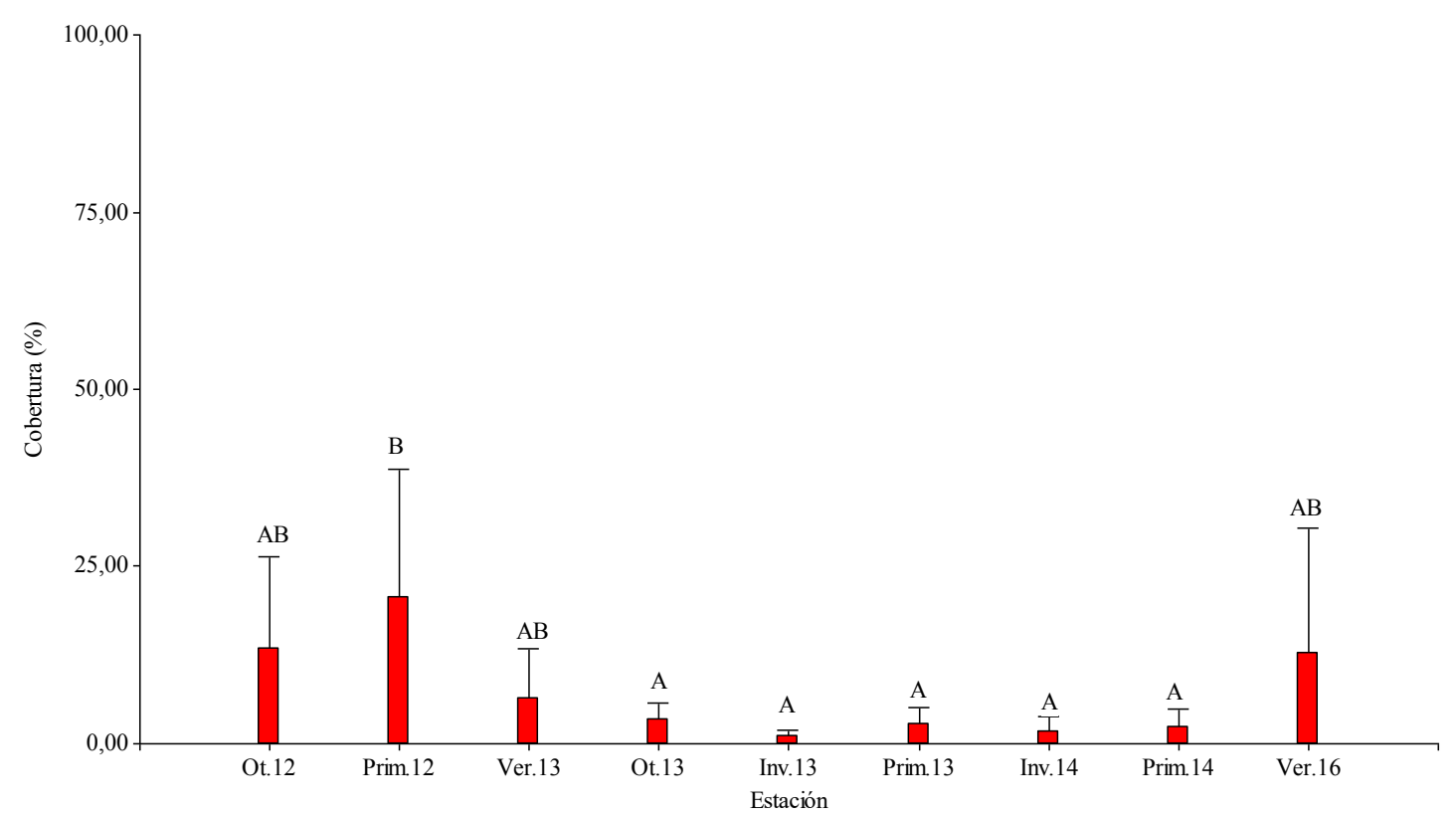

Figura 4.41.Porcentaje (\%) de cobertura del suelo en el sitio Iturburu en otoño (ot), primavera (Prim) y verano (Ver) del período 2012-2016. Medias con una letra diferente indican diferencias significativas $(p<0,05)$

La riqueza específica no mostró diferencias estadísticamente significativas para este sitio, y sus valores variaron entre 3 y 5 especies por fecha (Figura 4.42).

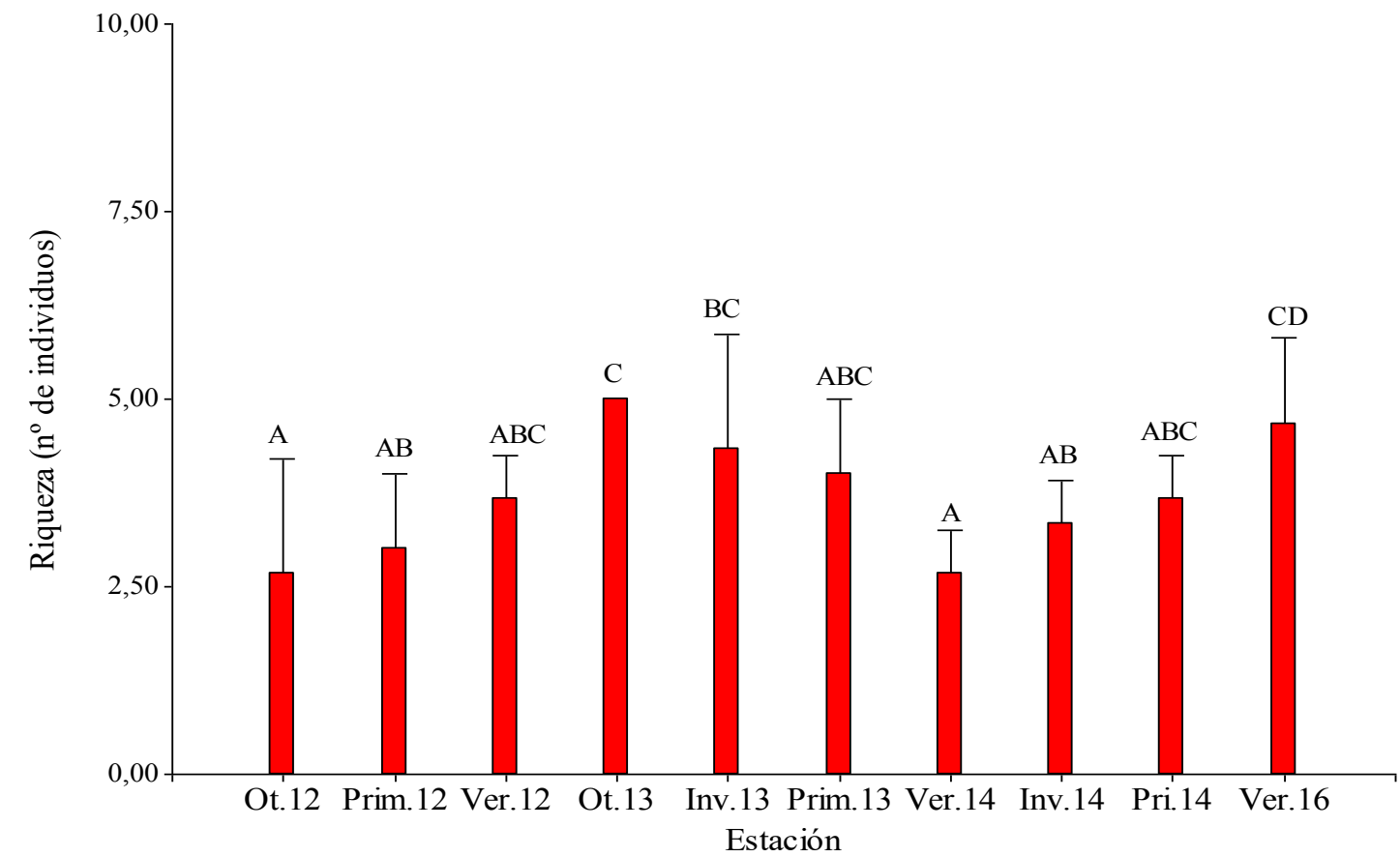

Figura 4.42. Riqueza específica en el sitio Iturburu en otoño (ot), primavera (Prim) y verano (Ver) del período 2012-2016. Medias con una letra diferente indican diferencias significativas $(p<0,05)$.

La cobertura de especies con valor forrajero evidenció una recuperación paulatina, mostrando diferencias altamente significativas entre fechas $(p<0,001)$. Desde la primavera del año 2013 se observan porcentajes de cobertura superiores al 89\%, excepto en verano de 2013 donde este porcentaje es inferior (42\%). En verano del año 
2016, el porcentaje de cobertura de especies con valor forrajero fue de $76 \%$ (Figura $4.43)$.

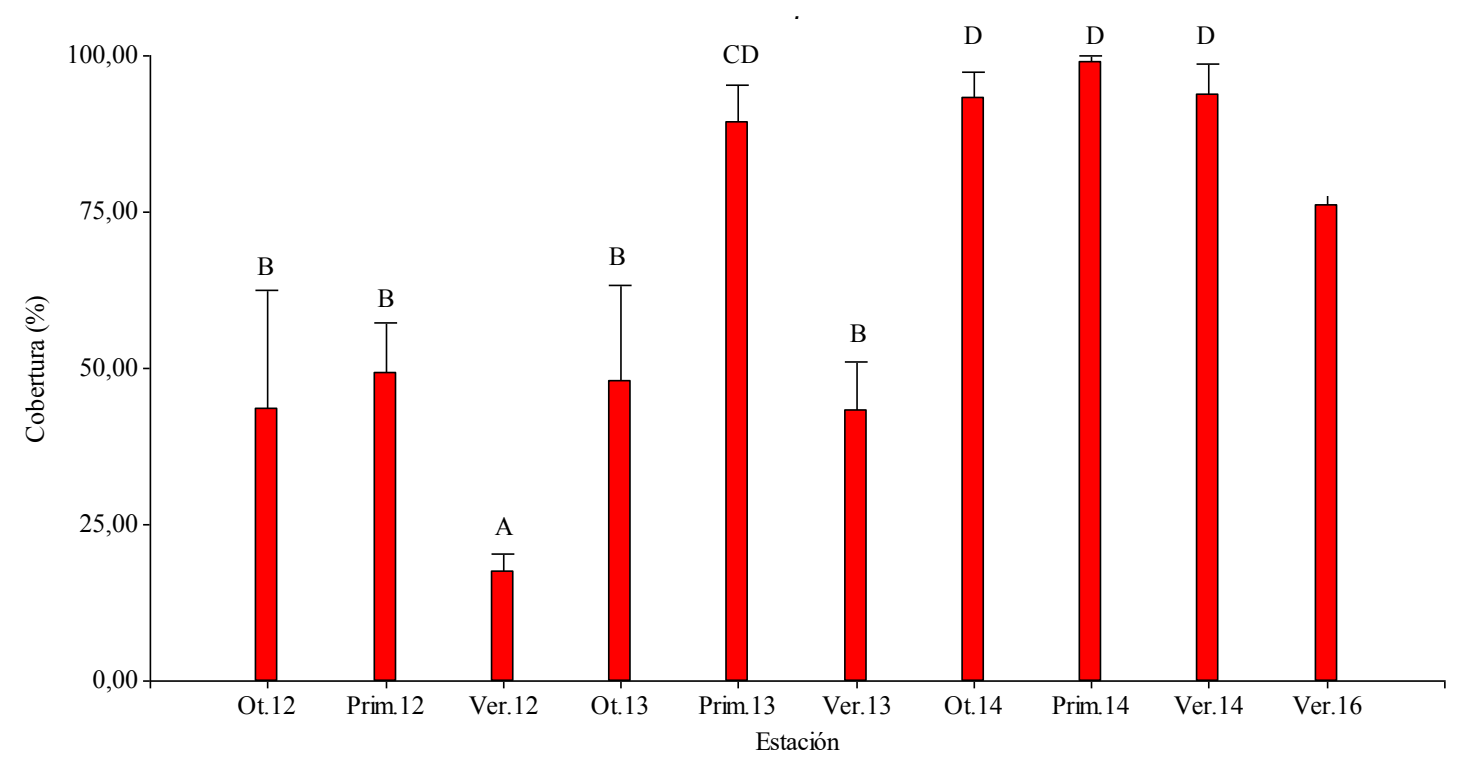

Figura 4.43. Porcentaje (\%) de cobertura de especies con valor forrajero en el sitio Iturburu. Medias con una letra común no son significativamente diferentes $(\mathrm{p}<0,05)$.

4.3.5- Efectos de la rehabilitación activa y pasiva en la cobertura.

En el sitio Bosero, los ensayos de rehabilitación activa, rehabilitación pasiva y control presentaron diferencias significativas para la cobertura del suelo. Los menores porcentajes de cobertura se observaron en el tratamiento de rehabilitación pasiva (37\%), mientras que los máximos niveles de cobertura se registraron en el control. En el tratamiento de rehabilitación activa la recuperación de la cobertura del suelo fue de $81 \%$. El sitio Erripa no presentó diferencias significativas $(p=0,0857)$ entre los ensayos de rehabilitación y el control, con valores que fluctuaron entre 78\% y 41\%. En el sitio Iturburu las diferencias entre tratamientos fueron altamente significativas $(p=0,0036)$, el mayor porcentaje de cobertura se registró en el control (95\%). Comparando los tipos de rehabilitación, la cobertura total fue mayor en las parcelas de rehabilitación activa (83\%) que en las de rehabilitación pasiva (52\%) (Figura 4.44). 


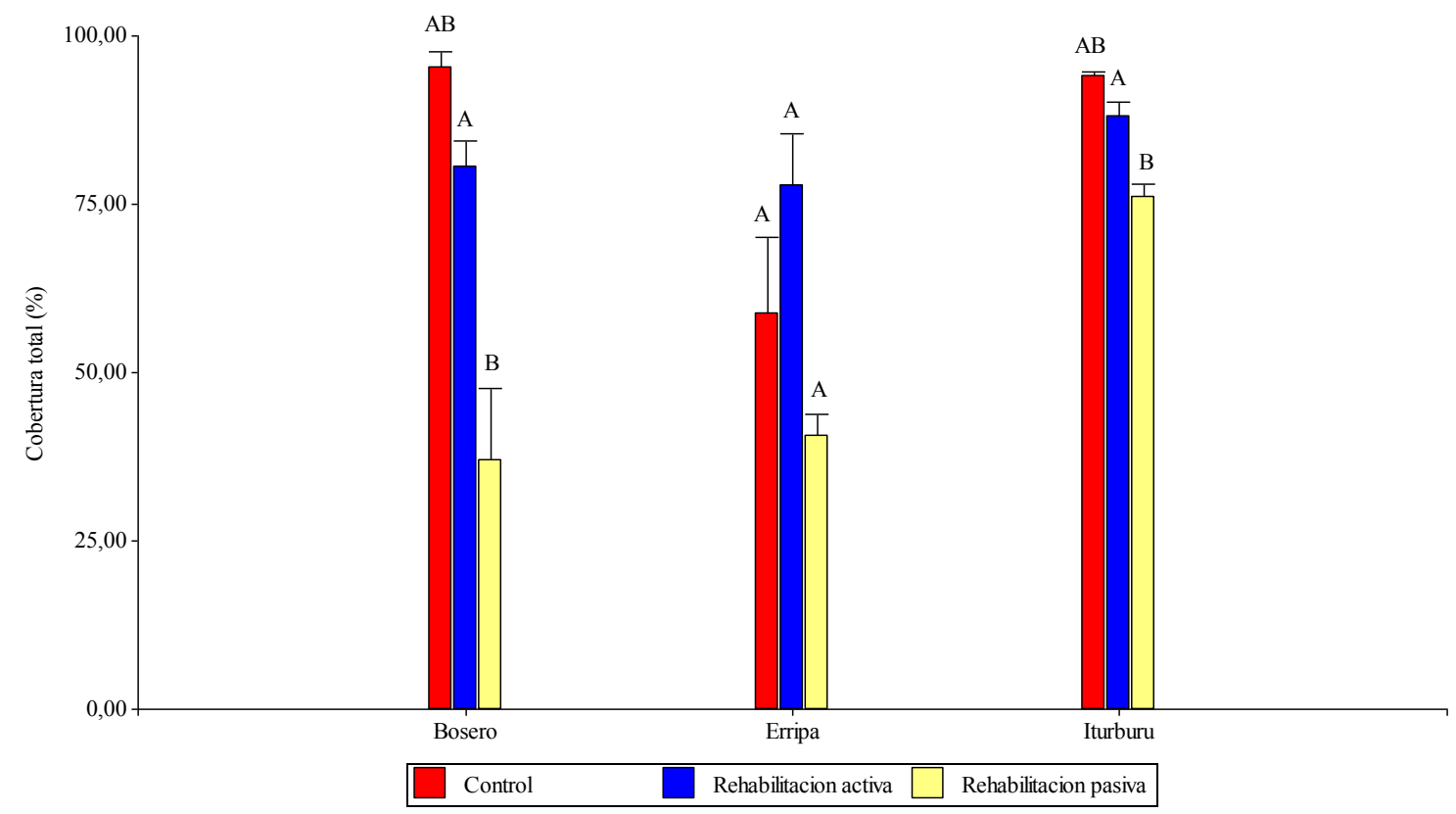

Figura 4.44. Porcentaje (\%) de cobertura del suelo de especies leñosas y herbáceas en cada sitio. Medias con una letra diferente indican diferencias significativas $(p<0,05)$.

El porcentaje de cobertura de especies de ciclo de vida perenne respecto de la cobertura total del suelo presentó un comportamiento variable entre sitios. En el sitio Bosero las diferencias fueron significativas $(p=0,036)$, con valores máximos de cobertura en el control y valores mínimos en el tratamiento de rehabilitación pasiva. En el sitio Erripa no se observaron diferencias significativas $(p=0,439)$, con porcentajes de cobertura que variaron entre $41 \%$ y 59\%. El sitio Iturburu presentó diferencias significativas ( $p$ $=0,049)$, alcanzando valores de $86 \%$ en el control y $85 \%$ en el tratamiento de rehabilitación activa (Figura 4.45).

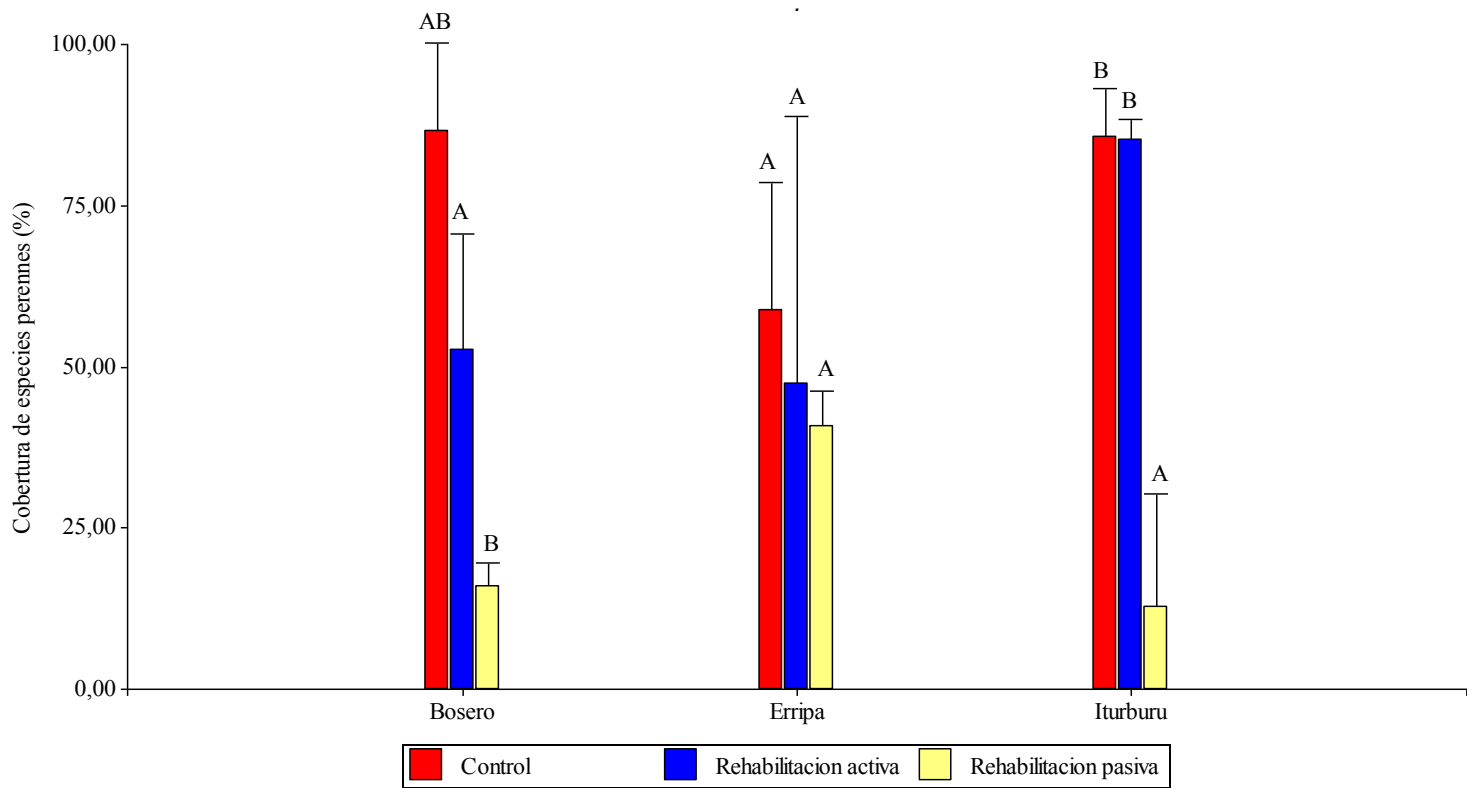

Figura 4.45. Porcentaje (\%) de cobertura del suelo de especies leñosas y herbáceas de ciclo de vida perenne en cada sitio. Medias con una letra diferente indican diferencias significativas $(p<0,05)$. 
La cobertura de especies de ciclo de vida perenne con valor forrajero presentó diferencias significativas entre tratamientos en el sitio Bosero $(p=0,0491)$, observándose los menores porcentajes de cobertura en el control respecto de los tratamientos de rehabilitación activa y pasiva. En el sitio Erripa no se observaron diferencias significativas entre tratamientos $(p=0,95)$ y los valores de cobertura de forrajeras variaron entre $41 \%$ y $50 \%$. En Iturburu, las diferencias fueron altamente significativas $(p=0,0036)$ con $56 \%$ de cobertura de especies forrajeras en el ensayo de rehabilitación activa y 13\% de cobertura en el ensayo de rehabilitación pasiva. En el control no se registró la presencia de especies con valor forrajero (Figura 4.46).

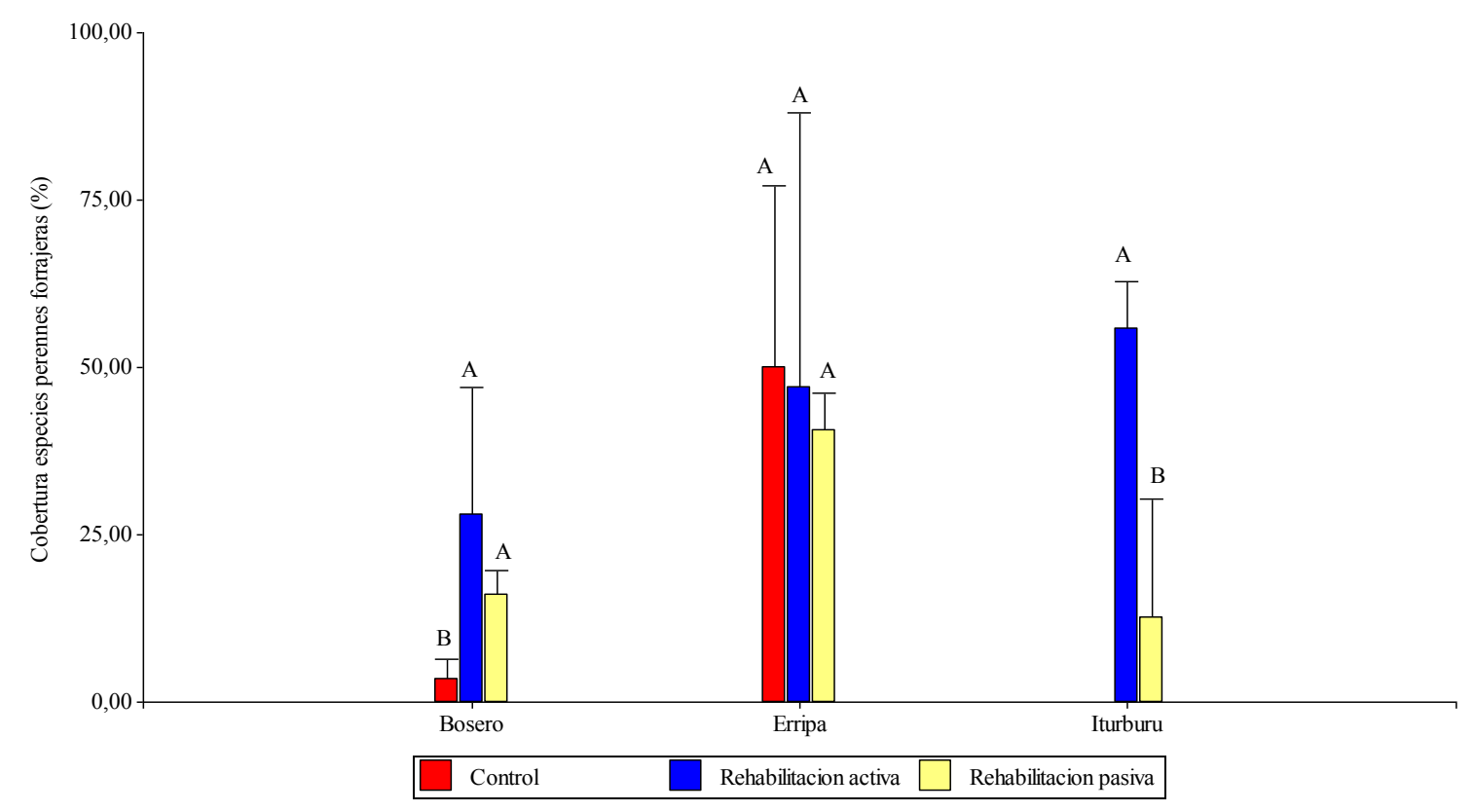

Figura 4.46. Porcentaje (\%) de cobertura del suelo de especies leñosas y herbáceas de ciclo de vida perenne y valor forrajero en cada sitio. Medias con una letra diferente indican diferencias significativas $(p<0,05)$.

La cobertura de especies exóticas no presentaron diferencias significativas entre sitios ( $p=0,061)$, siendo lo menores porcentajes de cobertura de estas especies registrados en el sitio Erripa. La cobertura de las especies nativas que colonizaron el área fueron similares entre los sitios $\sin$ observarse diferencias significativas $(p=0,18)$ (Figura 4.47). 


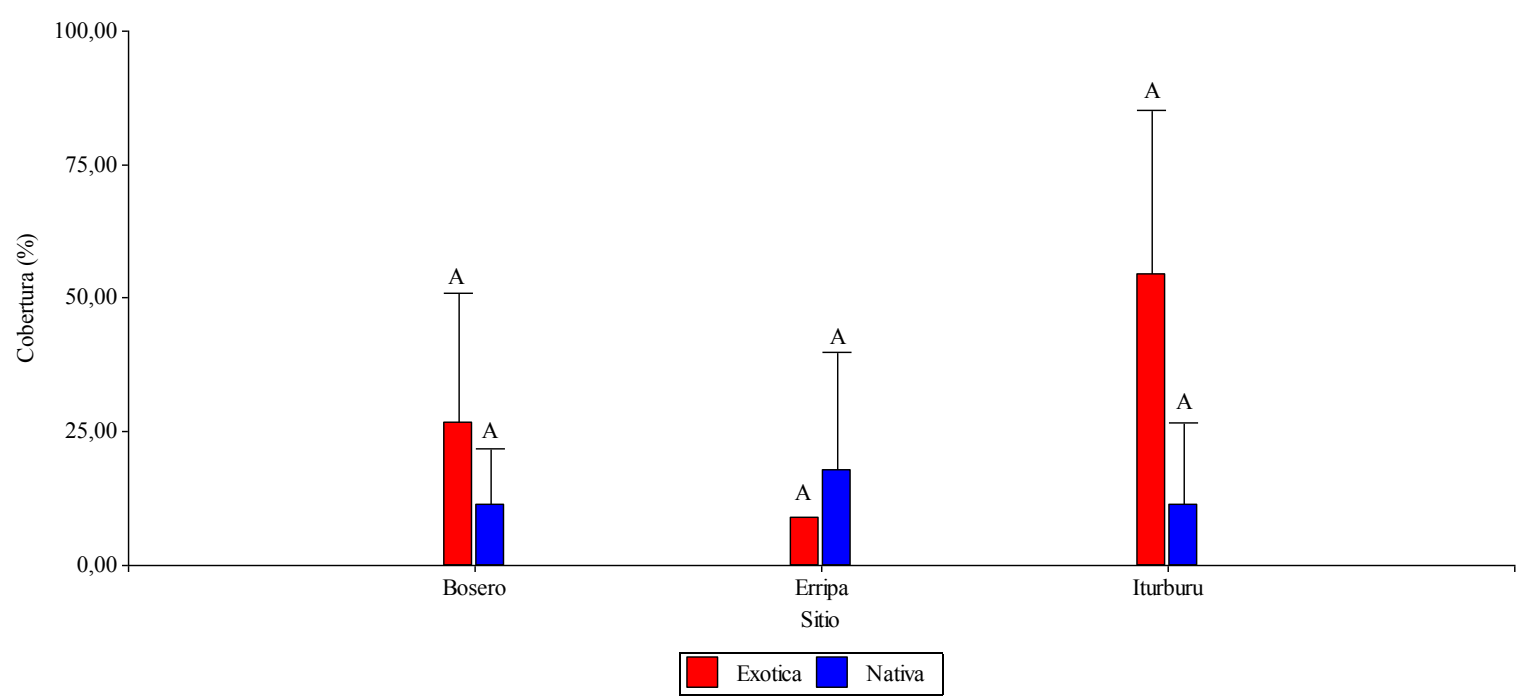

Figura 4.47. Porcentaje (\%) de cobertura del suelo de especies leñosas y herbáceas nativas y exóticas. Medias con una letra diferente indican diferencias significativas $(p<0,05)$.

4.3.6- Relación entre variables ambientales y los efectos de la rehabilitación.

Los dos primeros ejes del análisis de componentes principales, que relaciona la abundancia y riqueza del reclutamiento en los ensayos de rehabilitación activa y pasiva con variables ambientales, permitieron explicar el 78,9\% de la variabilidad de los datos.

La componente principal uno (CP1) explicó el 58,4 \% de la variabilidad y nos permitió diferenciar los sitios según sus características ambientales. Los sitios Erripa e Iturburu se asocian con mayores valores de las siguientes variables: contenido de materia orgánica (M.O.), nitrógeno total (Nt), fósforo (ppm), $\mathrm{pH}$, densidad aparente $\left(\mathrm{gr} / \mathrm{m}^{2}\right)$. Por su parte, el sitio Bosero, aparece asociado a condiciones de suelos de mayor salinidad respecto de los dos sitios restantes (Figura 4.48).

La componente principal dos (CP2), que explica el 20,5\% de la variabilidad, permite observar las diferencias entre la abundancia y la riqueza de especies reclutadas en los ensayos de rehabilitación activa y pasiva. Si bien el sitio Bosero se asoció a una mayor riqueza total y a la ocurrencia de mayores precipitaciones, los sitios Iturburu y Erripa se asociaron al elevado porcentaje de cobertura total, mayor cobertura y riqueza de especies forrajeras y mayor abundancia (Figura 4.48). 


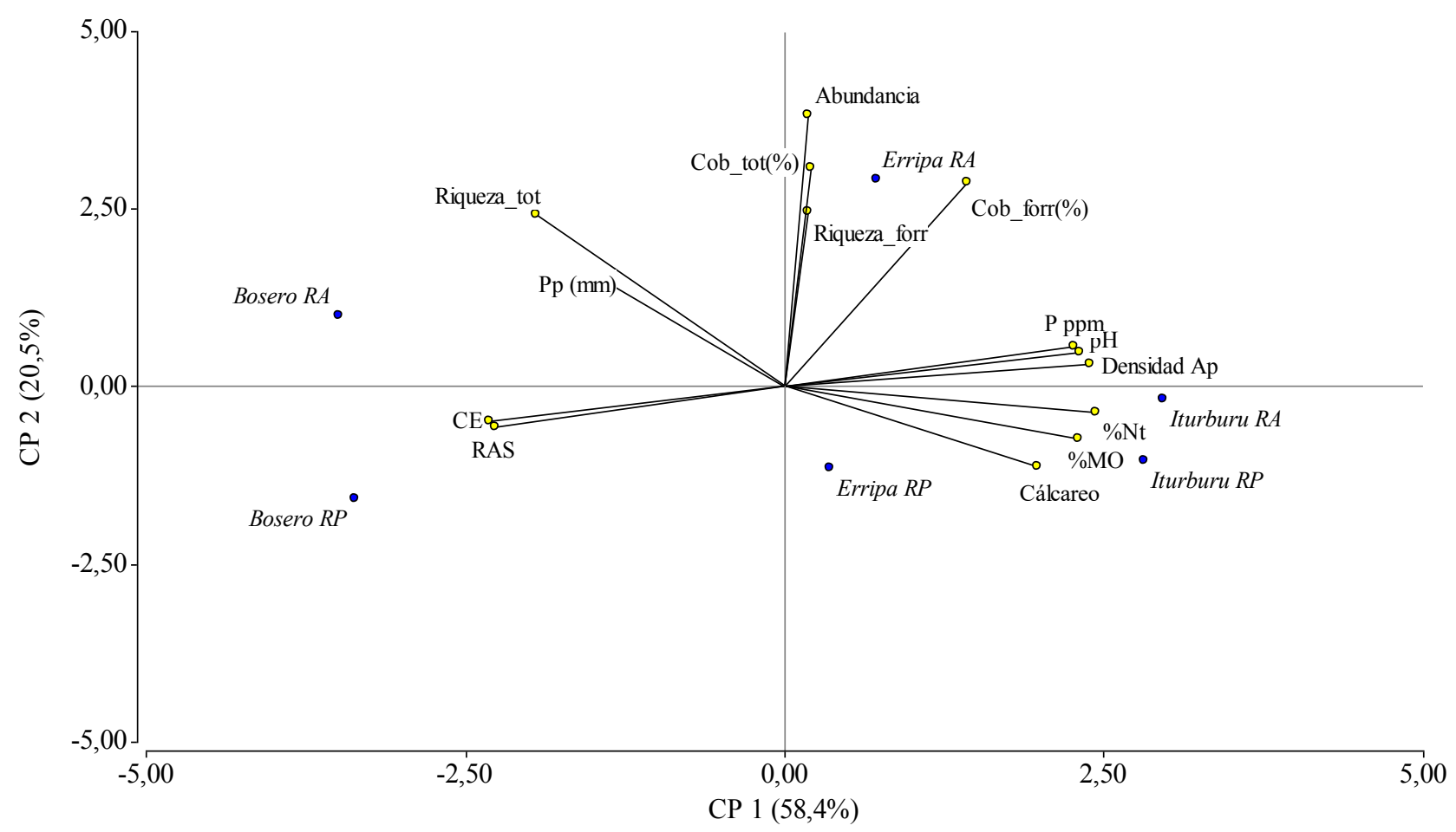

Figura 4.48. Análisis de componentes principales (A.C.P.).(Sito)R.P= Rehabilitación Pasiva en el sitio.(Sitio) R.A.= Rehabilitación activa en el sitio. Pp media= Precipitación media mensual. Pppm= Fósforo $(\mathrm{ppm})$. \%M.O.= Porcentaje de materia orgánica en el suelo. $\% \mathrm{Nt}=$ Porcentaje de nitrógeno total en el suelo. $\mathrm{Ce}=$ Conductvidad eléctrica. $\mathrm{RAS}=$ Relación de adsorción de sodio.

\section{4-4- Discusión.}

\section{Tratamientos pregerminativos}

Las especies seleccionadas en este trabajo crecen y se desarrollan bajo una amplia gama de condiciones ambientales, desde suelos poco profundos en zonas elevadas hasta áreas deprimidas del paisaje con suelos más profundos (Ludwing et al. 2005; Tongway y Hindley 2005; Godagnone y Bran 2009). Para realizar ensayos de rehabilitación activa es importante conocer los métodos más adecuados que favorezcan la propagación de las especies seleccionadas, especialmente en zonas que presenten déficit hídrico en alguna estación del año (Torres et al. 2014).

Las semillas de algunas especies seleccionadas en el presente trabajo para los tratamientos de rehabilitación activa, presentan dormición física debido a la cubierta dura e impermeable que poseen (Catalán y Balzarini 1992; Villagra et al. 2011), por lo que resultó necesario aplicar tratamientos pregerminativos para romper la latencia y promover la germinación. Los diferentes tratamientos pregerminativos aplicados a las semillas de especies nativas presentes en el Noreste de la Patagonia nos permitió 
identificar cuáles son los más adecuados y lograr la producción de ejemplares con similares grados de desarrollo.

Las especies $C$. microphylla y $G$. decorticans mostraron un mejor comportamiento a la exposición al ácido sulfúrico durante 32 minutos, aunque los porcentajes de germinación fueron bajos. Los resultados obtenidos en los presentes ensayos con $C$. microphylla fueron más elevados que los reportados por Peláez et al. (1996). Esto autores no obtuvieron respuesta en el control y en los tratamientos de escarificación mecánica y los mejores porcentajes de germinación fueron exponiendo las semillas a ácido sulfúrico concentrado durante una hora. Para la especie G. decorticans, Pece et al. (2014) reportaron porcentajes superiores a los aquí obtenidos para esta especie. Estos autores, sirviéndose de diferentes métodos de escarificación mecánica, procedieron a despuntar y embeber en agua las semillas alcanzando porcentajes de germinación de $82 \%$. La diferencia en los resultados alcanzados con la escarificación mecánica podrían deberse al método empleado en la degradación del pericarpio de las semillas de $G$. decorticans. Pece et al. (2014) emplearon métodos en los cuales se fracturaba el pericarpio, mientras que en este trabajo se usaron lijas, evidenciando la necesidad de un tratamiento más agresivo para obtener mejores resultados.

Schinus johnstonii mostró un mayor porcentaje de germinación cuando las semillas no fueron expuestas a ningún tratamiento de escarificación y solo se eliminó el pericarpio. Estos resultados concuerdan con los reportados por Díaz Arias (2016) quién removió el pericarpio a las semillas de Schinus fasciculatus y aplicó tratamientos de escarificación física y química a sus semillas, obteniendo los porcentajes de germinación más altos en el testigo, al cual solamente se le retiró la cubierta exterior y remojaron sus semillas con agua a temperatura ambiente.

Las especies del género Prosopis mostraron una mejor respuesta en aquellas semillas que fueron expuestas al tratamiento de escarificación química durante 32 minutos, a excepción de $P$. denudans, que ofreció una mejor respuesta a la escarificación mecánica. Estos resultados concuerdan con los obtenidos por de Villalobos et al. (2002), de Villalobos y Peláez (2001), Villagra (2000), para semillas de P. caldenia, P. flexuosa y $P$. alpataco, respectivamente. Sin embargo, los tiempos de exposición de las semillas al ácido sulfúrico empleados por estos autores fue mayor, usando períodos de exposición de 45 minutos. Por otra parte, Catalán y Balzarini (1992) y Prokopiuk y 
Chifa (2000) observaron para P. flexuosa mayores porcentajes de germinación en la escarificación mecánica en comparación con la escarificación química. Posiblemente, estas diferencias se deberían a la eficiencia en la aplicación de los tratamientos de lijado de la cubierta seminal que provocarían diferencias en los resultados obtenidos por los diferentes autores.

Las compuestas leñosas, que carecen de un epicarpio duro e impermeable, no fueron sometidas a tratamientos pregerminativos que degraden la cubierta seminal. Las semillas de este tipo mostraron porcentajes de germinación bajos, excepto para la especie Cyclolepis genistoides que alcanzó 43\% de germinación. Estos resultados concuerdan con los porcentajes de germinación reportados por Peter et al. (2014), excepto para la especie $C$. genistoides, donde estos autores obtuvieron valores inferiores de germinación a los reportados en el presente estudio.

Las gramíneas presentaron porcentajes de germinación muy variables. Los resultados observados para las especies Nassella longiglumis, Nassella tenuis y Piptochaetium napostaense concuerdan con los reportados por Bonvissuto y Busso (2007) en una estepa arbustivo graminosa del Monte Austral, en la provincia de Neuquén. Para la especie Pappophorum caespitosum, ampliamente difundida en la zona y de excelente aptitud forrajera, los porcentajes de germinación de sus semillas estuvieron por debajo del 50 \% y coinciden con los reportados por Entio et al. (2016) y Kröpfl et al. (2011).

Si bien las especies Jarava plumosa y Poa ligularis son de amplia distribución en el área de estudio y de alto grado de preferencia por parte del ganado doméstico, no se registraron antecedentes sobre la germinación y la propagación de estas especies. La especie $P$. ligularis no mostró respuesta frente a los tratamientos, mientras que $J$. plumosa presentó porcentajes de germinación elevados.

\section{Supervivencia y crecimiento de especies nativas}

La supervivencia temprana de los individuos plantados fue elevada, estos valores pueden asociarse con las prácticas de rustificación previas al trasplante a campo. Para la obtención de altos porcentajes de supervivencia, el plantel de individuos destinados a la rehabilitación ecológica no debe ser demasiado longevo, siendo deseable usar ejemplares que a la hora del trasplante estén por ingresar en su primera etapa vegetativa (Cortina com. pers.). Los individuos de especies nativas producidos en invernadero que 
serán destinados a ensayos de rehabilitación ecológica deberían ser sometidos a tratamientos de rustificación, con la finalidad de que se adapten paulatinamente a las condiciones ambientales de alta insolación, mayor evapotranspiración y marcado estrés hídrico bajo las cuales se desarrollaran (Cortina y Del Campo 2006). López Launstein et al. (2012) observaron mayor supervivencia en individuos de tres especies del género Prosopis que fueron sometidos a tratamientos de rustificación, induciendo diferentes niveles de estrés hídrico, previos al trasplante a campo. Por otra parte, Guarnaschelli et al. (2006), han demostrado que plantas sometidas a períodos de estrés moderado pueden desarrollar resistencia y soportar períodos de estrés prolongados, mejorando su supervivencia y crecimiento ante condiciones limitantes.

La especie leñosa Condalia microphylla fue la que mostró menores valores de supervivencia. Esta respuesta puede deberse a la alta sensibilidad al estrés hídrico que posee esta especie en la etapa de establecimiento. Estos efectos adversos fueron reportados por Peláez et al. (1996) para el establecimiento de renovales de esta especie en un área del caldenal de la provincia de La Pampa, donde registró porcentajes de supervivencia inferiores a los reportados en este trabajo.

Los elevados valores de supervivencia temprana obtenidos para Prosopis flexuosa son coincidentes con los reportados por López Lauenstein et al. (2012) para la supervivencia de diferentes especies del género Prosopis. En ese estudio P. flexuosa mostró elevado porcentaje de supervivencia, tanto bajo condiciones de estrés hídrico moderado y severo en ensayos en invernadero, como también bajo condiciones ambientales contrastantes en ensayo a campo. La especie Prosopis flexuosa crece y se desarrolla bajo una amplio gradiente de precipitaciones y temperatura, haciéndola tolerante a elevados niveles de estrés abiótico (Alvarez y Villagra 2009). Esta característica de la especie le permitiría establecerse y desarrollarse en suelos arenosos y suelos francos con profundidades variables. Además, posee un rápido crecimiento de su raíz principal que le permite explorar el suelo más profundo en busca de humedad. Goeffroea decorticans y Schinus johnstonii presentaron porcentajes de supervivencia temprana similares a los de $P$. flexuosa, sin registrarse diferencias entre los distintos sitios de ensayo.

La supervivencia tardía, evaluada en el verano 2015- 2016, mostró porcentajes inferiores a la supervivencia temprana y variables de acuerdo a la especie considerada. Esta disminución podría estar relacionada con la variabilidad inter e intra anual de las 
precipitaciones en concordancia con lo referido por Godagnone y Bran (2009). Los mayores registros de precipitación ocurrieron en el otoño y en la primavera y los más bajos en verano, momento en que las necesidades evapotranspirativas de las plantas son máximas a causa de la alta exposición a la luz solar, las elevadas temperaturas y los fuertes vientos. El umbral crítico a superar en la introducción de especies a campo en zonas áridas y semiáridas es la primer temporada estival post trasplante, en la cual se observarán las mayores tasas de mortalidad (Maestre et al. 2006). Además, en el área de estudio, se observaron numerosas poblaciones de liebre patagónica (Dolichotis patagonum) que ramonearon los ejemplares de especies leñosas y herbáceas y causaron severos daños.

P. flexuosa y S. johnstonii fueron las especies que alcanzaron los mayores porcentajes de supervivencia tardía sin mostrar diferencias entre sitios, lo cual demuestra la capacidad de estas especies de ajustarse a un amplio rango de condiciones de fertilidad del suelo y disponibilidad hídrica. G. decorticans y C. microphylla arrojaron valores de supervivencia tardía bajos, debido a los daños causados por el marcado estrés hídrico registrado en la temporada estival de los meses de diciembre de 2013 y enero- febrero de 2014. En G. decorticans se observaron cortes del tallo al ras del suelo, ocasionado por el ramoneo de las liebres patagónicas, que poseen el hábito de eliminar individuos de poco porte que obstruyan su panorama e impidan observar posibles depredadores (Alonso Roldán et al. 2017). Las especies P. flexuosa y S. johnstonii superaron los períodos de escasez de precipitaciones y altas temperaturas de forma más eficiente que las otras especies leñosas, registrándose la pérdida de la totalidad de sus hojas y la coloración amarilla del tallo principal. En un área con marcado estrés hídrico, Jobbágy et al. (2011) y Villagra et al. (2011) observaron que los individuos juveniles de $P$. flexuosa presentaban un xilema con numerosos vasos pequeños y agrupados, lo que podría indicar una mayor resistencia a la cavitación por estrés hídrico. Esta adaptación de los individuos juveniles de P. flexuosa podría ser la causal de los elevados porcentajes de supervivencia tardía en los ensayos de rehabilitación activa, además que en $P$. flexuosa y $S$. johnstonii no se registraron daños causados por la fauna silvestre. Posiblemente, la morfología de los renovales de $P$. flexuosa, S. johntonii y $C$. microphylla, los cuales presentan un tallo leñoso, más rígido y con mayor número de espinas que $G$. decorticans, haya influido en el grado de daño causado por liebre patagónica en los ensayos de reintroducción de especies. 
El crecimiento de las especies $P$. flexuosa y $S$. johnstonii fue mayor que el de las especies $G$. decorticans y $C$. microphylla. Se dispone de escasos antecedentes acerca del crecimiento de G. decorticans. Giménez et al. (2013) evaluaron, mediante el conteo y medición del espesor de los anillos del tronco, el incremento diamétrico de $G$. decorticans, observando un crecimiento mayor al registrado en este trabajo. La comparación de estos resultados se dificulta debido al efecto generado por la fauna silvestre sobre esta especie los cuales causaron menores ritmos de crecimiento. En cambio, no se cuenta con datos sobre $C$. microphylla pero nuestros resultados mostraron una baja tasa de crecimiento respecto de las demás especies evaluadas.

Prosopis flexuosa, al ser una especie muy difundida a lo largo de la diagonal árida Argentina, cuenta con innumerables estudios donde se evalúan diferentes aspectos de su ecología. Diversos autores han reportado las tasas de crecimiento de ejemplares adultos y de plantines de esta especie, indicando valores de crecimiento en altura y diámetro del tallo que varía de acuerdo a la región en que se desarrolle el trabajo. López Lauenstein et al. (2012) reportaron para las provincias de Córdoba y La Rioja tasas de incremento de la altura y del diámetro del cuello de los individuos de $P$. flexuosa superiores a los registrados para el Noreste de la Patagonia. Dalmasso (2010) evaluó el crecimiento de P. flexuosa en la restauración de taludes petroleros abandonados en la región de la Payunia, provincia de Neuquén. Este autor registra incrementos de la altura y del diámetro de la copa de $30 \%$ y 40\%, respectivamente. Villagra et al. (2005), empleando técnicas de dendrocronología, evaluaron el incremento diamétrico de ejemplares adultos y renovales de $P$. flexuosa de la provincia de Mendoza reportando valores del orden de los 25 milímetros para los juveniles. Las diferencias observadas en el crecimiento de esta especie podría deberse a diferencias entre las poblaciones estudiadas y a la adaptación a las características ambientales de cada zona. Las variables climáticas y edáficas de cada lugar en particular, actúan modificando el comportamiento de $P$. flexuosa, que es una especie freatófita facultativa. Ésta desarrolla un sistema radicular dimórfico constituido por una raíz principal leñosa, vertical, y de rápido desarrollo comparado con la parte aérea del individuo, y una corona de raíces superficiales. Este sistema radical le permite a la especie explotar más eficientemente el agua disponible en el suelo superficial o el agua de la napa freática, según su disponibilidad. Además, este comportamiento de la especie le permite independizarse de los regímenes 
pluviométricos debido a la exploración de recursos hídricos profundos (Jobbágy et al. 2011; Villagra 2000; Villagra et al. 2011).

Las gramíneas mostraron un elevado porcentaje de supervivencia temprana, siendo Pappophorum caespitosum la que presentó menor porcentaje de supervivencia. Esta especie megatérmica es una $\mathrm{C} 4$ y mostró ser sensible a las bajas temperaturas, tanto en su etapa de establecimiento como en su etapa madura. Esta sensibilidad a la temperatura se manifiesta por la baja proporción de follaje verde de sus individuos y la coloración violácea de sus hojas durante el invierno (Dalmasso 1994; Rauber et al. 2014). En la temporada estival del año 2016, la supervivencia descendió notablemente pero no presentó diferencias entre las especies. Este descenso en la supervivencia tardía se debe, en gran parte, a los daños ocasionados por el ramoneo del ganado vacuno (bordes de las parcelas) y la fauna nativa. El crecimiento de las gramíneas presentó diferencias debidas, en mayor medida, al porte característico de cada una de ellas. Así, $P$. napostaense fue la que mayor altura alcanzó, seguida de $N$. tenuis y $P$. caespitosum. De acuerdo a la caracterización de las especies realizada, $N$. longiglumis debería haber alcanzado una altura similar a la de $P$. napostaense, pero debido al alto grado de preferencia que posee, esta especie no logró desarrollarse ya que evidenció un mayor grado de consumo que las otras especies por la fauna autóctona. Es posible que la mayor parte del daño observado en $N$. longiglumis pueda adjudicarse a $D$. patagonum, que basa su dieta principalmente en especies graminiformes (Puig et al. 2010).

En todos los individuos de las gramíneas plantadas se observó, desde la primera etapa de crecimiento, la generación de estructuras reproductivas. Este sería un rasgo deseable que alentaría la adopción de estas especies para rehabilitar sitios con avanzados signos de degradación y que requieren de una rápida recuperación de la cobertura del suelo. En la provincia de La Rioja se han desarrollado experiencias de rehabilitación ecológica de pastizales naturales. Quiroga et al. (2009) evaluaron el efecto del agregado de semillas de Pappophorum phylipianum bajo diferentes tratamientos de rehabilitación activa, demostrando que la introducción de semillas de las especies deseadas, combinadas con elementos que generen condiciones favorables a nivel de micrositio, permitirían la rehabilitación de estos ambientes áridos. Las especies leñosas, que tienen ritmos de maduración reproductiva más lento (Whitford 2002), no generaron estructuras reproductivas durante los años de ensayo y sería deseable continuar con el monitoreo 
para establecer el período necesario para que comiencen a producir estructuras reproductivas.

\section{Efecto de los individuos trasplantados sobre el reclutamiento}

El efecto que tuvieron los individuos de las especies leñosas trasplantados sobre el reclutamiento, no mostró diferencias entre las especies empleadas en los ensayos de rehabilitación activa. Sin embargo, la abundancia de individuos reclutados y la riqueza de especies espontáneas en los sitios Bosero e Iturburu fueron más altas respecto del sitio Erripa. El reclutamiento de las especies herbáceas presentó un patrón similar al de las especies leñosas. Las diferencias en las tasas de reclutamiento entre sitios sugieren que la textura del suelo actuaría como una de las principales limitantes frente al establecimiento de renovales de especies nativas, dado que es una de las variables que más influye sobre el agua que retendrá en su matriz. El estrés hídrico es señalado como el factor limitante más importante en el establecimiento de la vegetación en la región (Gaitán et al. 2008; Maestre et al. 2001; Soliveres et al. 2014). El sitio Erripa, que posee suelos arenosos, posiblemente retiene menos agua, mientras que en los sitios Bosero e Iturburu, con suelos franco arenosos, la mayor retención de agua posiblemente determina un estrés hídrico menos marcado que en Erripa, permitiéndole a las plántulas establecerse y desarrollarse.

Dentro de las especies reclutadas en los ensayos de rehabilitación no se registraron leñosas, posiblemente por la ausencia de un banco de semillas viable y por la ausencia en las cercanías de fuente de semillas. Los ejemplares de leñosas trasplantados no fructificaron en el período de mediciones. Las especies reclutadas fueron todas herbáceas de ciclo de vida anual y perenne. Aunque estas especies anuales registradas son preferidas por el ganado, no son una fuente de forraje importante debido al escaso volumen que presentan. Las especies herbáceas trasplantadas en los ensayos de rehabilitación activa generaron estructuras reproductivas en un corto lapso de tiempo, permitiéndole diseminarse rápidamente, formar un banco de semillas homogéneo en el área de ensayo y colonizar espacios vacíos próximos a los ejemplares trasplantados. Resultados similares fueron obtenidos por Bisigato y Bertiller (1999; 2004), quienes observaron mayores porcentajes de establecimiento y supervivencia de plántulas en sitios cercanos a ejemplares adultos de especies herbáceas $\mathrm{y}$, en menor medida, de especies leñosas. Estas especies actuarían como facilitadoras ya que las condiciones a 
nivel de micrositio que generan ofrecen condiciones favorables para el establecimiento de plántulas de especies leñosas y herbáceas. Los individuos adultos de estas especies mejoran la disponibilidad de humedad edáfica y de elementos nutritivos para las plantas. Este efecto facilitador también fue reportado para otros ecosistemas áridos y semiáridos del mundo. En ecosistemas mediterráneos de España, dominados por Stipa tenacissima (Esparto), Maestre et al. (2001) observaron el efecto positivo que esta especie tuvo sobre la supervivencia de plántulas de especies leñosas implantadas debajo de las matas. Maestre et al. (2006), obtuvo elevados niveles de supervivencia de Quercus coccifera y Pistaccia lenticus trasplantados al reparo de S. tenassissima que actúa como especie nodriza. Cortina et al. (2011), reportaron el efecto facilitador a nivel de micrositio de semillas de Ramnus lycioides y S. tenacissima en áreas sombreadas reduciendo el estrés hídrico de las plántulas. Por su parte, Valencia et al. (2015), observaron que el proceso de arbustificación genera un impacto positivo sobre la diversidad funcional de especies debido a la mayor cantidad de micrositios con condiciones favorables disponibles para la instalación de plántulas de especies nativas.

\section{Efecto de la rehabilitación pasiva y activa}

Los parámetros edáficos evaluados variaron entre sitios y sus valores dependieron del relieve y el tipo de suelo. Además de la exposición a los vientos y el régimen pluviométrico, los sitios difirieron en su historia de uso del suelo, variables que afectaron la respuesta a los diferentes tratamientos de rehabilitación aplicados.

Si bien en los ensayos de rehabilitación pasiva se recuperó la cobertura vegetal total y la cobertura de especies perennes en similar porcentaje que en los ensayos de rehabilitación activa, fue solamente en estos últimos donde se obtuvieron mejores valores de cobertura de especies con valor forrajero. En el Noreste de la Patagonia la recuperación de áreas degradadas se alcanza eliminando el factor causante de disturbio y tomando acciones proactivas para recuperar las especies más deseables.

El éxito relativo de las tareas de rehabilitación activa y pasiva en regiones áridas y semiáridas depende en gran parte del grado de deterioro del ambiente. El grado de estabilidad del ecosistema y la posibilidad de recuperarse tras una serie de disturbios, estará determinada por los umbrales de degradación superados. Estos umbrales pueden ser bióticos o abióticos (Hobbs et al. 2006). Existe una dificultad creciente en la recuperación si se han superado umbrales bióticos o abióticos. Con la eliminación del 
factor causante de disturbio se da lugar a la sucesión secundaria del ecosistema y se recobran los atributos perdidos del sistema biótico. En cambio, si el umbral superado fue el abiótico, con la degradación y pérdida de las propiedades del suelo, las tareas de recuperación serán más dificultosas y onerosas, ya que habrá que actuar para restaurar el sustrato degradado (Harris et al. 2006; Hobbs y Cramer 2008; Papanastasis 2009). En los sitios del presente trabajo se habría superado solo el umbral biótico. En términos generales, la cobertura total del suelo fue más baja en el sitio Erripa que en los otros dos, y similar entre los tratamientos de rehabilitación y el control. Esto podría deberse a que este sitio estuvo muchos años bajo agricultura extensiva de secano, lo que eliminó las semillas del banco y disminuyó la provisión e ingreso de las mismas desde áreas próximas, dificultando la recolonización en las áreas destinadas a rehabilitación pasiva y al control. En el área de rehabilitación activa, si bien existió ingreso de semillas aportadas por los individuos trasplantados, las condiciones ambientales del sitio podrían haber dificultado el establecimiento y desarrollo de las plántulas de estas especies. En los sitios Bosero e Iturburu el ganado bovino, presente con una carga animal media, causó la eliminación de la cobertura de especies palatables, en su mayoría nativas, permitiéndole a las especies exóticas, de bajo valor forrajero, dispersarse en las áreas externas a los ensayos de rehabilitación activa y pasiva. En las áreas clausuradas las exóticas estuvieron ausentes, posiblemente debido a la ocupación del terreno por parte de las nativas, ya sean plantadas o espontáneas. La probabilidad de que un ambiente sea colonizado por especies invasoras está relacionado negativamente con la diversidad de especies, ya que se supone que más especies usarán más recursos, obstruyendo la colonización de especies exóticas (D’Antonio y Meyerson 2002; Gibson 2009; Vitousek et al. 1997).

En los tres sitios, en las áreas no clausuradas, se observó la aparición espontánea de especies exóticas, de ciclo de vida anual, que colonizaron extensas áreas. Estas especies fueron Salsola kali (cardo ruso), Hirschfeldia incana (mostacilla) y Diplotaxis tenuifolia (flor amarilla) que aparecen acompañadas por otras especies anuales nativas y especies anuales naturalizadas, preferidas por el ganado, pero que no representan una fuente de forraje por el escaso volumen que generan (Schismus barbatus, Medicago mínima, Dichondra sp y Erodium cicutarium) (Giorgetti et al. 1997). Si bien en la región no se han desarrollado experiencias similares de rehabilitación de ecosistemas, Bisigato y Bertiller (1997) observaron el reemplazo de especies nativas por exóticas a 
medida que aumentaba la presión de pastoreo. En nuestro trabajo, la carga animal puede haber actuado como modelador de la comunidad, disminuyendo la competencia entre las especies nativas y exóticas en los controles, explicando la mayor cobertura de estas últimas fuera de las áreas clausuradas de los sitios Bosero e Iturburu.

Otros autores han evaluado la rehabilitación pasiva en tierras áridas y semiáridas. Beltran et al. (2014) evaluó la recuperación de la cobertura del sistema en la Isla Santa Cruz, California, eliminando el ganado. Luego de 40 años de exclusión registró una disminución de $30 \%$ del suelo desnudo, un incremento de $23 \%$ de la vegetación leñosa y 47\% de vegetación herbácea. Tabeni et al. (2016) en la provincia de Mendoza, evaluó la recuperación en tierras agrícolas abandonadas. Luego de 40 años, estas tierras recuperaron la cobertura hasta alcanzar $34 \%$ de la cobertura total del suelo, la cual estaba conformada por arbustos y no se registraron especies herbáceas anuales ni perennes. Loydi et al. (2012), en pastizales templados de Sierra de la Ventana, observó la recuperación de la cobertura de pastos perennes, anuales y la riqueza de ellos en áreas clausuradas al pastoreo de ganado equino cimarrón. Además, en los sitios pastoreados, cuantifica el porcentaje de suelo desnudo, el cual es muy superior al encontrado en las áreas clausuradas. Rey Benayas et al. (2008) plantea que la recuperación de los ambientes que fueron empleados en la producción agrícola, posteriormente abandonados y colonizados por especies de plantas y animales mediante la rehabilitación pasiva, demandarán un lapso de tiempo mayor a la rehabilitación activa, debido, entre otras limitaciones, a la baja tasa de dispersión de semillas, ya que provendrán de lugares distantes. Frente a estas limitaciones, la rehabilitación activa se presenta como una práctica importante ya que reduciría el tiempo de recuperación de los ambientes degradados y permitiría introducir especies deseables. En nuestro trabajo, a pesar de haber alcanzado la recuperación de la cobertura vegetal en los ensayos de rehabilitación pasiva, se observó una menor colonización de especies forrajeras. Posiblemente, la composición del banco de semillas sea la causa de la menor presencia de estas especies, por lo que es importante continuar con el monitoreo de la dinámica natural de la vegetación para conocer el tiempo requerido en recuperar la cobertura de especies con valor de uso forrajero.

Las propiedades más importantes a recuperar en los ensayos de rehabilitación ecológica son la cobertura, la diversidad de especies y la productividad primaria neta del ecosistema. En varias ocasiones es observable una recuperación espontánea, cuando los 
disturbios son de baja o media intensidad, que favorecen la dinámica de las poblaciones vegetales presentes, por lo que es deseable mantener niveles bajos de pastoreo o fuegos de baja intensidad (Palmer et al. 1997). Sin embargo, cuando los disturbios son de gran magnitud puede ser necesaria la intervención activa para la recuperación de la funcionalidad del sistema. Existe un amplio debate entre la aplicación de tratamientos de rehabilitación activa y pasiva debido a la variedad de resultados que se alcanzan en los diferentes ecosistemas del mundo que son intervenidos activa o pasivamente. Zahawi et al. (2013; 2014), para los bosques templados de Costa Rica, realza la potencialidad de la restauración pasiva frente a la restauración activa. Indica niveles de recuperación de la vegetación madura similares, aunque en lapsos de tiempo mayores, de aquellos ambientes degradados por la producción campesina. Además, es menor el número de horas de trabajo y son menores los costos en materiales e insumos requeridos para lograr la recuperación de esos ambientes. En comparación con la rehabilitación activa, no solo presenta una desventaja en relación al tiempo requerido, sino también en la percepción que los campesinos locales pueden tener del proyecto de restauración y de sus objetivos, tomando los resultados alcanzados como un fracaso y destinando esas tierras a usos no compatibles con la restauración y la conservación del patrimonio natural. Sin embargo, Prach y del Moral (2015) indican que la restauración pasiva no siempre es más lenta que la restauración activa, y las metas de restauración no deben enfocarse siempre en el rápido desarrollo de la estructura y función de la vegetación madura, sino que es importante considerar el costo económico y social de desarrollo del proyecto. Incluso una vegetación menos madura puede poseer altos valores de conservación y proporcionar servicios ambientales importantes. En regiones áridas y semiáridas Méndez et al. (2008) consideran que la dispersión de semillas, la sucesión y la funcionalidad de los ecosistemas son elementos claves que están referidos a la restauración pasiva de estos ambientes $\mathrm{y}$, en reiteradas oportunidades, son complementarios a intervenciones activas. Sin embargo, Valladares y Gianoli (2007) indican que conocer aspectos ecológicos de las especies empleadas en restauración activa son fundamentales para lograr obtener óptimos resultados en la reintroducción de especies nativas. Estos autores plantean que es necesario conocer los mecanismos de facilitación y la heterogeneidad ambiental de los sitios a restaurar. 


\section{5- Conclusiones.}

La rehabilitación activa nos permite dirigir la composición de las comunidades degradadas y así obtener resultados más satisfactorios en cuanto a los objetivos perseguidos por la rehabilitación, los cuales implican devolver el uso forrajero a los sistemas intervenidos.

La rehabilitación pasiva es una alternativa más adecuada para rehabilitar grandes extensiones de tierra, aunque la composición florística de los sitios rehabilitados dependerá de las semillas que estén presentes en el banco y de los regímenes de precipitación del área.

En este trabajo se identificaron las especies nativas con mayores probabilidades de éxito en ensayos de rehabilitación activa en el área de estudio. Así mismo, los resultados obtenidos permitieron determinar las técnicas más adecuadas para la producción de dichas especies.

El empleo de tratamientos pregerminativos en las diferentes especies leñosas nos permitió homogeneizar la producción y facilitó el manejo de los ejemplares en las etapas de rustificación. Esta etapa resultó indispensable para lograr la adaptación de los ejemplares producidos a las condiciones de campo.

Las especies $P$. flexuosa y $S$. johntonii, utilizadas en la rehabilitación activa, mostraron plasticidad a los cambios estacionales en cuanto a la disponibilidad hídrica, revelando buenas aptitudes para ser usadas en la recuperación de la funcionalidad de zonas semiáridas del Noreste de la Patagonia.

En cambio, C. microphylla y G. decorticans presentaron niveles de supervivencia y crecimiento bajos, por lo que consideramos seguir evaluando su autoecología para obtener mejores resultados de supervivencia y crecimiento.

Ninguna de las especies leñosas empleadas en este trabajo generaron estructuras reproductivas, por lo que es necesario continuar con su seguimiento para evaluar el momento en que producirán semillas y cuál será la viabilidad de las mismas.

Por su elevada supervivencia y capacidad reproductiva, las especies herbáceas perennes con valor forrajero poseen una alta potencialidad para la rehabilitación de áreas secas con marcados signos de degradación. 
Los trabajos presentados en este capítulo consideran el comportamiento de las especies seleccionadas bajo diferentes condiciones ambientales en el Noreste de la Patagonia. Sin embargo, los ensayos se han efectuado en parcelas experimentales de reducida superficie para facilitar el manejo y seguimiento de los ejemplares trasplantados y evaluar sus efectos en la recuperación de los atributos perdidos. Es de importancia utilizar para futuros proyectos de rehabilitación ecológica la información aquí generada y comprobar la pertinencia que estos resultados tendrían en proyectos de mayor extensión destinados a recobrar la capacidad productiva de las tierras degradadas del Noreste de la región Patagónica. 


\section{Capítulo V}

\section{Consideraciones Finales y Conclusiones.}

En el presente trabajo se analizaron aspectos básicos de la vegetación, de los suelos y del uso de la tierra en el Noreste de la provincia de Río Negro, de relevante importancia para evaluar el estado actual de los recursos naturales involucrados en la producción agropecuaria en áreas de Monte. Estos aspectos, evaluados en conjunto, nos permitieron identificar áreas con diferentes grados de conservación y áreas con severos síntomas de degradación, las cuales requieren de una intervención para rehabilitarlas y permitir que vuelvan a ser tierras productivas. Además, el análisis de imágenes satelitales nos permitieron integrar los resultados obtenidos y nos proporcionaron una visión sinóptica de los fenómenos que se desarrollan en el área de estudio.

Los principales aportes de este trabajo están en relación a:

I)- Ampliar el conocimiento de las comunidades vegetales nativas, de los suelos y de las formas de uso del suelo en el Noreste de la provincia de Río Negro e identificar áreas degradadas:

Los factores preponderantes en el modelado de los ecosistemas del Monte del Noreste de Río Negro son el sobrepastoreo, el fuego y su reemplazo por cultivos extensivos de secano. La inadecuada determinación de la carga animal, conjugada con sequías cíclicas, provocaron la disminución de la cobertura de especies palatables y la proliferación de especies con poco o nulo valor forrajero. Fuegos intensos, por otra parte, afectaron negativamente a las leñosas y a la fertilidad del suelo. Estos factores fueron causantes de un ciclo de degradación de la vegetación leñosa y herbácea generando amplias superficies de suelos con escasa o nula cobertura vegetal durante lapsos de tiempo variables, donde los factores erosivos, principalmente el viento, contribuyeron a la pérdida de la capa superficial del suelo.

La disminución en la cobertura de la vegetación impacta negativamente sobre la composición de la vegetación y las propiedades de los suelos. En el Monte rionegrino, la menor cobertura de la vegetación estuvo asociada con una menor 
cobertura y riqueza de especies leñosas y herbáceas y un aumento de los signos de erosión de los suelos.

Dentro de los sistemas naturales del Noreste de la Patagonia, aquellos cuya vegetación presenta coberturas intermedias de los estratos leñosos alto y bajo son los que muestran mayores valores de conservación. Son los sistemas con mayor diversidad de especies vegetales y probablemente proveen una mayor diversidad de hábitats para la fauna silvestre. El monte denso puede considerarse un estado degradado, producto del proceso de arbustificación, en el cual las leñosas presentan menor diversidad específica y una estructura vertical relativamente más homogénea, que podría limitar la presencia de ciertas especies de la fauna autóctona.

Los sistemas menos diversos son los más susceptibles frente a los disturbios. A medida que la diversidad de especies y la diversidad funcional de un sistema natural aumentan, aumentan las posibilidades de adaptación frente a las condiciones estresantes. En el Noreste del Monte rionegrino, los sistemas con cobertura leñosa intermedia, con estratos arbustivos y herbáceos diversos, tendrían, desde esta perspectiva, una mayor estabilidad frente a la ocurrencia de disturbios. Sin embargo, la intensidad y la frecuencia de éstos son variables determinantes para establecer los umbrales de degradación de los ecosistemas.

Las mejores condiciones de fertilidad del suelo se asocian con un mayor desarrollo del estrato arbustivo bajo. La cobertura del monte intermedio y en algunos casos de monte abierto, son las condiciones más favorables para la conservación del suelo, posiblemente porque en ellos coexisten especies leñosas y herbáceas. Además, las herbáceas son más fácilmente descompuestas incorporándose a la materia orgánica al suelo.

Por otro lado, las unidades productivas censadas en el área de estudio son de elevada superficie, con escasa infraestructura para el apotreramiento y el aprovisionamiento de agua de bebida para el ganado. En ellas se observó una degradación diferencial de los campos utilizados para la ganadería extensiva. Se detectaron sectores con altos niveles de degradación de la vegetación y se observaron otros con signos de sub utilización. El adecuado uso de los recursos forrajeros, con rotaciones y cargas acorde a la productividad primaria del 
sistema, al igual que la delimitación de cuadros de menor superficie, con mayor número de aguadas, redundaría en un aprovechamiento más homogéneo del estrato herbáceo. Además, la vegetación contaría con los descansos para recuperar la biomasa removida por los herbívoros y generar estructuras reproductivas que posteriormente integren el banco de semillas del suelo.

Los resultados obtenidos en el análisis de la vegetación, de los suelos, del uso histórico y actual del suelo, permiten no rechazar la primera hipótesis de trabajo: "En el Noreste de la provincia de Río Negro los disturbios antrópicos (pastoreo, avance de la frontera agropecuaria y mal manejo del fuego) han provocado una degradación del ecosistema, que se manifiesta en una marcada pérdida de la diversidad vegetal y un empobrecimiento del sustrato que afecta las actividades productivas desarrolladas en el sector".

De los resultados de este trabajo se desprende que la planicie loéssica es la unidad geomorfológica con mayores riesgos de degradación. Esto se debe, en términos generales, a que en ella se desarrollan actividades agrícolas extensivas de secano que implican la remoción completa de la vegetación natural. Los suelos de esta unidad presentan elevados índices de erodabilidad y serían los más susceptibles de degradación frente a condiciones de vientos intensos y eventos climáticos extremos.

A escala de paisaje, el uso de la teledetección satelital cuantitativa permitió identificar áreas con diferentes niveles de degradación, en particular aquellas con presencia de suelo desnudo y las que muestran avanzados síntomas de degradación de la vegetación. La identificación de dichas áreas facilitó la selección de los sitios para los ensayos de rehabilitación.

II)- Generar información de base que sea de utilidad a la hora de la toma de decisiones en temas referidos al ordenamiento del territorio y la planificación de los usos del suelo:

Sobre la base de la información obtenida en este estudio es posible plantear pautas para el ordenamiento territorial del Noreste de la Patagonia. El ordenamiento territorial se entiende como una regulación del uso del territorio, establecida por el Estado, que propugna por el desarrollo sustentable. La Ley Nacional de Presupuestos Mínimos de Protección Ambiental de los Bosques 
Nativos (26.331) promueve la conservación de los mismos mediante el ordenamiento territorial y establece criterios para zonificar el territorio como base para su ordenamiento. En este sentido, el ordenamiento debe establecer cuáles son los usos del suelo más apropiados para diferentes áreas, con el fin de reducir riesgos ambientales que afecten la productividad y la calidad de vida, impulsar formas de uso de la tierra que permitan reducir impactos sobre la biodiversidad y dónde focalizar los esfuerzos de conservación.

El capítulo 3 del presente trabajo puede ser considerado como un aporte al ordenamiento de los recursos naturales de la provincia de Río Negro. Permite, a una escala de mayor detalle, identificar áreas que poseen altos valores de conservación como así también otras que pueden ser objeto de tareas de restauración o rehabilitación ecológica.

III)- Conocer el comportamiento y la dinámica de los sistemas naturales a los que se les ha removido el agente causante del disturbio (rehabilitación pasiva). Evaluar la supervivencia, el crecimiento y el efecto facilitador que de en algunas especies nativas implantadas para promover la recuperación de ambientes degradados (rehabilitación activa):

Los resultados mostraron niveles de cobertura total y de cobertura de especies perennes similares en los tratamientos de rehabilitación pasiva, rehabilitación activa y testigo. Sin embrago, en los tratamientos de rehabilitación activa se alcanzaron los mayores porcentajes de cobertura de especies con valor forrajero. La rehabilitación activa permitiría aumentar la cobertura de especies forrajeras de los sistemas naturales de la zona. La rehabilitación activa requiere más horas de trabajo, insumos y conocimientos teórico/ prácticos acerca de la viverización, rustificación y trasplante a campo de los ejemplares de las especies seleccionadas. Pero los efectos perseguidos son alcanzados en menos tiempo respecto de la rehabilitación pasiva.

El ensayo de rehabilitación activa nos permitió conocer el comportamiento a campo de las diferentes especies nativas trasplantadas en condiciones de ausencia total de la cobertura vegetal. Mediante el análisis de la supervivencia y el crecimiento de los ejemplares trasplantados, fue posible determinar cuáles son las especies que mejor se comportaron en los ensayos de rehabilitación. 
Condalia microphylla y Geoffroea decorticans demostraron ser menos tolerantes ante la falta de humedad registrada en la temporada estival, mientras que Prosopis flexuosa y Schinus johnstonii, son más resistentes al estrés hídrico. Estos resultados nos indican que el umbral crítico a superar en los ensayos que constan de reintroducción de ejemplares de especies leñosas sería la primera temporada estival post trasplante. Las especies herbáceas utilizadas mostraron un comportamiento más plástico ante las condiciones locales $\mathrm{y}$, además, alcanzaron la madurez reproductiva en el primer período de crecimiento. Los resultados obtenidos en este trabajo nos permiten concluir que es deseable el uso de las especies leñosas Prosopis flexuosa y Schinus johnstonii, y de las especies herbáceas Nassella tenuis, Nassella longiglumis, Piptochaetium napostaense y Pappophorum caespitosum, en tareas de rehabilitación activa en ecosistemas del Monte rionegrino.

En los ensayos de rehabilitación activa, la introducción de ejemplares, tanto de especies herbáceas como leñosas, demostraron tener un efecto positivo en el reclutamiento de especies nativas. Las especies reclutadas anuales ofrecen poco volumen de forraje aunque son altamente palatables. También se registraron especies perennes de alta palatabilidad que ofrecen cobertura y estabilidad al suelo a lo largo del año.

El uso combinado de especies leñosas y herbáceas ayuda a recobrar rápidamente los niveles de cobertura del suelo y recuperar los atributos deseados de los sistemas intervenidos. Mediante la adecuada selección del pool de especies es posible una recomposición de las especies preferidas por el ganado y de aquellas que, a pesar de no ser consumidas, generan micrositios favorables para el establecimiento de otras plántulas, bien por ser fijadoras de suelo o por aportar materia orgánica y nutrientes.

Los resultados obtenidos permiten no rechazar la segunda hipótesis de trabajo: "Con el manejo adecuado y la implementación de acciones tendientes a la recuperación, tales como la reintroducción de especies, es posible generar una mejora sustancial de las áreas degradadas del Monte favoreciendo su rehabilitación." 
En los ensayos de rehabilitación pasiva, en los cuales solamente se retiró el agente causante del disturbio (pastoreo), se observó la recuperación de la cobertura total, aunque la composición específica de esa cobertura estuvo integrada, en mayor medida, por especies sin valor forrajero.

La producción en vivero de especies del Monte es posible y algunas de ellas requieren mínimos tratamientos pregerminativos y responden a la rustificación. Desde el punto de vista técnico, su viverización es factible aunque también habría que considerar aspectos económicos. Sería deseable implementar una red de viveros dedicados a la producción de especies nativas, articulando con comunidades locales, y empleando los lineamientos centrales de la producción de especies para rehabilitación ecológica, con la finalidad de cubrir la demanda generada La producción de ejemplares no debería estar limitada a las especies involucradas en este trabajo sino que sería importante efectuar estudios de base acerca de la reproducción y la viverización de otras especies presentes en los diferentes ambientes de la región.

En el lapso de tiempo de este trabajo, los ensayos de rehabilitación activa permitieron recuperar las especies con valor forrajero. Consideramos necesario continuar con el monitoreo de los individuos trasplantados de especies leñosas para evaluar su crecimiento, la generación de estructuras reproductivas, y su comportamiento en el reclutamiento de otras especies. Por otro lado, consideramos necesario continuar con el monitoreo de las clausuras de rehabilitación pasiva para determinar el tiempo requerido para alcanzar el potencial perdido y rehabilitar la productividad de los sistemas naturales.

Es imperante abandonar la escala de ensayo y extrapolar las actividades desarrolladas en parcelas demostrativas a áreas degradadas de mayor superficie para detener la degradación de los suelos del Noreste de la Patagonia. Además, este trabajo aporta información de base como herramienta para el manejo sustentable de los recursos vegetación y suelo involucrados en la producción, útil tanto para los productores locales como para aquellos encargados de la planificación y la gestión ambiental. 


\section{Bibliografía.}

Abraham, E., del Valle, H.F., Roig, F., Torres, L., Ares, J.O., Coronato, F., Godagnone, R., 2009. Overview of the geography of the Monte Desert biome (Argentina). Journal of Arid Environments. 73, 144-153.

Abraham, E., Guevara, J.C., Candia, R.J., Soria, N.D., 2016. Dust storms , drought and desertification in the Southwest of Buenos Aires Province, Argentina. Revista de la Facultas de Ciencias Agrarias de Cuyo. 48, 221-241.

Abraham, M.E., Corso, M.L., Maccagno, P., 2011. Capitulo 1. Tierras secas y desertificación en Argentina., En: Evaluación de La Desertificación en Argentina. Resultados Del Proyecto LADA/FAO. pp. 11-64.

Addinsoft 2007. XLSTAT. Analyse de domeés et statistiqueavec MS Excel. Adinsoft, NY, USA.

Adler, P.B., Milchunas, D.G., Lauenroth, W.K., Sala, O.E., Burke, I.C., 2004. Functional traits of graminoids in semi-arid steppes: A test of grazing histories. Journal of Applied Ecology 41, 653-663.

Adler, P.B., Milchunas, D.G., Sala, O.E., Burke, I.C., Lauenroth, W. illiam K., 2005. Plant traits and ecosystem grazin effects: Comparision of U.S. sagebrush steppe and patagonian steppe. Ecological Application. 15, 774-792.

Aguiar, M., 1999. Estructura y funcionamiento de los ecosistemas Patagónicos, En: SAGPyA-Argentina (Ed.), Patagonia XXI: Hacia una diversificación productiva y sostenibilidad ambiental. Buenos Aires, pp. 1-19.

Aguiar, M.R., Sala, O.E., 1999. Patch structure, dynamics and implications for the functiong of arid ecosystems. Trends in Ecology and Evolution. 14, 273-277.

Alexander, S., Nelson, C.R., Aronson, J., Lamb, D., Cliquet, A., Erwin, K.L., Finlayson, C.M., de Groot, R.S., Harris, J.A., Higgs, E.S., Hobbs, R.J., Robin Lewis, R.R., Martinez, D., Murcia, C., 2011. Opportunities and Challenges for Ecological Restoration within REDD+. Restoration Ecology. 19, 683-689.

Alonso Roldán, V., Baldi, R., Del Valle, H., Deutschman, D.H., 2017. Living on the edge : heterogeneity in vegetation type cover as key factor of the habitat occupied by Dolichotis patagonum at landscape scale. Journal of Arid Environments. 140, 42-49.

Altamirano, A., Pérez, D., 2010. Supervivencia temprana de Cercidium praecox (Fabaceae). En: Perez, D.R., Rovere, A.E., Farinaccio, F.M. Rehabilitación en el desierto, Ensayos con plantas nativas en Aguada Pichana. Vazquez- Mazzini. Buenos Aires. 49-55.

Alvarez, J.A., Villagra, P.E., 2009. Proropis flexuosa DC. (Fabaceae, Mimosoidae). Kurtziana. 35, 47-61.

Alvarez, J.A., Villagra, P.E., Cony, M.A., Cesca, E.M., Boninsegna, J.A., 2006. Estructura y estado de conservación de los bosques de Prosopis flexuosa D. C. 
(Fabaceae, subfamilia: Mimosoideae) en el noreste de Mendoza (Argentina). Revista Chilena de Historia Natural. 1, 75-87.

Aronson, J., Floret, C., Floc'h, E., Ovalle, C., Pontanier, R., 1993. Restoration and rehabilitation of degraded ecosystems in arid and semi-arid lands. I. A view from the South. Restororation Ecology. 1, 8-17.

Aronson, J., Renison, D., Ovalle, C., Del Pozo, A., Mende, R. De, 2007. Restauración del Capital Natural: sin reservas no hay bienes ni servicios. Ecosistemas. 16, 1524.

Ayesa, J., Bran, D., Cecchi, G., Marcolin, A., Plunkett, S., 1986. Relación entre paisajesuelo-vegetación en el monte del este rionegrino. EEA INTA Bariloche.

Ayesa, J., Lopez, C.R., Umaña, F., Bran, D., Lagorio, P., 2010. Cartografía de la cobertura del suelo en Patagonia norte.EEA INTA Bariloche. pp. 208-211.

Bayer, W., 2011. Equivalente oveja, oveja patagónica y equivalente vaca. Sitio Argentino de Producción animal. www.produccion-animal.com.ar

Beltran, R.S., Kreidler, N., Van Vuren, D.H., Morrison, S.A., Zavaleta, E.S., Newton, K., Tershy, B.R., Croll, D.A., 2014. Passive Recovery of Vegetation after Herbivore Eradication on Santa Cruz Island, California. Restororation Ecology. 22, 790-797.

Bertiller, M., Bisigato, A., 1998. Vegetation dynamics under grazing disturbance. The state-and-transition model for the Patagonian steppes. Ecología Austral. 8, 191199.

Bertiller, M.B., 1999. Estructura y funcionamiento del monte patagónico, En: SAGyPArgentina (Ed), Patagonia XXI: Hacia una diversificación productiva $y$ sostenibilidad Ambiental. pp. 21-27.

Bertiller, M.B., Marone, L., Baldi, R., Ares, J.O., 2009. Biological interactions at different spatial scales in the Monte desert of Argentina. Journal of Arid Environments. 73, 212-221.

Bilenca, D., Codesido, M., González Fischer, C., Perez Carusi, L., 2009. Impactos de la actividad agropecuaria sobre la biodiversidad en la ecorreión pampeana: impactos de la expansión agrícola y de la intensificación de la agricultura y la ganadería de campo, con algunas recomendaciones de manejo para su mitigación. Buenos Aires. INTA.

Bisigato, A.J., Bertiller, M.B., 2004. Temporal and micro-spatial patterning of seedling establishment. Consequences for patch dynamics in the southern Monte, Argentina. Plant Ecology. 174, 235-246.

Bisigato, A.J., Bertiller, M.B., 1999. Seedling emergence and survival in contrasting soil microsites in Patagonian Monte shrubland. Journal of Vegetation Science.1, $335-342$.

Bisigato, A.J., Bertiller, M.B., 1997. Grazing effects on patchy dryland vegetation in northern Patagonia. Journal of Arid Environments. 36, 639-653. 
Bisigato, A.J., Bertiller, M.B., Ares, J.O., Pazos, G.E., 2005. Effect of grazing on plant patterns in arid ecosystems of Patagonian Monte. Ecography. 5, 561-572.

Bisigato, A.J., Laphitz, R.M.L., 2009. Ecohydrological effects of grazing-induced degradation in the Patagonian Monte, Argentina. Austral Ecology. 34, 545-557.

Bisigato, A.J., Laphitz, R.M.L., Carrera, A.L., 2008. Non-linear relationships between grazing pressure and conservation of soil resources in Patagonian Monte shrublands. Journal of Arid Environments. 72, 1464-1475.

Bonvissuto, G.L., Busso, C.A., 2007. Germination of grasses and shrubs under various water stress and temperature conditions. Phyton. 76, 119-131.

Borrelli, P., Oliva, G., 2001. Efectos de los animales sobre los pastizales. En: Borrelli, P. y Oliva G. Ganadería ovina sustentable en la Patagonia Austrtal. Ed. INTA Reg. Pat. Sur. pp. 99-128.

Botero, R., Russo, R., 2000. Utilización de árboles y arbustos fijadores de nitrógeno en sistemas sostenibles de producción animal en suelos ácidos tropicales, en: Sanchez M. y Rosales-Méndez, M. Agroforestería para la producción animal en latinoamérica. pp. 121-143.

Bradley, B. a., Mustard, J.F., 2005. Identifying land cover variability distinct from land cover change: Cheatgrass in the Great Basin. Remote Sensing of Environment. 94, 204-213.

Bradshaw, A.D., 1996. Underlying principles of restoration. Cananadian Journal of Fisheries and Aquatic Science. 53, 3-9.

Bradshaw, A.D., Chadwick, M.J. 1989. The restoration of land. University of California

Press, Berkeley, California.

Bran, D., Lopez, C., Auesa, J. 2000. Regiones ecológicas de Río Negro. Informe ténico EEA INTA Bariloche. INTA.

Bran, D.E., Cecchi, G.A., Gaitán, J.J., Ayesa, J.A., López, C.R., 2007. Efecto de la severidad de quemado sobre la regeneración de la vegetación en el Monte Austral. Ecología Austral. 17, 123-131.

Busso, C.A., Montenegro, O.A., Torres, Y.A., Giorgetti, H.D., Rodriguez, G.D., 2016. Aboveground net primary productivity and cover of vegetation exposed to various disturbances in arid Argentina. Applied Ecology and Environment Research. 14, 51-75.

Calabrese, G.M., Rovere, A.E., Zeberio, J.M. 2013. Costras biológicas en sitios de Monte con diferentes niveles de perturbación. En: Restauración Ecológica en la Diagonal Árida de la Argentina. Pérez, D., Rovere A., E., Rodriguez- Araujo M.E. (eds). Vazquez- Mazzini. Buenos Aires. Pp 112- 120.

Carrera, A.L., bertiller, M.B., Larreguy, C. 2008. Leaf litterfall, fine-root production, and descomposition in shrublands with different canopy structure induced by grazzin in the Pagonian Monte, Argentina. Plant and Soil. 31.1, 39-50. 
Catalán, L.A., Balzarini, M., 1992. Improved laboratory germination conditions for several arboreal Prosopis species: P. chilensis, P. flexuosa, P. nigra, P.alba, P. caldenia and P. affinis. Seed Science Technology. 20, 293-298.

Cesa, A., Paruelo, J.M., 2011. Changes in vegetation structure induced by domestic grazing in Patagonia (Southern Argentina). Journal of Arid Environments. 75, 1129-1135.

Chazdon, R.L., Brancalion, P.H., Lamb, D., Laestadius, L., Calmon, C., Kumar, C. 2017. Conservation Letters. 10, 125-132.

Chirino, E., Vilagrosa, A., Cortina, J., Valdecantos, A., Fuentes, D., Trubat, R., Luis, V.C., Puértolas, J., Bautista, S., Baeza, M.J., Peñuelas, J.L., Vallejo, V.R., 2009. Ecological restoration in degraded drylands: the need to improve the seedling quality and site conditions in the field, En: Groosberg, S.P. (eds.) Forest Management. Pp. 85-158.

Chuvieco, E., 2008. Teledetección ambiental: La observación de la Tierra desde el Espacio. $3^{\circ}$ ed. Editorial Planeta. Barcelona.

Chuvieco, E., 1995. Fundamentos de Teledeteccion Espacial, 2. ed. RIALP ediciones.Madrid.

Cingolani, A.M., Noy-Meir, I., Renison, D., Cabido, M., 2008. La ganadería extensiva, ¿ es compatible con la conservación de la biodiversidad y de los suelos ? Ecología Austral. 18, 253-271.

Cingolani, A.M., Posse, G., Collantes, M.B., 2005. Plant functional traits, herbivore selectivity and response to sheep grazing in Patagonian steppe grasslands. Journal of Applied Ecology. 42, 50-59.

Cingolani, A.M., Renison, D., Tecco, P.A., Gurvich, D.E., Cabido, M., 2008. Predicting cover types in a mountain range with long evolutionary grazing history: a GIS approach. Journal of Biogeography. 35, 538-551.

Clewell, A.F., Aronson, J., 2007. Ecological Restoration. Pinciples, values, and structure of an emerging profession. $1^{\circ}$ ed. Island Press, London.

Cortina, J., Amat, B., Castillo, V., Fuentes, D., Maestre, F.T., Padilla, F.M., Rojo, L., 2011. The restoration of vegetation cover in the semi-arid Iberian southeast. Journal of Arid Environments. 75, 1377-1384.

Cortina, J., Del Campo, A., 2006. Evaluación del éxito de la reintroducción de especies leñosas en ambientes mediterráneos, en: Cortina, J., Peñuelas, J.L., Puértolas, J., Vilagrosa, A., Savé, R. eds. Calidad de Planta Forestal para Restauración de Ambientes Mediterráneoas. Estado Actual de Conocimientos. Pp. 2-26.

Cortina, J., Maestre, F.T., Vallejo, R., Baeza, M.J., Valdecantos, A., Pérez-Devesa, M., 2006. Ecosystem structure, function, and restoration success: Are they related? Journal for Nature Conservation. 14, 152-160.

Crouzeilles, R., Curran, M., Ferreira, M. S., Lindenmayer, D. B., Grelle, C. E., Rey Benayas, J. M. 2016. A global meta-analysis on the ecological drivers of forest restoration success. Nature communications. 7, 11666- 11674. 
Cueto, V. R., Lopez de Casenave, J., Marone, L., 2008. Neotropical austral migrant landbirds: population trends and habitat use in the central Monte desert, Argentina. The Condor, 110.1, 70-79.

D’Antonio, C., Meyerson, L. a., 2002. Exotic Plant Species as Problems and Solutions in Ecological Restoration: A Synthesis. Restororation Ecology. 10, 703-713.

Dalmasso, A., 1994. Fenología de cinco gramíneas nativas de interés forrajero. Pappophorum caespitosum, Trichloris crinita, Setaria leucopila, Digitaria californica y Diplachne dubia. Multequina. 4, 9-34.

Dalmasso, A.D., 2010. Revegetación de áreas degradadas con especies nativas. Boletín de la Sociedad Argentina Botánica. 45, 149-171.

De Berasategui, L., 2004. Estadísticas climáticas del valle de Viedma- 30 años. Boletín de información técnica $N^{\circ} 20$. EEA Valle Inferior. Ediciones INTA.

De Inalbon, M.R., Valenzuela, A., 2005. Procedimientos analíticos para suelos normales y salinos. Técnicas utilizadas en el laboratorio de suelos y agua. Estación Experimental Agropecuaria Sáenz Peña - Chaco - Argentina. PA Revisión: 1.

De León, M., 2004. El manejo de los pastizales naturales. Informe técnico $N^{o}$. INTA EEA Manfredi. 8 p.

De Paz, M., Gobbi, M.E., Raffaele, E., 2013. Mantillo de las especies leñosas de matorrales del NO de la Patagonia: abundancia, composición, estructura y heterogeneidad. Boletín de la Sociedad Argentina Botánica. 48, 525-541.

de Villalobos, A.E., Peláez, D.V., Bóo, R.M., Mayor, M.D., Elia, O.R., 2002. Effect of high temperatures on seed germination of Prosopis caldenia Burk. Journal of Arid Environments. 52, 371-378.

de Villalobos, a. E., Peláez, D.V., 2001. Influences of temperature and water stress on germination and establishment of Prosopis caldenia Burk. Journal of Arid Environments. 49, 321-328.

del Valle, H.F., 1998. Patagonian soils: a regional synthesis. Ecología Austral. 8, 103123.

Delgado-Baquerizo, M., Maestre, F.T., Gallardo, A., Bowker, M.A., Wallenstein, M.D., Quero, J.L., Ochoa, V., Gozalo, B., García-Gómez, M., Soliveres, S., GarcíaPalacios, P., Berdugo, M., Valencia, E., Escolar, C., Arredondo, T., BarrazaZepeda, C., Bran, D., Carreira, J.A., Chaieb, M., Conceição, A. a, Derak, M., Eldridge, D.J., Escudero, A., Espinosa, C.I., Gaitán, J., Gatica, M.G., GómezGonzález, S., Guzman, E., Gutiérrez, J.R., Florentino, A., Hepper, E., Hernández, R.M., Huber-Sannwald, E., Jankju, M., Liu, J., Mau, R.L., Miriti, M., Monerris, J., Naseri, K., Noumi, Z., Polo, V., Prina, A., Pucheta, E., Ramírez, E., RamírezCollantes, D.A., Romão, R., Tighe, M., Torres, D., Torres-Díaz, C., Ungar, E.D., Val, J., Wamiti, W., Wang, D., Zaady, E., 2013. Decoupling of soil nutrient cycles as a function of aridity in global drylands. Nature. 502, 672-670.

Delgado-Baquerizo, M., Maestre, F.T., Gallardo, A., Eldridge, D.J., Soliveres, S., Bowker, M.A., Prado-Comesaña, A., Gaitán, J., Quero, J.L., Ochoa, V., Gozalo, B., García-Gómez, M., García-Palacios, P., Berdugo, M., Valencia, E., Escolar, C., 
Arredondo, T., Barraza-Zepeda, C., Boeken, B.R., Bran, D., Cabrera, O., Carreira, J.A., Chaieb, M., Conceição, A.A., Derak, M., Ernst, R., Espinosa, C.I., Florentino, A., Gatica, G., Ghiloufi, W., Gómez-González, S., Gutiérrez, J.R., Hernández, R.M., Huber-Sannwald, E., Jankju, M., Mau, R.L., Miriti, M., Monerris, J., Morici, E., Muchane, M., Naseri, K., Pucheta, E., Ramírez, E., Ramírez-Collantes, D.A., Romão, R.L., Tighe, M., Torres, D., Torres-Díaz, C., Val, J., Veiga, J.P., Wang, D., Yuan, X., Zaady, E., 2015. Human impacts and aridity differentially alter soil $\mathrm{N}$ availability in drylands worldwide. Global Ecology and Biogeogrphy. 25, 3645 .

Demaría, M.R., Aguado Suarez, I., Steinaker, D.F., 2008. Reemplazo y fragmentacion de pastizales pampeanos semiaridos en San Luis, Argentina. Ecología Austral. 18, $55-70$.

Di Rienzo, J., Casanoves, F., Balzarini, M., Gonzalez, L., Tablada, E., Robledo, C., 2008. Grupo InfoStat, FCA, Universidad Nacional de Córdoba. Argentina.

Díaz, S., Cabido, M., Zak, M., Martinez Carretero, E., Araníbar, J., 1999. Plant functional traits, ecosystem structure and land-use history along a climatic gradient in central-western Argentina. Journal of Vegetation Science. 10, 651-660.

Díaz, S., Lavorel, S., McIntyre, S., Falczuk, V., Casanoves, F., Milchunas, D.G., Skarpe, C., Rusch, G., Sternberg, M., Noy-Meir, I., Landsberg, J., Zhang, W., Clark, H., Campbell, B.D., 2007. Plant trait responses to grazing - A global synthesis. Global Changge Biology. 13, 313-341.

Díaz Arias, D., 2016. Germinación y propagación vegetativa de Schinus fasciculatus (Anacardiaceae ) (Tesina de grado). Universidad Nacional del Sur. Bahia Blanca.

Dobson, A.P., Bradshaw, A.D., Baker, A.J.M., 1997. Hopes for the Future : Restoration Ecology and Conservation Biology. Science (80). 277, 515-522.

Eldridge, D.J., Bowker, M.A., Maestre, F.T., Roger, E., Reynolds, J.F., Whitford, W.G., 2011. Impacts of shrub encroachment on ecosystem structure and functioning: towards a global synthesis. Ecology Letters. 14, 709-22.

Eldridge, D.J., Poore, A.G., Ruiz-Colmenero, M., Lentic, M., Soliveres, S., 2016. Ecosystem structure, function, and composition in rangelands are negatively affected by livestock grazing. Ecological Applications. 26, 1273-1283.

English, N.B., Weltzin, J.F., Fravolini, a., Thomas, L., Williams, D.G., 2005. The influence of soil texture and vegetation on soil moisture under rainout shelters in a semi-desert grassland. Journal of Arid Environments. 63, 324-343.

Entio, L.J., Mujica, M.M., Busso, C.A., Torres, Y.A., Ithurrart, L.S., 2016. Light effects on seed germination of two spontaneous population of Pappophorum vaginatum. Semiárida 26, 11-20.

Esterlich, H.D., Fernandez, B., Morici, F., Chirino, C., 2005. Persistencia de los cambios provocados por los fuegos controlados en diferentes estructuras del bosque de caldén (Prosopis caldenia Burk.). Revista de la Facultad de Agronnomía de La Pampa 16, 23-30. 
Etcheverría, M.P., Folguera, A., 2006. Hoja geológica 4163- II/IV y I/II. Viedma y General Conesa. Instituto de Geología y Recursos Minerales, Servicio Geológico Minero Argentino. Boletin 366. Buenos Aires.

Etcheverría, M. P., Folguera, A., 2009. Hoja geológica 3963- I y II. Colonia Julia y Echarren y Pedro Luro. Instituto de Geología y Recursos Minerales, Servicio Geológico Minero Argentino. Boletin 382. Buenos Aires.

Foster, D., Swanson, F., Aber, J., Burke, I., Brokaw, N., Tilman, D., Knapp, A., 2003. The Importance of Land-Use Legacies to Ecology and Conservation. Bioscience $53,77-88$.

Fraterrigo, J.M., Rusak, J. a, 2008. Disturbance-driven changes in the variability of ecological patterns and processes. Ecology Letters. 11, 756-70.

Funk, F.L.A., Peter, G., Lloydi, A., Kröpfl, A.I., Distel, R., 2012. Recuperación estructural y funcional de los espacios entre arbustos al cabo de 10 años de exclusión del pastoreo en una estepa semiárida del noreste de la Patagonia. Ecología Austral 22, 195-202.

Gaitán, J.J., Bran, D., Oliva, G., Maestre, F.T., Aguiar, M.R., Jobbágy, E.G., Buono, G., Ferrante, D., Nakamatsu, V., Ciari, G., Salomone, J., Massara, V., 2014. Plant species richness and shrub cover attenuate drought effects on ecosystem functioning across Patagonian rangelands Plant species richness and shrub cover attenuate drought effects on ecosystem functioning across Patagonian rangelands. Biology Letters. (10).22. 1-4.

Gaitán, J.J., Bran, D.E., Murray, F., 2007. Efecto de la severidad de quemado sobre la concentración de carbono orgánico en montículos e intermontículos en el monte austral. Ciencia del Suelo. 25, 195-199.

Gaitan, J.J., Lopez, C.R., Bran, D.E., 2008. Indicadores edáficos y de la vegetación para el monitoreo de la desertificación en la estepa patagónica. Asociación Argentina Ciencias del Suelo. 1, 1-8.

Gaitán, J.J., López, C.R., Bran, D.E., 2009. Efectos del pastoreo sobre el suelo y la vegetación en la estepa patagónica. Ecología Austral. 27, 1-10.

Gaitan, J.J., Oliva, G.E., Bran, D.E., Maestre, F.T., Aguiar, M.R., Jobbagy, E.G., Buono, G.G., Ferrante, D., Nakamatsu, V.B., Ciari, G., Salomone, J.M., Massara, V., 2014. Vegetation structure is as important as climate for explaining ecosystem function across Patagonian rangelands. Journal of Ecology. 102, 1419-1428.

García-Palacios, P., Soliveres, S., Maestre, F.T., Escudero, A., Castillo-Monroy, A.P., Valladares, F., 2010. Dominant plant species modulate responses to hydroseeding, irrigation and fertilization during the restoration of semiarid motorway slopes. Ecology Engineering. 36, 1290-1298.

García, D., 2006. La escala y su importancia en el analisis espacial. Ecosistemas. 15, 718.

Gardi, C., Angelini, M., Barceló, S., Comerma, J., Cruz Gaistardo, C.,Encina Rojas, A., Jones, A., Krasilnikov, P., Mendonça Santos Brefin, M.L., Montanarella, L., Muniz Ugarte, O., Schad, P., Vara Rodríguez, M.I., Vargas, R. (eds), 2014. Atlas 
de suelos de América Latina y el Caribe. Comisión Europea - Oficina de Publicaciones de la Unión Europea, Luxembourg. Pp. 176.

Gasch, C., Huzurbazar, S., Stahl, P., 2014. Measuring soil disturbance effects and assessing soil restoration success by examining distributions of soil properties. Applied Soil Ecology. 76, 102-111.

Gibson, D.J., 2009. Grasses \& Grassland Ecology, $1^{\circ}$ ed. Oxford University, New York. Pp 315.

Giménez, A.M., Hernández, P., Ríos, N., Calatayu, F., 2013. Crecimiento de árboles individuales de Geoffreea decorticans Burk., en un bosque del Chaco semiárido, Argentina. Madera Bosques. 19, 37-51.

Giorgetti, H.D., Busso, C.A., Montenegro, O.A., Rodríguez, G.D., Kugler, N.M., 2006. Cattle Raising in Central, Semiarid Rangeland of Argentina. Rangeland Journal. $32-36$.

Giorgetti, H.D., Montenegro, O.A., Rodriguez, G., Busso, C.A., Burgos, M.A., Flemert, A.C., Toribio, M.B., Horvitz, S.S., 1997. The comparative influence of past management and rainfall on range herbaceous standing crop in east-central Argentina : 14 years of observations. Journal of Arid Environments. 36, 623-637.

Godagnone, R.E., Bran, D.E., 2009. Inventario integral de los recursos naturales de la provincia de Río Negro. INTA. Ediciones INTA. Pp 392.

Golluscio, R.A., 2009. Receptividad ganadera: marco teórico y aplicaciones prácticas. Ecología Austral 19, 215-232.

Golluscio, R.A., Austin, A., García Martínez, G., Gonzalez- Polo, M., Sala, O.E., Jackson, R.B. 2009. Sheep grazing decreases organic carbon and nitrogen pools in the Patagonian steppe: combination of direct and indirect effects. Ecosystems. 12, 686-697.

Golluscio, R.A., Deregibus, V.A., Paruelo, J.M., 1998. Sustainability and range management in the Patagonian steppes. Ecología Austral 8, 265-284.

Gómez, D.A., Aranibar, J.N., Tabeni, S., Villagra, P.E., Garibotti, I.A., Atencio, A., 2012. Biological soil crust recovery after long-term grazing exclusion in the Monte Desert (Argentina). Changes in coverage, spatial distribution, and soil nitrogen. Acta Oecologica 38, 33-40.

González, F. 2010. Supervivencia temprana de Senna aphylla (Fabaceae) plantada aislada y asociada a un sub-arbusto nativo. En: Perez, D.R., Rovere, A.E., Farinaccio, F.M. Rehabilitación en el desierto, Ensayos con plantas nativas en Aguada Pichana. Vazquez- Mazzini. Buenos Aires. 61-65.

Gonnet, J. M., 2001. Influence of cattle grazing on population density and species richness of granivorous birds (Emberizidae) in the arid plain of the Monte, Argentina. Journal of Arid Environments. 48. 4, 569-579

Grime, J.P., 1998. Benefits of plant diversity to ecosystems : immediate, filter and founder effects. Journal of Ecology. 86, 902-910. 
Guarnaschelli, A.B., Prystupa, P., Lemcoff, J.H., 2006. Drought conditioning improves water status, stomatal conductance and survival of Eucalyptus globulus subsp . bicostata seedlings. Annals of Forest Science. 63, 941-950.

Guevara, J.C., Grünwaldt, E.G., Estevez, O.R., Bisigato, A.J., Blanco, L.J., Biurrun, F.N., Ferrando, C.A., Chirino, C.C., Morici, E., Fernández, B., Allegretti, L.I., Passera, C.B., 2009. Range and livestock production in the Monte Desert, Argentina. Journal of Arid Environments. 73, 228-237.

Hang, S., Mazzarino, M.J., Nuñez, G., Oliva, L., 1995. Influencia del desmonte selectivo sobre la disponibilidad de nitrógeno en años húmedos y secos en sistemas silvopastoriles en el chaco árido Argentino. Agroforestería en las Américas. 2, 914.

Hantson, S., Chuvieco, E., Pons, X., Domingo, C., Cea, C., Moré, G., Cristobal, J., Tejeiro, J.J.P.J.A., 1988. Cadena de pre-procesamiento estándar para las imágenes Landsat del Plan Nacional de Teledetección. Revista de Teledetcción. 36, 51-61.

Harris, J.A., Hobbs, R.J., Higgs, E., Aronson, J., 2006. Ecological Restoration and Global Climate Change. Restoration Ecology. 14, 170-176.

Hobbs, R.J., Arico, S., Aronson, J., Baron, J.S., Cramer, V.A., Epstein, P.R., Ewel, J.J., Klink, C.A., Ariel, E., Norton, D., Ojima, D., Richardson, D.M., Sanderson, E.W., Zamora, R., Zobel, M., 2006. Novel Ecosystems: Theoretical and Management Aspects of the New Ecological World Order LOGA Novel ecosystems : theoretical and management aspects of the new ecological world order. Global Ecology and Biogeography. 15, 1-7.

Hobbs, R.J., Cramer, V.A., 2008. Restoration Ecology: Interventionist Approaches for Restoring and Maintaining Ecosystem Function in the Face of Rapid Environmental Change. Annual Review of Environment and Resources. 33, 39-61.

Jaramillo, D.F. 2002. Introducción a la Ciencia del Suelo. $1^{\mathrm{o}}$ ed. Ed. Universidad Nacional de Medellín. Colombia.

Jobbágy, E.G., Nosetto, M.D., Villagra, P.E., Jackson, R.B., 2011. Water subsidies from mountains to deserts: Their role in sustaining groundwater-fed oases in a sandy landscape. Ecological Applications. 21, 678-694.

Kangas, A., Maltamo, M., 2006. Forest inventory: Managing Forest Ecosystems, $1^{\mathrm{o}}$ ed. Berlin, Alemania. Springer. Pp. 362.

King E., Hobbs, R.J., 2006. Identifying linkages among conceptual models of ecosystem degradation and restoration: Towards an integrative framework. Restoration Ecology. 14. 3. 369-378

Kowaljow, E., Rostagno, C.M., 2013. Enramado y riego como alternativas de rehabilitación de regiones semiáridas afectadas por el tendido de ductos. Ecología Austral. 23, 62-69.

Kröpfl, A.I., Cecchi, G.A., Villasuso, N.M., Distel, R.A., 2011. Degradation and Recovery Processes in Semi-Arid Patchy Rangelands of Northern Patagonia, Argentina. Land Degradation and Development. 24, 393-399. 
Kröpfl, A.I., Deregibus, V.A., Cecchi, G.A., 2015. Un modelo de estados y transiciones para el Monte oriental rionegrino. Phyton. 9457, 390-396.

Kröpfl, A.I., Deregibus, V., Cecchi, G.A., 2007. Disturbios en una estepa arbustiva del Monte : cambios en la vegetación. Ecología Austral. 17, 257-268.

Kröpfl, A.I., Villasuso, N.M., 2008. Guia para el reconocimiento de especies de los pastizales del Monte Oriental de Patagonia. INTA. Ediciones INTA. Pp. 117.

Kröpfl, A.I., Villasuso, N.M., 2012. Guia para el reconocimiento de especies de los pastizales del Monte Oriental de Patagonia. INTA. Ediciones INTA. Pp. 117.

Kufner, M. B., Chambouleyron, M. 1991. Actividad espacial de Dolichotis patagonum en relación a la estructura de la vegetación en el Monte Argentino. Studies on Neotropical Fauna and Environment. 26, 4, 249-255.

Landi, M., Renison, D., 2010. Forestación con Polylepis australis en suelos erosionados de las Sierras Grandes de Córdoba: evaluación del uso de terrazas y vegetación nodriza. Ecología Austral. 20, 47-55.

Lauenroth, W., 1998. Guanacos, spiny shrubs and the evolutionary history of grazing in the Patagonian steppe. Ecología Austral. 8, 211-215.

León, R.J.C., Bran, D., Collantes, M.B., Paruelo, J.M., Soriano, A., 1998. Grandes unidades de vegetación de la Patagonia extraandina. Ecología Austral. 8, 125-144.

Lini, R., 2008. Evaluación del desmonte para uso agrícola en el noreste rionegrino mediante el uso de información geográfica. Servicio Forestal de zonas áridas. Ministerio de Producción de la Provincia de Río Negro.

López de Luzuriaga, A., Olano, J.M., 2006. Con los pies en el suelo: incluyendo la estructura espacial de los datos en los análisis multivariantes. Ecosistemas. 15. 3. $1-9$.

Lopez Lauenstein, D., Fernández, M.E., Verga, A., 2012. Respuesta diferenciada a la sequia de plantas jovenes de Prosopis chilensis, P. flexuosa y sus hibridos interespecificos: Implicancias para la reforestacion en zonas aridas. Ecología Austral 22, 43-52.

Loydi, A., Distel, R.A., 2010. Diversidad florística bajo diferentes intensidades de pastoreo por grandes herbívoros en pastizales serranos del Sistema de Ventania, Buenos Aires. Ecología Austral 20, 281-291.

Loydi, A., Zalba, S.M., Distel, R.A., 2012. Vegetation change in response to grazing exclusion in montane grasslands, Argentina. Plant Ecology and Evolution. 145, $313-322$.

Ludwing, J., Wilcox, B.P., Breshears, D.D., Tongway, D.J., Imeson, A.C., 2005. Vegetation patches and runoff- erosion as interacting ecohydrological processes in semiaris landscapes. Ecology. 86, 288-297.

Maestre, F.T., 2016. BIODESERT: Assessing the impacts of grazing and climate change in global drylands. Universidad Rey Juan Carlos, Móstoles. España. 
Maestre, F.T., Bautista, S., Cortina, J., Bellot, J., 2001. Potential for using facilitation by grasses to establish shrubs on a semiarid degraded steppe. Ecological Applications. 11. 6, 1641-1655.

Maestre, F.T., Bowker, M.A., Puche, M.D., Belén Hinojosa, M., Martínez, I., GarcíaPalacios, P., Castillo, A.P., Soliveres, S., Luzuriaga, A.L., Sánchez, A.M., Carreira, J.A., Gallardo, A., Escudero, A., 2009. Shrub encroachment can reverse desertification in semi-arid Mediterranean grasslands. Ecology Letters. 12, 930-41.

Maestre, F.T., Cortina, J., Vallejo, R., 2006. Are ecosystem composition, structure, and functional status related to restoration success? A test from semiarid mediterranean steppes. Restoration Ecology. 14, 258-266.

Maestre, F.T., Delgado-baquerizo, M., Jeffries, T.C., Eldridge, D.J., Ochoa, V., Gozalo, B., Quero, J.L., Garcia- Gomez, M., Gallardo, A., Ulrich, W., Bowker, M.A., Arredondo, T., Barraza-Zepeda, C., Bran, D.E., Florentino, A., Gaitán, J.J., Gutierrez, J.R., Huber-Sannwald, E., Jankju, M., Mau, R.L., Miriti, M., Naseri, K., Ospina, A., Stavi, I., Wang, D., Woods, N.N., Yuan, X., Zaady, E., Singh, B.K., 2015. Increasing aridity reduces soil microbial diversity and abundance in global drylands. Ecology. 112, 51. 15685-15689.

Maestre, F.T., Eldridge, D.J., Soliveres, S., 2016. A multifaceted view on the impacts of shrub encroachment. Applied Vegetation Science. 19, 369-370.

Maestre, F.T., Eldridge, D.J., Soliveres, S., Kéfi, S., Delgado-Baquerizo, M., Bowker, M.A., García-Palacios, P., Gaitán, J., Gallardo, A., Lázaro, R., Berdugo, M., 2016. Structure and Functioning of Dryland Ecosystems in a Changing World. Annual Review in Ecology, Evolution and Systematic. 47, 215-37.

Maestre, F.T., Puche, M.D., 2009. Indices based on surface indicators predict soil functioning in Mediterranean semi-arid steppes. Applied Soil Ecology. 41, 342350 .

Marone, L., 1991. Habitat features affecting bird spatial distribution in the Monte desert, Argentina. Ecología Austral. 1, 77-86.

Martinez, H., Náñez, C., Lizuain, A., Dal Molin, C., Turel, A., 2001. Hoja geológica 4166- II. San Antonio Oeste. Instituto de Geología y Recursos Minerales, Servicio Geológico Minero Argentino. Boletin 254. Buenos Aires.

Marty, J. 2015. Fire effects on plant biodiversity across multiple sites in California vernal pool grasslands. Ecological Restoration. 33,266-273.

Mateucci, S., Colma, A., 1982. Metodología para el estudio de la vegetación. Monografía $n^{\circ} 22$, Serie Biología. Secretaría General de la OEA, Washington D.C.

Mcadoo, J.K., Swanson, J.C., Murphy, P.J., Shaw, N.L., 2016. Evaluating strategies for facilitating native plant establishment in northern Nevada crested wheatgrass seedings. Restoration Ecology. 25, 53-62.

McNaughton, S.J., 1985. Ecology of a Grazing Ecosystem : The Serengeti. Ecological Monogrph. 55, 259-294. 
Meli, P., Martínez-Ramos, M., Rey-Benayas, J.M., 2013. Selecting Species for Passive and Active Riparian Restoration in Southern Mexico. Restoration Ecology. 21, 163-165.

Méndez, M., García, D., Maestre, F.T., Escudero, A., 2008. More Ecology is Needed to Restore Mediterranean Ecosystems: A Reply to Valladares and Gianoli. Restoration Ecology. 16, 210-216.

Mihoč, M.A.K., Pescador, D.S., Sánchez, A.M., Cavieres, L.A., Escudero, A., 2016. Soil under nurse plants is always better than outside: a survey on soil amelioration by a complete guild of nurse plants across a long environmental gradient. Plant and Soil 1, 1-13.

Milchunas, D.G., Sala, O.E., Lauenroth, W.K., 1988. A generalizaed model of the effects of grazzing by large herbivores on grassland comunnity structure. The American Naturalist. 132, 87-106.

Milesi, F. A., Marone, L., Lopez de Casenave, J., Cueto, V. R., Mezquida, E. T., 2002. Gremios de manejo como indicadores de las condiciones del ambiente: un estudio de caso con aves y perturbaciones del hábitat en el Monte central, Argentina. Ecología Austral. 12. 2, 149-161.

Milgrom, T., 2008. Environmental aspects of rehabilitating abandoned quarries: Israel as a case study. Landscape and Urban Planing. 87, 172-179.

Ministerio de Agricultura, Ganadería y Pesca de la Nación. Secretaría de Agricultura, Ganadería y Pesca. Subsecretaría de Ganadría, 2010. Anuario: Ganados y Carnes. $1^{\mathrm{o}}$ ed. M. A. G. y P. Buenos Aires.

Miranda, J.D., Padilla, F.M., Pugnaire, F.I., 2004. Sucesión y restauración en ambientes semiáridos. Ecosistemas 13, 55-58.

Moore, M., Covington, W., Fulé, P.Z., 1999. Reference conditions and ecological restoration: a southwestern ponderosa pine perspective. Ecological Aplications. 9, $1266-1277$.

Morello, J., Mateucci,S.D., Rodriguez, A.F., Silva, M.E., 2012. Ecoregiones y complejos ecosistémicos argentinos $1^{\circ}$ ed. Orientación Gráfica editora. Buenos Aires.Pp 603.

Moreno, C., 2001. Métodos para medir la biodiversidad. $1^{\text {o }}$ ed. Zargosa. España.

Morici, E., Muiño, R., S., P., 2006. Efecto de la distancia a la aguada sobre la estructura del estrato herbáceo en matorrales de Larrea sp. pastoreados por bovinos en zonas áridas de Argentina. Archivos de Zootecnia. 55, 149-159.

Neri, A.C., Sánchez, L.E., 2010. A procedure to evaluate environmental rehabilitation in limestone quarries. Journal of Environmental Management. 91, 2225-2237.

Nittmann, J.J., 2010. Rehabilitación de canteras a partir de transplante directo de individuos adultos. En: Perez, D.R., Rovere, A.E., Farinaccio, F.M. Rehabilitación en el desierto, Ensayos con plantas nativas en Aguada Pichana. VazquezMazzini. Buenos Aires. 44-48. 
Novák, J., Prach, K., 2003. Vegetation succession in basalt quarries: Pattern on a landscape scale. Applied Vegetation Science. 6, 111-116.

Oesterheld, M., Aguiar, M., Paruelo, J., 1998. Ecosistemas patagónicos. Ecología Austral. 8, 75-84.

Ovalle, C., Aronson, J., Del Pozo, A., Avendaño, J., 1999. Restoration and Rehabilitation of mixed espinales in central Chile: 10 year report and appraisal. Arid soil Research and Rehabilitation. 13, 369-381.

Palmer, M.A., Ambrose, R.F., Poff, N.L., 1997. Ecological theory and comunity Restoration ecology. Restoration Ecology. 5, 291-300.

Panigatti, J.L., 2010. Argentina: 200 años- 200 suelos. INTA. Ediciones INTA. Pp. 345.

Papanastasis, V.P., 2009. Restoration of degraded grazing lands through grazing management: Can it work? Restoration Ecology. 17, 441-445.

Pece, M., Sobrero, M., Acosta, M., Rossi, F., 2014. Tratamientos pregerminativos en Geoffroea decorticans (Gillies ex Hook. \& Arn.) Burkart var. decorticans. Foresta Veracruzana. 16, 31-36.

Peláez, D.V., Bóo, R.M., Elía, O.R., 1996. The germination and seedling survival of Condalia microphylla Cav. in Argentina. Journal of Arid Environments. 32, 173179.

Perrow, M.R., Davy, A.J., 2002. Handbook of Ecological Restoration. Volumen 1Principles of restoration. Cambridge University Press, Cambridge. Pp. 461.

Peter, G., Funk, F., Loydi, A., Casalini, A., Leder, C., 2012. Variación de la composición y cobertura específicas del pastizal bajo diferentes presiones de pastoreo en el Monte Rionegrino. Pyton 9457, 233-237.

Peter, G., Leder, C., Calvo, D., Cruz, A., Torres Robles, S., 2014. Evaluación de tratamientos pregerminativos en seis especies nativas del ecotono monte- espinal del noreste de la Patagonia. Bioscriba 1, 1-10.

Pezzola, A., Winschel, C., 2004. Estudio multitemporal de la degradación del monte nativo en el partido de Patagones- Buenos Aires. Boletín de información técnica. EEA Hilario Ascasubi. Ediciones INTA.

Pol R. G., Camin, S.R., Ast, A.A. 2005. Situación ambiental en la Ecorregión del Monte. En: A. Brown, U. Martinez Ortiz, M. Acerbi y J. Corcuera (Eds.). La Situación Ambiental Argentina 2005. Fundación vida Silvestre, Buenos Aires, Argentina. Pp. $227-$ 233.

Prach, K., del Moral, R., 2015. Passive restoration is often quite effective: Response to Zahawi et al. (2014). Restoration Ecology. 23, 344-346.

Prokopiuk, D., Chifa, C., 2000. Comparación de tratamientos pregerminativos en semillas de algarrobo blanco (Prosopis alba Grises). Comunicaciones Cientificas y Tecnológicas Universidad Nacional del Nordeste. 1, 199-204. 
Puig, S., Cona, M.I., Videla, F., Mendez, E., 2010. Diet of the mara (Dolichotis patagonum), food availability and effects of an extended drought in Northern Patagonia (Mendoza, Argentina). Mammalian Biology. 75, 389-398.

Quezada, A., Pérez, D.R. 2010. Establecimiento inicial de Prosopis flexuosa var. depressa (Fabaceae) en diferentes tipos de suelo. En: Perez, D.R., Rovere, A.E., Farinaccio, F.M. Rehabilitación en el desierto, Ensayos con plantas nativas en Aguada Pichana. Vazquez- Mazzini. Buenos Aires. 56-60.

Quiroga, E., Blanco, L., Orionte, E., 2009. Evaluación de estrategias de rehabilitación de pastizales áridos. Ecología Austral. 19, 107-117.

Rabbi, S.M., Tighe, M., Delgado-Baquerizo, M., Cowie, A., Robertson, F., Dalal, R., Page, K., Crawford, D., Wilson, B.R., Schwenke, G., McLeod, M., Badgery, W., Dang, Y.P., Bell, M., O’Leary, G., De Liu, L., Baldock, J., 2015. Climate and soil properties limit the positive effects of land use reversion on carbon storage in Eastern Australia. Scientific Reports. 5, 17866.

Rauber, R., Steinaker, D., Demaría, M., Arroyo, D., 2014. Factores asociados a la invasión de pajas en bosques de la región semiárida central Argentina. Ecología Austral. 24, 320-326.

Rey Benayas, J.M., Bullock, J.M., Newton, A.C., 2008. Creating woodland islets to reconcile ecological restoration, conservation, and agricultural land use. Frontiers in Ecology and the Environment. 6, 329-336.

Rey Benayas, J. M., Newton, A. C., Diaz, A., Bullock, J. M. 2009. Enhancement of biodiversity and ecosystem services by ecological restoration: a meta-analysis. Science. 325. 5944, 1121-1124.

Rostagno, C.M., del Valle, H.F., Videla, L., 1991. The influence of shrubs on some chemical and physical properties of an aridic soil in north-eastern Patagonia, Argentina. Journal of Arid Environments. 20, 179-188.

Rueda, C. V., Baldi, G., Veron, S., Jobbagy, E.G., 2013. Apropiación humana de la producción primaria en el Chaco Seco. Ecología Austral 44-54.

Sabattini, R., Muzzachiodi, N., Dorsch, A., 2002. Manual de practicas de manejo del monte nativo. UNER. 56 p.

Sala, O.E., Chapin, S., Armesto, J.J., Berlow, E., Bloomfield, J., Dirzo, R., HuberSanwald, E., Huenneke, L.F., Jackson, R.B., Kinzig, A., Leemans, R., Lodge, D.M., Mooney, H.A., Oesterheld, M., Poff, L., Sykes, M.T., Walker, B.H., Walker, M., Wall, D.H., 2000. Global Biodiversity Scenarios for the Year 2100. Science (80-. ). 287, 1770-1774.

Santibañez-Andrade, G., Castillo-Argüero, S., Martínez-Orea, Y., 2015. Evaluación del estado de conservación de la vegetación de los bosques de una cuenca heterogénea del Valle de México. Bosque 36, 299-313.

Scholes, R.J., Archer, S.R. 1997. Tree- grass interactions in savannas. Annual Review of Ecology and Systematics. 28, 517-544. 
Soliveres, S., Maestre, F.T., Eldridge, D.J., Delgado-Baquerizo, M., Quero, J.L., Bowker, M.A., Gallardo, A., 2014. Plant diversity and ecosystem multifunctionality peak at intermediate levels of woody cover in global drylands. Global Ecology and Biogeography. 1-9.

Soriano, A., Sala, O., 1983. Ecological strategies in a Patagonian arid steppe. Vegetation. 56, 9-15.

Soteras, F., Renison, D., Becerra, A.G., 2014. Restoration of high altitude forests in an area affected by a wildfire: Polylepis australis Bitt. seedlings performance after soil inoculation. Trees - Structure and Function. 28, 173-182.

Steibel, P.E., Troiani, H.O., Williamson, T., 2000. Agregados al catálogo de las plantas naturalizadas y adventicias de la provincia de La Pampa, Argentina. Revista de la Facultad de Agronomía de La Pampa. 11, 75-90.

Tabeni, S., Yannelli, F.A., Vezzani, N., Mastrantonio, L.E., 2016. Indicators of landscape organization and functionality in semi-arid former agricultural lands under a passive restoration management over two periods of abandonment. Ecological Indicators. 66, 488-496.

Thibault, K.M., White, E.P., Morgan Ernest, S., 2004. Temporal Dynamics in the Structure and Composition of a Desert Rodent Community. Ecology. 85, 26492655.

Tongway, D.J., Hindley, N.L., 2005. Landscape function analysis: Procedures for monitoring and assessing landscapes. CSIRO. Pp. 80.

Torrella, S.A., Oakley, L., Ginzburg, R.G., Adamoli, J.M., Galleto, L., 2011. Estructura , composición y estado de conservación de la comunidad de plantas leñosas del bosque de tres quebrachos en el Chaco Subhúmedo Central. Ecología Austral. 21, $179-188$.

Torres, R.C., Giorgis, M.A., Trillo, C., Volkmann, L., Demaio, P., Heredia, J., Renison, D., 2014. Post-fire recovery occurs overwhelmingly by resprouting in the Chaco Serrano forest of Central Argentina. Austral Ecology. 39, 346-354.

Torres, R.C., Giorgis, M., Trillo, C., 2015. Supervivencia y crecimiento de especies con distinta estrategia de vida en plantaciones de areas quemadas y no quemadas: un estudio de caso con dos especies lenosas en el Chaco Serrano, Argentina. Ecología Austral. 25, 135-143.

Torres Robles, S.S., Arturi, M.F., Contreras, C., Peter, G., Zeberio, J.M., 2015. Variaciones geográficas de la estructura y composición de la vegetación leñosa en el límite entre el Espinal y el Monte en el noreste de la Patagonia. Boletín de la Sociedad Argentina de Botánica. 50, 209-215.

Ulrich, W., Soliveres, S., Maestre, F.T., Gotelli, N.J., Quero, J.L., Delgado-Baquerizo, M., Bowker, M.A., Eldridge, D.J., Ochoa, V., Gozalo, B., Valencia, E., Berdugo, M., Escolar, C., García-Gomez, M., Escudero, A., Prina, A., Alfonso, G., Arredondo, T., Bran, D., Cabrera, O., Cea, A.P., Chaieb, M., Contreras, J., Derak, M., Espinosa, C.I., Florentino, A., Gaitan, J., Muro, V.G., Ghiloufi, W., GomezGonzalez, S., Gutierrez, J.R., Hernandez, R.M., Huber-Sannwald, E., Jankju, M., 
Mau, R.L., Hughes, F.M., Miriti, M., Monerris, J., Muchane, M., Naseri, K., Pucheta, E., Ramirez-Collantes, D.A., Raveh, E., Rommo, R.L., Torres-Diaz, C., Val, J., Veiga, J.P., Wang, D., Yuan, X., Zaady, E., 2014. Climate and soil attributes determine plant species turnover in global drylands. Journal of Biogeography. 41, 2307-2319.

Valencia, E., Maestre, F., Le Bagousse-Pinguet, Y., Quero, J.L., Tamme, R., Börger, L., 2015. Functional diversityenhances the resistence of ecosystem multifunctionality to aridity in mediterranean drylands. New Phytologist. 206. 2. 660-671.

Valla, J.J., 2007.Botánica: morfología de las plantas superiores. $1^{\circ}$ ed.Hemisferio Sur Editora. Buenos Aires. Pp. 332.

Valladares, F., Gianoli, E., 2007. How Much Ecology Do We Need to Know to Restore Mediterranean Ecosystems?. Restoration Ecology. 15, 363-368.

Vallejo, R., Allen, E.B., Aronson, J., Pausas, J., Cortina, J., Gutierrez, J.R., 2009. Restoration of mediaterranean- type woodlands and shrublands, en: Van Andel, J., Aronson, J. Restoration of Mediterranean Woodlands. 11, 130-144.

Van Andel, J., Aronson, J., 2012. Restoration ecology. The new frontier. Wiley Blackwell. United Kingdon.Pp 403.

van Auken, O.W. 2009. Causes and consecuences of woody plant encroachment into western North American grasslands. Journal of Environmental Management. 90, 2931- 2942.

Van Wambeke, A., Scoppa, C., 1980. Las taxas climáticas de los suelos argentinos. CIRN- 168. Buenos Aires. INTA.

Verheyen, K., Guntenspergen, G.R., Beisbrouck, B., Hermy, M., 2003. An integrated analysis of the effects of past land use on forest herb colonization at the landscape scale. Journal of Ecology. 91, 731-742.

Viglizzo, E.F., Carreño, L.V., Pereyra, H., F., R., Clatt, J., Pincén, D., Jobbaghy, E.G., 2012. Expansión de la Frontera Agropecuaria en Argentina y su Impacto Ecológico-Ambiental. INTA. Ediciones INTA.

Villagra, P.E., 2000. Aspectos ecológicos de los algarrobales argentinos. Multequina. 9, $35-51$.

Villagra, P.E., Defossé, G.E., del Valle, H.F., Tabeni, S., Rostagno, M., Cesca, E., Abraham, E., 2009. Land use and disturbance effects on the dynamics of natural ecosystems of the Monte Desert: Implications for their management. Journal of Arid Environments. 73, 202-211.

Villagra, P.E., Giordano, C.V., Alvarez, J.A., Cavagnaro, J.B., Guevara, A., Sartor, C., Passera, C., Greco, S., 2011. Ser planta en el desierto : estrategias de uso de agua y resistencia al estrés hídrico en el Monte Central de Argentina. Ecología Austral. $21,29-42$.

Villagra, P.E., Villalba, R., Boninsegna, J.A., 2005. Structure and growth rate of Prosopis flexuosa woodlands in two contrasting environments of the central Monte desert. Journal of Arid Environments. 60, 187-199. 
Vitousek, P., D’Antonio, C., Loope, L., Rejmanek, M., Westbrooks, R., 1997. Introduced species: a significant component of Human-caused global environmental change. New Zeland Journal of Ecology. 21, 1-16.

Vourlitis, G.L., Fernandez, J.S., 2012. Changes in the soil , litter, and vegetation nitrogen and carbon concentrations. Journal of Arid Environments. 82, 115-122.

Wang, Z., 2009. The dynamics of ecosystem restoration: theoretical considerations on the basis of species richness. Plant Ecology. 209, 205-217.

Ward, D., Wiegand, K., Getzin, S., 2013. Walter' s two-layer hypothesis revisited: back to the roots! Oecologia 172, 617-630.

Whitford, W.G., 2002. Ecology of desert systems, $1^{\circ}$ ed. London.

Zahawi, R.A., Holl, K.D., Cole, R.J., Reid, J.L., 2013. Testing applied nucleation as a strategy to facilitate tropical forest recovery. Journal of Applied Ecology. 50, 8896.

Zahawi, R.A., Reid, J.L., Holl, K.D., 2014. Hidden Costs of Passive Restoration. Restoration Ecology. 22, 284-287.

Zeberio, J.M., 2012. Avance de la frontera agropecuaria en el noreste patagónico y sus consecuencias en los procesos de desertificación y pérdida de biodiversidad., En: Dos Santos Afonso, M., Rosa, T.S. (Eds.), Ciencia Y Tecnología Ambiental. Un Enfoque Integrador. Asociación Argentina para el progreso de la ciencia, Buenos Aires. 216-221.

Zeberio, J.M., Luna, M.A., Calabrese, G.M., 2015. Unidades de paisaje del noreste de Patagonia: Aportes para el manejo sustentable de las tierras secas. G.M. Calabrese (ed). Bariloche. Pp 64.

Zuloaga F. O., Nicora, E.G., Rugolo de Agrasar, Z.E, Morrone, O., Pensiero, J., Cialdella, M., 1994. Catálogo de la familia Poaceae en la República Argentina. Monography Systematic Botanical Missouri Botanical Garden. 47:1-178.

Zuloaga F. O.,Morrone,O., 1996. Catálogo de las plantas vasculares de la República Argentina I. Pteridophyta, Gymnospermae y Angiospermae (Monocotiledoneae), Monography Systematic Botanical Missouri Botanical Garden. 60:1-323.

Zuloaga F. O., Morrone, O., 1999a. Catálogo de las plantas vasculares de la República Argentina II. Acanthaceae-Euphorbiaceae (Dicotyledoneae), Monography Systematic Botanical Missouri Botanical Garden. 74:1-621.

Zuloaga F. O., Morrone, O., 1999b. Catálogo de las plantas vasculares de la República Argentina II. Fabaceae-Zygophylaceae (Dicotyledoneae), Monography Systematic Botanical Missouri Botanical Garden. 74:623-1269.

Zuleta, G., Fernandez, A., Leiva, A.B., Tchilinguiran, P., 2007. Ecología de disturbios y restauración de estepas arbustivas del monte austral en explanadas petroleras abandonadas de la cuenca neuquina. Libro de Resúmenes II congreso de Hidrocarburos. I.A.P.G. Buenos Aires. 